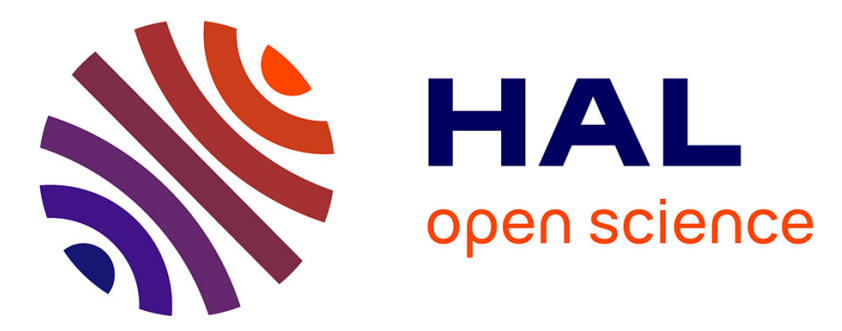

\title{
Facilitando sistemas alimentarios sostenibles
}

Allison Loconto

\section{To cite this version:}

Allison Loconto. Facilitando sistemas alimentarios sostenibles: Manual para innovadores. Institut national de recherche pour l'agriculture, l'alimentation et l'environnement. FAO, 263 p., 2021, Allison Loconto, 978-92-5-133952-7. 10.4060/ca9917es . hal-03173228

\section{HAL Id: hal-03173228 \\ https://hal.inrae.fr/hal-03173228}

Submitted on 18 Mar 2021

HAL is a multi-disciplinary open access archive for the deposit and dissemination of scientific research documents, whether they are published or not. The documents may come from teaching and research institutions in France or abroad, or from public or private research centers.
L'archive ouverte pluridisciplinaire HAL, est destinée au dépôt et à la diffusion de documents scientifiques de niveau recherche, publiés ou non, émanant des établissements d'enseignement et de recherche français ou étrangers, des laboratoires publics ou privés.

\section{(1)(1) $\$(0)$}

Distributed under a Creative Commons Attribution - NonCommercial - ShareAlikel 4.0 

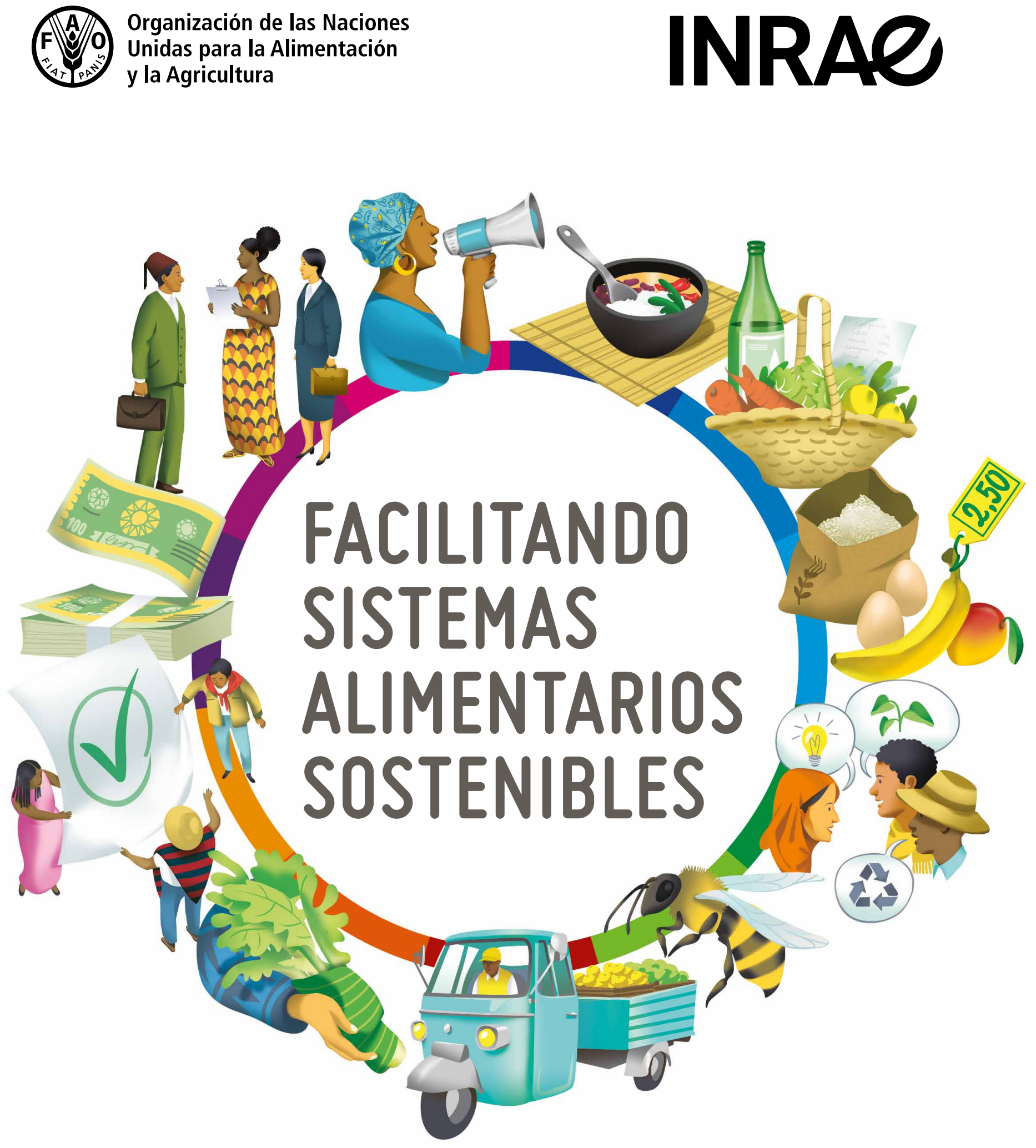

MANUAL PARA INNOVADORES 


\section{FACILITANDO}

SISTEMAS

ALIMENTARIOS

SOSTENIBLES

MANUAL PARA INNOVADORES

Publicado por:

Organización de las Naciones Unidas para la Alimentación y la Agricultura (FAO) y el Instituto Nacional Francés para la Agricultura, la Alimentación y el Medio Ambiente (INRAE)

Roma, 2021 
Cita requerida:

FAO e INRAE. 2021. Facilitando sistemas alimentarios sostenibles: Manual para innovadores. Roma. https://doi.org/10.4060/ca9917es

Las denominaciones empleadas en este producto informativo y la forma en que aparecen presentados los datos que contiene no implican, por parte de la Organización de las Naciones Unidas para la Alimentación y la Agricultura (FAO) ni del Instituto Nacional Francés para la Agricultura, la Alimentación y el Medio Ambiente (INRAE), juicio alguno sobre la condición jurídica o nivel de desarrollo de países, territorios, ciudades o zonas, ni sobre sus autoridades, ni respecto de la demarcación de sus fronteras o límites. La mención de empresas o productos de fabricantes en particular, estén o no patentados, no implica que la FAO o el INRAE los aprueben o recomienden de preferencia a otros de naturaleza similar que no se mencionan.

Las opiniones expresadas en este producto informativo son las de su(s) autor(es), y no reflejan necesariamente los puntos de vista o políticas de la FAO ni del INRAE.

ISBN 978-92-5-133952-7 [FAO]

(c) FAO, 2021

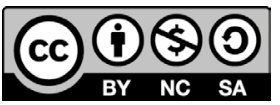

Algunos derechos reservados. Esta obra se distribuye bajo licencia Creative Commons AtribuciónNoComercial-Compartirlgual 3.0 Organizaciones intergubernamentales (CC BY-NC-SA 3.0 IGO; https:// creativecommons.org/licenses/by-nc-sa/3.0/igo/deed.es).

De acuerdo con las condiciones de la licencia, se permite copiar, redistribuir y adaptar la obra para fines no comerciales, siempre que se cite correctamente, como se indica a continuación. En ningún uso que se haga de esta obra debe darse a entender que la FAO refrenda una organización, productos o servicios específicos. No está permitido utilizar el logotipo de la FAO. En caso de adaptación, debe concederse a la obra resultante la misma licencia o una licencia equivalente de Creative Commons. Si la obra se traduce, debe añadirse el siguiente descargo de responsabilidad junto a la referencia requerida: “La presente traducción no es obra de la Organización de las Naciones Unidas para la Alimentación y la Agricultura (FAO). La FAO no se hace responsable del contenido ni de la exactitud de la traducción. La edición original en [idioma] será el texto autorizado".

Todo litigio que surja en el marco de la licencia y no pueda resolverse de forma amistosa se resolverá a través de mediación y arbitraje según lo dispuesto en el artículo 8 de la licencia, a no ser que se disponga lo contrario en el presente documento. Las reglas de mediación vigentes serán el reglamento de mediación de la Organización Mundial de la Propiedad Intelectual http://www.wipo.int/amc/en/mediation/rules y todo arbitraje se llevará a cabo de manera conforme al reglamento de arbitraje de la Comisión de las Naciones Unidas para el Derecho Mercantil Internacional (CNUDMI).

Materiales de terceros. Si se desea reutilizar material contenido en esta obra que sea propiedad de terceros, por ejemplo, cuadros, gráficos o imágenes, corresponde al usuario determinar si se necesita autorización para tal reutilización y obtener la autorización del titular del derecho de autor. El riesgo de que se deriven reclamaciones de la infracción de los derechos de uso de un elemento que sea propiedad de terceros recae exclusivamente sobre el usuario.

Ventas, derechos y licencias. Los productos informativos de la FAO están disponibles en la página web de la Organización (http://www.fao.org/publications/es) y pueden adquirirse dirigiéndose a publications-sales@ fao.org. Las solicitudes de uso comercial deben enviarse a través de la siguiente página web: www.fao.org/ contact-us/licence-request. Las consultas sobre derechos y licencias deben remitirse a: copyright@fao.org. 


\section{RESUMEN}

Los sistemas alimentarios sostenibles son fundamentales para garantizar que las generaciones actuales y futuras tengan seguridad alimentaria y puedan llevar una dieta saludable. Para hacer la transición hacia la sostenibilidad, es necesario reconstruir muchas actividades del sistema alimentario, y un sinnúmero de actores en todo el mundo están empezando a actuar localmente. Si bien algunos cambios son más fáciles que otros, saber cómo navegar a través de ellos para promover prácticas de consumo y producción sostenibles requiere un conjunto complejo de aptitudes. El presente manual está dirigido a los "innovadores de sistemas alimentarios sostenibles", y es realizado por un grupo de innovadores de Asia, África, América y Europa que están dirigiendo iniciativas para cultivar, compartir, vender y consumir alimentos más sostenibles en sus contextos locales. Incluye experiencias que están cambiando las estructuras organizativas de los sistemas alimentarios locales para hacerlos más sostenibles. Esta guía está escrita como un libro donde "eliges tu propia aventura". Cada lector - solo o en un grupo facilitado - puede desarrollar un viaje personalizado de aprendizaje y acción en línea con sus propias prioridades. Los temas tratados en esta guía son organizados en cuatro categorías de innovaciones: involucramiento de los consumidores, producción de manera sostenible, llevando los productos al mercado y organización. 

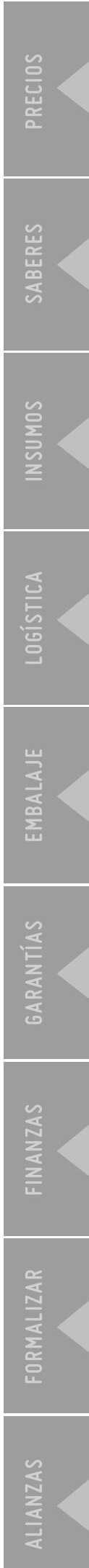


\section{ÍNDICE}

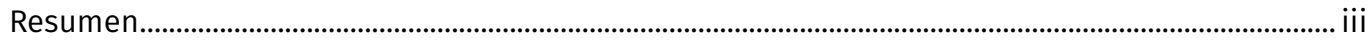

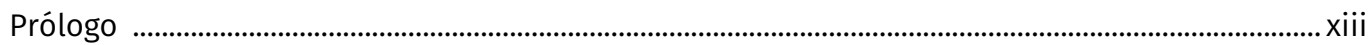

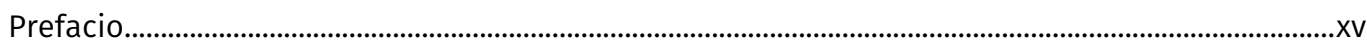

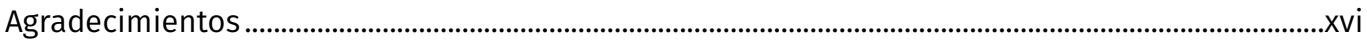

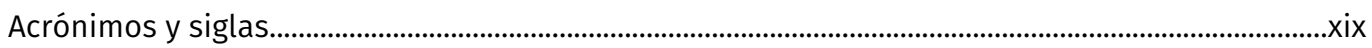

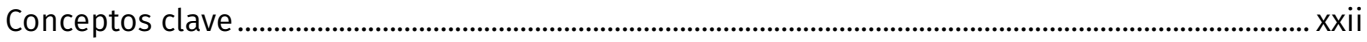

Introducción

(Re)valorización de la agricultura en los sistemas alimentarios................................................7

\section{INVOLUCRANDO A LOS CONSUMIDORES}

1. Atraer a los consumidores y mantenerlos comprometidos ........................................ 23

2. Conocer sus mercados .................................................................................................................. 43

3. Encontrar el precio "correcto" ............................................................................................61

\section{PRODUCIR DE MANERA SOSTENIBLE}

4. Compartir y cocrear conocimiento para una producción sostenible ........................ 87

5. Conocer y acceder a insumos sostenibles .......................................................................... 103

\section{COMERCIALIZACIÓN DE PRODUCTOS}

6. Manténgase conectado a través de la logística ........................................................ 125

7. Embalaje sostenible........................................................................................................ 143

8. Garantías para la sostenibilidad ....................................................................................157

\section{ORGANIZARSE}

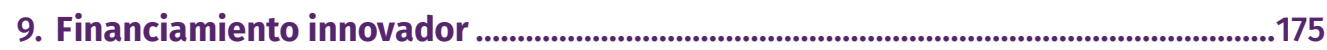

10. Formalizar el trabajo colectivo ........................................................................... 195

11. Alianzas y promoción ............................................................................................ 215 


\section{Cuadros}

Cuadro 1: Ejemplo de estructura de tarifas ASC .................................................................................................3

Cuadro 2: Matriz de capacidad del productor y requisitos del mercado........................................................ 46

Cuadro 3: Cuestionario para el consumidor para encontrar un sitio de mercado ........................................52

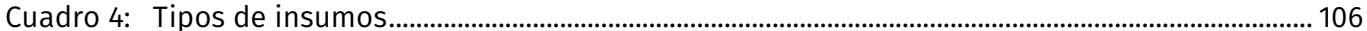

Cuadro 5: Plantilla para categorizar insumos.......................................................................................................107

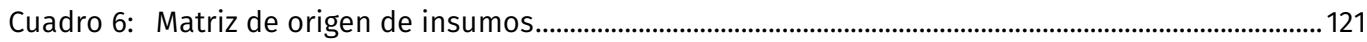

Cuadro 7: Tipología de diferentes sistemas de distribución ...........................................................................135

Cuadro 8: Ejemplos de diferentes opciones de embalaje según las diferentes características del producto ..................................................................................................................................146

Cuadro 9: Ejemplos de diferentes tamaños de envase para diferentes consumidores ...........................152

Cuadro 10: ¿Cómo se construye la confianza en diferentes sistemas de garantía? ....................................165

Cuadro 11: ¿Cómo se comparan los costos entre los sistemas de garantía? ................................................166

\section{Figuras}

Figura 1: Posibles aventuras de aprendizaje por primer capítulo de elección ...................................................6

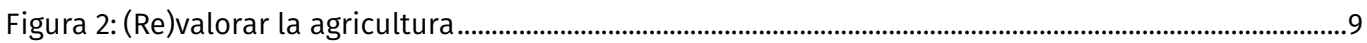

Figura 3: Ejemplo de una plantilla con los resultados de una investigación de Mercado Participativo de un SPG 


\section{Recuadros}

Recuadro 1: Inclusión social de consumidores de bajos ingresos en una ASC 28

Recuadro 2: Las redes sociales como herramienta para la comunicación interna (Finlandia)............... 30

Recuadro 3: La importancia del mensaje visual en el sitio web de Lavka Lavka (Federación de Rusia)..31

Recuadro 4: Una demostración de cocina para fortalecer los vínculos con los consumidores (Filipinas)

Recuadro 5: Las visitas de campo de los consumidores refuerzan las relaciones

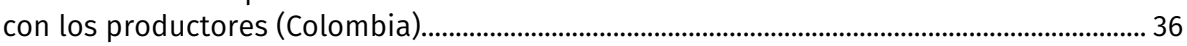

Recuadro 6: Compromiso de los consumidores y limitaciones de tiempo en los modelos ASC (Reino Unido de Gran Bretaña e Irlanda del Norte) ................................37

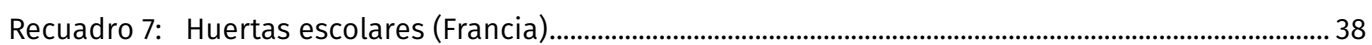

Recuadro 8: Programa escolar para educar a los futuros consumidores (Kenya) .......................................39

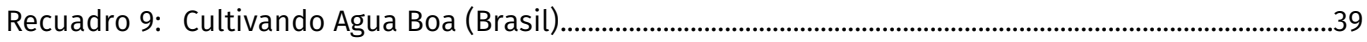

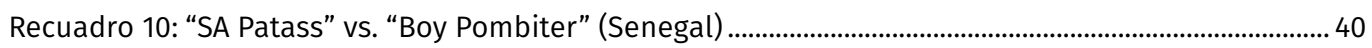

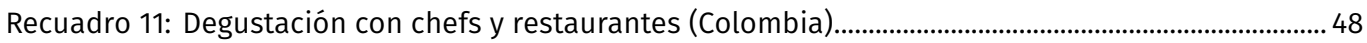

Recuadro 12: Visitas de agricultores a plantas de procesamiento (Colombia)............................................. 49

Recuadro 13: ¿Cuándo y cómo dirigir un grupo de enfoque? (Ecuador) .........................................................50

Recuadro 14: Feria agroecológica de Carcelén (Ecuador) .................................................................................51

Recuadro 15: Un estudio de mercado realizado por correo electrónico (Colombia) .....................................51

Recuadro 16: Mercados «campesinos» de Pekín (BFM), "el mercado móvil” (China)....................................53

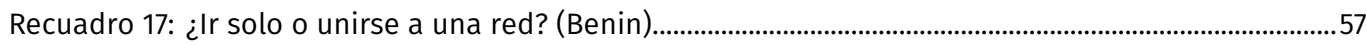

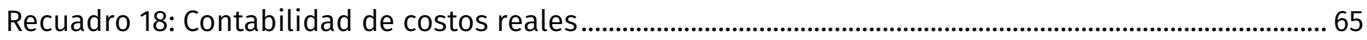

Recuadro 19: Enseñarles a los niños a mantener registros (Uganda).............................................................67

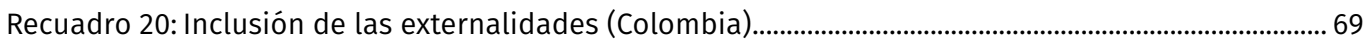

Recuadro 21: Tres criterios a definir cuando una transacción es aceptable

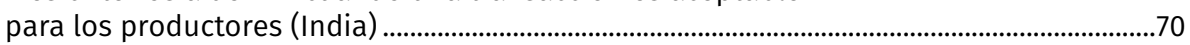

Recuadro 22: Enseñar a los consumidores cómo producir sus propios alimentos (Uganda) ....................73

Recuadro 23: Estudios de mercado como medio para compartir información (Uganda).............................74

Recuadro 24: Tres tipos diferentes de intermediarios transparentes (República de Corea e India) ........75

Recuadro 25: Comités de fijación de precios y mecanismos de fijación de precios en ASC .........................77

Recuadro 26: Investigación de Mercado Participativo (IMP) (Uganda) ............................................................78

Recuadro 27: Relación de reparto de precios en el sector del té (República Unida de Tanzanía) ............79

Recuadro 28: Modelo de Cosecha Compartida para calcular el precio adecuado (China)...........................8 80

Recuadro 29: El Gobierno como intermediario transparente (India) ................................................................81

Recuadro 30: Programas de compras públicas e influencia en los precios (Brasil) ..................................... 82

Recuadro 31: El programa TRIT para intercambios de agricultores (República Unida de Tanzanía).........91

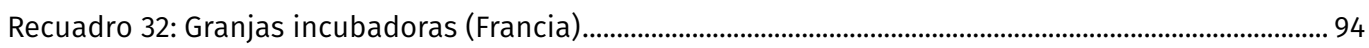


Recuadro 33: Investigación-acción para promover las prácticas agroecológicas (Ecuador)

Recuadro 34: Alianza sociedad civil-sector público para promover el concepto de Ecosalud (Colombia)

Recuadro 35: Asociaciones entre agricultores e investigadores (Kenya) .......................................................98

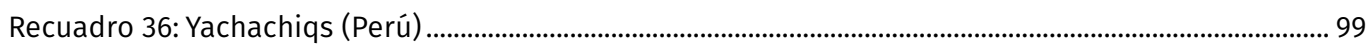

Recuadro 37: Escuela para la formación de líderes en seguridad y soberanía alimentaria y nutricional (Colombia)....................................................................... 100

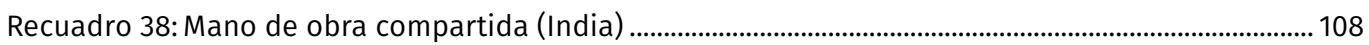

Recuadro 39: Fertilizantes saludables derivados de residuos de restaurantes (Colorado, USA) ............ 109

Recuadro 40: Husk Power Systems (India) ...................................................................................................110

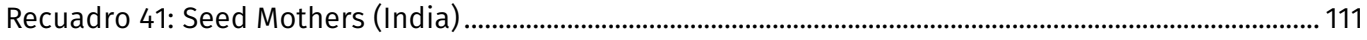

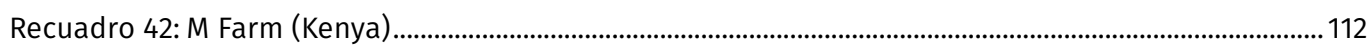

Recuadro 43: Anicytor, tracción de energía verde para herramientas agrícolas (Etiopia).........................114

Recuadro 44: Herramientas manuales de Agrovision para agricultores pequeños y

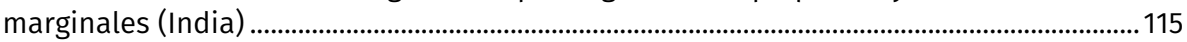

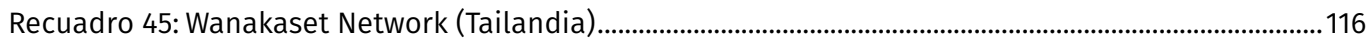

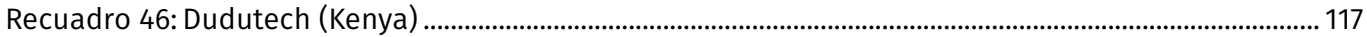

Recuadro 47: Dos ejemplos de gestión del agua (Zimbabue, India y República Unida de Tanzanía)....118

Recuadro 48: Ayudando al ciclo natural de polinizadores (Malasia) ..............................................................119

Recuadro 49: Encontrándose en el medio, convirtiendo la desventaja en ventaja

(República Democrática Popular Lao)........................................................................................130

Recuadro 50: Elaboración de arroz parbolizado en el Centro Songhai (Benin) ............................................132

Recuadro 51: Sistema de distribución y transporte Ecovida (Brasil)..............................................................134

Recuadro 52: La basura de la feria se convierte en fertilizante en la capital (Brasil) ................................. 137

Recuadro 53: La trazabilidad favorece la prevención de riesgos (Tailandia)..................................................138

Recuadro 54: Trazabilidad mediante una simple identificación y distinción codificada por colores (República Unida de Tanzanía)........................................139

Recuadro 55: Pruebas de contaminación participativas (India) ......................................................................... 140

Recuadro 56: Participación en la reglamentación de la inocuidad de los alimentos (India)...................141

Recuadro 57: Reducir, reutilizar, reciclar (China) .................................................................................................145

Recuadro 58: Envasado en un proyecto de pesca artesanal orgánica (Tailandia) .......................................149

Recuadro 59: Paquetes de fibra natural para entrega en el hogar en FreshVeggies (Uganda)................149

Recuadro 60: ¿Cómo diseñar un paquete original y atractivo? (Colombia)................................................... 151

Recuadro 61: Externalización de la impresión (Colombia) ...............................................................................153

Recuadro 62: Información obligatoria sobre el etiquetado (Colombia) .....................................................154

Recuadro 63: Rainforest Alliance (República Unida de Tanzanía) .................................................................... 161

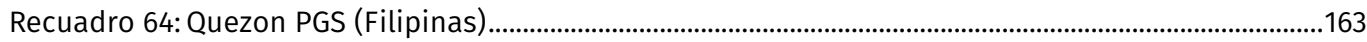

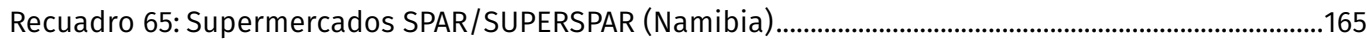


Recuadro 66: Certificación Fairtrade (FloCert).

Recuadro 67: SPG, registro de inocuidad de los alimentos y contratación pública (Bolivia).....................170

Recuadro 68: Grupos comunitarios de ahorro y préstamo (Kenya) ...............................................................179

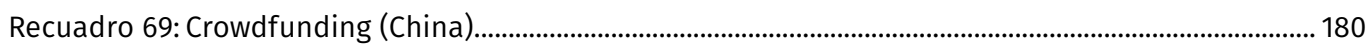

Recuadro 70: Controles verdes de los consumidores (Brasil)....................................................................... 180

Recuadro 71: Plan Paramparagat Krishi Vikas Yojana (PKVY) del Ministerio de Agricultura (India) .......182

Recuadro 72: Uso de celebridades para patrocinar su iniciativa (Perú) ...........................................................183

Recuadro 73: Financiación de proyectos nacionales de innovación (Chile) ................................................ 184

Recuadro 74: Movilización de fondos públicos de desarrollo regional (Croacia).......................................... 184

Recuadro 75: Fondos de Asistencia Oficial para el Desarrollo (AOD) (Alemania e India)............................185

Recuadro 76: Fondo Nacional de Desarrollo Agro-Silvo-Pastoril (Senegal) .................................................. 186

Recuadro 77: El programa del Fondo Comunitario de Ecoturismo (Trinidad y Tobago) ..............................187

Recuadro 78: Un caso de servicios ecológicos adquiridos por el Gobierno (China) .................................. 188

Recuadro 79: Certificación Fairtrade como garantía crediticia (América Latina y África).......................... 189

Recuadro 80: Programas de RSE en la industria del chocolate (Costa de Marfil)........................................ 190

Recuadro 81: Creación de redes de tres empresas social y ambientalmente sostenibles (Hungría).... 191

Recuadro 82: Monedas locales, lo que funciona y lo que no (Colombia) ......................................................192

Recuadro 83: Liderazgo orgánico - un concepto de estilo de vida..................................................................200

Recuadro 84: ChocoTogo - una empresa procesadora de propiedad de los empleados (Togo) ............. 202

Recuadro 85: Hansalim - una estructura cooperativa de agricultores y consumidores

(República de Corea) .............................................................................................................................204

Recuadro 86: Maputo Earth Market (Mozambique) .................................................................................................. 205

Recuadro 87: Green Net Cooperative/Earth Net Foundation (Tailandia) ........................................................206

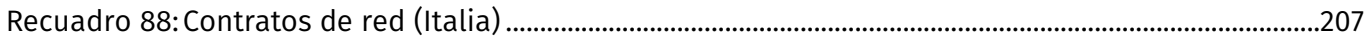

Recuadro 89: Tierra Viva, Agricultores Orgánicos (Chile) .................................................................................208

Recuadro 90: El crecimiento de un modelo de red (Colombia) ........................................................................210

Recuadro 91: Participación de jóvenes y mujeres en iniciativas agroecológicas sostenibles (Brasil) ..212

Recuadro 92: SPG: redes, asociaciones y promoción en el trabajo (Filipinas) ...............................................218

Recuadro 93: Campaña de consumidores ¡Que Rico Es! (Ecuador) ................................................................. 220

Recuadro 94: Modelos de canastas: creación de capital social (Ecuador) ......................................................223

Recuadro 95: Asociación con ONG (Togo).............................................................................................................. 224

Recuadro 96: Búsqueda y acercamiento a personas influyentes en las políticas (Kenya).........................225 


\section{Consejos}

Consejo 1: Identificar a los consumidores potenciales.......................................................................................26

Consejo 2: Trate de no explotar la generosidad de los demás .........................................................................32

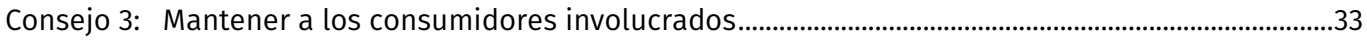

Consejo 4: Crear una experiencia de compra agradable ......................................................................................34

Consejo 5: La sorpresa es un componente importante para fomentar la lealtad ......................................35

Consejo 6: El servicio personalizado cultiva una agradable experiencia del cliente y crea consumidores asiduos ............................................................................................................ 36

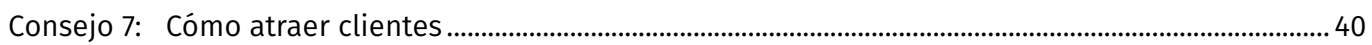

Consejo 8: Cree una matriz que compare su capacidad con los requisitos del mercado ......................... 45

Consejo 9: Haga que la información recopilada sea fácilmente accesible y comprensible para los otros miembros ............................................................................................ 47

Consejo 10: Asegúrese de que conoce las leyes nacionales y los requisitos para la alimentación escolar ..................................................................................55

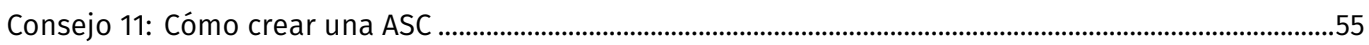

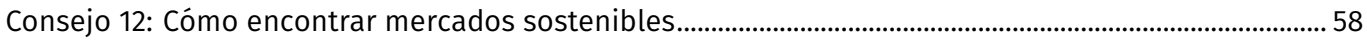

Consejo 13: Tome nota de las tareas diarias de la granja ................................................................................67

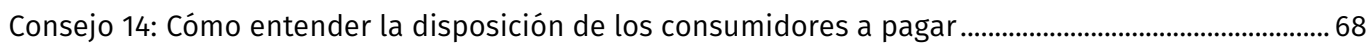

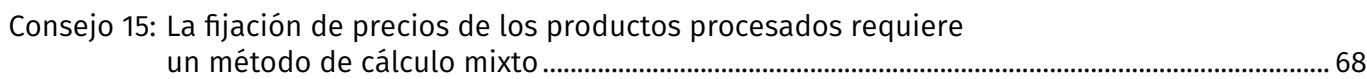

Consejo 16: Estabilizar los ingresos de los productores mediante la diversificación .................................... 71

Consejo 17: Ayudar a los consumidores a conocer el precio "correcto" .............................................................72

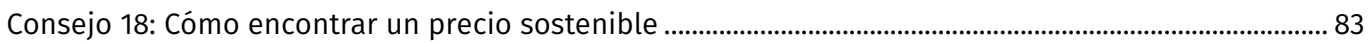

Consejo 19: Saber cuándo son más apropiados los enfoques formales e informales ................................... 89

Consejo 20: Reflexione sobre la sostenibilidad de sus prácticas agrícolas ....................................................90

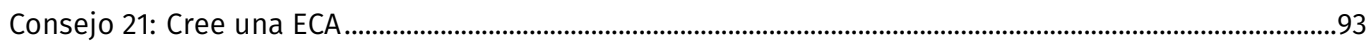

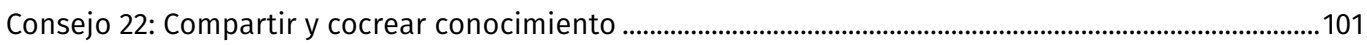

Consejo 23: Cómo crear su propio banco de semillas ................................................................................112

Consejo 24: Obtener herramientas y/o máquinas sostenibles ..........................................................................116

Consejo 25: Gestionar y acceder a insumos sostenibles.............................................................................. 121

Consejo 26: Gestionar los residuos de forma eficiente ......................................................................................136

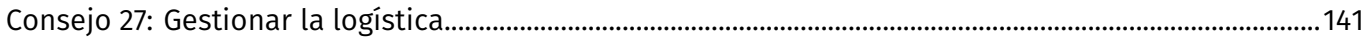

Consejo 28: Desarrollar un diseño atractivo .......................................................................................................150

Consejo 29: Desarrollar un embalaje atractivo y sencillo...................................................................................152

Consejo 30: Empaquetar productos sostenibles que venden .......................................................................155

Consejo 31: Recopile información sobre los sistemas de garantía de su zona ............................................164 
Consejo 32: Simplificar y estandarizar los procesos administrativos ............................................................169

Consejo 33: Iniciar un sistema de garantía (cuando nadie lo pide todavía) ................................................170

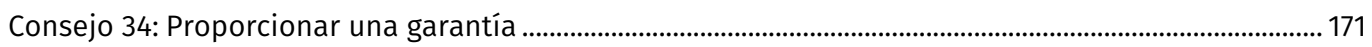

Consejo 35: Reinvierta dinero de las ventas de productos ............................................................................178

Consejo 36: Usar un presupuesto participativo ........................................................................................................181

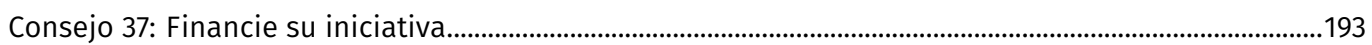

Consejo 38: Formar una iniciativa de sistema alimentario sostenible .........................................................199

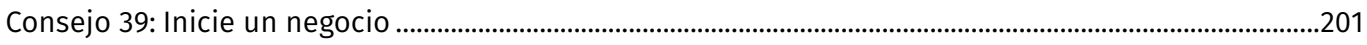

Consejo 40: Verifique el registro legal de las empresas sociales en su país...................................................202

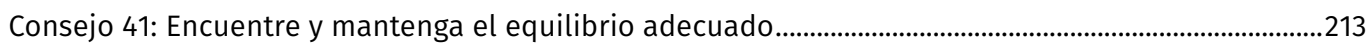

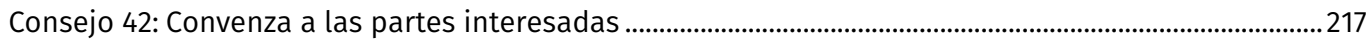

Consejo 43: Cree asociaciones para el trabajo de promoción ..........................................................................221

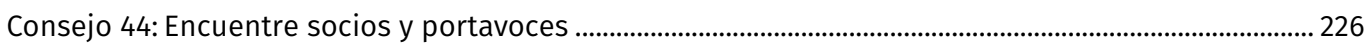



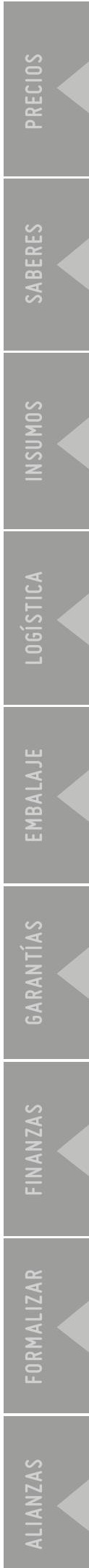


\section{PRÓLOGO}

En 2018, la FAO organizó dos eventos relacionados con la innovación: el primero fue un panel interactivo y una feria de innovación durante el Segundo Simposio Internacional sobre Agroecología realizado en abril de 2018, y el segundo fue el Simposio sobre Innovación que tuvo lugar en noviembre de 2018. Ambos eventos reconocieron la innovación como una solución a los desafíos que enfrentan los actuales sistemas agrícolas y alimentarios en la búsqueda de sostenibilidad. Ambos eventos resaltaron claramente la innovación en la agenda como un medio a través del cual la FAO puede ayudar a los países miembros a alcanzar los Objetivos de Desarrollo Sostenible (ODS).

En 2019, el Informe del Grupo de Expertos de Alto Nivel del Comité de Seguridad Alimentaria Mundial sobre Agroecología y otros enfoques innovadores para la agricultura sostenible reforzó las lecciones recogidas en la serie Ahorrar y Crecer de la FAO. El cierre de los ciclos de nutrientes, la integración de los sistemas de producción y la mitigación inteligente del cambio climático ofrecen innumerables oportunidades de innovación en los sistemas de producción agroecológica. La necesidad de nuevas formas de cocrear y compartir conocimientos sobre la agricultura sostenible es una prioridad para garantizar que los usuarios accedan a nuevos tipos de información, tecnologías y prácticas y que las innovaciones se difundan. Una mayor participación de los agricultores, consumidores y organizaciones locales en la investigación, comercialización y garantía de la sostenibilidad de los alimentos y productos agrícolas está abriendo nuevas vías para procesos dinámicos de aprendizaje.

Las innovaciones del sistema alimentario son particularmente necesarias, ya que el sistema alimentario mundial es responsable de la doble carga actual de malnutrición, donde el hambre y la obesidad pueden coexistir en el mismo país o incluso en el mismo individuo. El Informe sobre el Estado de la Inseguridad Alimentaria de 2019 pone de relieve los factores que impulsan estos fenómenos, que incluyen los conflictos, la pobreza y la marginación, pero también las desigualdades existentes y crecientes en el acceso y la utilización de los alimentos. Este manual que se publica en medio de la crisis de COVID-19, pone de manifiesto la urgente necesidad de introducir innovaciones en los sistemas alimentarios, que propendan por la reubicación y diversificación de los mismos para fortalecer su resiliencia. Los cambios en la organización del sistema alimentario pueden dar prioridad al acceso a los alimentos para las comunidades vulnerables, promover la agricultura sostenible, incluyendo la protección de la biodiversidad, y fomentar dietas saludables y nutritivas. Para estas transiciones es fundamental aumentar los intercambios entre productores y consumidores, y cambiar la forma en que interactúan e influyen en sus entornos alimentarios. En lugar de permanecer pasivos, los consumidores se están volviendo cada vez más activos en la reorganización de los sistemas alimentarios a medida que buscan alimentos saludables y cultivados de manera sostenible, así como sistemas comerciales que construyan economías locales e incluyan a pequeños agricultores. 
Este manual se basa en una gran cantidad de experiencias de más de 20 países, e ilustra cómo los cambios del sistema alimentario hacia la sostenibilidad ya están en marcha. Estas innovaciones desafian y cambian las normas, las instituciones, las prácticas y las relaciones existentes entre los actores del sistema alimentario. Este recurso está destinado a ayudar a los actores que quieran contribuir a esta transición. Basándose en conocimientos científicos y experimentales, los consejos y sugerencias que se proporcionan en este manual inspiran una actitud positiva respecto de la capacidad innovadora de los actores locales en todo el mundo y las perspectivas para permitir la aparición de sistemas alimentarios sostenibles.

\section{Rémi Nono Womdim}

Director Adjunto

División de Producción y Protección Vegetal (NSP)

FAO

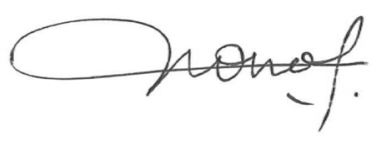

\section{Anna Lartey}

Directora

División de Nutrición y Sistemas Alimentarios (ESN)

FAO

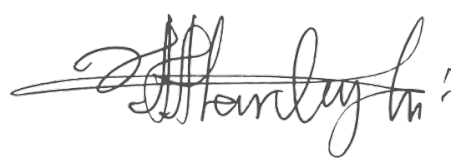




\section{PREFACIO}

Este manual es el resultado de un esfuerzo verdaderamente colaborativo. El proceso comenzó en 2013 con el propósito de entender mejor por qué y cómo los actores locales construyen sistemas alimentarios locales a través de la construcción de mercados para productos alimenticios sostenibles, incluso de manera independiente de la certificación formal. Esto se convirtió en un proyecto de investigación participativa que documentó iniciativas innovadoras y conocimiento colectivo avanzado en cuatro continentes sobre las innovaciones institucionales necesarias para apoyar la transición a sistemas alimentarios sostenibles. A partir de un pequeño grupo de tres mujeres, nuevos colaboradores se unieron cada año y el proceso se expandió y trascendió nuestras experiencias geográficas, de género y organizativas.

El resultado de esta experiencia es el presente manual, que es el tercero de una serie de publicaciones FAO/INRAE relacionadas con las innovaciones institucionales en los mercados nacionales y locales para la agricultura sostenible. Las ideas y el texto que se encuentran en este manual se escribieron colectivamente a partir de dos grupos de trabajo de redacción (en Chiang Mai, Tailandia en 2016 y en Nueva Delhi, India en 2017) y grupos de trabajo virtuales a lo largo de 2017. En 2018, el borrador de los manuales fue probado en iniciativas nacientes en Nueva Delhi, India y Thies, Senegal. Estas experiencias ayudaron a poner en práctica el material incluido en este manual y a asegurar que será de interés para los usuarios.

Con este manual, el mensaje central que queremos transmitir es que permitir el cambio en el sistema alimentario requiere colaboración y pensamiento sistémico sobre lo que es necesario para producir los alimentos que comemos - en términos de conocimiento, materiales, tecnologías, relaciones, valores y procesos naturales. Dada la rica diversidad cultural y biológica del mundo, no hay necesidad que dos sistemas alimentarios compartan exactamente las mismas características para que sean considerados como sostenibles. En lugar de ser una limitación, esta realidad debe considerarse como una oportunidad para innovar, para crear nuevas reglas sobre cómo crecer, comercializar y comer alimentos. Por lo tanto, la importancia de involucrar a otros en la visión colectiva de cómo deberían verse los futuros sistemas alimentarios es un paso fundamental para llevar a cabo la transformación del sistema alimentario. Esperamos que este manual contribuya a este objetivo.

Allison Marie Loconto
Directora Adjunta
Laboratoire Interdisciplinaire
Sciences, Innovations et
Société (LISIS)
INRAE

Anne-Sophie Poisot
Coordinadora de
Proyectos
División de Producción y
Protección Vegetal (NSP)
FAO

\author{
Marcello Vicovaro \\ Consultor de \\ Mercados Sostenibles \\ División de Nutrición y \\ Sistemas Alimentarios (ESN) \\ FAO
}




\section{AGRADECIMIENTOS}

El presente manual fue escrito colectivamente, a través de una serie de talleres y grupos de trabajo, y representa las contribuciones de las siguientes personas:

Allison Loconto, INRAE/FAO

Marcello Vicovaro, FAO

Pilar Santacoloma, FAO

Anne-Sophie Poisot, FAO

Ashish Gupta, Jaivik Haat/Gram Disha Trust

Michael Commons, Earth Net Foundation

Jocelyn Parot, URGENCI

Oscar Javier Nieto, Familia de la Tierra

Carmen Cabling, Quezon PGS

Jaime Aguirre, Familia de la Tierra

Jelena Petrov, RERA SD

Julie Matovu, FreshVeggies Ltd

Judith Hitchman, URGENCI

Rosinah Mbenya, PELUM Kenya

Emmanuel Simbua, Tea Research Institute of Tanzania (TRIT)

Ross Mary Borja, Fundación Ekorural

Patricia Flores, IFOAM Organics International

Andrea Moya, Claudia Helena Prieto Parque Temático en Salud Pública Chaquen, subred Integrada de Prestación de Servicios de Salud Sur.

Mathew John, Keystone Foundation

José Antonio da Silva Marfil, Ecovida

Darli Bengh, Ecovida

Shi Yan, Shared Harvest

Chris May, IFOAM Organics International

René Piamonte, Biodynamic advisor (Terrahabilis - Demeter)

Susan Boohaker, FAO/American University of Rome

Collier Lumpkin, FAO/American University of Rome

Zachary Reif, FAO/American University of Rome 
Esta labor se llevó a cabo bajo los auspicios de la Iniciativa Básica 3 (Sostenibilidad en TODAS las cadenas de valor) del Programa de Sistemas Alimentarios Sostenibles de One Planet Network. Queremos dar las gracias a la FAO (NSP y ESN), al Instituto Nacional de Investigación Francés para la Agricultura, la Alimentación y el Medio Ambiente (INRAE), a la Universidad Gustave Eiffel, a la Oficina Federal Suiza para la Agricultura (FOAG) y a los Proyectos Piloto de Enfoque Integrado del Programa de Sistemas Alimentarios Resilientes del Fondo Mundial para el Medio Ambiente (FMAM IAP) por su apoyo financiero e institucional a lo largo de este proceso. También agradecemos el apoyo institucional que recibimos de cada organización que colaboró con nosotros para lograr esta publicación.

Queremos agradecer específicamente a nuestros colegas de la FAO - Florence Tartanac, Renée van Dis, Jorge Fonseca, Guido Santini y Michael Clark - sus comentarios sobre capítulos específicos y el texto general. Damos las gracias a dos revisores anónimos por los comentarios que contribuyeron a la mejora del texto. También queremos dar las gracias a nuestros colegas de la India y Senegal por haber proporcionado comentarios sobre el manual durante dos pruebas nacionales. Damos las gracias a Andrés Celis y Jaime Aguirre por la traducción y redacción de la versión en español y a Studio Bartoleschi por el diseño gráfico.

Queremos dedicar esta versión a nuestro querido amigo y compañero en este viaje René Piamonte, quien no pudiera leer la versión final del libro, pero nos inspiró muchísimo. 

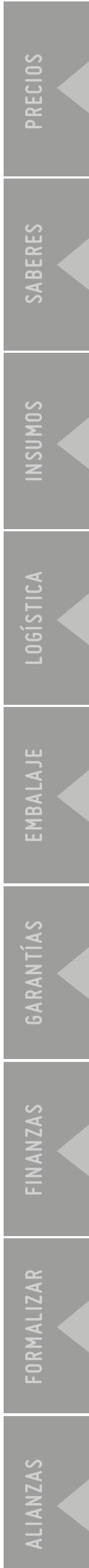


\section{ACRÓNIMOS Y SIGLAS}

\begin{tabular}{|c|c|}
\hline ACOPA & Asociación de Consumidores de Productos Agroecológicos de Paraná - Brasil \\
\hline ANPE & Asociación Nacional de Productores Orgánicos del Perú \\
\hline AOD & Asistencia Oficial para el Desarrollo \\
\hline APM & Agricultores pequeños y marginales \\
\hline ASC & Agricultura sostenida por la comunidad \\
\hline BAFS & Bureau of Agriculture and Fisheries Standards - Filipinas \\
\hline BFM & Mercado de Agricultores de Pekín - China \\
\hline BMZ & Ministerio Federal de Cooperación y Desarrollo Económico - Alemania \\
\hline BPA & Buenas prácticas agrícolas \\
\hline CACP & Comisión de Costos y Precios Agrícolas - India \\
\hline $\operatorname{CDC}$ & Capacitación de capacitadores \\
\hline $\mathrm{CDPH}$ & Centro para el Desarrollo del Potencial Humano - Colombia \\
\hline CEDEAO & Comunidad Económica de los Estados de África Occidental \\
\hline CONAB & Companhia Nacional de Abastecimento - Brasil \\
\hline COPACO & Comités de Participación Comunitaria en Salud Pública - Colombia \\
\hline ECA & Escuelas de campo para agricultores \\
\hline ELUM & Uso ecológico de tierras \\
\hline FAO & Organización de las Naciones Unidas para la Agricultura y la Alimentación \\
\hline FDOA & Fortalezas, debilidades, oportunidades y amenazas \\
\hline FDT & Familia de la Tierra - Colombia \\
\hline FIDA & Fondo Internacional de Desarrollo Agrícola \\
\hline FMAM & Fondo Mundial para el Medio Ambiente \\
\hline FNDASP & Fondo Nacional de Desarrollo Agro-Silvo-Pastoral - Senegal \\
\hline FNRAA & Fondo Nacional de Investigación Agrícola y Agroalimentaria - Senegal \\
\hline
\end{tabular}


FSSAI Autoridad de Normas y Seguridad Alimentaria de la India

IFOAM Federación Internacional de Movimientos de Agricultura Orgánica

IICA Instituto Interamericano de Cooperación para la Agricultura

ILUD Diseño integrado de uso de la tierra

IMP Investigación del mercado participativo

INRAE Instituto nacional francés de agricultura, alimentación y medio ambiente

IPBES Plataforma Intergubernamental Científico-normativa sobre Diversidad Biológica y Servicios de los Ecosistemas

JKUAT Jomo Kenyatta University of Agriculture - Kenya

LANAC Laboratoire National d'Analyses et de Contrôle - Senegal

MASIPAG Magsasaka at Siyentista Para sa Pag-unlad ng Pagsasaka - Filipinas

MFGS MASIPAG Farmers Guarantee System - Filipinas

MIDIS Ministerio de Desarrollo e Inclusión Social - Perú

MIP Manejo integrado de plagas

MKSP Mahila Kisan Sashaktikaran Programme - India

MVMAM Medios de Vida Mejorados por Acceso a Mercados - Uganda

NMSA National Mission on Sustainable Agriculture - India

NOA Namibian Organic Association - Namibia

NRWRP National Reforestation and Watershed Rehabilitation Programme - Trinidad y Tobago

ODS Objetivo de Desarrollo Sostenible

OFN Open Food Network

OGM Organismo genéticamente modificado

ONG Organización no gubernamental

OSC Organizaciones de la sociedad civil

PAA Programa de Compra de Alimentos - Brasil

PAAMG Grupo de Gestión del Programa de Compra de Alimentos - Brasil

PKVY Traditional Farming Progressive Scheme - India

PMS Precio mínimo de sustentación 


\begin{tabular}{ll} 
PNAE & Programa Nacional de Alimentación Escolar - Brasil \\
\hline REDD & $\begin{array}{l}\text { Reducción de las emisiones derivadas de la deforestación y la degradación } \\
\text { de los bosques }\end{array}$ \\
\hline RERA SD & $\begin{array}{l}\text { Institución pública para el desarrollo y coordinación del Condado } \\
\text { de Split-Dalmacia (Croacia) }\end{array}$ \\
\hline RSC & responsabilidad social corporativa \\
\hline SADMAD & Sistema de Alimentos Sostenibles para Combatir la Desnutrición en Dakar - Senegal \\
\hline SAFA & Evaluación de la sostenibilidad de los Sistemas Alimentarios y Agrícolas \\
\hline SAG & Servicio Agrícola y Ganadero - Chile \\
\hline SAS & Sistema Alimentario Sostenible \\
\hline SCOPE & The Schools and Colleges Permaculture Programme - Kenya \\
\hline SHARP & $\begin{array}{l}\text { Autoevaluación y Valoración Holística de la Resiliencia Climática } \\
\text { de Agricultores y Pastores }\end{array}$ \\
\hline SIC & Sistema de control interno \\
\hline SPG & Sistemas Participativos de Garantía \\
\hline TAC & Comité de Acción de Turismo - Trinidad y Tobago \\
\hline TIDCO & Tourism and Industrial Development Company of Trinidad and Tobago \\
\hline TRIT & Tea Research Institute of Tanzania \\
\hline TWG & Grupo de Trabajo Técnico \\
\hline UE & Unión Europea \\
\hline UEMOA & Unión Económica y Monetaria del África Occidental \\
\hline VMOV & Visión, misión, objetivos y valores \\
\hline WATCO & The Wakulima Tea Company - República Unida de Tanzanía \\
\hline
\end{tabular}




\section{CONCEPTOS CLAVE}

AGROECOLOGÍA: es un enfoque integrado que aplica simultáneamente conceptos y principios ecológicos y sociales al diseño y gestión de los sistemas alimentarios y agrícolas. Busca optimizar las interacciones entre las plantas, los animales, los seres humanos y el medio ambiente, considerando los aspectos sociales que necesitan ser abordados para asegurar un sistema alimentario sostenible y justo. Los 10 Elementos de la Agroecología son una guía para los generadores de políticas, los profesionales y las partes interesadas en la planificación, gestión y evaluación de la transición agroecológica: diversidad, sinergias, eficiencia, resiliencia, reciclaje, cocreación e intercambio de conocimientos, valores humanos y sociales, cultura y tradiciones alimentarias, gobernanza responsable, economía circular y solidaria. Los 10 elementos están interconectados y son interdependientes (FAO, 2018a).

CANASTAS: también conocidos como paniers o box-schemes, son un tipo específico de relación directa con el mercado o cadena de suministro corta, en la que el productor organiza una entrega en la canasta de los productos directa y regularmente a los consumidores. Aunque el nivel de compromiso puede diferir sustancialmente, estos esquemas a menudo se equiparan con la agricultura sostenida por la comunidad (ASC, ver definición más abajo).

CERTIFICACIÓN: es un procedimiento mediante el cual una parte proporciona una garantía escrita de que un producto, proceso o servicio cumple con ciertas normas (ISO, 2012). La certificación puede entenderse como una forma de comunicación a lo largo de la cadena de suministro. La certificación demuestra al comprador que el proveedor cumple ciertos criterios, que podrían ser más convincentes que si el proveedor facilitara la garantía por sí mismo. En este manual, utilizamos la palabra "garantía" en lugar de "certificación", ya que estamos explorando cómo una variedad de actores puede asegurar que otros actores estén siguiendo normas específicas para la sostenibilidad (FAO, 2003).

ECONOMIA CIRCULAR: se basa en "compartir, alquilar, reutilizar, reparar, renovar y reciclar" productos y materiales en un circuito idealmente cerrado. El objetivo es reducir los residuos, manteniendo los productos y materiales dentro de la economía (Whitaker et al, 2017).

AGRICULTURA SOSTENIDA POR LA COMUNIDAD (ASC): es una asociación entre una granja y los consumidores, donde se comparten los riesgos y las recompensas de la agricultura. Desarrollado originalmente como el modelo del Teikei en Japón en la década de 1970, cada ASC se organiza de manera diferente. Sin embargo, cuatro principios fundamentales son comunes: “1) Asociación: La ASC se basa en una asociación, generalmente formalizada como un contrato individual entre cada consumidor y el productor, y caracterizada por un compromiso mutuo de suministrarse mutuamente (dinero y alimentos) durante un período de tiempo 
prolongado, más allá de cualquier acto de intercambio único. Los contratos, orales o escritos, pueden durar varios meses, una temporada o un año. 2) Local: Los ASC forman parte de un enfoque activo para relocalizar la economía. Sin embargo, "local" en el movimiento ASC no se limita a un significado geográfico. La idea es que los productores locales estén bien integrados en sus áreas circundantes: su trabajo debe beneficiar a las comunidades que los apoyan. 3) Solidaridad: Los ASC se fundamentan en la solidaridad entre productores y grupos de apoyo e implican compartir tanto los riesgos como los beneficios de una producción saludable adaptada al ritmo natural de las estaciones y respetuosa del medio ambiente, del patrimonio natural y cultural, y de la salud, asi como pagar un precio justo suficiente para que los agricultores y sus familias puedan mantener sus granjas y vivir de manera digna. 4) El dúo productor/consumidor se basa en el contacto directo de persona a persona y la confianza, sin intermediarios ni jerarquía" (Bashford et al, 2013; URGENCI, 2016).

SISTEMA ALIMENTARIO: comprende todos los elementos (recursos naturales, personas, insumos, procesos, infraestructuras, instituciones, productos, etc) y las actividades relacionadas con la producción, elaboración, distribución, preparación y consumo de alimentos, así como los resultados de esas actividades, incluyendo los resultados socioeconómicos y ambientales (HLPE, 2014). En este manual, también consideramos el manejo de residuos al final de la vida útil como un elemento esencial de un sistema alimentario.

INNOVACIÓN: es el proceso mediante el cual las personas u organizaciones se apropian e implementan del diseño y la producción de bienes y servicios nuevos para ellas, independientemente de si son nuevos para sus competidores, su país o el mundo (FAO, 2014). "La innovación en la agricultura abarca todas las dimensiones del ciclo de producción a lo largo de la cadena de valor, desde la producción agrícola, forestal, pesquera o ganadera, hasta la gestión de insumos y recursos, incluyendo la organización y el acceso a los mercados. Puede, por ejemplo, implicar la plantación de nuevas variedades de cultivos, la combinación de prácticas tradicionales con nuevos conocimientos científicos, la aplicación de nuevas prácticas de control de plagas y poscosecha, o la participación en los mercados de formas nuevas y más gratificantes. La innovación no se trata solo de la tecnología, que por sí sola puede permanecer en la estantería. También se trata, y tal vez es lo más importante, de procesos sociales, económicos, institucionales/organizativos y de políticas, que tengan un impacto en la vida de las familias agricultoras" (FAO, 2018d).

En este manual, LA AGRICULTURA ORGÁNICA se utiliza para referirse a aquellas granjas agroecológicas que han sido certificadas frente a un estándar orgánico público o privado. La certificación puede realizarse a través de una parte directa (como en la India), un tercero o de un Sistema de Participativo de garantía (SPG). La frecuencia del uso de este término por los propios innovadores locales depende de las regulaciones nacionales para la producción orgánica, su base de consumidores, y las tradiciones e historia de la agricultura orgánica en su país de operación. A veces, incluso cuando algunos productores están certificados como orgánicos, prefieren utilizar el término "agroecológico" para definir sus prácticas. 
SISTEMAS DE PARTICIPATIVOS DE GARANTÍA (SPG): son sistemas de garantía de calidad centrados localmente. Certifican a los productores sobre la base de la participación activa de las partes interesadas, y se basan en la confianza, las redes sociales y el intercambio de conocimientos (IFOAM, 2019). En este manual, junto con la certificación, discutimos los SPG como una de las maneras que pueden garantizar prácticas sostenibles.

PRECIO CORRECTO: es el precio aceptable/razonable para todas las partes implicadas en la transacción. El precio correcto es justo y sostenible. La verdadera contabilidad de costos puede ayudar a los actores a obtener el precio adecuado.

CADENA DE SUMINISTRO: es una secuencia de procesos (toma de decisiones y ejecución) y flujos (material, información y dinero) que tienen como objetivo satisfacer las necesidades finales del cliente, y que se llevan a cabo dentro y entre diferentes etapas a lo largo de una franja, desde la producción hasta el consumo final. La cadena de suministro no solo incluye al productor y sus proveedores, sino también, dependiendo de los flujos logísticos, a transportadores, almacenes, minoristas y los propios consumidores. En un sentido más amplio, las cadenas de suministro también pueden incluir el desarrollo de nuevos productos, la comercialización, operaciones, distribución, finanzas y el servicio al cliente (FAO, 2007).

SISTEMA ALIMENTARIO SOSTENIBLE (SAS): es un sistema alimentario que proporciona seguridad alimentaria y nutrición para todos de manera que no se pongan en peligro las bases económicas, sociales y ambientales, para generar seguridad alimentaria y nutrición para las generaciones futuras (HLPE, 2014).

ECONOMIA SOLIDARIA: es un movimiento que pretende transformar el actual sistema social y económico en uno basado en intercambios cooperativos, solidarios, cortos y directos, de circuitos que conectan las necesidades individuales con las de la comunidad. Se basa en prácticas de producción, intercambio y uso de bienes y servicios que satisfacen las necesidades económicas y sociales de las comunidades locales, territoriales e internacionales. Promueve la democracia económica, la justicia social, la conciencia ambiental, la soberanía alimentaria, la equidad de género y un enfoque pluralista y multicultural. La Economía Solidaria ya se está manifestando a través de miles de iniciativas ciudadanas, prácticas solidarias y redes de colaboración en todo el mundo.

TRAZABILIDAD: se define como la capacidad de rastrear el historial, la aplicación o la ubicación de un elemento o actividad mediante la identificación registrada. Esto comprende dos aspectos principales: por una parte, la identificación del producto mediante una marca y, por otra, el registro de los datos de los productos a lo largo de la cadena de producción, elaboración y distribución (FAO, 2016b). 
TRANSPARENCIA: en un sistema alimentario se define como la disponibilidad de información, especialmente la del precio adecuado y la contabilidad de costos reales, en el dominio público o a petición de cualquier parte interesada de una cadena de suministro. En un sistema alimentario sostenible, la información está disponible libremente sin prejuicios que puedan perjudicar a los productores y consumidores.

INTERMEDIARIO TRANSPARENTE: en una cadena de valor alimentario sostenible, son los individuos o entidades que trabajan para proporcionar intercambios transparentes, asequibles y fácilmente accesibles entre el productor y el consumidor final. Todas estas funciones de los actores, especialmente las monetarias, están disponibles en el dominio público; en un caso ideal, éstas están comprometidas a proporcionar un acceso equitativo a los productores como mínimo y a los consumidores finales como mucho.

CONTABILIDAD DE COSTOS REALES (también denominada contabilidad de costos totales o impacto total): "reúne en la ecuación del desarrollo los bienes no relacionados con el mercado, como los activos ambientales y sociales, para permitir el análisis de los costos y beneficios de las decisiones empresariales y/o políticas. Con este fin, aspectos como los servicios de los ecosistemas o la salud (entre otros), deben tener un valor monetario. El objetivo final no es monetizar la naturaleza o las personas, sino traducir los recursos invisibles (como los activos intelectuales, humanos, sociales y naturales que no se capturan en las cuentas financieras históricas) en una moneda común para la toma de decisiones estratégicas sobre el impacto y las dependencias que afectan la creación general de valor" (FAO, 2017). 



\section{INTRODUCCIÓN}

"Necesitamos promover un cambio transformador en la forma en que producimos y consumimos alimentos. Tenemos que proponer sistemas alimentarios sostenibles que ofrezcan alimentos saludables y nutritivos y que también preserven el medio ambiente.

La agroecología puede ofrecer varias contribuciones a este proceso (..) la agroecología puede mejorar la resiliencia de los agricultores, especialmente en los países en desarrollo donde se concentra el hambre. Puede contribuir a impulsar la economía local. Puede salvaguardar los recursos naturales y la biodiversidad, asi como promover la adaptación al cambio climático y su mitigación. También puede promover la cultura local y el conocimiento tradicional. Estos múltiples beneficios hacen de la agroecología un camino importante para cumplir con la Agenda 2030 y abordar los desafíos que están interrelacionados.

José Graziano da Silva, ex Director General de la FAO Discurso de apertura en el 2o Simposio Internacional de Agroecología. Roma, Italia, 3 de abril de 2018

Vivimos en un momento crítico en el que está claro que la humanidad debe tomar medidas inmediatas para garantizar que los sistemas alimentarios que nos alimentan hoy, mañana y en el futuro sean sostenibles (FAO, 2012). La llegada del Antropoceno (Crutzen, 2006) y la velocidad sin precedentes de la pérdida de biodiversidad según lo informado por el IPBES (Brondizio et al, 2019) ha traído grandes preocupaciones sobre la capacidad del planeta Tierra para apoyar los hábitos dietéticos y de estilo de vida contemporáneos. Esto es particularmente cierto en los debates sobre la seguridad alimentaria para los centros urbanos en crecimiento, tanto en los países en desarrollo como en los desarrollados (Fressoz y Bonneuil, 2016). De hecho, el estudio de la Comisión EAT-Lancet sobre dietas saludables sostiene que, dado que "gran parte de la población mundial está inadecuadamente alimentada y muchos sistemas y procesos ambientales son empujados más allá de las fronteras seguras por la producción de alimentos, se necesita urgentemente una transformación mundial del sistema alimentario" (Willett et al, 2019). Esto significa que no podemos centrarnos solo en la sostenibilidad de las prácticas de producción de alimentos (por ejemplo, enfoques agroecológicos y resistentes al clima), sino que también debemos abordar la sostenibilidad de la demanda de alimentos saludables y diversificados. Pero, ¿quién es responsable de reequilibrar la demanda y la oferta de alimentos ahora y en 
el futuro? La creación de los Objetivos de Desarrollo Sostenible (ODS) como una nueva forma donde la comunidad mundial dirija el progreso para la superación de los desafíos sociales (Kanie y Biermann, 2017) sugiere que este reequilibrio es complejo, ya que los desafios sociales contemporáneos son interdependientes. Para la transición a sistemas alimentarios sostenibles, el cambio debe fomentarse en muchos aspectos críticos: cómo cultivamos y comemos alimentos, cómo usamos y conservamos los recursos naturales, cómo los transformamos en alimentos, energía y materiales, que son transportados, distribuidos y a veces desperdiciados; cómo los reciclamos una vez que ya no sean útiles en su forma original, cómo financiamos nuestras actividades, cómo organizamos nuestro trabajo y nuestras comunidades, y cómo valoramos los diferentes tipos de conocimiento que los diversos actores aportan a las actividades del sistema alimentario. Los cambios necesarios se recortan a través de las escalas de acción-desde los niveles de intervención local hasta los niveles territorial, nacional, regional e internacional- y todos tienen un papel que desempeñar, no pueden ser impulsados por los gobiernos ni por el sector privado por sí solos. Una miríada de ciudadanos individuales y grupos organizados de ciudadanos, investigadores y profesionales también deben contribuir.

Esto parece una tarea desalentadora, y si se delega solo a unos pocos actores que trabajan a escala global, entonces ciertamente lo es. Sin embargo, la variedad mundial de sistemas alimentarios ofrece oportunidades para cambios incrementales y en pequeña escala que pueden acumularse y conectarse a medida que se producen cambios mundiales. El ODS 12 - "Producción y consumo responsables" - establece metas para asegurar patrones sostenibles de consumo y producción. El trabajo realizado en el marco del Programa de Sistemas Alimentarios Sostenibles de One Planet Network (UN Environment, 2020), que contribuye a lograr el ODS 12, ofrece información sobre cómo las iniciativas a pequeña escala de actores especializados pueden superar los numerosos desafios que dificultan la sostenibilidad de los sistemas alimentarios convencionales. A partir de estas experiencias, podemos aprender cómo generar los cambios necesarios para influir e inspirar una transición más amplia en el sistema alimentario mundial.

Es en este contexto que discutimos la innovación en sistemas alimentarios sostenibles. Para garantizar que los futuros sistemas alimentarios sean sostenibles, se necesitan ideas, prácticas y formas de organización nuevas (u olvidadas) para garantizar que todas las actividades que llevan a nuestra boca alimentos cultivados de suelo o de organismos acuáticos sean sostenibles desde el punto de vista ambiental, económicamente inclusivas y socialmente justas.

Investigaciones realizadas en el pasado y años de experiencia práctica han demostrado que los pequeños agricultores y las familias agricultoras de los países en desarrollo han encontrado soluciones innovadoras a los desafios de la sostenibilidad en sus sistemas alimentarios locales (FAO, 2014, 2016a, 2018b, 2018c). A lo largo de los años, han utilizado numerosas palabras para describir lo que están haciendo: por ejemplo, sistemas agroecológicos de alimentos, agricultura sostenida por la comunidad, sistemas alimentarios tradicionales, mercados de agricultores, esquemas de cajas, cadenas cortas de valor alimentario, conjuntos alimentarios, sistemas agroalimentarios alternativos, sistemas alimentarios locales, mercados anidados, redes alimentarias campesinas. Con demasiada frecuencia, estas actividades pasan desapercibidas o permanecen dentro del ámbito de las comunidades locales. Es necesario compartir horizontalmente ideas y experiencias para ampliar (aumentar el tamaño) o expandir (replicar y adaptar en otros lugares) el impacto 
de estas innovaciones para que sean más inclusivas, de modo que más actores locales puedan experimentar y de esta forma encontrar ideas y acciones adecuadas a sus propias comunidades. Esta forma de replicación adaptada fomenta la innovación. Este es el propósito de este manual: facilitar el intercambio de ideas y acciones innovadoras en todo el mundo.

\section{AUDIENCIA, OBJETIVOS Y ALCANCE}

Este manual tiene como objetivo ayudar a aquellos actores -personas que llamamos innovadores de sistemas alimentarios - que están experimentando activamente en (re)valorar la agricultura en el marco de sistemas alimentarios sostenibles, es decir, cambiando la forma en que producimos, transformamos, transportamos, almacenamos, vendemos y consumimos nuestros productos alimenticios y agrícolas. En las experiencias de los autores, estos actores pueden ser agricultores, investigadores, comerciantes, grupos de consumidores, consumidores individuales comprometidos, ONG, funcionarios locales, entre muchos otros (FAO, 2016a).

Los cambios en los sistemas alimentarios son complejos y no existen hojas de ruta ya preparadas. Por el contrario, los innovadores necesitan navegar por la gama de retos y oportunidades que se presentan a lo largo del camino. Como impulsores del cambio, los innovadores necesitan evaluar su posición en su sistema, asi como sus objetivos, para agregar valor en sus propios términos. Si usted se está haciendo algunas de las siguientes preguntas, entonces este manual le debe ayudar a encontrar algunas respuestas:

1. ¿Están los clientes preguntando sobre sus prácticas sostenibles y no está seguro de cómo comunicarlas?

2. ¿Desea saber cómo acceder a los insumos necesarios para cumplir con los requisitos de su mercado?

3. ¿Tiene una base de consumidores y un grupo de productores dedicado, pero no puede mantener una oferta constante?

4. ¿Ha oído hablar de los sistemas de garantía participativa y desea aprender más sobre ellos?

5. ¿Quiere aprender a cotizar sus productos en diferentes mercados?

6. ¿Quiere saber más sobre intermediarios transparentes y cómo podrían apoyar su iniciativa?

7. ¿Quiere aprender a organizar una visita a la granja para los consumidores?

8. ¿Está intentando trabajar con otras iniciativas pero no está seguro de cómo colaborar?

9. ¿Quiere saber más sobre la producción sostenible para poder calcular mejor sus precios?

10. ¿Ha agotado sus medios habituales para financiar su iniciativa y está buscando nuevas ideas? 
Este manual proporciona pautas en forma de consejos, listas de verificación y matrices que ayudarán a los innovadores del sistema alimentario local a pensar más estratégicamente sobre las oportunidades que pueden existir a su alrededor. Utiliza ejemplos escritos por innovadores de sistemas alimentarios que han evaluado cada enfoque. Su objetivo es inspirar al lector a probar (o evitar, o adaptar) una solución al problema que enfrenta. Escrito en un lenguaje informal y de fácil acceso, este manual proporciona sugerencias para identificar oportunidades de innovación, al tiempo que hace hincapié en soluciones factibles y de bajo costo para los países en desarrollo.

\section{2. ¿CÓMO SE DESARROLLA ESTE MANUAL?}

Este manual está escrito por innovadores en sistemas alimentarios sostenibles que comparten sus propias experiencias.

La colaboración comenzó en 2013 con un llamamiento de la Organización de las Naciones Unidas para la Agricultura y la Alimentación (FAO) y el Instituto Nacional Francés de Investigación para la Agricultura, la Alimentación y el Medio Ambiente (INRAE) para reunir innovaciones e iniciativas que conectasen a los productores sostenibles en pequeña escala con los consumidores de los mercados locales. En 2015 se celebró en Bogotá, Colombia, un primer taller de investigadores y profesionales, en el que se elaboró un conjunto inicial de desafios para los sistemas alimentarios locales sostenibles, con unos 50 participantes de 20 países. En 2016 se celebró en Chiang Mai (Tailandia) un segundo taller de investigadores y profesionales, en el que 15 participantes de 15 países hicieron una reunión de ideas y elaboraron la estructura de los capítulos del manual y las esferas iniciales en que se necesitaba orientación. En 2017, se realizaron dos rondas de tres grupos de trabajo con el objetivo de escribir y revisar el texto de cada capítulo. En noviembre de 2017, se celebró el tercer taller de investigadores y profesionales en Nueva Delhi, India, donde 25 personas de 21 países finalizaron el texto y desarrollaron los viajes de aprendizaje incluidos en este manual. En 2018, el manual fue probado con los socios: Jaivik Haat en la India y el proyecto FAO-Global Environment Facility Resilience Climatique en Senegal.

Las siguientes iniciativas sobre sistemas alimentarios sostenibles han participado en la redacción de este manual: Claudia Helena Prieto, Parque Temático en Salud Pública Chaquen (Colombia), CICODEV (Senegal), Earth Net Foundation (Tailandia), Ecovida (Brasil), Familia de la Tierra (Colombia), FreshVeggies Ltd. (Uganda), National Agro-Sylvo-Pastoral Development Fund (FNDASP) (Senegal), Fundación Ekorural (Ecuador), IFOAM Organics International (Perú y Nueva Zelanda), Jaivik Haat/Gram Disha Trust (India), Keystone Foundation (India), PELUM Kenya (Kenya), Quezon PGS (Filipinas), RERA SD (Croacia), Shared Harvest (China), Tea Research Institute of Tanzania (República Unida de Tanzanía), Terrahabilis - Demeter (Perú), the international CSA network URGENCI (Francia y el mundo). La orientación resultante está destinada a las personas que trabajan en espacios urbanos y rurales que desean asegurar que los alimentos se produzcan y consuman de manera sostenible. 


\section{3. ¿CÓMO LEER ESTE MANUAL?}

El manual está diseñado como una historia de "elige tu propia aventura" - no hay una manera "correcta" de empezar a leerlo.

- Se puede leer a partir de cualquier capítulo, dependiendo de intereses específicos. Por ejemplo, si usted está principalmente interesado en cómo apoyar la colaboración entre agricultores e investigadores, puede leer el capítulo sobre compartir y cocrear conocimientos (capítulo 4).

- Se puede utilizar en un curso de capacitación o en una reunión de planificación estratégica entre las partes interesadas que colaboran en una iniciativa de sistema alimentario sostenible. En este caso, puede utilizarse como herramienta para estructurar una discusión y conducir al desarrollo de un plan de acción (sección 3).

No importa cómo opte por leerlo, esperamos que el manual le lleve a una aventura de aprendizaje, un viaje de innovación que comienza desde su idea hasta la integración de más sostenibilidad en su sistema alimentario.

El siguiente capítulo proporciona una guía para diseñar su aventura de aprendizaje, que le ayudará a implementar el cambio que desea ver. Cada capítulo se puede leer por separado.

Imaginamos las secciones del manual como un círculo formado por interconexiones (figura 1), dadas las numerosas posibilidades de vínculos entre ellas.

La última sección de cada capítulo ofrece al lector posibles alternativas sobre como continuar la aventura de aprendizaje. Esto asegura que el manual ofrezca múltiples oportunidades para la exploración y el aprendizaje. 
Figura 1: Posibles aventuras de aprendizaje por primer capítulo de elección

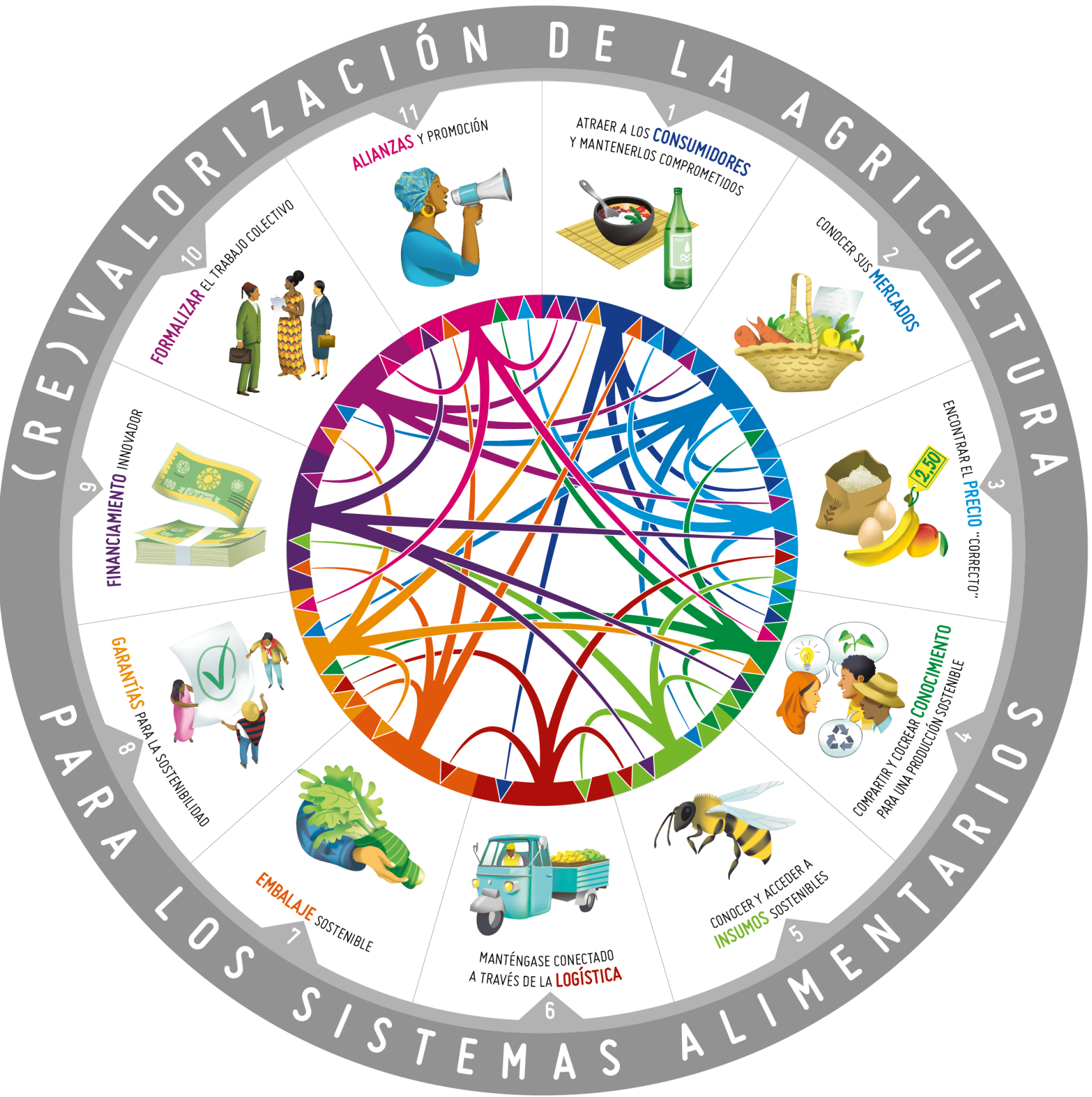




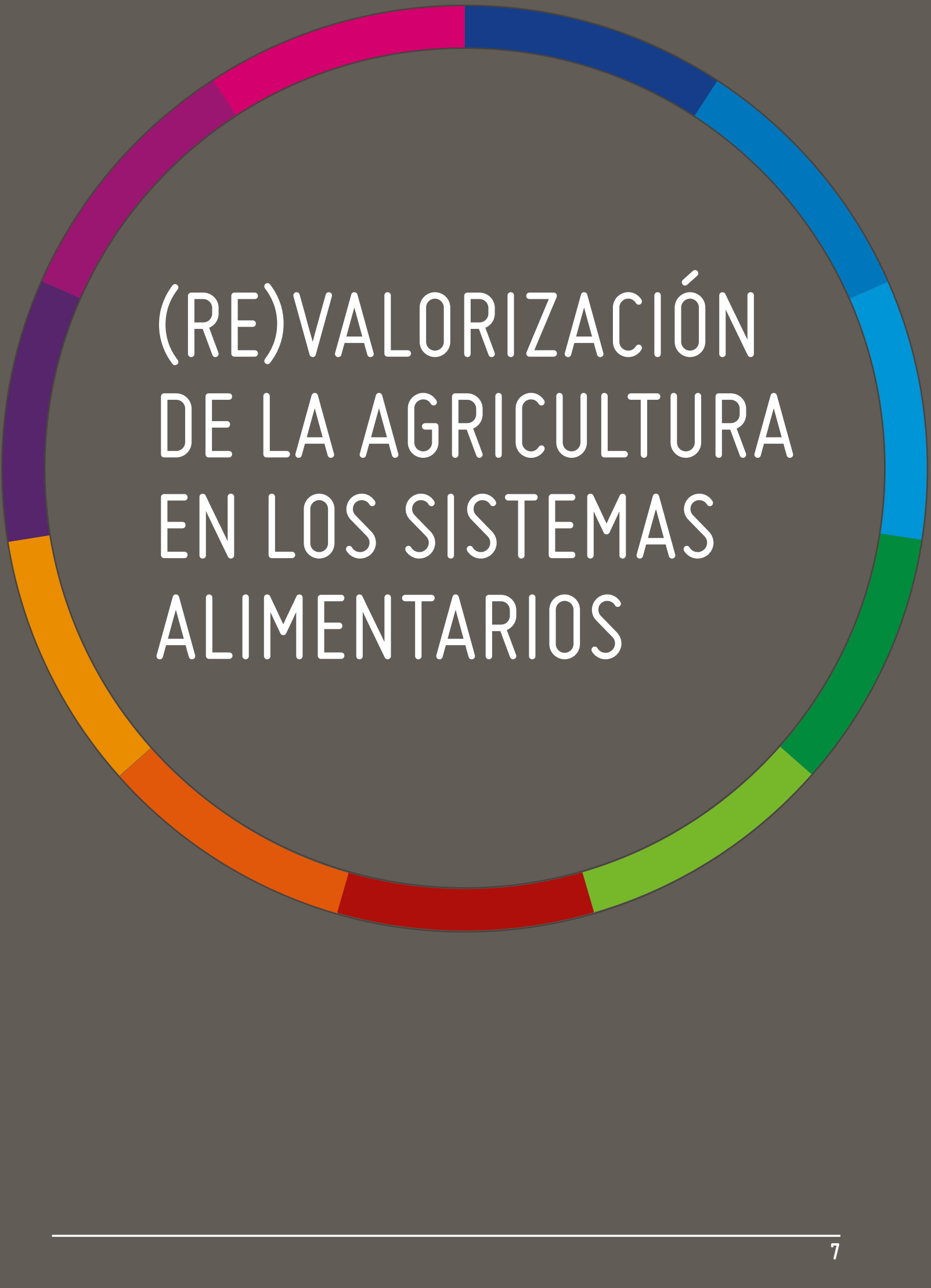




\section{"Usted necesita un agricultor al menos dos o tres veces al dia para comer; pero necesita un médico o un abogado sólo una vez al año (si realmente tiene mala suerte)"}

Un campesino y activista de alimentos de Himachal Pradesh, India

\section{1. ¿POR QUÉ ESTO ES IMPORTANTE?}

- La agricultura es uno de los principales factores que contribuyen al cambio climático, y a menudo es el primer sector que se ve afectado por él. Las transiciones en la agricultura, la ganadería, la pesca y las prácticas forestales son eficaces para reducir las emisiones de gases de efecto invernadero que contribuyen al cambio climático.

- En 2016, por primera vez en casi 70 años, la tasa de malnutrición mundial comenzó a aumentar. Esto es el resultado de la doble amenaza de desnutrición y obesidad que se encuentra cada vez más en el mismo país. La FAO advirtió que un mundo sin hambre y malnutrición probablemente no se logrará para 2030, a menos que se apliquen nuevos enfoques (FAO et al, 2017).

- A menudo la agricultura se "olvida" o se considera como "trabajo pesado". Esta perspectiva ignora la belleza de los paisajes agrícolas, el valor que los agricultores aportan a las economías nacionales, y la salud y diversidad de todos los seres vivos.

- Las experiencias de todo el mundo sugieren que los enfoques agroecológicos pueden cambiar las formas en que los productores, los consumidores, los intermediarios y los encargados de formular políticas valoran la sostenibilidad y la agricultura, aunque esto requiere trabajo y tiempo.

- A escala mundial, los consumidores reconocen cada vez más los fuertes vínculos entre los métodos de producción de alimentos y la calidad de los alimentos (en términos de inocuidad de los alimentos, nutrición y efectos ambientales). En consecuencia, son cada vez más exigentes en términos de calidad e información sobre las prácticas de producción agrícola y el origen de los alimentos.

- Antes de comenzar a hacer cambios en su sistema de alimentos, es importante que usted vislumbre su objetivo, qué valores quiere que su sistema (re)produzca, y cómo planea llegar allí. Por estas razones, y muchas más, la revaluación de la agricultura dentro de la sociedad (y específicamente, a través de cambios en el sistema alimentario) es fundamental para asegurar la sostenibilidad de nuestras actividades humanas. 


\section{2. ¿QUÉ SIGNIFICA "VALOR» EN ESTE MANUAL?}

El valor es el resultado de un proceso de evaluación y negociación sobre la riqueza de un bien o un servicio (VATIN, 2013); es un compromiso entre calidad y precio. Este término también se refiere a la forma en que un producto crea valor para los actores que lo están elaborando, utilizando y comercializando (FAO, 2018b). Por último, el valor de los alimentos cultivados y consumidos también está relacionado con los valores sociales y culturales de la comunidad en cuestión (por ejemplo, conservación del medio ambiente, salud y bienestar, equidad, solidaridad, economía local, tradición y dignidad humana) (Ostrom et al, 2017).

La forma en que un sistema alimentario crea valor para las personas está vinculada a la forma en que se organiza el sistema y a los valores que se priorizan. La literatura sobre las diversas economías (Gibson-Graham, 2008) se centra en las posibilidades de realizar nuevos mundos económicos mediante la organización de la empresa, el trabajo, la propiedad, las transacciones y las finanzas de maneras alternativas que puedan repriorizar los valores sociales y los tipos específicos de actividades económicas productivas. La figura 2 es una representación gráfica simple de una priorización del valor de la agricultura dentro de los sistemas alimentarios actuales: el valor que produce para el desarrollo económico (es decir, contribuir a una economía de mercado), el valor que crea para la salud humana y la nutrición (es decir, alimentar la economía alimentaria) y el valor que crea para los procesos ecológicos del planeta (es decir, participar en la economía de la naturaleza). De hecho, estamos ampliando continuamente las demandas humanas que se imponen a la agricultura, y a su cada vez menor base de recursos naturales, para satisfacer las necesidades de la expansión de la nutrición y las economías de mercado (FAO, 2012).

Figura 2: (Re)valorar la agricultura

COMO SE PRIORIZA EL VALOR HOY DÍA

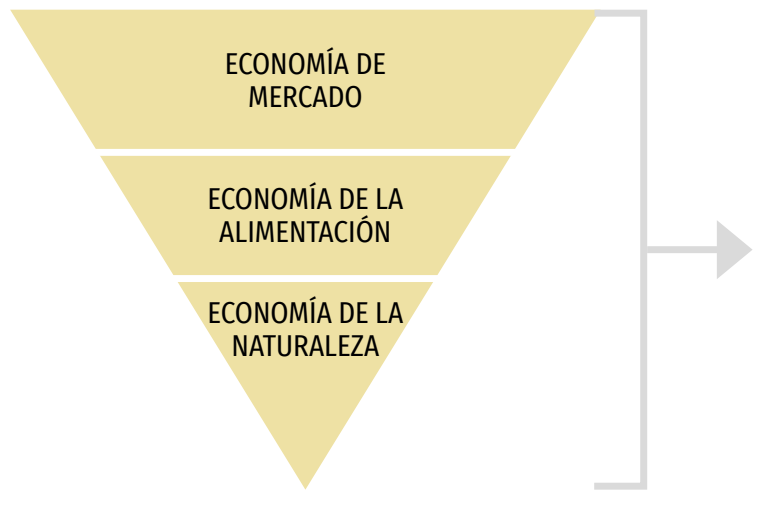

COMO SE PODRÍA PRIORIZAR EL VALOR EN EL FUTURO

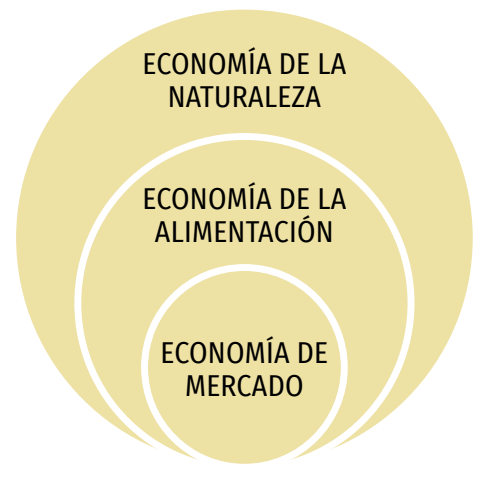

Fuente: Lluvia de ideas de los autores Chiang Mai, 2016. Adaptada de Jaime Aguirre y O. Nieto, Familia de la Tierra, Colombia. 
En las economías de mercado, el valor económico (o monetario) de la agricultura es muy importante, ya que proporciona los medios para vivir vidas saludables y productivas. Sin embargo, para garantizar estos mismos beneficios entre las generaciones futuras, el valor económico de la agricultura no puede ser su único valor. Si se descuidan continuamente los valores sociales, nutricionales y ecológicos (es decir, la economía de la nutrición y la economía de la naturaleza), se perpetuarán las modalidades insostenibles de producción y consumo, junto con las consecuencias perjudiciales para el medio ambiente, la salud y la sociedad que ya se han observado. De hecho, si este camino se sigue continuamente, el hipotético triángulo presentado en la Figura 2 se derribará.

Los cambios sistémicos deben volver a priorizar la forma en que la agricultura contribuye a estas tres economías diferentes, para establecer una base sólida y saludable compuesta por una economía de la naturaleza, en lugar de una frágil centrada en la extracción de recursos. El fortalecimiento de las formas regenerativas de la agricultura, donde las prácticas de producción pueden restaurar los ecosistemas y traer salud a los agricultores, enriquecerá la forma en que nos alimentamos a nosotros mismos y garantizará que esto sea económicamente viable e inclusivo para todos los actores. Así pues, la economía de mercado, con su importante enfoque en la generación de riqueza, debe reintegrarse en la economía de la nutrición, para proporcionar salud universal y eliminar la inseguridad alimentaria y nutricional. Para que se cumplan los ODS, estos valores deben alcanzarse dentro de los límites planetarios actuales de la economía de la naturaleza.

En el contexto de este manual, se entiende con precisión que "revalorizar" el papel de la agricultura es esta repriorización de los valores.

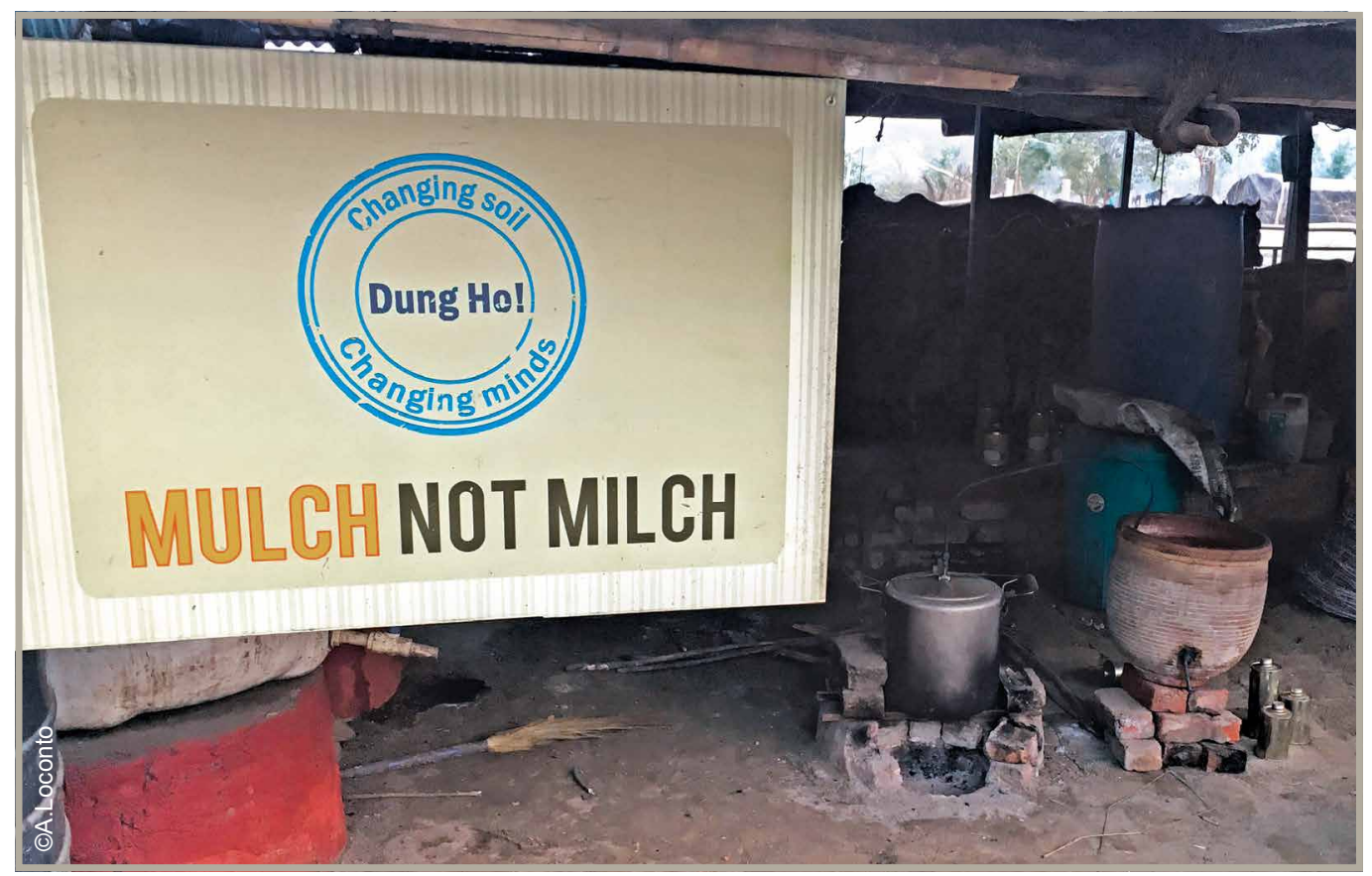


La agricultura puede revalorarse de múltiples maneras, teniendo en cuenta sus contribuciones económicas, culturales, sociales y ambientales:

- Una mayor diversificación de los sistemas agrícolas (por ejemplo, sistemas arroz/pescado o arroz/pato o sistemas agroforestales) puede generar una variedad de productos y servicios con un alto valor ecológico, económico y cultural.

- Numerosos ejemplos de diferentes agroecosistemas muestran que la adopción de prácticas agroecológicas regenerativas en la granja puede crear valores ecológicos, de salud y sociales a través de una mejor conservación del agua, la salud del suelo, el aumento de la biodiversidad, el retorno de la vida silvestre, y entornos ecológicos y de vida saludables para el agricultor y su familia, con condiciones de trabajo más seguras.

- La creciente resiliencia de la producción y el consumo agroecológicos aportará valor económico, social y ecológico, tanto a los productores como a los consumidores durante períodos de estrés ambiental, como sequías, inundaciones u otros fenómenos climáticos.

- Otra forma de entender la "revaluación" es a través de la adición de valor, usando tecnologías de procesamiento para aumentar la vida útil, para crear nuevos productos y subproductos, y para hacer que los productos tradicionales estén más disponibles, recuperando así el valor ecológico, nutricional, cultural y económico. Algunos ejemplos incluyen la fermentación (para convertir las materias primas en nuevos productos de valor añadido, por ejemplo, encurtidos, kimchi, queso, vino, carnes curadas naturalmente, pan de masa fermentada, salsa de soya, tempeh, miso); otras formas de valor añadido pueden tener lugar en la granja o en economías locales utilizando tecnologías biológicas naturales, como la conversión de residuos en hongos; elaboración de inoculantes microbianos a partir de materiales animales y vegetales y suelos locales; preparación de plaguicidas botánicos o elaboración de biopesticidas locales mediante hongos o bacterias, vermicompost o biocarbón.

- El valor medicinal y nutricional puede crearse mediante el cultivo y el consumo de "variedades nativas", y de especies desatendidas y subutilizadas, cuyas propiedades medicinales, químicas y nutritivas específicas pueden confirmarse a partir de la experiencia o verificarse mediante pruebas de laboratorio y otros métodos.

- Las innovaciones institucionales pueden crear valor a través de la diversificación de los servicios que las granjas pueden proporcionar. Por ejemplo:

- Educación: los agricultores sostenibles pueden ser maestros maravillosos que proporcionan ejemplos de nuevos estilos de vida y modos de cultivo para otros miembros de la comunidad, tanto cercanos como lejanos.

- Solidaridad: la confianza y la amistad entre los consumidores y los agricultores se pueden crear mediante la agricultura sostenida por la comunidad (ASC) y otras formas de vínculos directos entre la producción y el consumo.

- Comunidades: en muchos países en desarrollo, los intercambios de conocimientos basados en la comunidad y la confianza interpersonal se construyen y revitalizan con sistemas de garantía participativa (SPG) para la agricultura orgánica, donde los productores administran el proceso de certificación.

Revalorizar la agricultura en sistemas alimentarios sostenibles, significa también repriorizar los valores económicos, sociales, culturales, nutricionales y/o ecológicos en las decisiones que se toman sobre cómo, dónde y cuándo producir, comerciar y consumir alimentos. 
Requiere cambios en algunas instituciones de gobernanza del sistema alimentario y en las infraestructuras que unen a productores y consumidores. Esto significa que todo actor existente del sistema alimentario que tenga la capacidad de producir, procesar, comerciar y consumir, debe encontrar maneras de hacer más sostenible su actividad.

Una "iniciativa sobre sistemas alimentarios locales sostenibles" se refiere al grupo de actividades relacionadas con la producción, elaboración, intercambio, investigación y educación que reúnen a personas y organizaciones que trabajan juntas para hacer más sostenible la producción y el consumo agroalimentario local.

En la mayoría de los casos, esto se refiere al grupo de actores que es el principal facilitador de las prácticas sostenibles dentro de su sistema alimentario local (por ejemplo, Familia de la Tierra, Freshveggies PGS y Bhoomi Ka).

Fuente: FAO, 2016; 2018.

En todo el mundo, hay un gran número de personas comprometidas a revaluar la agricultura y la sostenibilidad, pero necesitan ideas prácticas, herramientas y habilidades para hacer que los sistemas alimentarios sean más funcionales. Los nuevos actores tendrán que aprender a producir, comerciar y consumir alimentos de manera sostenible y, en consecuencia, se necesitarán nuevos tipos de conocimientos, tecnologías e interacciones.

Para reequilibrar la oferta y la demanda de alimentos sostenibles, y para garantizar que los actores viejos y nuevos sean responsables de las transiciones hacia sistemas alimentarios sostenibles, se necesitan más oportunidades para que estos actores piensen y trabajen colectivamente. Basándose en sus valores repriorizados, los actores pueden imaginar futuros sistemas alimentarios sostenibles, y actuar localmente para hacer de esto una realidad, que es precisamente el propósito de este manual.

En la siguiente sección, presentamos una herramienta de intercambio de ideas que puede usarse dentro de una iniciativa para imaginar escenarios futuros, aclarar valores y planificar acciones futuras. 


\section{USAR EL MANUAL PARA INICIAR EL APRENDIZAJE Y CURSO DE ACCIÓN}

Este manual se puede utilizar como material de apoyo para sesiones de formación o para sesiones colectivas de intercambio de ideas. En esta sección, ofrecemos notas de los facilitadores para guiar a un grupo a través de la lectura del manual. Utilizamos un ejemplo desarrollado mientras se prueba el manual para ilustrar un posible escenario.

El plazo propuesto es de una hora y media para preparar el escenario, y luego de dos a tres horas para trabajar a través del manual y construir un plan de acción. Si está utilizando el manual en una sesión de formación, querrá tomar más tiempo (al menos dos días para cubrir todos los temas), pero si lo está utilizando en una reunión de estrategia de medio día o de un día, puede hacerlo rápidamente en esta cantidad de tiempo.

Pasos sencillos para comenzar la trayectoria:

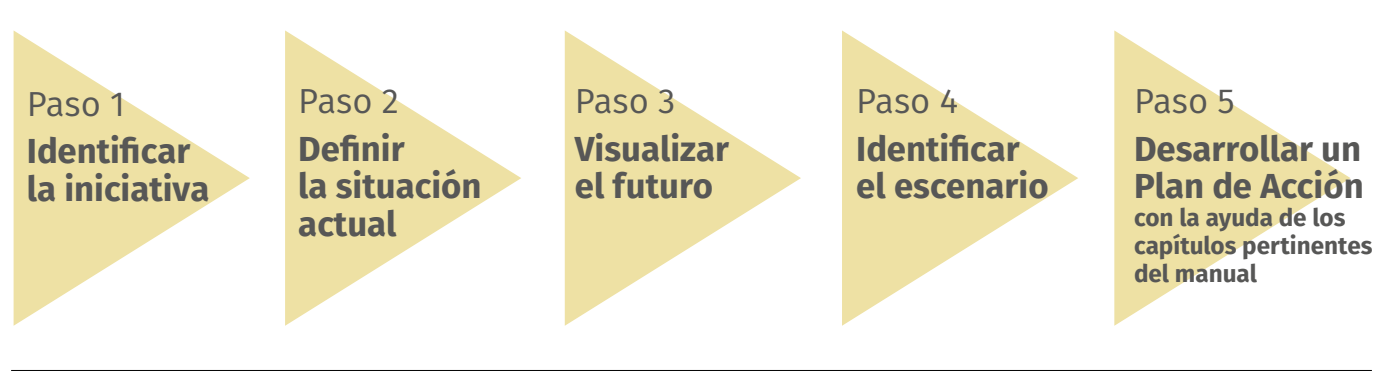

\section{Paso 1: Identificar la iniciativa}

\section{Facilitador:}

- Usted puede usar este ejercicio con un grupo de personas, que ya están trabajando juntas en un proyecto o iniciativa de sistemas alimentarios específicos, para hacer una lluvia de ideas colectiva sobre desafios, escenarios y posibles soluciones.

- Si está utilizando este ejercicio durante una sesión de formación o talleres con personas que trabajan en diferentes iniciativas, dirija una discusión (15 minutos) para que el grupo identifique colectivamente una iniciativa que estarán explorando durante este ejercicio.

[Algunas de las preguntas principales pueden ser: ¿hay algún problema específico que esté tratando de resolver en este momento? ¿Ha realizado recientemente un ejercicio de planificación estratégica en el que discute algunas ideas para objetivos futuros? Puede seleccionar uno de los proyectos del participante como caso práctico; el participante proporcionará la información sobre su iniciativa, mientras que otros miembros del grupo le ayudarán a pensar a través de preguntas y soluciones\}. 
Si usted está en un grupo grande, podría dividirse en diferentes grupos de un máximo de ocho a diez participantes, que trabajarán en diferentes iniciativas.

Designe un relator, que redacte la información producida durante el ejercicio, y un portavoz, que presente el escenario y el plan de trabajo al final del taller.

\section{Paso 2: Definir la situación actual}

\section{Facilitador de grupo:}

- Dirija una discusión (30 minutos) que resalte los diferentes elementos de la situación actual de la iniciativa o del sistema alimentario local que los participantes desean mejorar.

[El grupo debe proporcionar suficiente información para describir el escenario actual que se presentará en la plenaria.]

ESCENARIO ACTUAL

\begin{tabular}{|c|c|}
\hline \multicolumn{2}{|c|}{ Nombre de la iniciativa Campaña Bhoomika (situación en noviembre de 2017) } \\
\hline País / región India / Delhi & \\
\hline $\begin{array}{l}\text { Alcance } \\
\text { ¿A qué nivel (local, territorial, } \\
\text { nacional, global) de } \\
\text { intervención está trabajando? }\end{array}$ & A nivel nacional \\
\hline $\begin{array}{l}\text { Valor(es) } \\
\text { ¿Cuál es el valor (qué visión } \\
\text { está tratando de lograr su } \\
\text { iniciativa para un sistema } \\
\text { alimentario sostenible)? }\end{array}$ & $\begin{array}{l}\text { Comida "limpia, verde y justa". } \\
\text { - Valores gandhianos. } \\
\text { - Conexiones sostenibles, interacción directa, transparencia, } \\
\text { conocimiento interpersonal. } \\
\text { Inclusividad = todos los actores de la cadena de suministro se } \\
\text { conocen entre sí, incluyendo los pequeños productores. } \\
\text { - Empresa de productores/agricultores. }\end{array}$ \\
\hline $\begin{array}{l}\text { Plazo } \\
\text { ¿Cuál es el plazo para la } \\
\text { acción? }\end{array}$ & $\begin{array}{l}\text { La iniciativa tiene un año, y actualmente está trabajando en un plan } \\
\text { de proyecto de tres años. El objetivo es crear un órgano institucional } \\
\text { que apoye una campaña nacional de sensibilización de los } \\
\text { ciudadanos, y que promueva el apoyo a las políticas en materia de } \\
\text { alimentos limpios, verdes y justos. } \\
\text { Plazo = diez años. }\end{array}$ \\
\hline
\end{tabular}




\section{Paso 3: Imaginar el futuro}

\section{Facilitador de grupo:}

Dirija una discusión (15 minutos) para identificar la visión focal del escenario, especificando qué valor(es) definirá(n) el estado futuro de su iniciativa.

Tómese su tiempo para definir con precisión cuál es la cuestión central, ya que esto debería ayudar a captar el valor que está tratando de integrar en el futuro sistema alimentario sostenible. Guíe el debate para que se manifiesten claramente algunos de los valores fundamentales que la iniciativa pretende alcanzar. Ayude a los participantes a plantear preguntas al líder del escenario para revelar los valores fundamentales. Consolide estos valores en una visión prospectiva que capture el estado futuro deseado de la iniciativa.

Escriba esto como su visión "twitteable" de una línea:

\section{Bhoomika será reconocida a nivel nacional como una plataforma institucionalizada para} conectar a los pequeños productores y consumidores sostenibles.

140 caracteres máx.

\section{Paso 4: Identificar el escenario}

Luego, a partir del escenario actual, discuta las posibles incertidumbres que podrian ocurrir en los próximos cinco a diez años (30 minutos). Destaque las mayores amenazas y las mayores oportunidades que la iniciativa podría enfrentar dentro del plazo propuesto del plan de acción. A continuación, elija en cuál trabajar dentro del ejercicio.

Aliente los debates sobre las incertidumbres que se producen a nivel nacional e internacional y en el marco de la propia iniciativa, que deben incluir elementos positivos y negativos.

Ejemplo:

\section{Amenaza:}

"El nuevo marco reglamentario del Gobierno excluye los sistemas de garantía participativa como verificación/certificación de los alimentos orgánicos".

\section{Oportunidad:}

"Un nuevo escándalo alimentario en todo el país provoca una fuerte conciencia de los consumidores y la demanda de alimentos seguros y sostenibles". 


\begin{tabular}{|c|c|c|}
\hline Incertidumbres & Las mayores amenazas & Las mayores oportunidades \\
\hline $\begin{array}{l}\text { Cambio social } \\
\text { ¿Cuáles son los posibles } \\
\text { cambios sociales que } \\
\text { pueden afectar su } \\
\text { iniciativa? }\end{array}$ & $\begin{array}{l}\text { Los pequeños agricultores están } \\
\text { marginados sin ayuda alguna. } \\
\text { "No hay escape de la revolución } \\
\text { verde". } \\
\text { - La migración rural-urbana está } \\
\text { afectando la dinámica de la } \\
\text { población local: no se dispone del } \\
\text { tipo adecuado de personas en las } \\
\text { zonas rurales. }\end{array}$ & $\begin{array}{l}\text { Existe una enorme demanda de } \\
\text { "alimentos sostenibles" por parte } \\
\text { de los consumidores; los mercados } \\
\text { orgánicos nacionales están creciendo } \\
\text { anualmente en dos digitos. }\end{array}$ \\
\hline $\begin{array}{l}\text { Economía } \\
\text { ¿Qué cambios en el } \\
\text { comercio, los mercados } \\
\text { y la economía en general } \\
\text { influirán en cómo usted } \\
\text { creará los mercados? }\end{array}$ & $\begin{array}{l}\text { Hay una falta de transparencia. } \\
\text { - No se reconoce el verdadero } \\
\text { costo de los alimentos. } \\
\text { - Los medios de subsistencia de } \\
\text { los pequeños agricultores son } \\
\text { inadecuados. } \\
\text { - Los mercados urbanos están } \\
\text { dominados por supermercados y } \\
\text { los mercados tradicionales están } \\
\text { desapareciendo. } \\
\text { Los mercados rurales } \\
\text { dependen del sistema de } \\
\text { raciones del Gobierno. }\end{array}$ & $\begin{array}{l}\text { Se pueden crear mercados privados } \\
\text { en tierras privadas. } \\
\text { El acceso a Internet está } \\
\text { aumentando. } \\
\text { Se podría utilizar un nuevo } \\
\text { mecanismo de financiación para } \\
\text { ampliar rápidamente la iniciativa. }\end{array}$ \\
\hline $\begin{array}{l}\text { Conocimiento y tecnología } \\
\text { ¿Qué avances científicos } \\
\text { o nuevas tecnologías } \\
\text { cambiarán la forma en } \\
\text { que crece, procesa y } \\
\text { comercializa alimentos en } \\
\text { su iniciativa? }\end{array}$ & $\begin{array}{l}\text { OGM } \\
\text { industria agroquímica local } \\
\text { masiva. }\end{array}$ & $\begin{array}{l}\text { - Venta al por menor moderna } \\
\text { - Redes sociales } \\
\text { - Mercados campesinos } \\
\text { - Herramientas portátiles adecuadas } \\
\text { - Métodos agroecológicos de } \\
\text { producción (intensificación del } \\
\text { arroz sostenible) } \\
\text { Transición de la agroecología } \\
\text { tradicional a la moderna }\end{array}$ \\
\hline $\begin{array}{l}\text { Medio ambiente } \\
\text { ¿En qué tipo de ambiente } \\
\text { agroecológico va a cultivar } \\
\text { sus alimentos? }\end{array}$ & $\begin{array}{l}\text { Baja biodiversidad. } \\
\text { - Agotamiento del agua. } \\
\text { Baja capacidad de gestión } \\
\text { del agua. } \\
\text { Contaminantes orgánicos } \\
\text { persistentes. }\end{array}$ & Agricultura de tierras áridas \\
\hline $\begin{array}{l}\text { Política } \\
\text { ¿Qué cuestiones políticas } \\
\text { y de seguridad afectarán a } \\
\text { su iniciativa? }\end{array}$ & $\begin{array}{l}\text { Las regulaciones actuales de } \\
\text { seguridad alimentaria requieren } \\
\text { certificación continua. } \\
\text { Los mecanismos de financiación } \\
\text { para los pequeños productores } \\
\text { orgánicos (por ejemplo, para los } \\
\text { insumos) son incoherentes. }\end{array}$ & $\begin{array}{l}\text { Desde 2016, los programas } \\
\text { gubernamentales apoyan los } \\
\text { sistemas alimentarios sostenibles: } \\
\text { Sistema tradicional de mejora de } \\
\text { la agricultura } \\
\text { Ingresos monetarios para los } \\
\text { agricultores basados en el tiempo }\end{array}$ \\
\hline
\end{tabular}




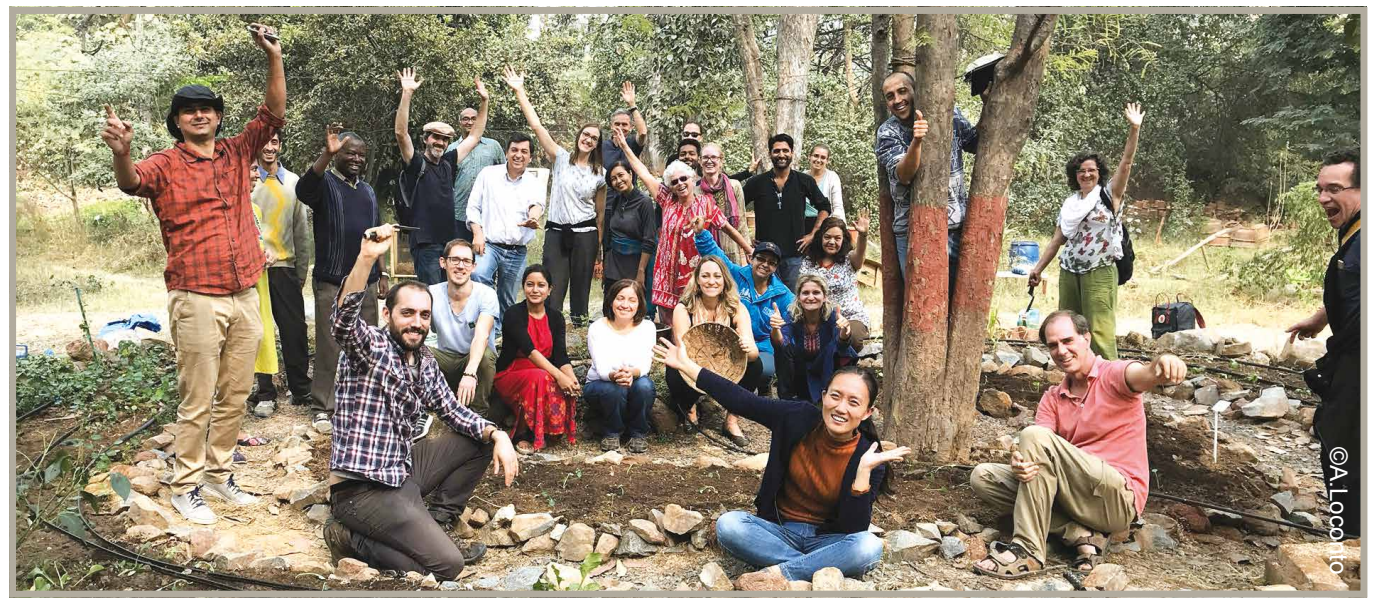

\section{Paso 5: Desarrollar un plan de acción con la ayuda de los capítulos pertinentes del manual}

\section{Facilitador:}

La cantidad de tiempo asignada a esta actividad depende de cómo haya organizado el taller.

Pida a los participantes que elijan un problema como escenario que abordarán desarrollando un plan de acción, ya sea para mitigar la mayor amenaza o para aprovechar la mayor oportunidad identificada anteriormente. Podría ser útil dividir el grupo en dos y hacer que un subgrupo trabaje sobre la(s) amenaza(s) y el otro trabajo sobre la(s) oportunidad(s).

A través de las discusiones, los participantes identifican primero el punto de entrada de su escenario (es decir, la cuestión prioritaria o el punto de partida para el trabajo). Con base a esta cuestión principal, deben identificar el capítulo del libro que podría proporcionar algunos consejos iniciales.

Utilice los capítulos del manual como un recurso para que los participantes lean y obtengan ideas para la acción o presente el contenido del capítulo seleccionado en un formato de capacitación (PowerPoint $u$ otro) para proporcionar algunas ideas y ejemplos de acciones concretos. El plan de acción resultante debe proporcionar una vía para abordar diversas cuestiones tratadas en el manual (es decir, comenzar con el capítulo 4, luego pasar al capítulo 8, etc.).

- Si usted está por su cuenta, el plan se convierte en su propia tabla personal de contenidos.

- Si se encuentra en una reunión de estrategia/lluvia de ideas, este ejercicio puede ayudar al grupo a definir el orden y la prioridad para abordar varios problemas y generar soluciones creativas.

- Si está en una sesión de formación, el ejercicio puede ayudar a reorganizar el orden de las sesiones en el resto del taller, de modo que se base en un enfoque interactivo fundamentado en problemas, que se construye colectivamente con los participantes, en lugar de seguir una plantilla/orden predefinido para determinar los temas. 


\begin{tabular}{|c|c|c|}
\hline \multicolumn{3}{|c|}{$\begin{array}{l}\text { La mayor amenaza o la mayor oportunidad - usted decide cuál será la guía de su experiencia. } \\
\text { La mayor amenaza: social, el tipo correcto de personas no están disponibles. Los que están dedicados a } \\
\text { la iniciativa no están dispuestos a permanecer con ella por cinco a diez años. }\end{array}$} \\
\hline Punto de entrada & Capítulo de referencia & $\begin{array}{l}\text { Medidas propuestas } \\
\text { (con base a los conocimientos del capítulo) }\end{array}$ \\
\hline $\begin{array}{l}\text { Entrar en la } \\
\text { organización }\end{array}$ & $\begin{array}{l}\text { Formalizar el } \\
\text { trabajo colectivo } \\
\text { (capitulo 10). }\end{array}$ & $\begin{array}{l}\text { Crear un diagrama que pueda demostrarles a los } \\
\text { miembros cómo la organización Bhoomika estál } \\
\text { estaría estructurada. } \\
\text { Revisar la visión y asegurar que todos la compartan. } \\
\text { Distribuir los roles y responsabilidades de todas las } \\
\text { personas comprometidas con el proyecto (incluyendo } \\
\text { voluntarios). } \\
\text { Gestionar el crecimiento de la organización: asegúrese } \\
\text { de cumplir primero con los requisitos legales. } \\
\text { Contratar a personas comprometidas al interior de la } \\
\text { red Bhoomika. }\end{array}$ \\
\hline $\begin{array}{l}\text { Se está quedando sin } \\
\text { dinero para crecer }\end{array}$ & $\begin{array}{l}\text { Financiamiento } \\
\text { innovador } \\
\text { (capitulo 9). }\end{array}$ & $\begin{array}{l}\text { Determinar las necesidades financieras para el } \\
\text { crecimiento (el plan de negocios). } \\
\text { - Consejo: intente el presupuesto participativo. } \\
\text { Desarrolle un fondo de inversión. } \\
\text { Trate de obtener la inversión del consumidor (por } \\
\text { ejemplo, aprenda sobre los modelos ASC). } \\
\text { - Ayude a los agricultores a acceder a los fondos del } \\
\text { grupo disponibles. }\end{array}$ \\
\hline $\begin{array}{l}\text { Atraer a los } \\
\text { consumidores }\end{array}$ & $\begin{array}{l}\text { Atraer a los } \\
\text { consumidores } \\
\text { y mantenerlos } \\
\text { comprometidos } \\
\text { (capitulo 1). }\end{array}$ & $\begin{array}{l}\text { Pruebe algunas de las sugerencias propuestas en la } \\
\text { pág. } 26 \text { con los consumidores potenciales. }\end{array}$ \\
\hline $\begin{array}{l}\text { Asociación tanto } \\
\text { para la creación de } \\
\text { capacidades para los } \\
\text { agricultores como } \\
\text { para el acceso a los } \\
\text { mercados }\end{array}$ & $\begin{array}{l}\text { Alianzas y promoción } \\
\text { (capítulo 11). }\end{array}$ & $\begin{array}{l}\text { Conéctese con el grupo adecuado de personas para } \\
\text { establecer colaboraciones (intente colaborar con la Ruta } \\
\text { Comestible). }\end{array}$ \\
\hline $\begin{array}{l}\text { La comercialización } \\
\text { como una manera de } \\
\text { recaudar capital }\end{array}$ & $\begin{array}{l}\text { Conocer sus mercados } \\
\text { (capítulo 2). }\end{array}$ & $\begin{array}{l}\text { Fusión con un punto de venta. } \\
\text { Por encima de todo, asegúrese de que las ventas en el } \\
\text { mercado continúen. }\end{array}$ \\
\hline \multirow[t]{2}{*}{$\begin{array}{l}\text { Creación de } \\
\text { capacidades para los } \\
\text { agricultores }\end{array}$} & $\begin{array}{l}\text { Compartir y cocrear } \\
\text { conocimiento para } \\
\text { una producción } \\
\text { sostenible (capítulo 4). }\end{array}$ & $\begin{array}{l}\text { Fomentar el intercambio de conocimientos entre } \\
\text { agricultores dentro de la red. } \\
\text { Desarrollar aprendizajes. }\end{array}$ \\
\hline & & Además, dejar las cosas al tiempo y al azar... \\
\hline
\end{tabular}

Una sesión plenaria de clausura para presentar el trabajo del grupo alentará el diálogo entre los participantes, para comparar los planes y decidir colectivamente sobre las acciones que potencialmente pueden abordar en los diferentes escenarios. 


\section{LA AVENTURA DEL APRENDIZAJE: ¿POR DÓNDE EMPEZAR, A DÓNDE IR?}

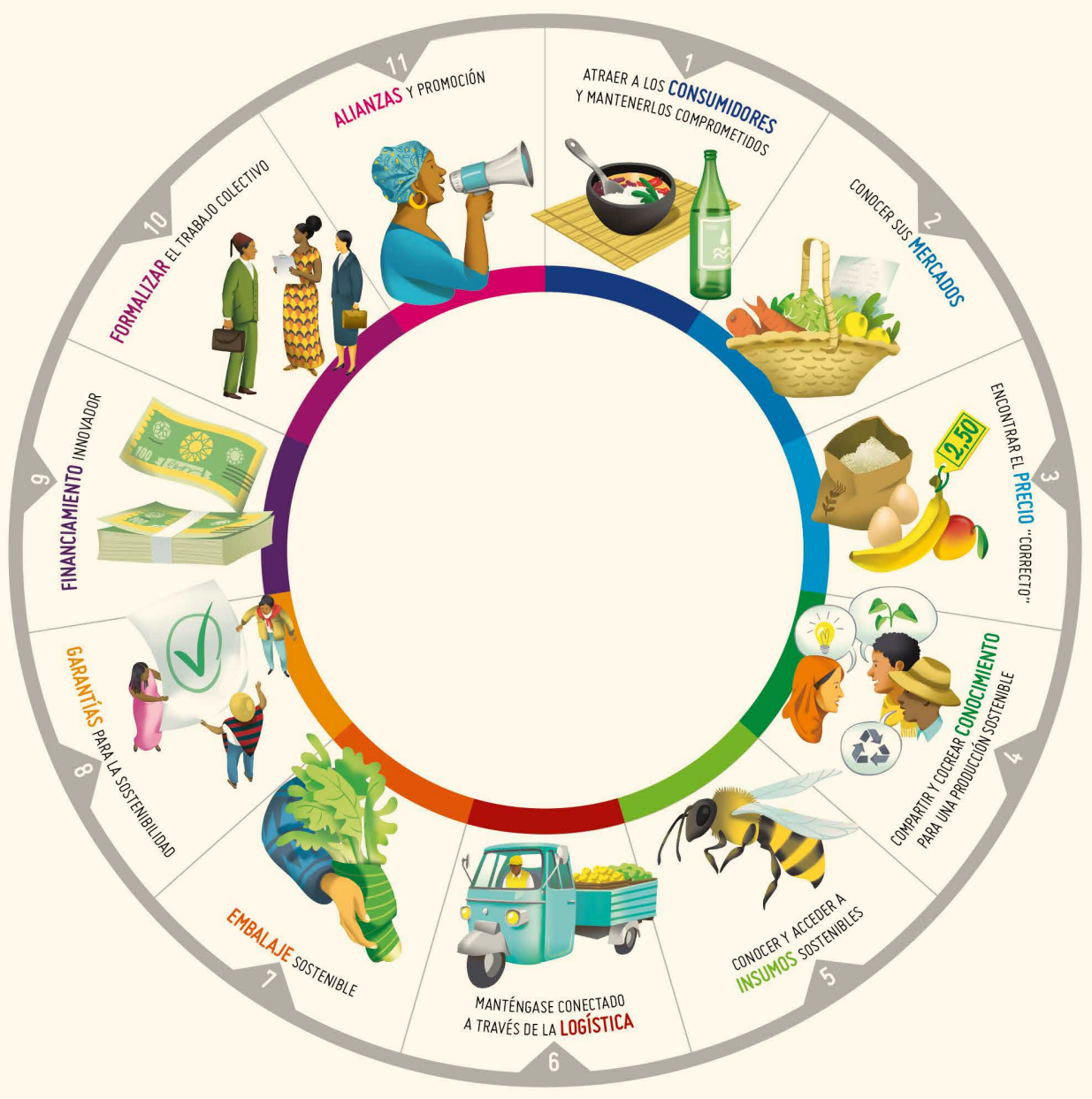

\section{Ahora está listo para comenzar su aventura de aprendizaje.}

Comience con el punto de entrada en el que usted o la mayoría de los participantes de su grupo están interesados y comience a leer y utilizar el contenido.

Cada capítulo le guiará a través de:

- por qué el tema es importante,

- cuáles son las ideas principales,

- consejos para tratar situaciones específicas,

- ejemplos de las propias experiencias de los autores,

- consejos para recordar las principales lecciones del capítulo, e

- ideas sobre dónde ir a continuación para continuar su aventura.

¡No puede perderse porque cada aventura será diferente! 


\section{ATRAER A LOS CONSUMIDORES Y MANTENERLOS COMPROMETIDOS}

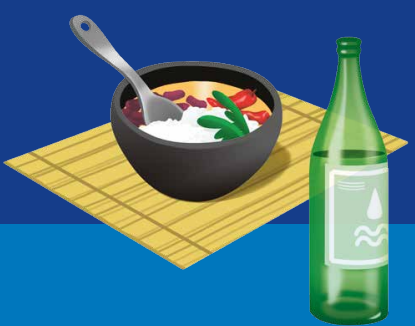

CONOCER SUS MERCADOS

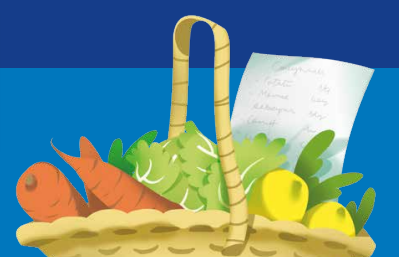

ENCONTRAR EL PRECIO “CORRECTO”
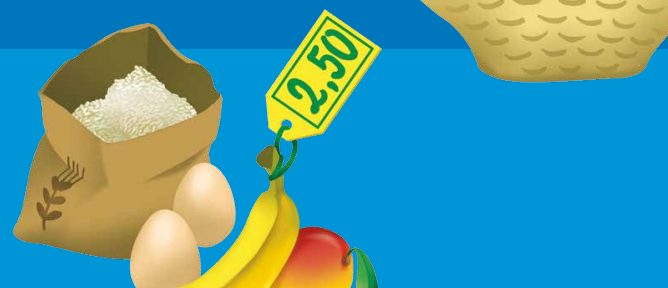

Este grupo de capítulos aborda el consumo sostenible.

Los consumidores son cada vez más importantes para salvaguardar los sistemas alimentarios sostenibles. No solo porque los consumidores estén cada vez más organizados e interesados en ellos -o porque los agricultores de los países en desarrollo suelen ser los primeros consumidores de sus propios productos-, sino también porque el consumo de alimentos es un acto cotidiano y universal.

Por lo tanto, si usted está buscando consejos sobre cómo encontrar a los consumidores, cómo establecer mercados y cómo negociar un precio justo, debe comenzar su aventura aquí. 


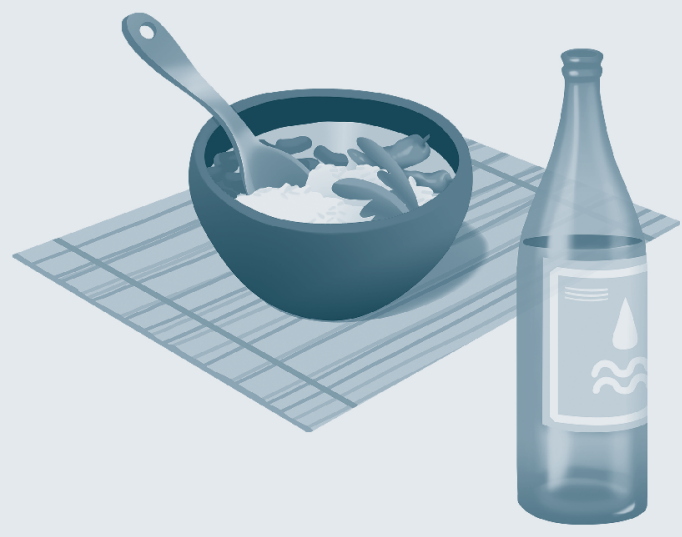

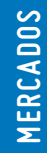
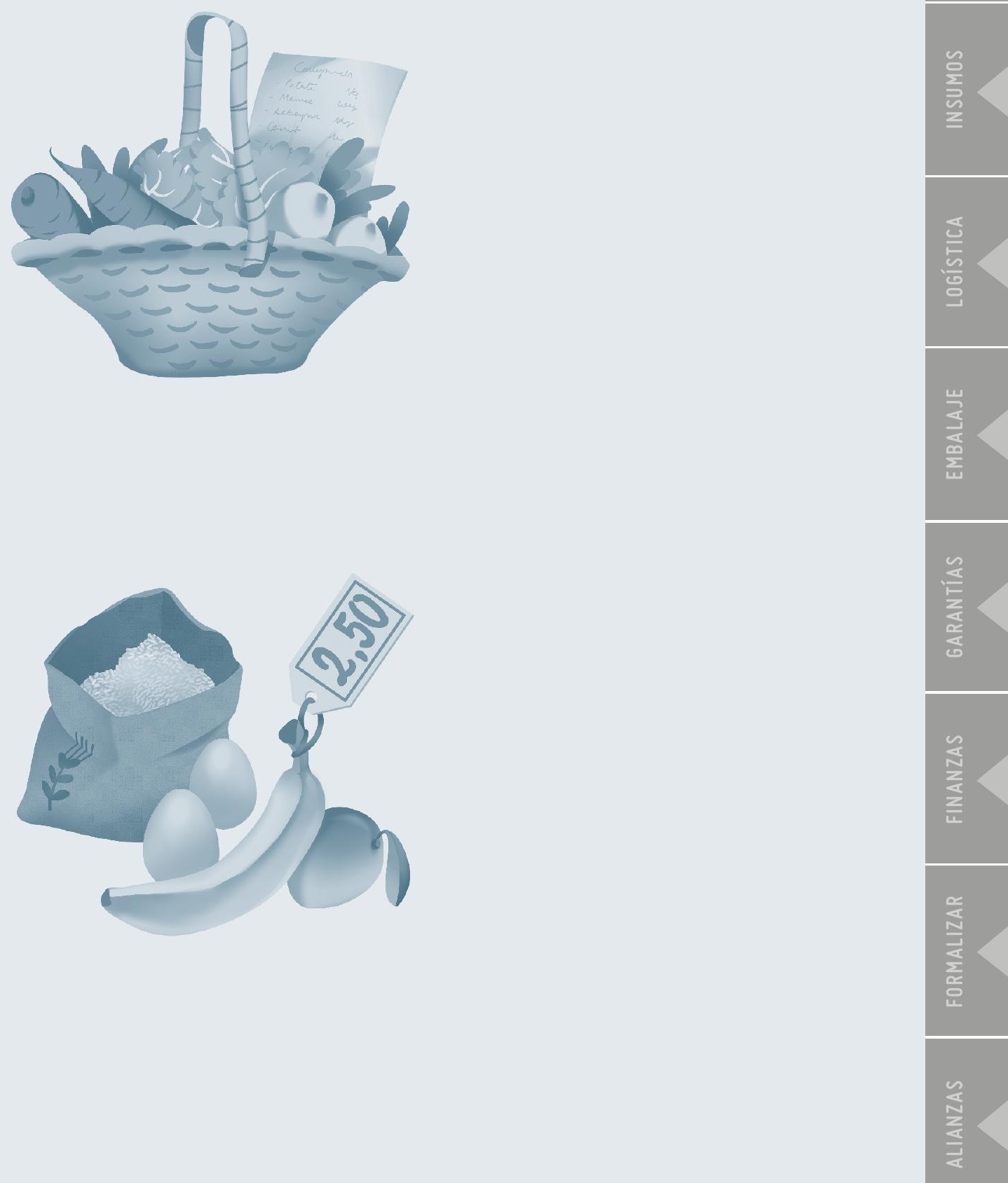
ATRAER A LOS CONSUMIDORES

$Y$ MANTENERLOS COMPROMETIDOS

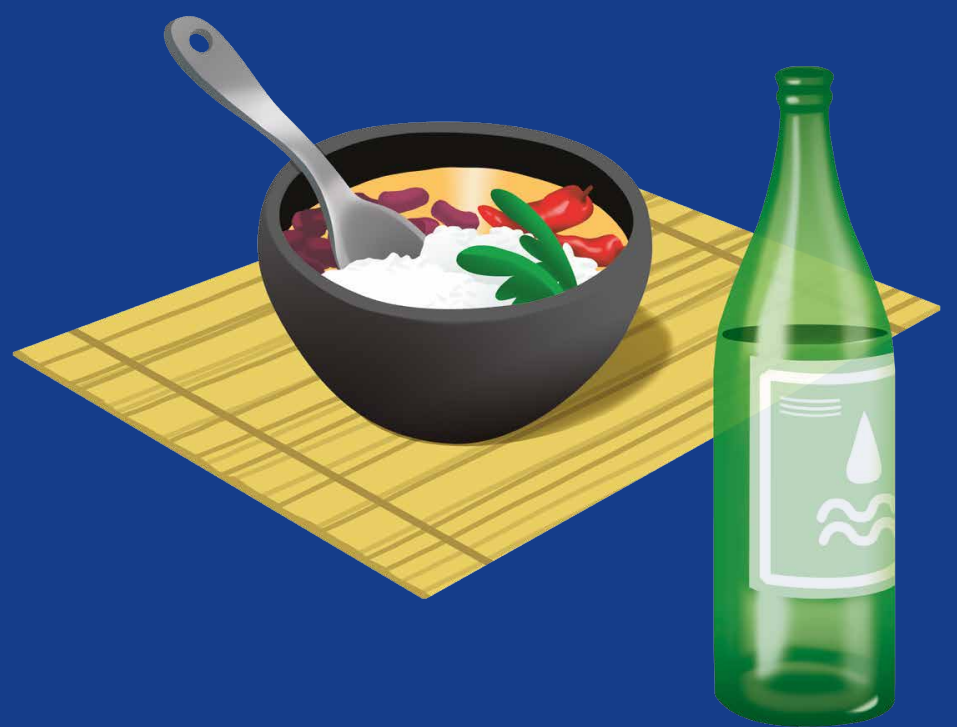



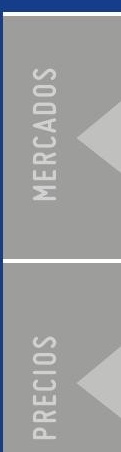

은

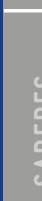

n
产
$\overline{2}$
立
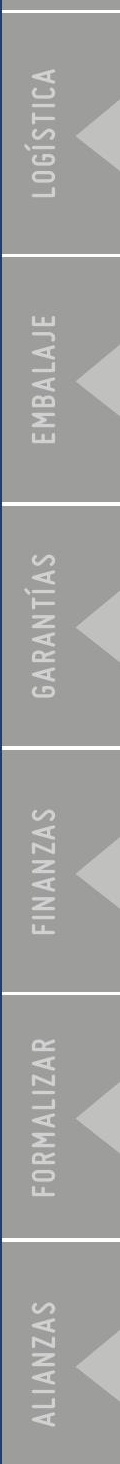


\section{1. ¿POR QUÉ ESTO ES IMPORTANTE?}

En los sistemas alimentarios sostenibles, tanto los productores como los consumidores acuerdan valorar los alimentos producidos de manera sostenible. A veces, los consumidores pueden alentar a los productores a integrar más sostenibilidad en sus prácticas, mientras que, en otros, los productores pueden convencer a los consumidores para que tomen decisiones más sostenibles. En este contexto, las organizaciones públicas también pueden ser consumidoras, al solicitar que se les suministren alimentos producidos de manera sostenible.

Los productores y los consumidores se enfrentan a retos diferentes:

- Los productores deben encontrar y desarrollar progresivamente salidas de mercado viables; encontrar clientes y mantenerlos comprometidos es un desafio clave para ellos.

Cuando todos los actores (incluyendo productores, intermediarios y consumidores) hacen esfuerzos para promover el consumo sostenible, todo el sistema se vuelve más sostenible.

- Los consumidores buscan alimentos que valoran y que sean fácilmente accesibles. Su principal desafio es llegar a un entendimiento compartido con los productores o intermediarios sobre las expectativas de calidad, cantidad y precio.

En ambos casos, se necesitan mejoras para restablecer las relaciones entre productores y clientes, aumentar la conciencia de los consumidores, (re)aprender sobre la producción de alimentos (incluyendo estacionalidad, diferencias de sabor por variedad) y (re)aprender sobre el consumo de alimentos cocinando y compartiendo recetas.

La introducción de estos temas a los niños y jóvenes puede ser divertida y garantizar que los actores de los futuros sistemas alimentarios sostenibles estén mejor informados.

\section{2. ¿QUIÉNES SON LOS CONSUMIDORES DE PRODUCTOS SOSTENIBLES?}

Todo el mundo puede convertirse en consumidor de productos sostenibles, no hay una identidad fija que pueda reconocerse fácilmente. Sin embargo, el interés por la alimentación sostenible suele estar provocado por cuatro preocupaciones principales que son independientes del poder adquisitivo (FAO, 2018b):

- preocupación por la salud,

- preocupación por el medio ambiente,

- preocupación por la protección de las pequeñas familias agricultoras y los sistemas alimentarios locales, y

- un interés en volver a conectar con el cómo y qué alimentos se cultivan.

Los consumidores también pueden comprar productos sostenibles si son fácilmente accesibles, asequibles, tienen el sabor o la calidad deseados, o pertenecen a una marca a la que son leales. 
Si bien la base de consumidores potenciales es grande, crear una base de consumidores real requiere mucho trabajo y tiempo. Dirigirse a grupos específicos conocidos por su compromiso existente con la salud o el medio ambiente puede resultar ser una buena estrategia para ahorrar tiempo; por ejemplo, estudiantes universitarios interesados en la ecología, vegetarianos o veganos, personas que con frecuencia cocinan comidas en casa, madres lactantes, practicantes de yoga, atletas, profesores universitarios, grupos religiosos, escuelas, hospitales, instalaciones para el cuidado de niños, restaurantes orgánicos o aquellos que promueven alimentos y nutrición saludables.

El nivel de compromiso que cada consumidor está dispuesto a hacer para comprar alimentos sostenibles y otros productos puede cambiar según la disponibilidad de tiempo y los ingresos a lo largo del año (además de los factores antes mencionados).

Hay diferencias notables entre los consumidores que comparten valores comunes con la iniciativa y están dispuestos a contribuir a su desarrollo (una minoría), y los consumidores aliados u ocasionales que pueden no compartir los valores de la iniciativa, pero desean comprar productos sostenibles. Para establecer una iniciativa viable, es necesario identificar a los consumidores potenciales que demuestren ambos tipos de nivel de compromiso.

Uno de los aspectos clave para tener una base de consumidores y mercados dedicada es la disponibilidad y continuidad del acceso al mercado. Consideremos un mercado campesino que proporciona acceso a las frutas y verduras de temporada; habrá ocasiones en que ciertos productos básicos pueden no estar disponibles durante todo el año. Además, los hábitos de los consumidores pueden variar temporalmente debido a los viajes y otros compromisos personales. Sin embargo, la plataforma del mercado debe estar disponible con una periodicidad fija que los consumidores puedan esperar y de la que estén informados. Este es uno de los aspectos clave del fomento de la confianza con los consumidores nuevos y existentes a lo largo del tiempo.

\section{CONSEJO 1}

\section{Identificar a los consumidores potenciales}

- En primer lugar, identificar a los consumidores principales que están disponibles no solo para dar su dinero, sino también su tiempo, conocimientos, habilidades e influencia política. Estos consumidores comprenden a las personas disponibles para convertirse en miembros de una iniciativa sostenible (a menudo local), y ayudar a los productores con la contratación de miembros, contabilidad, distribución, creación de sitios web, boletines, etc. Trate de empezar con amigos y miembros de otros grupos a los que usted pertenece (por ejemplo, religiosos, culturales, profesionales, deportes).

- En segundo lugar, identificar a los consumidores aliados. Estos son grupos que ya están organizados, y tienen una profunda comprensión de los valores, pero están principalmente interesados en las compras. Trate de acercarse a ellos en ferias comerciales, a través de sus sitios web o directamente en sus tiendas (por ejemplo, una cadena de tiendas de alimentos saludables).

- Finalmente, identifique a los consumidores ocasionales, es decir, a los individuos que solo quieren comprar sus productos y no están disponibles o interesados en ofrecer su tiempo o compartir valores. Usted puede identificar y conocer a estos consumidores a través de la publicidad, participando en ferias, mercados campesinos o eventos culturales. 


\section{1. ¿Está buscando consumidores que compran para sí mismos y sus familias, 0 aquellos que compran a granel para otros?}

Para definir una buena estrategia de mercadeo, los clientes pueden dividirse según la cantidad de compra. En general, hay dos categorías principales de consumidores:

- consumidores individuales que compran alimentos para ellos y sus familias; y

- consumidores a granel que compran para empresas o grandes grupos de consumidores (por ejemplo, restaurantes, hoteles, clubes de compra).

\subsubsection{Consumidores individuales}

\section{Pros}

+ Su pasión y entusiasmo por los productos sostenibles: pueden ser sus "mejores vendedores" si promueven los beneficios de los alimentos sostenibles a sus amigos y sus familias. Además, en el caso de los padres, su actitud hacia la alimentación puede tener una influencia positiva en sus hijos, que son potenciales consumidores futuros.

+ Usted puede aprender mucho sobre sus clientes, especialmente preguntándoles qué otras necesidades tienen. Esto puede darle un valioso perfil de sus prioridades y le ayudará a dirigirse a las personas adecuadas.

+ Los intercambios durante las actividades comerciales pueden ayudarle a desarrollar relaciones más estrechas y lealtad con algunos clientes.

\section{Contras}

- Tienden a ser volubles y pueden tener diferentes prioridades para cuándo y cómo le compran a usted. A menudo están buscando una amplia gama de productos y las pequeñas cantidades que compran significa que tendrá que mantener un gran inventario de productos. Esto, a su vez, puede ser problemático para la vida útil de los productosy generar desperdicio de alimentos.

\subsubsection{Consumidores a granel \\ Pros}

+ Las instituciones públicas, como los colegios, los hospitales, etc, pueden comprar alimentos producidos de manera sostenible. Estos consumidores a granel ofrecen la oportunidad de llegar a una amplia gama de personas. El consumo sostenible puede apoyar el desarrollo de patrones de alimentación más saludables entre los estudiantes y las personas con problemas de salud. Ambos tipos de personas pueden ser aliados importantes para ampliar el alcance de su iniciativa. También pueden mostrar su política sostenible de contratación pública.

+ Los clientes a granel, como las empresas de catering, los hoteles o restaurantes, los minoristas y los clubes de compra de consumidores, aprecian el "valor añadido" que sus empresas pueden obtener de la alimentación sostenible, como la demostración de la responsabilidad social y ambiental. Esto le da la oportunidad de llegar a los consumidores que no están dentro de su instalación inmediata (como comprar directamente de usted en su granja o el mercado campesino).

\section{Contras}

- Especialmente en el caso de la contratación pública, puede ser difícil cumplir los requisitos legales para participar en este mercado.

- Estos consumidores querrán pedir grandes cantidades de sus productos, por lo que es importante asegurarse de que usted puede proporcionarles la gama y la cantidad que están buscando. 


\section{Inclusión social de consumidores} de bajos ingresos en una ASC

\section{1} "La agricultura sostenida por la comunidad se ha construido históricamente sobre dos pilares: la soberanía alimentaria y una economía solidaria, que permite establecer diversas formas de apoyo para los necesitados. Este es un buen mecanismo para contratar a consumidores que quieren ser miembros activos de una iniciativa".

Una forma clave de utilizar el apoyo y la inclusión social en una ASC es a través de una escala móvil de pago por participación: por ejemplo, los pensionistas o estudiantes pueden pagar menos que los empleados. Esto tiende a variar de un lugar a otro. Sin embargo, una de las características comunes es el uso de la discreción y la confianza:

"Nadie cuestionará la declaración de alguien que tiene un problema financiero. Todos intentarán apoyarlo y encontrar soluciones".

Muchas ASC limitan el número de participaciones "subsidiadas" como parte de su modelo de negocio, mientras que otras están abiertas a discusión. Para garantizar tanto la inclusión social como la viabilidad económica del modelo, muchas empresas alemanas han demostrado innovación en su enfoque. En la reunión anual entre productores y consumidores, los productores indican el ingreso total que necesitan del grupo ASC para cubrir todos sus costos (incluyendo los aportes al plan de pensiones de vejez y salud, inversiones en nuevos equipos, agua, etc). Cada miembro del grupo escribe discretamente en un sobre la cantidad mensual que se siente capaz de pagar por su parte. A continuación, se agregan las cantidades. Si no alcanzan la suma especificada por el productor, hay una segunda ronda, en la que los que están en condiciones de hacerlo, aumentan la cantidad que están dispuestos a pagar. En muchos de estos grupos, la experiencia con este sistema es limitada, por lo que normalmente no hay una segunda ronda.

"Este es, en efecto, un caso de "a cada uno de acuerdo con su capacidad, a cada uno de acuerdo con sus necesidades".

Fuente: Judith Hitchman, URGENCI.

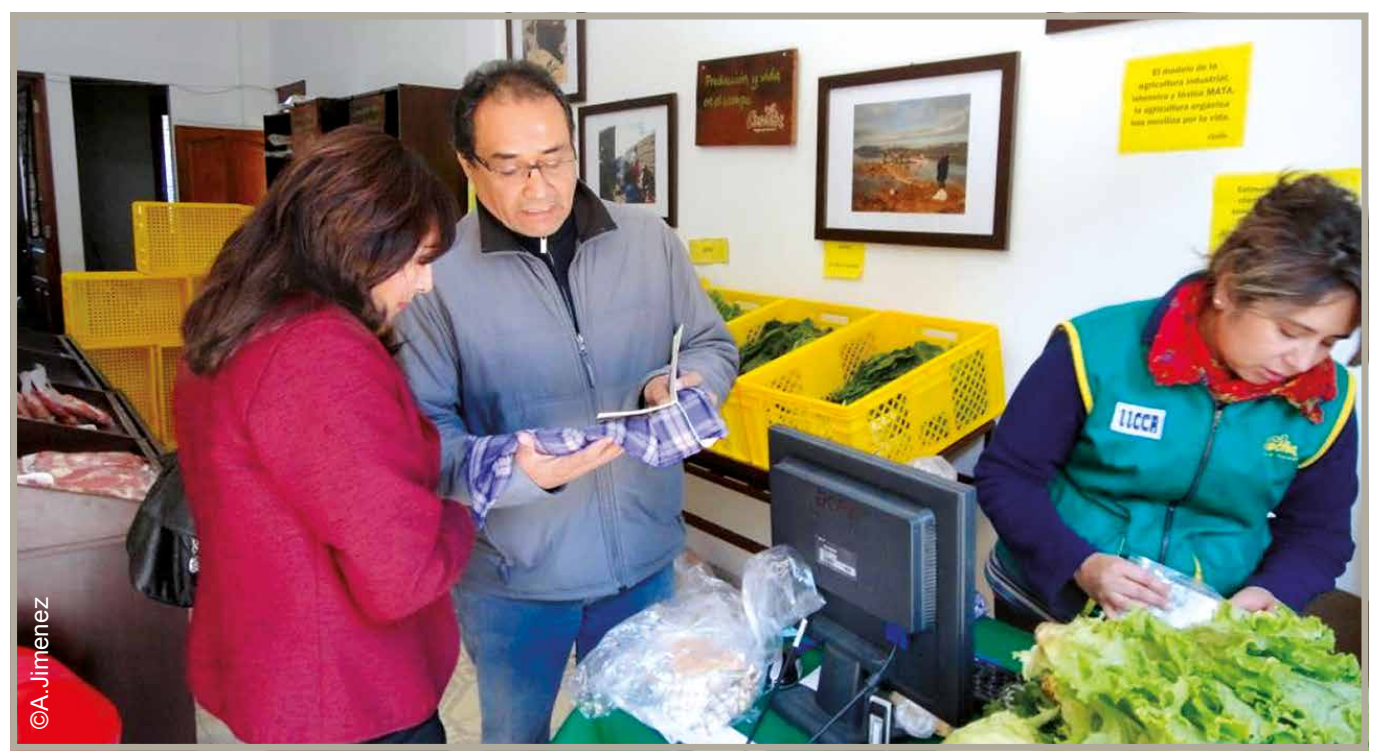




\section{CÓMO COMUNICARSE CON SUS CONSUMIDORES}

No existe una "vara mágica" para la comunicación entre productores, intermediarios y consumidores. El mejor enfoque es identificar algunos elementos comunes que resuenen con sus clientes actuales y potenciales. Es importante ajustar sus estrategias para diferentes audiencias: la comunicación interna entre los miembros de su iniciativa no requiere el mismo ritmo y lenguaje que la comunicación externa.

\subsection{Comunicación interna}

\subsubsection{Sencilla, fácil de usar, resiliente}

Si quiere irse por la alta tecnología o la baja tecnología, siempre hay muchas opciones.

Algunos grupos muy eficaces no utilizan nada más que una lista electrónica.

Por ejemplo, los grupos que organizan reuniones presenciales

Basta con echar un vistazo a su alrededor, ¿qué está usando la gente? regulares, como un ASC o un esquema periódico de cajas que tiene entregas semanales, necesitan de muy poca comunicación. Sus entregas son "universales", lo que significa que incluyen los mismos productos para todos. Por lo tanto, no hay necesidad de enviar o recoger pedidos, y la entrega sigue siendo el momento clave para el intercambio de información. La lista electrónica es suficiente como una herramienta secundaria para convocar reuniones y asambleas generales, para compartir la actualización de recetas y el calendario de los deberes voluntarios, así como para proporcionar indicaciones para llegar a la granja en días de colaboración.

La transparencia es una herramienta eficaz para crear iniciativas honestas basadas en la confianza y para comunicarse con los consumidores. La información clave, como la fuente de los productos, los precios y la disponibilidad estacional, ayuda a los consumidores a tomar decisiones informadas. Por otra parte, el acceso poco claro al mercado tiende a reducir la confianza de los consumidores a lo largo del tiempo.

\section{LISTA DE VERIFICACIÓN}

Explorar la mejor opción para la comunicación interna:

1. ¿Tiene la zona una buena conexión a Internet?

2. ¿Sus miembros tienen teléfonos celulares o smartphones?

3. ¿Tiene espacio suficiente para reuniones cara a cara?

4. ¿Cuáles son las prácticas sociales de sus grupos objetivo?

5. ¿Sus miembros tienen reuniones regulares, o se reúnen regularmente por otras razones (como recoger a los niños en el colegio o lugares de culto religioso)? 


\subsubsection{Redes sociales: eficaces para la movilización, limitadas para el compromiso}

Otras iniciativas optan por las redes sociales más que por las listas electrónicas. Se están desarrollando nuevas iniciativas de mercado de ventanas emergentes en torno a los grupos de Facebook, WhatsApp o WeChat. Los agricultores locales comparten el contenido de su próxima entrega con el grupo, generalmente cada dos semanas. Los clientes piden su parte simplemente respondiendo a la publicación.

Las redes sociales son flexibles, fáciles de configurar y utilizar, y de bajo costo ( $i a$ menudo gratis!). Asimismo, los consumidores y los productores controlan cuando acceden a la información. Antes de pasar demasiado tiempo en las redes sociales, asegúrese de que sus consumidores tienen acceso a Internet y a los smartphones. Si no están utilizando las redes sociales aún, jes poco probable que llegue a ellos de esta manera!

Las redes sociales como herramienta para la comunicación interna (Finlandia)

2

Las ventas directas entre productores y consumidores han disminuido significativamente durante los últimos 30 años en Finlandia. Sin embargo, la demanda de productos locales y orgánicos ha aumentado en los últimos años. Reko responde a esta creciente demanda. En sueco, "reko" es una abreviatura de "consumo justo". Los primeros círculos Reko comenzaron en 2013 en Jakobstad y Vasa, ambas ciudades situadas en la zona de habla sueca del oeste de Finlandia. Facebook se utiliza como la principal plataforma de comunicación, lo que hace que la administración sea muy fácil. Un círculo Reko se basa en un grupo cerrado de Facebook, por lo que los productores y consumidores interesados en participar deben solicitar la membresía al grupo. Los administradores, que a menudo comprenden un pequeño grupo de consumidores, aceptan las solicitudes de los agricultores sobre la base de los principios Reko, y luego el negocio puede comenzar.

Las entregas se realizan semanalmente 0 cada dos semanas dependiendo del tamaño del grupo. Para cada entrega, los agricultores comparten un anuncio en Facebook, y los consumidores hacen sus pedidos en forma de comentarios bajo los anuncios. Cuando un círculo Reko ha comenzado, su supervisión requiere muy poco esfuerzo. Los administradores solo necesitan aceptar aplicaciones de nuevos miembros y establecer fechas de entrega. La participación es gratuita, ya que es un sistema basado $100 \%$ en la venta directa, que no incurre en ningún costo logístico. El hecho de que una iniciativa de este tipo haya llegado a más de 400.000 clientes en tan solo un par de años, en un país de 5.5 millones, subraya el fuerte impacto potencial de las redes sociales.

Fuente: adaptado de https://urgenci.net/reko-awinning-concept-in-finland. 


\subsection{Comunicación externa: atraer nuevos consumidores}

\subsection{1. ¡Cuidado con sus modales!}

El idioma que utilice debe adaptarse a los consumidores con los que se comunica. Conceptos idénticos pueden ser atractivos $u$ ofender a diferentes personas. Por ejemplo, palabras como "sostenible" generalmente atraerán más a los consumidores altamente educados, mientras que otros consumidores pueden identificarse más con "orgánico", "natural" o "local". Si presenta sus iniciativas exactamente en los mismos términos a los consumidores de barrios marginales o incluso a los consumidores de clase media, a menudo pueden sentirse excluidos. Muchos testimonios apuntan en la misma dirección: si quiere trabajar con consumidores de todos los segmentos de la sociedad, las palabras clave deben ser cuidadosamente elegidas. La forma debe ser diferente, pero el contenido debe seguir siendo el mismo:

\section{todos los consumidores buscan la historia detrás de la comida que comen.}

\subsubsection{Tenga en cuenta su imagen}

En menos de una década, las redes sociales se han convertido en la forma preferida de comunicación virtual en todo el mundo, reformulando las reglas de la comunicación por Internet. Utilizar una sola imagen o un video para ilustrar o componer un mensaje, usando las redes sociales, se ha convertido en un "deber".

La importancia del mensaje visual en el sitio web de Lavka Lavka (Federación de Rusia)

Lavka Lavka es una cooperativa de agricultores ubicada en Moscú, Rusia. Opera una tienda en línea, un mercado campesino y un restaurante para suministrar a sus clientes alimentos frescos y de alta calidad de los agricultores locales. Como Lavka Lavka también opera una tienda en línea, se han desarrollado un sitio web (http://lavkalavka.com/page/chtotakoe-fermerskiy-kooperativ-lavkalavka) y una página de Facebook (https://www.facebook. com/lavkalavkarestaurant/) para proporcionar
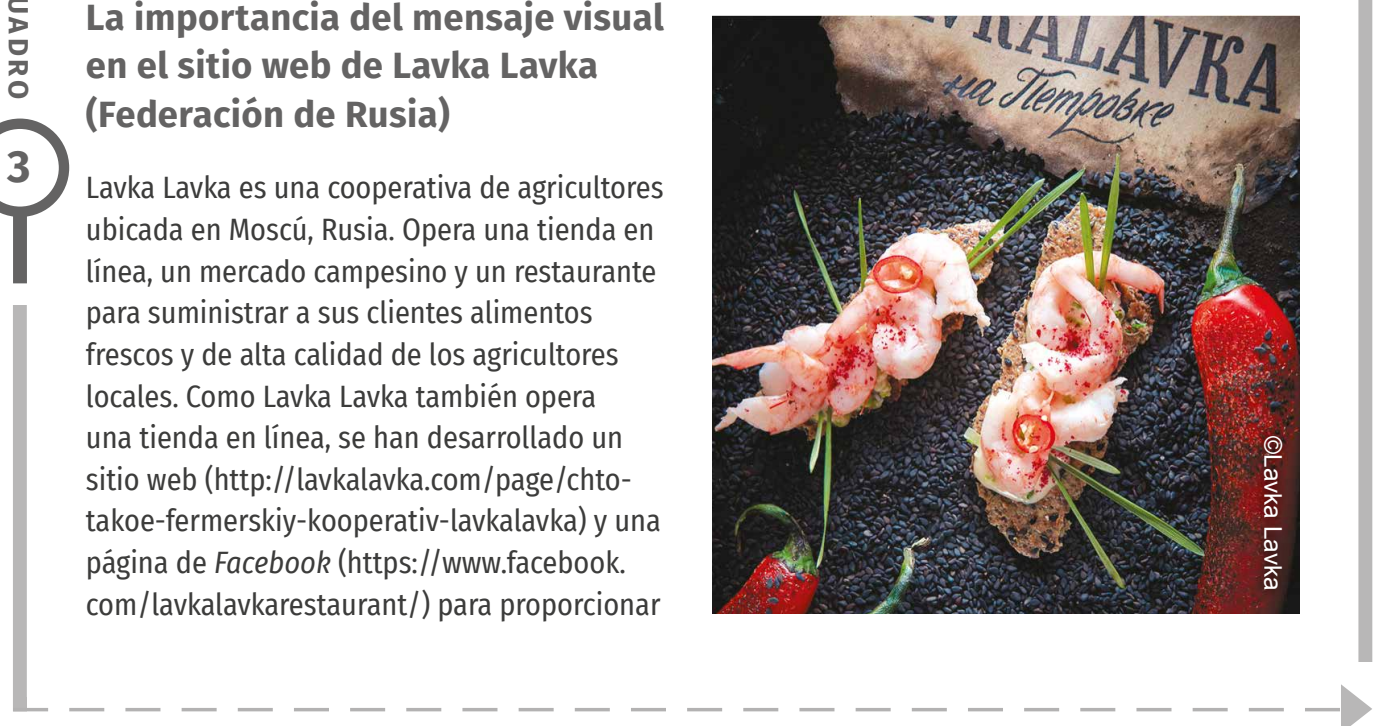
información sobre la disponibilidad de alimentos frescos y sabrosos y para compartir las historias de los agricultores. El sitio web de Lavka Lavka es un portal de información utilizado para conectar la ciudad con el campo y a los consumidores con los productores.

La cooperativa reconoce que la comida no es simplemente comer: es una experiencia multisensorial que involucra olor, tacto y vista. Dado que la distancia puede ser una barrera, los mensajes visuales se utilizan estratégicamente para comunicar los valores de la cooperativa, para captar y mantener la atención de los clientes y, en última instancia, para construir el primer vínculo entre consumidores y productores. En su sitio web, Lavka Lavka muestra muchas fotografías de los diferentes agricultores de los que obtienen los productos para el mercado, acompañadas de biografías cortas. Al hacer clic en la imagen, los consumidores pueden ver los productos disponibles de ese agricultor específico. Del mismo modo, imágenes de especialidades culinarias tradicionales y productos

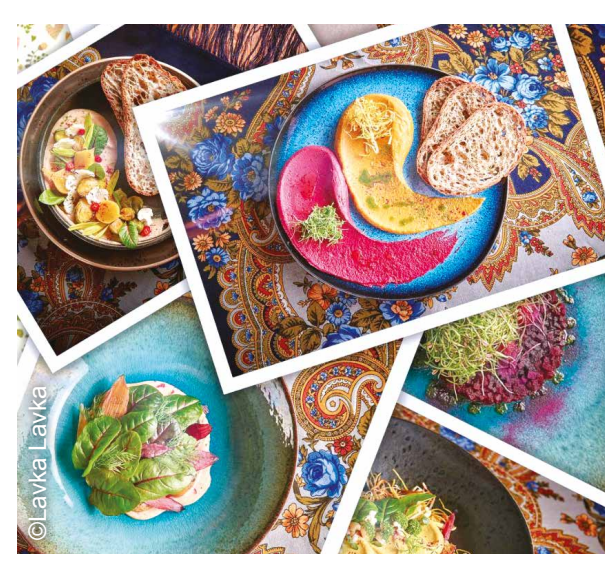

alimenticios se muestran en la página web. En el siguiente ejemplo se muestran el plato en sí y los ingredientes utilizados para prepararlo: una composición fotográfica que atrae la atención de los que lo ven y aumenta su deseo de probarlo.

Fuente: adaptado de http://restoran.lavkalavka.com/en y http://lavkalavka.com/page/chto-takoefermerskiy-kooperativ-lavkalavka.

\subsubsection{Construir alianzas}

Dada su accesibilidad general por la mayoría de los residentes locales, los medios de comunicación locales son un recurso útil. La ayuda de los periodistas locales es crucial en las primeras etapas del proyecto. Un par de artículos (con imágenes) le ayudarán a difundir las noticias sobre su iniciativa. Cientos de personas sabrán que se ha lanzado, y que se está invitando a la gente a llamar a su puerta.

Las redes locales también son importantes. Probablemente existan redes asociativas, comerciales, técnicas, educativas y religiosas preexistentes en el área donde usted opera. Estas redes seguramente tienen acceso a personas con ideas afines, que han estado buscando el tipo de iniciativa que está creando.

\section{CONSEJO 2}

Trate de no explotar la generosidad de los demás

Sea honesto y transparente acerca de los intereses y valores comunes y cómo planea usar cualquier información que se comparta. Asegúrese de conocer los requisitos legales sobre privacidad y protección de datos en su país. 


\section{CÓMO MANTENER a LOS CLIENTES INVOLUCRADOS}

Los consumidores de todo el mundo tienden a explorar nuevos sabores y a constantemente buscar oportunidades para un buen negocio, un mejor precio, una mayor calidad y proveedores fiables. Por lo tanto, es dificil retener a los clientes existentes si no hay un esfuerzo deliberado para entender y responder a sus necesidades. A través del uso de una buena comunicación y reciprocidad, el proceso de venta es la mejor oportunidad para que los productores involucren a los clientes y los cambien de ser meros exploradores a miembros leales y comprometidos de su iniciativa.

Si los clientes no están satisfechos con cómo usted vende sus productos, es probable que nunca hagan negocios con usted de nuevo. Por lo tanto, crear una experiencia de compra consistente y agradable es una parte integral de la creación de confianza y lealtad. La reciprocidad, como el proceso a través del cual los clientes son recompensados de alguna manera por su lealtad, es otro factor importante para asegurar que sus clientes sigan regresando. Crear consumidores leales requiere una estrategia que no tiene que ser costosa (como regalar demasiado y gratis), ¡solo necesita ser inteligente!

\section{CONSEJO 3}

\section{Mantener a los consumidores involucrados}

1. Genere una estrecha relación con los consumidores, organizando eventos como jornadas de trabajo comunales, eventos sociales y actividades juveniles, directamente en la granja o en un espacio común. Estos eventos crean un sentido permanente de pertenencia donde el espacio se convierte en un "segundo hogar" donde los consumidores se sienten cómodos.

2. Trate de enseñar a los consumidores a producir sus propios productos para que puedan aprender sobre los costos de producción. Se trata de un paso importante para fomentar la comprensión de los precios fijados o propuestos por parte de los consumidores.

3. Comparta las historias de los productos, esto ayuda a los consumidores a apreciar y sentirse bien acerca de la calidad de los alimentos que traen a casa.

4. Informe a los consumidores sobre el ciclo de producción y las estaciones de los principales productos agrícolas, proporcionándoles, por ejemplo, un calendario de cuándo esperar ciertas frutas y verduras.

5. Comparta recetas y ofrezca clases sobre conservas, almacenamiento, cocina y otras prácticas de valor agregado.

6. Haga un seguimiento del estado de membresía de sus consumidores, al elegir estratégicamente el momento para renovar las suscripciones. Por ejemplo, esto se puede hacer durante las temporadas bajas, cuando hay menos cosecha que atender, o durante los tiempos de cosecha pico, cuando hay un mayor contacto con los consumidores.

7. Mantenga constantemente activa su comunicación con los consumidores, incluso durante las temporadas bajas.

8. Reciba comentarios de sus consumidores a través de encuestas de preferencias o sondeos. Cuando usted hace que sus productos favoritos estén más disponibles, es probable que ellos regresen.

9. Introduzca estratégicamente nuevos productos (basado en los comentarios de los consumidores): esto ayudará a mantener el interés de los consumidores y probablemente garantizará su permanencia como miembros.

10. Por último, realice encuestas de final de año y utilícelas s para ayudar a planificar las estrategias de producción de cultivos del próximo año. Estas informarán a los productores de las cuestiones relacionadas con las preferencias de los consumidores, los precios comparativos de los distintos productos y las ideas para que puedan cultivar nuevos cultivos. 


\subsection{Crear una experiencia de compra agradable}

Crear una experiencia de compra agradable es el paso fundamental para construir relaciones duraderas con sus clientes y mantenerlos involucrados.

\section{CONSEJO 4}

Crear una experiencia de compra agradable

1. Atienda muy bien a todos los clientes.

2. Muestre los precios.

3. Muestre la calidad.

4. Destaque la diversidad.

5. Sea creativo e innovativo.

6. Haga que su mercado sea atractivo.

7. Promocione su producto.

8. Aplique prácticas seguras de manipulación de alimentos.

9. Capacítese.
10. Nunca cometa estos graves errores:

a. vender productos de mala calidad,

b. fijar precios por encima de los precios del mercado,

c. tener un estante sucio y desordenado,

d. atender mal a los clientes;

e. dejar de venir al mercado sin contarles a los clientes y organizadores;

f. comer su comida y atender a los clientes al mismo tiempo, y

g. vender productos sin el peso exacto.

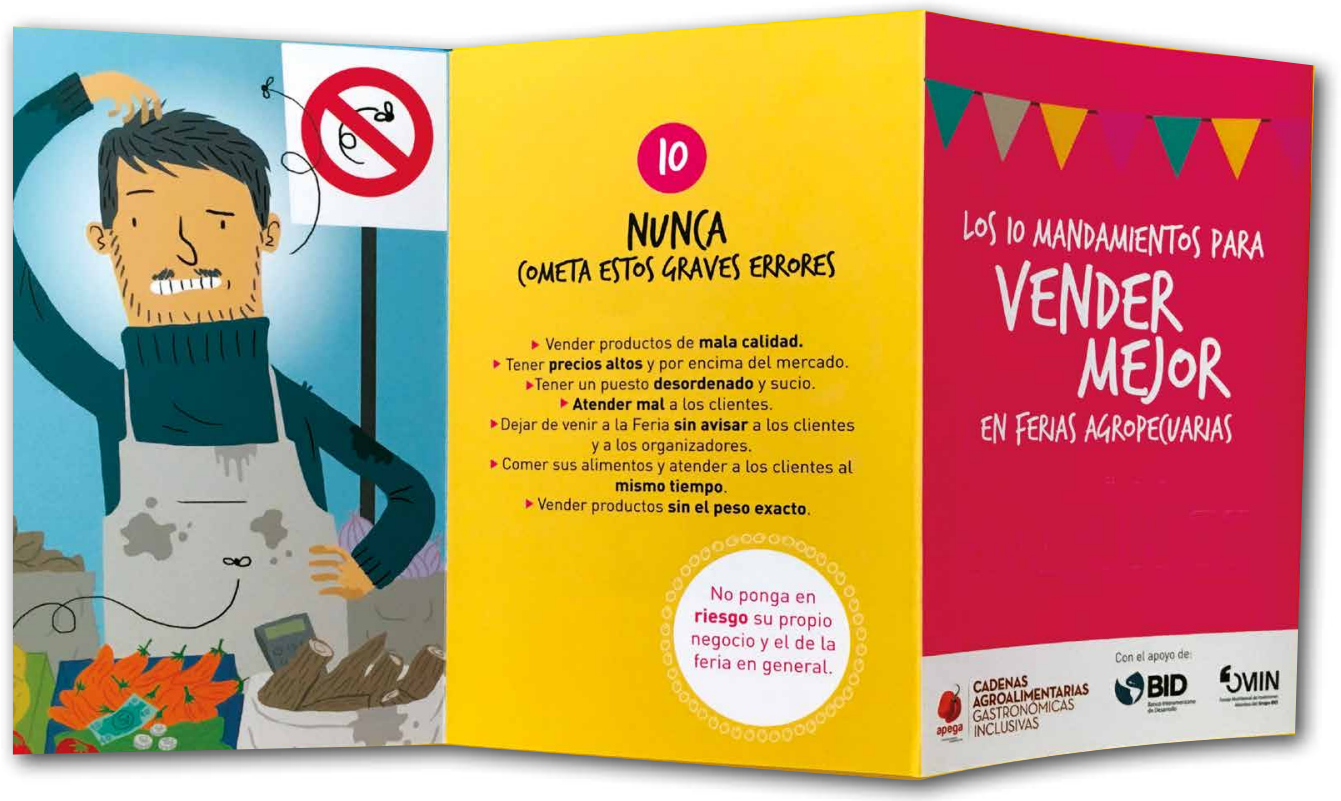

Fuente: Los 10 Mandamientos para vender mejor en los mercados campesinos del Perú, “Cadenas Agroalimentarias Gastronómicas Inclusivas" Agroferias Campesinas. 


\subsubsection{Programas de lealtad}

Los programas de lealtad incluyen una variedad de iniciativas dirigidas a vincular a los consumidores con los proveedores. Ellos deben confiar en la reciprocidad o en pequeños regalos para incentivar a los consumidores existentes a seguir regresando. Estos pueden incluir programas formales solo para miembros, o simplemente el hábito de dar un regalo gratuito cuando el consumidor compra una cierta cantidad.

\section{CONSEJO 5}

La sorpresa es un componente importante para fomentar la lealtad.

Además de los suministros programados, los productores pueden ofrecer productos a sus consumidores, lo que ayuda a reforzar su lealtad a un bajo costo.

\subsection{Haga un seguimiento con sus clientes para entender cómo satisfacerles mejor}

La frecuencia del intercambio de información es tan importante como la elección correcta de la palabra. Hay diferentes maneras de hacer un seguimiento con los consumidores: intercambio de correos electrónicos, llamadas por teléfono, charlas durante las entregas, volantes y reuniones regulares. Las encuestas de final de temporada y de inicio de temporada o los grupos de enfoque son una forma eficaz de evaluar la satisfacción general de los clientes con productos anteriores y sus solicitudes para la próxima temporada. Los clientes principales aprecian cualquier oportunidad de influir en la iniciativa: esto refuerza su sentimiento de pertenencia. Cuando diseñe sus encuestas, recuerde que el software libre que ofrece herramientas de votación bien diseñadas es abundante hoy en día.

La mayoría de las veces, los consumidores eligen ocultar su descontento, prefiriendo simplemente irse y nunca volver. iHaga todo lo posible para evitar esta situación! No obstante, si es el caso, trate de controlar los abandonos, y de entender las razones detrás de ellos, aunque es dificil recibir retroalimentación de aquellos que ya se fueron. Haga preguntas como: “¿Quién se fue?" “¿Cuándo?" “¿Por qué?”; si puede contestarlas, probablemente evitará repetir los mismos errores.

\subsection{Proporcionar servicios de apoyo para incentivar a los consumidores fieles}

Los servicios de atención al cliente, como demostraciones de cocina y visitas a granjas, son muy importantes para mantener la lealtad. Una experiencia de servicio excepcional anima a los clientes a volver. La calidad del servicio suele ser más importante que la rapidez de la entrega. Esencialmente, pasar más tiempo con los clientes fomenta resultados más positivos, ya que esto tiende a crear un sentimiento de importancia y atención. Es importante que sus servicios de atención al cliente se ofrezcan a través del canal preferido de sus clientes. Aunque las relaciones cara a cara siguen siendo las más comunes, el correo electrónico o las redes sociales son opciones factibles. 


\section{CONSEJO 6}

El servicio personalizado cultiva una agradable experiencia del cliente y crea consumidores asiduos

\section{Una demostración de cocina para fortalecer los vínculos con los consumidores (Filipinas)}

4

El Quezon PGS, en Filipinas, ha organizado dos demostraciones de cocina para mostrar su comida sostenible. Situado en su mercado campesino de los viernes, las demostraciones de cocina de Quezon han tenido lugar durante el Festival Anual de la Cosecha de Agosto, que atrae a aproximadamente entre 300 y 500 visitantes. Durante estas lecciones, los agricultores preparan platos para los consumidores utilizando sus propios productos que venden en el mercado. Algunos ejemplos de comidas preparadas incluyen ensaladas y pasteles de arroz y pollo. Al dirigirse a los compradores habituales del mercado, Quezon promueve una fuerte relación productorconsumidor. Las fechas de demostración de la cocina se anunciaron durante los días regulares del mercado, y se anunciaron en carteles distribuidos a través de una asociación con el gobierno municipal.

Fuente: Carmen Cabling, Quezon PGS.

\section{Las visitas de campo de los} consumidores refuerzan las relaciones con los productores

5 (Colombia)

Familia de la Tierra (FDT), una red de productores agroecológicos colombianos, utiliza "visitas de campo" para conectar a consumidores y productores. Al dirigirse a la clientela existente, FDT permite a los consumidores aprender más sobre los productos agrícolas. Grupos de 10 a 15 personas, en su mayoría formados por estudiantes y chefs, están invitados a una granja para observar la diversidad de cultivos. Estas visitas, organizadas por los productores locales, suelen durar alrededor de dos horas y abarcan una serie de temas, desde los principales procesos de producción de la granja hasta el uso culinario de los cultivos. Estas visitas son beneficiosas tanto para los productores como para los consumidores, ya que fomentan relaciones más sólidas y significativas.

Fuente: Jaime Aguirre, Óscar Nieto y Familia de la Tierra.

\subsection{Compartir y rotar responsabilidades}

Para mantener vinculados a la mayoría de los consumidores, es útil, siempre que sea posible, asignarles responsabilidades diferentes. El voluntariado no es sostenible a largo plazo si depende de un puñado de consumidores comprometidos. Las responsabilidades deben redistribuirse regularmente. Por ejemplo, las tareas simples pero que requieren de mucho tiempo, como 
la logística de la programación o la comprobación de que todo el mundo firma una lista de distribución, deben rotar entre los voluntarios. La organización de reuniones y conversaciones también debe compartirse entre los miembros del grupo básico.

\section{¡Usted debe evitar la "fatiga de los miembros" a toda costa!}

Compromiso de los consumidores y limitaciones de tiempo en los modelos ASC (Reino Unido de

\section{Gran Bretaña e Irlanda del Norte)}

Desde el punto de vista del consumidor, la pertenencia a un ASC varía de un ASC a otro y de un país a otro. "Una talla única" no se aplica en el contexto de la ASC. Sin embargo, lo que sigue siendo constante es el riesgo y el beneficio compartidos. Si la cosecha es abundante, los consumidores reciben una cantidad generosa de verduras (o cualquier otra cosa que hayan firmado). Por otra parte, si un acontecimiento adverso del clima ha deteriorado un cultivo, los consumidores deben pagar al productor. En el caso de una tormenta o inundación, los consumidores también se ofrecen a menudo para ayudar al productor a limpiar.

Muchas iniciativas de ASC experimentan tasas de rotación de los consumidores de hasta el $30 \%$, especialmente durante el primer año. El costo es rara vez la razón para abandonar el mercado, ya que la mayoría de las participaciones en la ASC tienen un precio muy competitivo en comparación con la compra de frutas y verduras orgánicas (o a veces incluso convencionales) en los supermercados. Por el contrario, la cantidad de tiempo necesario para participar en tales iniciativas parece ser la principal razón para que los consumidores abandonen el mercado. Estas son personas que por lo general no habían anticipado el tiempo necesario para preparar y cocinar tantas verduras diferentes.

Con el fin de incentivar la participación de los consumidores en la iniciativa de la ASC, en particular en términos de tiempo, es posible que los miembros de algunos grupos de la ASC intercambien algunas horas de trabajo mensual en la granja por una parte o la totalidad de su participación. De este modo, la cantidad pagada por sus alimentos se desmonetiza, pero aún conserva su valor (ver el cuadro que figura a continuación, que muestra un ejemplo de este tipo de desmonetización adoptado por un grupo ASC en el Reino Unido de Gran Bretaña e Irlanda del Norte).

La adopción de tales mecanismos (y hay muchos otros), no solo proporciona un incentivo para dedicar tiempo a la iniciativa de la ASC, sino que también fortalece considerablemente la inclusión social para aquellos consumidores con bajo poder adquisitivo y gran disponibilidad de tiempo, alentándolos a convertirse en miembros.

Fuente: Judith Hitchman, URGENCI.

Cuadro 1: Ejemplo de estructura de tarifas ASC

\begin{tabular}{l|c|c} 
Type d'abonnement & Heures de travail minimum & Frais annuel \\
Nivel 1 & 14 horas al mes & $£ 0$ \\
\hline Nivel 2 & 7 horas al mes & $£ 75$ \\
\hline Nivel 3 & 4 horas al mes & $£ 150$ \\
\hline Nivel 4 & 7 horas al año & $\begin{array}{c}£ 250 \text { (actualmente cerrado a } \\
\text { nuevos miembros }\end{array}$ \\
\hline
\end{tabular}




\section{EDUCAR A LOS CONSUMIDORES FUTUROS}

Un sistema alimentario no es sostenible si no vela por las generaciones futuras. Educar a los niños para que coman y disfruten de alimentos diversificados y saludables es de vital importancia para garantizar que tengan una vida saludable y para asegurar la supervivencia y el crecimiento de su iniciativa sostenible.

$x$
n
2
0
0

7 manera de conseguir que los niños y sus familias entiendan y se comprometan con la alimentación sostenible. En la escuela primaria Jean Guehenno, en Caen, Normandía, al igual que en miles de escuelas de todo el mundo, las huertas escolares se han utilizado como una herramienta educativa multifacética. Incluso si el espacio es limitado en un entorno urbano, siempre es posible cultivar algo comestible. Además, cultivar alimentos es una actividad pedagógica emocionante; es una manera de aprender sobre la naturaleza, las plantas, el sol, el agua, el viento y las semillas desde una edad temprana.

Hay muchos enfoques posibles. Los niños pueden cocinar los productos comestibles cosechados del jardín y cantar canciones sobre verduras o jardinería. También pueden aprender sobre las diferencias entre las plantas y la vegetación en diferentes partes del mundo. Se puede calcular la economía de la producción y el consumo, y se pueden enseñar los fundamentos de la sostenibilidad. Un huerto escolar es más que un proyecto de una sola clase. Es un proyecto escolar: diferentes maestros pueden elegir diferentes maneras de relacionarse con la misma huerta. También es un proyecto comunitario: los padres y activistas locales de alimentos pueden asociarse con las actividades. En la escuela Jean Guehenno, los padres participan en visitas a la granja pedagógica cercana, cuyos productores ayudaron a establecer el huerto escolar. Estos padres voluntarios son entrenados en el lugar como facilitadores del taller para el día: algunos padres son responsables de organizar un juego sobre la clasificación de las "familias" de las plantas, mientras que otros facilitan las pruebas a ciegas sobre las verduras. La clave es hacer pleno uso de la visita a la granja, preparándola con antelación y recordando el material aprendido allí durante las siguientes clases. Un huerto escolar es una manera muy eficiente de mantener vivos estos recuerdos, ya que requiere de un compromiso regular.

Fuente: Jocelyn Parot, URGENCI.

Para saber más sobre este tema, visite: https://eathink2015.org/en/download/SchoolGarden-Guide-WEB.PDF.

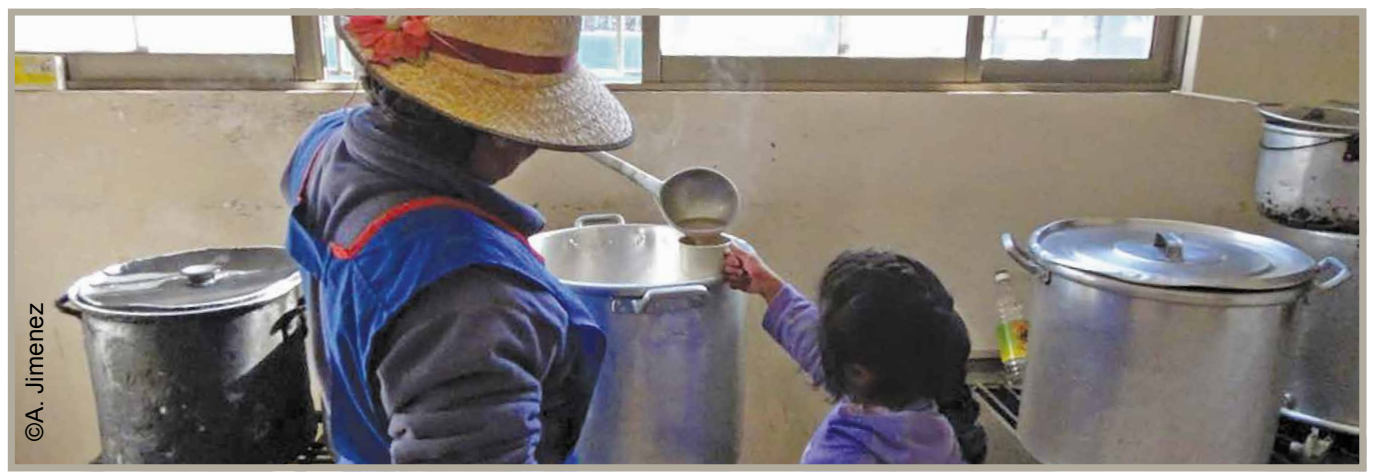




\section{Programa escolar para educar a los futuros consumidores (Kenya)}

8

En Kenya, el Programa de Permacultura de

Escuelas y Universidades (SCOPE) es una organización de redes que actualmente cuenta con 18 ONG miembros y trabaja con escuelas y comunidades en 12 condados de todo el país. Su objetivo principal es formar y preparar a los jóvenes dentro y fuera de las escuelas para comprender el valor nutricional, aprender sobre prácticas de consumo más saludables y participar en la producción agrícola.

Para ello, el programa adopta el enfoque del diseño integrado del uso de la tierra (ILUD por sus siglas en inglés). El ILUD es un proceso integral paso a paso que implica trabajar con todos los actores de las escuelas: estudiantes, maestros, padres y líderes locales; y utiliza todo el terreno escolar para diseñar y establecer un huerto escolar basado en los principios de la permacultura.

El enfoque se basa en los siguientes pasos:

1. Análisis situacional: los actores observan la situación existente para desarrollar una comprensión común de los problemas actuales y los recursos potenciales que tienen actualmente.

2. Formación holística de metas: los actores definen su visión para el ambiente escolar.

3. Diseño integrado: los actores rediseñan sus tierras creando conexiones entre los diversos elementos de su entorno.

4. Plan de acción: los actores desarrollan un plan de implementación y monitoreo para su proyecto.

Este proceso brinda a los niños la oportunidad de crecer en entornos donde aprenden y practican la producción, preparación y consumo de alimentos saludables.

Es importante que el huerto se convierta en una parte viva del plan de estudios de la escuela y que los estudiantes se involucren activamente en las diferentes actividades, desde la planificación, pasando por el cultivo y la cosecha, hasta la alimentación.

Fuente: Rosinah Mbenya, PELUM.

Para saber más, visite

http://www.fao.org/docrep/009/a0218e/ a0218e00.htm.

\section{Cultivando Agua Boa (Brasil)}

La inclusión de los niños en acciones educativas, transformadoras y sostenibles es

9 fundamental para motivar a los consumidores presentes y futuros de alimentos sostenibles. A la luz de ello, el programa "Cultivando Agua Boa", organizado por la Fundación Itaipu Binacional, desarrolla proyectos destinados a la preservación del agua y el medio ambiente, apoyando la agroecología y las intervenciones educativas en las escuelas primarias públicas del oeste de Paraná en Brasil. A los niños y a los cocineros de comedores se les enseña sobre dietas saludables, un tema incluido en el plan de estudios de la escuela. En particular, la escuela organizó un concurso entre cocineros de diferentes escuelas para crear recetas saludables, que luego fueron recopiladas en un libro de recetas. Estas acciones involucran a toda la comunidad escolar, familias de niños, agricultores agroecológicos, medios de comunicación locales y regionales y otros organismos sociales.

Fuente: Darli Benghi, Ecovida, Brasil. 


\section{"SA Patass" vs. "Boy Pombiter" (Senegal)}

En el marco del programa SADMAD (Sistema

Alimentario Sostenible para combatir la malnutrición en Dakar), el CICODEV (una organización de defensa del consumidor) llevó a cabo un estudio sobre los hábitos alimenticios de los hogares y los estudiantes de varios barrios de Dakar. El estudio reveló un alto consumo de batatas, con casi el $95 \%$ en la forma de papas fritas o tubérculos no procesados. Sin embargo, también había una considerable prevalencia de pasabocas industriales procesados vendidos a los niños por vendedores de fuera de las escuelas. El equipo se dio cuenta de que el diseño de una herramienta de comunicación alrededor de la batata podría estimular la conciencia de los niños y aumentar su consumo de alimentos locales y nutritivos.

En Senegal, en todas las clases sociales, la lucha es el deporte nacional favorito de los hombres, las mujeres y los niños. La mayoría de los luchadores son considerados modelos sociales y viven en los suburbios de Dakar, cerca de las áreas a las que apunta el programa SADMAD. Esto ofreció la oportunidad perfecta para desarrollar un mensaje de servicio público sobre las cualidades nutricionales de la batata en comparación con la batata blanca. Con los luchadores llevando este mensaje en un formato de dibujos animados en Wolof (una lengua local ampliamente hablada), CICODEV fue capaz de llegar a públicos locales y nacionales. El video fue diseñado en colaboración con el Laboratoire National d'analises et de Contrôle (LANAC), de la Direction du Commerce Intérieur, un diseñador gráfico, el señor Ousmane Diallo, el señor Becaye Mbaye, un conocido reportero y figura emblemática del luchador senegalés, y la señora Khar Mbaye, una gran cantante e icono nacional que prestó su voz.

Fuente: Khady Ndoye, CICODEV, Senegal.

Para ver el video en Wolof, visite

https://www.youtube.com/

watch?v=BlHnHzOAoPU\&t=3s.

\section{CONSEJO 7}

\section{Cómo atraer clientes}

- Para evitar la decepción y el fracaso, usted tiene que saber lo que sus clientes necesitan y esperan. Explique siempre claramente lo que puede proporcionar y cómo.

- No todos los agricultores son buenos vendedores, pero es importante que algunos agricultores vayan al mercado para poder compartir la historia del producto.

- Se necesitan habilidades específicas para una buena comunicación, incluyendo, por ejemplo, el tipo de lenguaje que usa. Recuerde que no siempre puede hacer todo... jalguien con buenas habilidades de comunicación puede ayudar!

- Aumentar la concientización de los consumidores a través de la comunicación, la educación y el compromiso es fundamental para ampliar su base de clientes. 


\section{LA AVENTURA DEL APRENDIZAJE, ¿DÓNDE SEGUIR?}

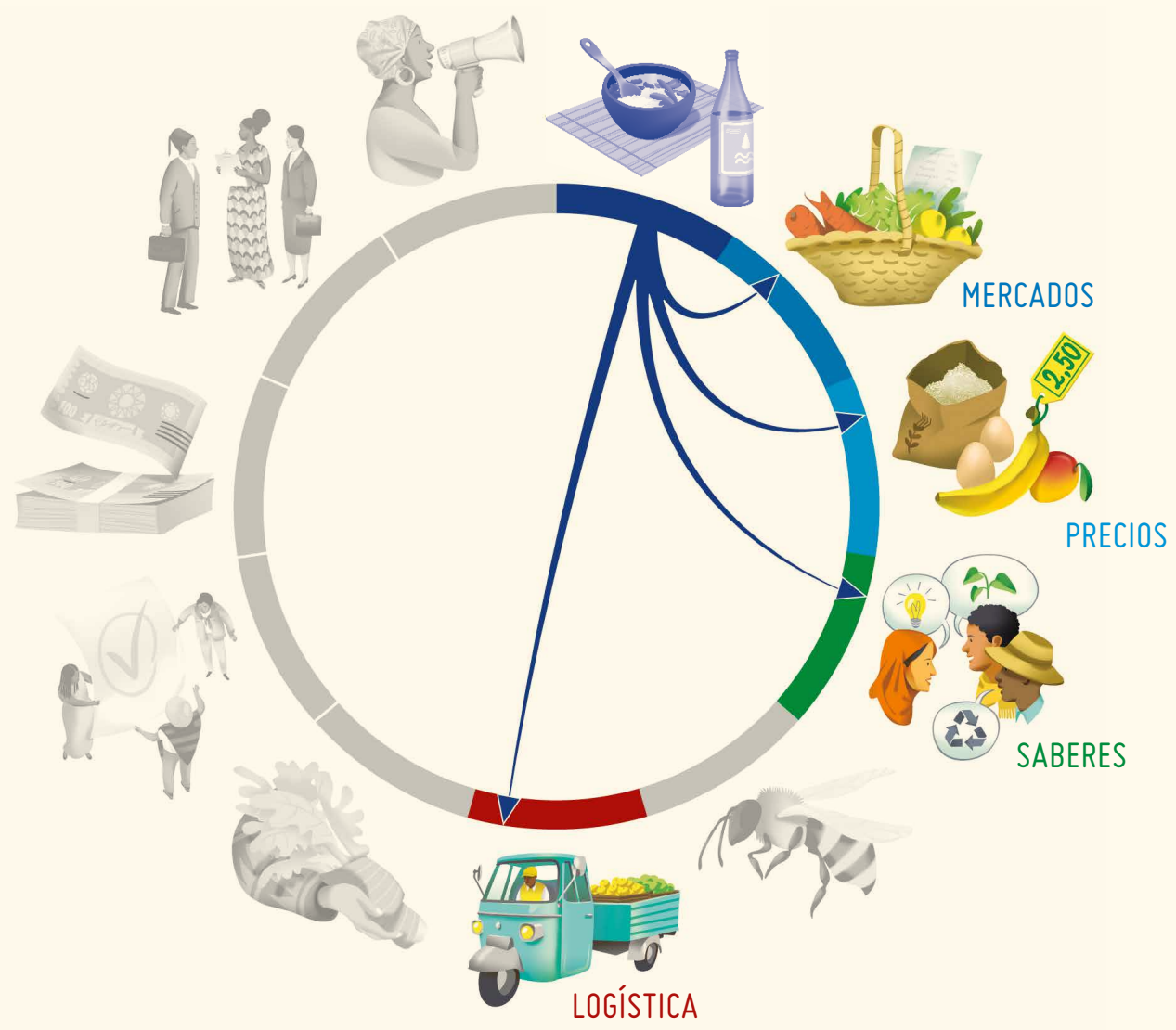

- ¿Tiene una base de consumidores y un grupo de productores dedicado, pero no puede mantener una oferta constante? Lea el Capítulo 6: Manténgase conectado a través de la logística.

- ¿Desea conocer los mecanismos innovadores de fijación de precios como el ASC que se trata en este capítulo? Puede visitar el Capítulo 3: Encontrar el precio "correcto" para descubrir más.

¿Está interesado en los enfoques educativos y de aprendizaje que van más allá de los huertos escolares? Vaya al Capítulo 4: Compartir y cocrear conocimientos para una producción sostenible.

- ¿Desea obtener más información sobre los requisitos del mercado que sus consumidores solicitan? Puede ir al Capítulo 2: Conocer sus mercados.

¿0 quizás otro desafío vino a la mente mientras leía, qué capítulo puede ayudarle a resolverlo? 
2

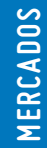

CONOCER

SUS

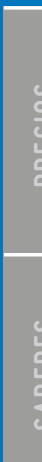

MERCADOS

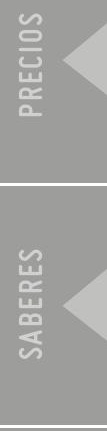

$n$
$\frac{2}{2}$
$\underline{n}$

든
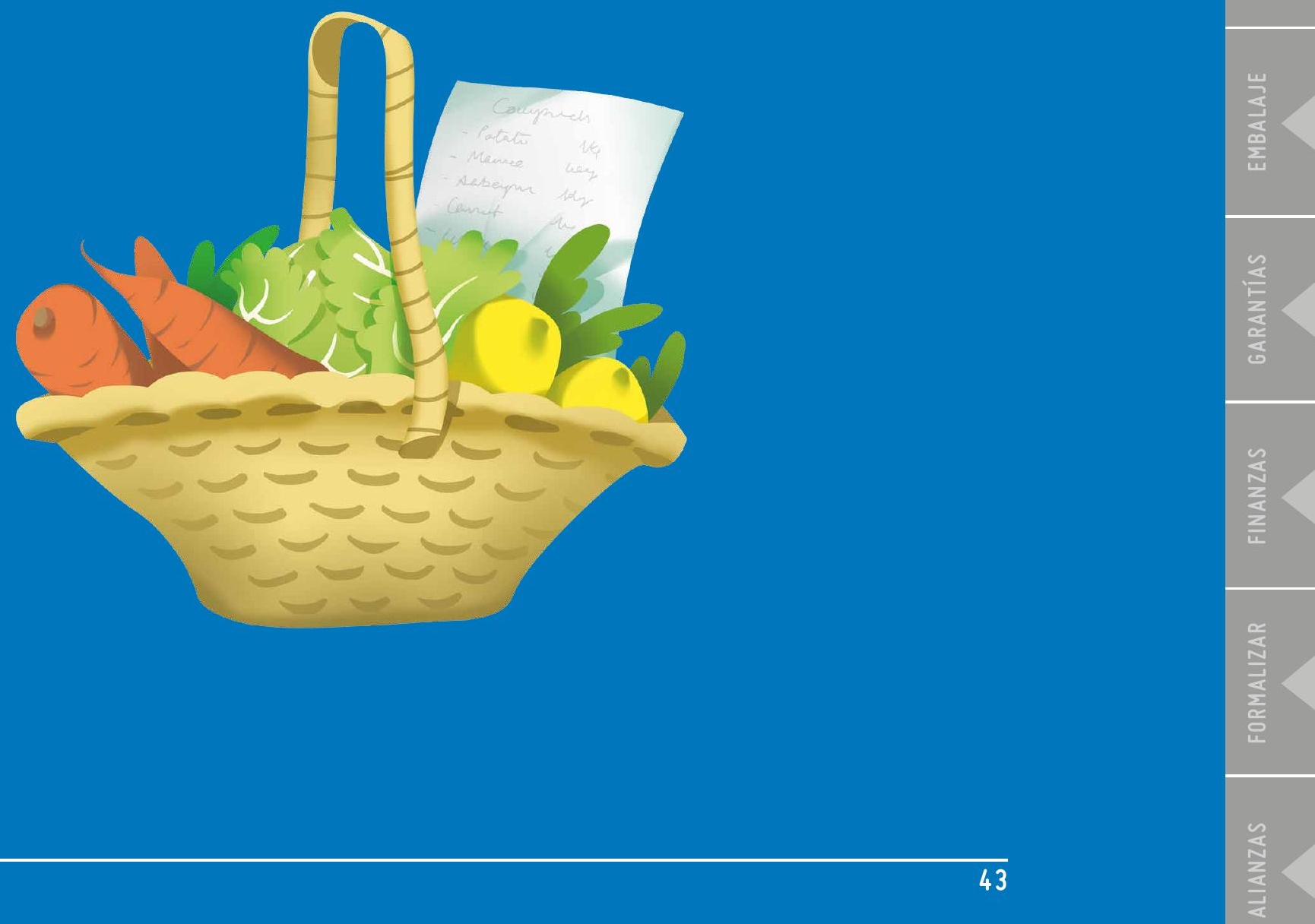


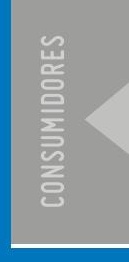

号
온
폴

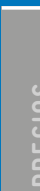

$\approx$
$\frac{0}{4}$
$\frac{\pi}{\alpha}$
$\alpha$
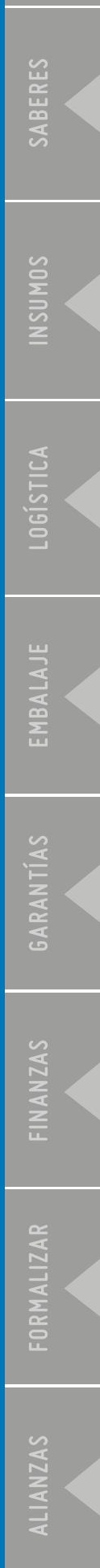


\section{1. ¿POR QUÉ ESTO ES IMPORTANTE?}

Los mercados son plataformas fisicas y virtuales para el intercambio de productos. Pueden ser intercambios cara a cara en ubicaciones geográficas específicas o pueden ser simples acuerdos verbales, escritos o digitales. Estos acuerdos determinan el valor de un producto. Los mercados sostenibles incluyen ambos tipos. Son construidos por actores que acuerdan intercambiar equitativamente productos que se producen de manera sostenible, ahora y en el futuro.

Este capítulo ofrece consejos sobre:

- cómo identificar los mercados sostenibles a los que puede acceder;

- cómo determinar qué mercados se adaptan mejor a sus productos, y

- cómo crear nuevos mercados sostenibles en sus comunidades.

Este tipo de información se conoce con frecuencia como "investigación de mercado" o "análisis de mercado", ya que incluye información sobre los productos que planea producir cada temporada, cómo hacer crecer su negocio y cómo diversificar sus productos. Es un paso importante para la comercialización de sus productos, y debe ayudarle a tomar mejores decisiones con respecto a sus actividades de producción, procesamiento, empaquetado y distribución.

Los puntos tratados en este capítulo también pueden ser útiles para probar nuevos productos, expandir sus mercados o incluir nuevos actores en su iniciativa.

\section{2. ¿QUÉ DEBO PRODUCIR PARA QUÉ MERCADO?}

La demanda no se equipara automáticamente a un mercado. Primero, usted necesita saber qué mercados ya existen para sus productos, y qué ofrecen y demandan.

\section{CONSEJO 8}

Cree una matriz que compare su capacidad con los requisitos del mercado

Siguiendo el modelo que se presenta a continuación, utilice las columnas para enumerar todos los mercados conocidos, y utilice las filas para enumerar algunos requisitos clave basados en su capacidad para abastecer estos mercados. Lo que liste en ambos dependerá de su sistema de producción/adquisición.

1. Haga una lista de su capacidad para suministrar productos, vuelva a ordenar la lista según sus prioridades (por ejemplo, tiene sus propios camiones de transporte, tiene cantidades a granel de frijoles) para organizar la información que ha recopilado y hacer un mejor uso de ella.

2. Utilice un *sistema de clasificación para comparar la importancia de cada capacidad para cada mercado. Es posible que necesite cambiar el significado de cada fila. Enumere lo que significa el * en una leyenda.

3. Una vez que haya identificado y priorizado algunos mercados clave como aquellos en los que su capacidad satisface mejor su demanda, hágase las siguientes preguntas:

a. ¿La demanda ya está bien establecida o está surgiendo?

b. ¿La demanda es consistente a lo largo del año, o está activa solo durante temporadas específicas?

c. Es posible que desee resaltar estas diferencias con colores diferentes, o identificar las columnas con símbolos diferentes. 
Cuadro 2: Matriz de capacidad del productor y requisitos del mercado

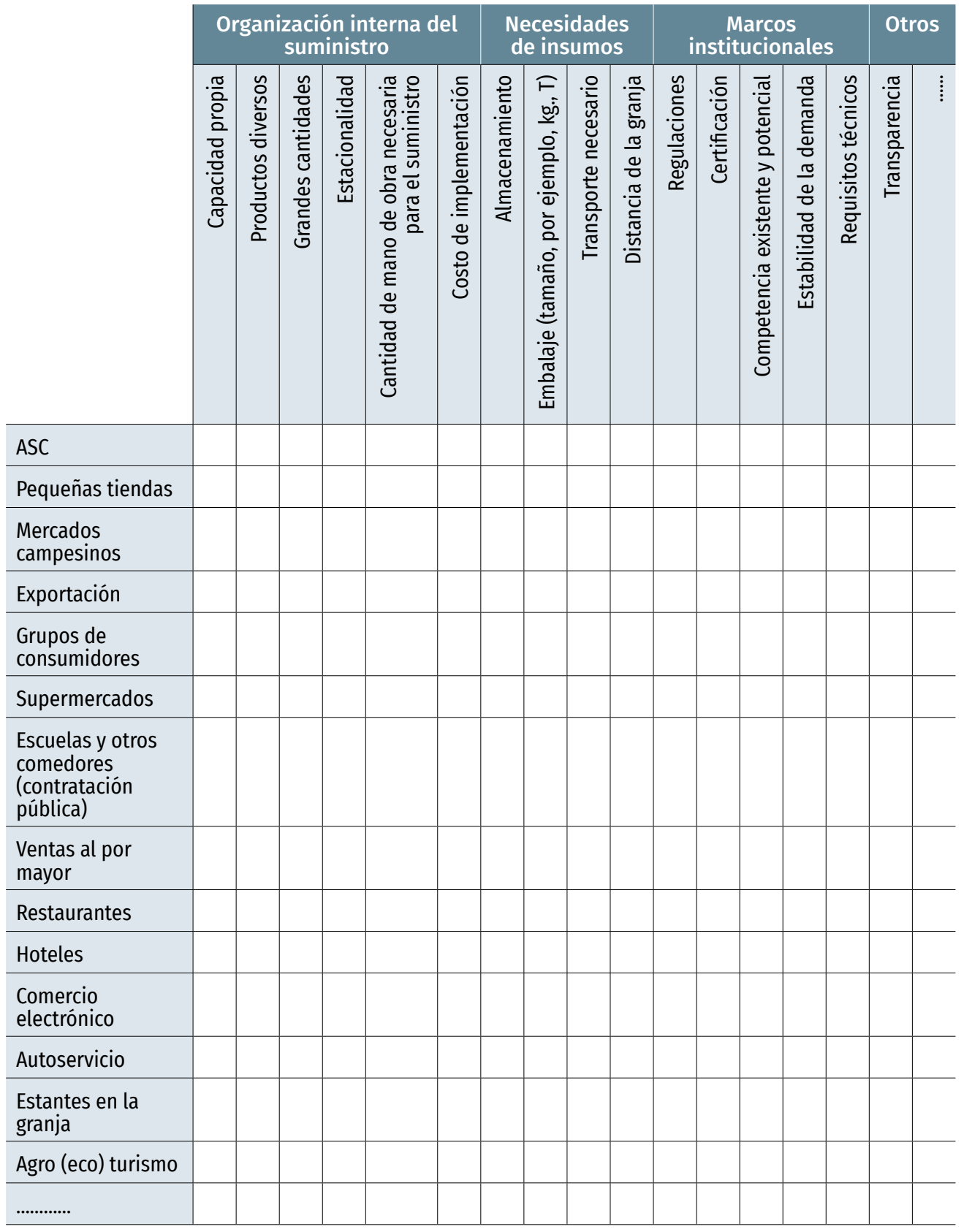

Una vez completada, usted debe evaluar todas estas necesidades dependiendo de los mercados elegidos. Obtenga cotizaciones de precios para los servicios e insumos necesarios, incluyendo costos de inversión para la infraestructura productiva y la logística del transporte.

Leyenda: * = con la menor demanda, ${ }^{* * * * *}=$ con la mayor demanda

- Un plan de negocios será la mejor herramienta para implementar la información que ha extraído de su matriz.

- Organice un taller con sus miembros para completar la matriz juntos. Algunos de sus miembros pueden ya tener experiencia con algunos mercados y es importante construir sobre sus redes existentes. 


\section{3. ¿CÓMO SE PUEDE ENCONTRAR LA INFORMACIÓN NECESARIA PARA LLENAR LA MATRIZ?}

Para obtener la información, realice una búsqueda en Internet, llame a personas que sepa que dirigen los mercados o que ya venden sus productos allí. Visite los mercados y entreviste a los responsables para preguntar cuáles son los requisitos de sus proveedores.

\section{CONSEJO 9}

Haga que la información recopilada sea fácilmente accesible y comprensible para los otros miembros

1. Cree una plantilla de informe de mercado que pueda actualizar regularmente con información nueva a medida que la reciba. Los temas clave que se incluirán en el informe son los que permiten a la iniciativa tomar medidas y tomar mejores decisiones sobre la producción y el mercadeo, como las asociaciones estratégicas, los mercados estratégicos y el orden de preferencia para incluir nuevos mercados. Por ejemplo, lanzar su iniciativa con los miembros, luego con el municipio, luego en ferias locales, y luego empezar a exportar (estas pueden ser acciones paralelas y/o secuenciales).

2. Todas las decisiones o elecciones de comercialización adoptadas deben basarse en un análisis de mercado, y deben incluir los términos tomados de la clasificación en la tabla de capacidades.

3. Dependiendo de sus medios de comunicación habituales, esta información puede estar disponible en un sitio web o en sus oficinas. Los informes pueden ser escritos formal o informalmente, no se preocupe si solo es un pedazo de papel con una lista. ¡Empiece desde aquí y deje que crezca con el tiempo!

Puede obtener información más específica mediante la participación directa de diferentes actores. Las siguientes secciones describen algunos enfoques exitosos.

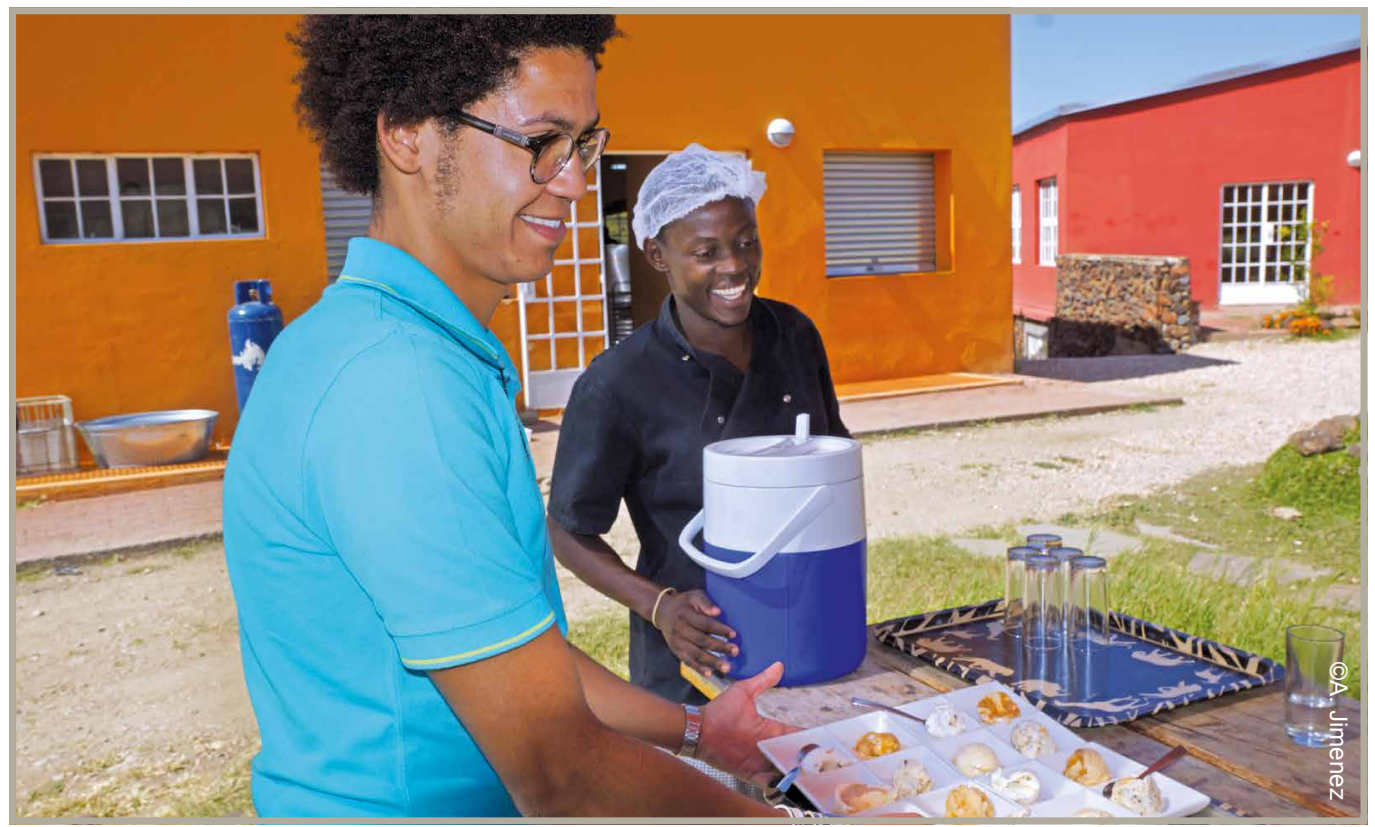




\subsection{Degustación}

La mejor manera de saber si sus productos se van a vender, es recibir comentarios directos sobre cómo saben. Trate de organizar una degustación con diferentes grupos para determinar si diferentes mercados necesitan diferentes versiones de su producto.

\section{Degustación con chefs y} restaurantes (Colombia)

Una manera de mantener el interés de cocineros y profesores de gastronomía es a través de la degustación de múltiples variedades de papa. Para ello, se organizaron diferentes actividades de degustación con jóvenes chefs en formación en la Escuela de Cocina Verde Oliva, con consumidores finales, y con reconocidos chefs de la escena culinaria de Bogotá. Familia de la Tierra y cinco restaurantes participantes, celebraron un evento en el que se presentaron diferentes papas nativas a través de las creaciones culinarias de cinco chefs y cinco conceptos. La elaboración del menú de degustación incluyó la participación de más de 20 personas, y se realizó en las instalaciones de uno de los restaurantes. El cartel fue utilizado para dar a conocer el evento, y fue desarrollado conjuntamente con el equipo de diseño del restaurante.

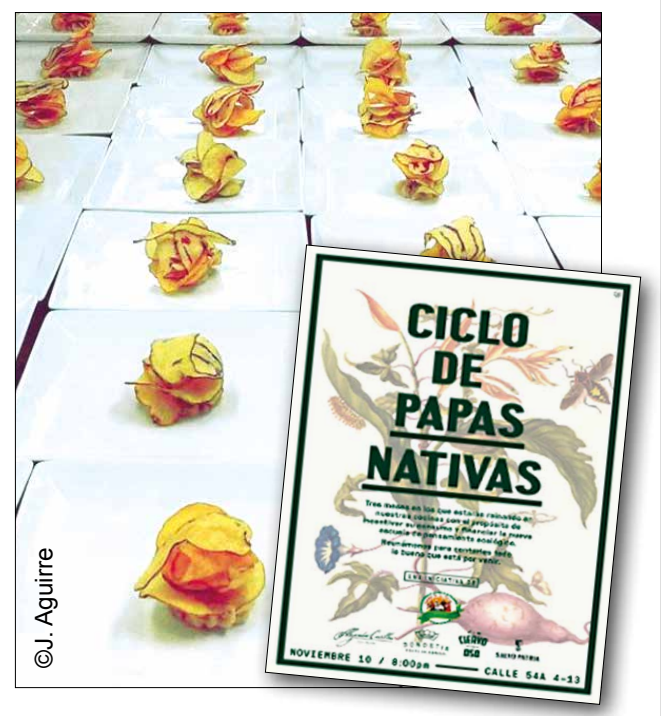

Este tipo de evento permitió a FDT recabar información de los consumidores sobre las preferencias de producción, preparación y sabor de este producto.

Fuente: Jaime Aguirre, Óscar Nieto, FDT.

\subsection{Visitas a granjas y establecimientos de procesamiento}

Dependiendo de a quién se atiende en la visita (consumidores o productores), su ámbito de aplicación debe adaptarse en consecuencia. Mientras que el propósito de este tipo de visita es compartir algunas prácticas agrícolas, debe ser principalmente un medio para obtener información importante que le ayude a lanzar nuevos productos o servicios. Por lo tanto, céntrese en demostrar algunas de estas nuevas ideas, y en darles a los consumidores la oportunidad de participar en algunas actividades. 


\section{Visitas de agricultores a plantas de procesamiento (Colombia)}

En el caso de las papas fritas nativas

producidas por Familia de la Tierra, la organización de visitas a las plantas de procesamiento se considera muy importante para los productores de la asociación. Cuando los productores aprenden sobre todo el ciclo de vida del producto, desde el procesamiento hasta la adición de valor, pueden observar cómo se fríen y empacan sus papas. Pueden entender por qué tienen que seleccionar las papas adecuadas para producir papas fritas. El objetivo principal de estas visitas es el intercambio de información para mejorar todo el proceso y crear confianza entre los diferentes actores del sistema.

Fuente: Jaime Aguirre, Óscar Nieto, FDT.

\subsection{Grupos de enfoque}

Los grupos de enfoque son un medio eficaz de recopilar información de una muestra de consumidores potenciales. Pueden tener lugar para diferentes propósitos (tanto para investigación en profundidad como para pruebas de productos) y en diferentes momentos a lo largo de la temporada. Por ejemplo, si usted ofrece muchos cursos de capacitación en su comunidad, debe aprovechar estos para realizar grupos de enfoque. Piense en los elementos sobre los que desea saber más, y de quién, y continuación establezca el grupo de enfoque. Cuando los grupos de enfoque se organizan con fines de investigación, los participantes generalmente no reciben ningún pago. Sin embargo, si se les hacen preguntas específicas sobre sus productos o sobre una campaña publicitaria que desea lanzar, jsus opiniones inestimables deben recibir algún tipo de compensación!

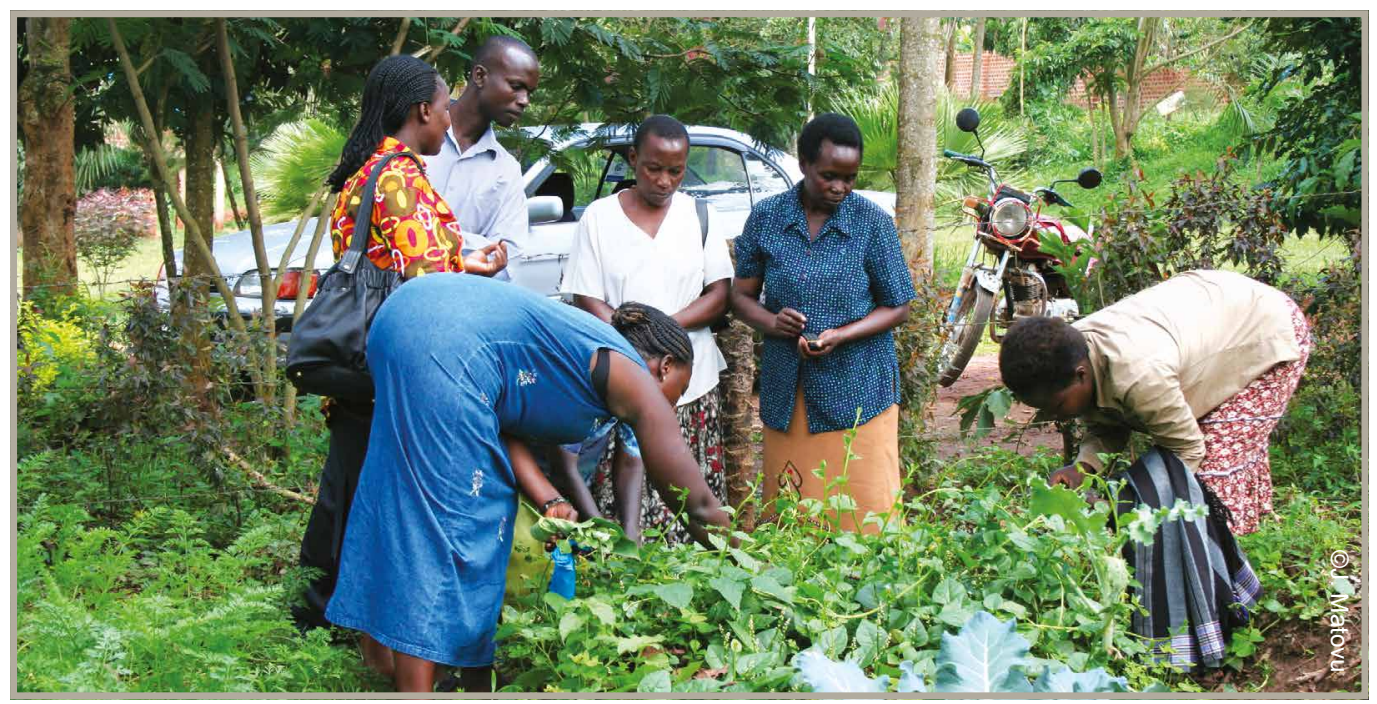




\section{¿Cuándo y cómo dirigir un grupo} de enfoque? (Ecuador)

\section{3}

Para contribuir a la comprensión de las

redes alimentarias alternativas, y más específicamente, de los canales de mercado agroecológicos, la Fundación EkoRural realizó un estudio de caso que se centró en las relaciones productor-consumidor desarrolladas a través de un esquema de cajas comunitarias ecuatorianas, organizado por la Fundación Utopía. El objetivo de este estudio era comprender mejor las relaciones económicas y sociales entre los consumidores de Utopía y la asociación de agricultores agroecológicos que abastecen a Utopía: Nueva Generación de Tzimbuto. Como parte de este estudio, se realizaron varias entrevistas para aclarar las diferentes concepciones de la agroecología como sistema de producción, las expectativas y la comunicación de la calidad de los productos entre productores y consumidores, los factores que rigen las opciones de compra, los motores de la participación en la iniciativa, las dificultades encontradas, y la creación de vínculos sociales entre consumidores, entre productores y entre consumidores y productores.

Se llevaron a cabo grupos de enfoque y sesiones de información de seguimiento para comprobar la información obtenida en las entrevistas, ofrecer nuevas oportunidades de debate y buscar nuevas aclaraciones sobre temas de especial interés.

Dinámica de grupo durante un grupo de enfoque

Para entender y contextualizar mejor la información discutida durante un grupo de enfoque, es importante prestar atención a la dinámica del grupo (Morgan, 1997). Ekorural atestigua estas dinámicas en la descripción de un grupo de enfoque específico que ellos sostuvieron.

\section{Durante la discusión no todos los} participantes tuvieron la misma voz. Algunas personas estaban hablando más que otras y a veces surgieron pequeños desacuerdos sobre cuál sería el mejor enfoque. Los participantes también tenían diferentes estilos de contribución. Una señora hablaba mucho, pero también se repetía a veces, o se tomaba tiempo para desarrollar sus ideas mientras hablaba. Otra participante hablaba menos, pero parecía pensar más cuidadosamente en sus palabras. El facilitador trató de incluir la opinión de todas las personas presentes, pidiendo específicamente su opinión a los participantes más silenciosos, y pasando a la siguiente pregunta de discusión cuando los participantes empezaron a repetir puntos que ya se habian mencionado.

Fuente: Ross Mary Borja, Fundación Ekorural.

\subsection{Actividades durante ferias y exposiciones}

Las ferias agroecológicas proporcionan un espacio no solo para la venta y compra de productos agroecológicos, sino también para eventos culturales y talleres que se llevan a cabo. Esas actividades contribuyen al fortalecimiento de las relaciones entre los productores y los consumidores y al intercambio de información y experiencias. Por lo tanto, estos acontecimientos son una oportunidad para recopilar información sobre el mercado. 


\section{Feria agroecológica de Carcelén} (Ecuador)

Carcelén es una parroquia y ciudad satélite situada en el norte de Quito, la capital del Ecuador. Su feria agroecológica es una buena oportunidad para organizar actividades que concienticen sobre un comportamiento más responsable de los consumidores, y para conectar a los productores con los consumidores, creando un espacio para el intercambio de información sobre sus respectivas necesidades y expectativas. Por ejemplo, se han realizado talleres de cocina y cosmética natural artesanal yvisitas a granjas que permiten a los consumidores ser testigos de la producción de artículos vendidos en la feria. También hay una tienda de información donde los consumidores pueden hacer preguntas sobre los productos vendidos, etc. (Kok, 2017). La feria pertenece a una serie de actividades vecinales organizadas para recuperar valores tradicionales perdidos en comunidades rurales que alguna vez albergaron migrantes, principalmente la primera generación de habitantes de Carcelén. Según lo descrito por el Presidente de la Asociación de Productores participantes:

La feria es muy hermosa porque también hay un componente de los consumidores que acompañan a los productores en sus campos. Cada mes, visitemos a nuestros socios (los productores) y organizamos grupos grandes de 40 personas. El evento se llama allin ruway (quechua para «hacerlo bien»). Hemos utilizado el quechua porque queremos reforzar la conexión entre los consumidores y los cultivadores.

Fuente: Ross Mary Borja, Fundación Ekorural, Ecuador.

\subsection{Nuevas tecnologías de la información y la comunicación}

Las aplicaciones móviles, Internet y las redes sociales se utilizan cada vez más para compartir información entre productores y consumidores.

\section{Un estudio de mercado realizado por correo electrónico (Colombia)}

(15)

Agroindustrias Nutriandina S.A.S. es una

empresa colombiana que surgió de las necesidades ambientales, sociales y económicas de la comunidad de Sumapaz en Bogotá. Esta empresa produce y comercializa alimentos orgánicos que implementan prácticas agrícolas sostenibles que contribuyen a la protección del medio ambiente y al crecimiento de la rentabilidad de los agricultores, al mismo tiempo que favorecen la salud de los consumidores. La empresa llevó a cabo investigaciones de mercado a través de una encuesta por correo electrónico para evaluar el interés y la opinión de clientes activos y potenciales en relación con la apertura de una nueva tienda, dónde debía ubicarse, qué productos debería tener y los servicios que debería prestar. Como parte de este estudio, también se recogieron los datos sociodemográficos de sus consumidores, incluyendo sus preferencias, hábitos de consumo y el servicio ideal que esperan de una tienda de alimentos orgánicos. Esto ayudó a la empresa a determinar que su grupo objetivo de consumidores orgánicos son habitantes 
de clase media de Bogotá entre 30 y 60 años. A continuación, desarrollaron un conjunto de variables para incluirlas en un instrumento de encuesta, permitiéndoles recopilar más datos sobre el comportamiento y las preferencias de sus consumidores:

Cuadro 3: Cuestionario para el consumidor para encontrar un sitio de mercado

\begin{tabular}{|c|c|c|c|}
\hline \multirow{10}{*}{$\begin{array}{l}\text { Identificar a los } \\
\text { consumidores }\end{array}$} & \multirow{10}{*}{$\begin{array}{l}\text { Preferencias } \\
\text { y hábitos de } \\
\text { consumo }\end{array}$} & $\begin{array}{l}\text { ¿Sabe la diferencia entre un producto orgánico } \\
\text { y un producto alimenticio tradicional? }\end{array}$ & Cerrado \\
\hline & & ¿Come alimentos orgánicos? & Cerrado \\
\hline & & $\begin{array}{l}\text { ¿Cree que consumir alimentos orgánicos } \\
\text { beneficia su salud? }\end{array}$ & Cerrado \\
\hline & & ¿Qué tipo de comida orgánica come? & $\begin{array}{l}\text { Elección } \\
\text { múltiple }\end{array}$ \\
\hline & & $\begin{array}{l}\text { ¿Con qué frecuencia come alimentos } \\
\text { orgánicos? }\end{array}$ & Cerrado \\
\hline & & $\begin{array}{l}\text { ¿Sabe qué es el yacón y los efectos } \\
\text { beneficiosos que tiene para su cuerpo? }\end{array}$ & Cerrado \\
\hline & & $\begin{array}{l}\text { ¿Le gustaría poder encontrar un lugar en } \\
\text { el mercado donde se puedan consumir } \\
\text { productos derivados del yacón? }\end{array}$ & Cerrado \\
\hline & & $\begin{array}{l}\text { ¿Cuánto dinero gasta mensualmente en } \\
\text { productos orgánicos? }\end{array}$ & Cerrado \\
\hline & & ¿Dónde compra sus productos orgánicos? & $\begin{array}{l}\text { Elección } \\
\text { múltiple }\end{array}$ \\
\hline & & $\begin{array}{l}\text { En comparación con los productos } \\
\text { tradicionales, ¿cuánto más estaría dispuesto a } \\
\text { pagar por alimentos orgánicos? }\end{array}$ & Cerrado \\
\hline \multirow{5}{*}{$\begin{array}{l}\text { Identificar los } \\
\text { posibles lugares } \\
\text { geográficos para } \\
\text { establecer un } \\
\text { punto de venta }\end{array}$} & \multirow{9}{*}{$\begin{array}{l}\text { Factores } \\
\text { clave de } \\
\text { éxito }\end{array}$} & $\begin{array}{l}\text { ¿Qué tan lejos estaría dispuesto a viajar } \\
\text { para comprar en una tienda de alimentos } \\
\text { orgánicos? }\end{array}$ & Cerrado \\
\hline & & $\begin{array}{l}\text { ¿A cuál de estos puntos de la ciudad estaría } \\
\text { dispuesto a desplazarse para comprar en una } \\
\text { tienda orgánica? }\end{array}$ & Cerrado \\
\hline & & $\begin{array}{l}\text { ¿A cuál de estos barrios de Bogotá iría para } \\
\text { poder comprar productos orgánicos? }\end{array}$ & Cerrado \\
\hline & & $\begin{array}{l}\text { En una escala del } 1 \text { al } 5 \text {, con } 1 \text { siendo muy } \\
\text { mala y } 5 \text { siendo muy buena, ¿cómo valoraría la } \\
\text { facilidad de movimiento (transporte público) } \\
\text { en estos barrios? }\end{array}$ & $\begin{array}{l}\text { Escala } \\
\text { numérica }\end{array}$ \\
\hline & & $\begin{array}{l}\text { En una escala del } 1 \text { al } 5 \text {, con } 1 \text { siendo muy } \\
\text { mala y } 5 \text { siendo muy buena, ¿cómo valoraría la } \\
\text { seguridad en estos barrios? }\end{array}$ & $\begin{array}{l}\text { Escala } \\
\text { numérica }\end{array}$ \\
\hline \multirow{4}{*}{$\begin{array}{l}\text { Identificar las } \\
\text { caracteristicas } \\
\text { ideales que debe } \\
\text { tener el punto de } \\
\text { venta }\end{array}$} & & $\begin{array}{l}\text { ¿Cree que es importante que los productos } \\
\text { lleven un registro de seguridad alimentaria? }\end{array}$ & Cerrado \\
\hline & & $\begin{array}{l}\text { ¿Cree que es importante que los productos } \\
\text { lleven una etiqueta de certificación orgánica? }\end{array}$ & Cerrado \\
\hline & & $\begin{array}{l}\text { Marque los productos que le gustaría vender } \\
\text { en una tienda de alimentos orgánicos. }\end{array}$ & $\begin{array}{l}\text { Elección } \\
\text { múltiple }\end{array}$ \\
\hline & & $\begin{array}{l}\text { Seleccione los criterios que considere más } \\
\text { importantes para una buena tienda de } \\
\text { alimentos orgánicos. Puede seleccionar más } \\
\text { de uno. }\end{array}$ & $\begin{array}{l}\text { Elección } \\
\text { múltiple }\end{array}$ \\
\hline
\end{tabular}

Fuente: Andrea Moya, Agroindustrias Nutriandina SAS, Colombia. 


\section{4. ¿CÓMO ESTABLECER MERCADOS QUE TODAVÍA NO EXISTEN?}

Una vez que sepa qué oportunidades de mercado y qué mercados existen, necesita empezar a planificar y crear otros nuevos.

\subsection{Creación de un mercado campesino}

\subsection{1. ¿Cómo obtener espacio físico?}

Obtener el espacio físico necesario para mantener su mercado a veces puede ser un reto. A menos que su iniciativa tenga su propia construcción, usted tendrá que pedir prestado, arrendar o comprar un espacio. Las empresas privadas, las iglesias y las alcaldías podrían prestarle sus estacionamientos, jardines, parques o plazas; aunque a menudo tendrá que negociar el arreglo particular y respetar sus reglas para el uso de la propiedad.

Mercados «campesinos» de Pekín (BFM), "el mercado móvil" (China)

Cuando el primer mercado se abrió en septiembre de 2010, solo asistieron los que conocían a los organizadores. Se llevó a cabo en diferentes lugares de la ciudad y era conocido como "el mercado móvil". Desde entonces, el número de vendedores ha aumentado de menos de 10 a más de 40 , y el número de seguidores de Weibo (una plataforma de red social) ha aumentado a más de 80.000 . En 2013, había más de 200 proveedores que solicitaron unirse al BFM. El mercado aún no ha establecido normas escritas para los procedimientos relativos a la selección de nuevos proveedores, pero la organización trata de mantener una cierta diversidad y equilibrio entre "los valores globales y locales, los valores de justicia empresarial y social, y los vendedores modernos y tradicionales".

El BFM sigue siendo un mercado móvil, y casi toda la información relativa a su próxima ubicación se obtiene directamente de las sugerencias de los consumidores. Estos lugares incluyen, entre otros, al Centro de Eventos
BMW 4S, la Escuela Internacional Canadiense de Beijing, Iron Chef Kitchen, Plaza de Arte Vintage, Beijing New World Women's Shopping Mall, Children's Event Centre en Chongguang Mall, Nali Patio en Sanlitun Bar Street, el Red Wall Garden Hotel y Shijia Hutong. Además de encontrar lugares en donde alojar el BFM sin incurrir en costos monetarios, los consumidores también comparten consejos de construcción de organizaciones e información. La naturaleza móvil del mercado permite que se lleve a cabo simultáneamente en diferentes puntos de la ciudad, y anima a los consumidores a permanecer comprometidos para que sepan dónde se abre a continuación.

Fuente: Xueshi Li, la Universidad China de Hong Kong, Shenzhen y Allison Loconto, INRAE.

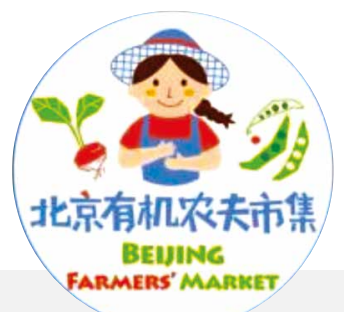

Para saber más, visite: https://www.facebook.com/farmersmarketbj. 


\subsubsection{Determinar quién puede vender y qué se puede vender en el mercado}

Antes de establecer un mercado campesino, es importante que las reglas de intercambio se determinen de antemano. A veces, hay restricciones sobre quién puede vender: ¿solo se les permite vender a los agricultores, o también pueden hacerlo los comerciantes? En otros casos, los propios productos están restringidos: ¿el mercado incluye solo productos orgánicos certificados, solo productos frescos o de temporada, o también productos procesados? Es importante ser transparente con otros actores que quieren administrar el mercado campesino, y acordar una «carta» de gobernanza del mercado.

\section{LISTA DE VERIFICACIÓN}

Redacción de una carta de mercado campesino:

1. ¿Quién puede vender en el mercado?

2. ¿Quién puede comprar en el mercado?

3. ¿Hay alguna restricción en los tipos de productos a vender?

4. ¿Son los precios fijos (dentro de un rango por producto) o competitivos (basados en las tarifas de mercado)?

5. ¿Qué formas de pago se permiten (efectivo, crédito, vales del Gobierno)?

6. ¿Cómo se manejan los pagos? ¿Estará en una ubicación centralizada manejada por el mercado, o individualmente con cada proveedor?

7. ¿Con qué frecuencia tendrá lugar el mercado?

8. ¿Dónde se llevará a cabo?

9. ¿Cómo se pagan las tarifas de funcionamiento del mercado (espacio, electricidad, agua, publicidad, etc)?

10. ¿Existe espacio para eventos educativos y de entretenimiento?

11. ¿Quién lo gestiona y cuál será la compensación?

\subsection{Establecer un programa de alimentación escolar}

Los programas de alimentación escolar son muchos y a menudo complejos. Los padres exigen cada vez más que los colegios incluyan opciones de comida más saludables y sostenibles. Aprenda sobre los programas de alimentación escolar de su área, y vea si hay asociaciones de padres que están interesadas en establecer un programa para abastecerse de las iniciativas de producción sostenible.

Visite el sitio web de Un Plus Bio (http:/ / www.unplusbio.org/), la primera asociación nacional creada en Francia en 2002 dedicada al desarrollo de programas de alimentación escolar orgánica. Tienen guías para padres y funcionarios locales de elección popular. 
CONSEJO 10

Asegúrese de que conoce las leyes nacionales y los requisitos para la alimentación escolar

Esto es importante, ya que no todas las escuelas individuales están siempre autorizadas para determinar sus estrategias de abastecimiento de alimentos.

\subsection{Configuración de una ASC}

La agricultura sostenida por la comunidad (ASC) es un término utilizado para describir una serie de modelos de venta directa entre productores y consumidores. Están surgiendo en todo el mundo y son relativamente fáciles de instalar: ¡solo necesitan de productores y consumidores dedicados en una comunidad dedicada!

\section{CONSEJO 11}

Cómo crear una ASC

Independientemente de si la ASC es iniciada por la comunidad o por el agricultor, se recomiendan los siguientes pasos.

\section{Entender el concepto}

Es importante entender qué tipo de producción se espera en una ASC (diversidad de productos, prácticas orgánicas o agroecológicas, continuidad de la producción, etc) y qué tipo de relación debe desarrollarse dentro de una comunidad ASC. Vale la pena ponerse en contacto con otras iniciativas de ASC en su región o país para obtener más información sobre el asunto.

Como consumidor, usted debe estar preparado para los compromisos, por lo que es realmente importante pensar si usted puede mantenerlos o no. Los compromisos clave incluyen el pago anticipado, la participación en las distribuciones, ayuda con la gestión del grupo y, a veces, con el trabajo agrícola.

Los riesgos y beneficios compartidos entre los agricultores y los consumidores son un elemento clave de una ASC. Significa que, si hay una cosecha excelente, el consumidor tendrá una parte mucho mayor y tendrá que congelarla o conservarla para la temporada "de vacas flacas". Por otra parte, en el caso de un evento climático, su cuota semanal puede ser más reducida.

\section{Planificación}

Como productor, es importante estimar sus capacidades y posibilidades. ¿Puede estimar cuántos hogares pueden abastecerse con sus productos? ¿Puede estimar cuánto tiempo de trabajo se necesita? ¿Es capaz de hacer el trabajo solo, o debe contratar a empleados?

\section{Busquemos a los miembros}

Para iniciar una ASC, la clave es encontrar un grupo básico de consumidores que puedan convertirse en socios.

- Si ya estaba vendiendo a través de otros canales de marketing, pregunte a sus clientes si estarían interesados en unirse a su iniciativa ASC.

- Pregunte a sus amigos o vecinos. Con ellos, no tendrá que empezar a crear confianza desde cero. 
Busque en grupos existentes: guarderías, organizaciones ambientales, grupos cívicos y lugares de trabajo, entre otros. Además, lugares como escuelas alternativas o centros de yoga podrían ser un buen sitio para encontrar personas que estén interesadas en alimentos saludables y asociaciones basadas en la comunidad.

- Póngase en contacto con su red local de ASC (si la hay) o cualquier ONG que ya esté trabajando en este tema.

\section{Organizar reuniones públicas}

Con los primeros aliados, prepárese para encontrar nuevos consumidores en reuniones públicas. No tenga miedo si no tiene mucha experiencia. La ASC es una asociación, los (otros) consumidores deben ayudarle a encontrar soluciones. Entre los posibles temas de la agenda de la reunión se pueden incluir:

$\checkmark$ ¿Qué es una ASC?

- ¿Por qué comer alimentos cultivados localmente? ¿Cuáles son los riesgos de la agricultura industrial?

¿Por qué los pequeños agricultores necesitan apoyo?

- ¿Cuáles son las ventajas de convertirse en miembro de una ASC?

- Evaluación del nivel de compromiso de los participantes.

- Compartir tareas/roles y crear un grupo principal.

Es muy valioso si usted puede invitar a un agricultor experimentado en ASC a su reunión.

La transparencia es crucial: todas sus preguntas o inquietudes deben ser discutidas, porque la ASC solo puede ser construida sobre bases fuertes y honestas.

\section{Recopilar los compromisos y establecer el calendario de la primera temporada}

¿Cuánto tiempo tarda todo esto? El plazo para establecer una ASC puede variar según sus circunstancias iniciales y la comunidad que le rodea. Sin embargo, en general, cuanto más tiempo dedique a planificar la fase inicial, hablar con la gente y elaborar el esquema de su establecimiento, más preparado estará.

Fuente: Be Part of ASC! Folleto de apoyo para Formación sobre la Agricultura Sostenida por la Comunidad, 2016.
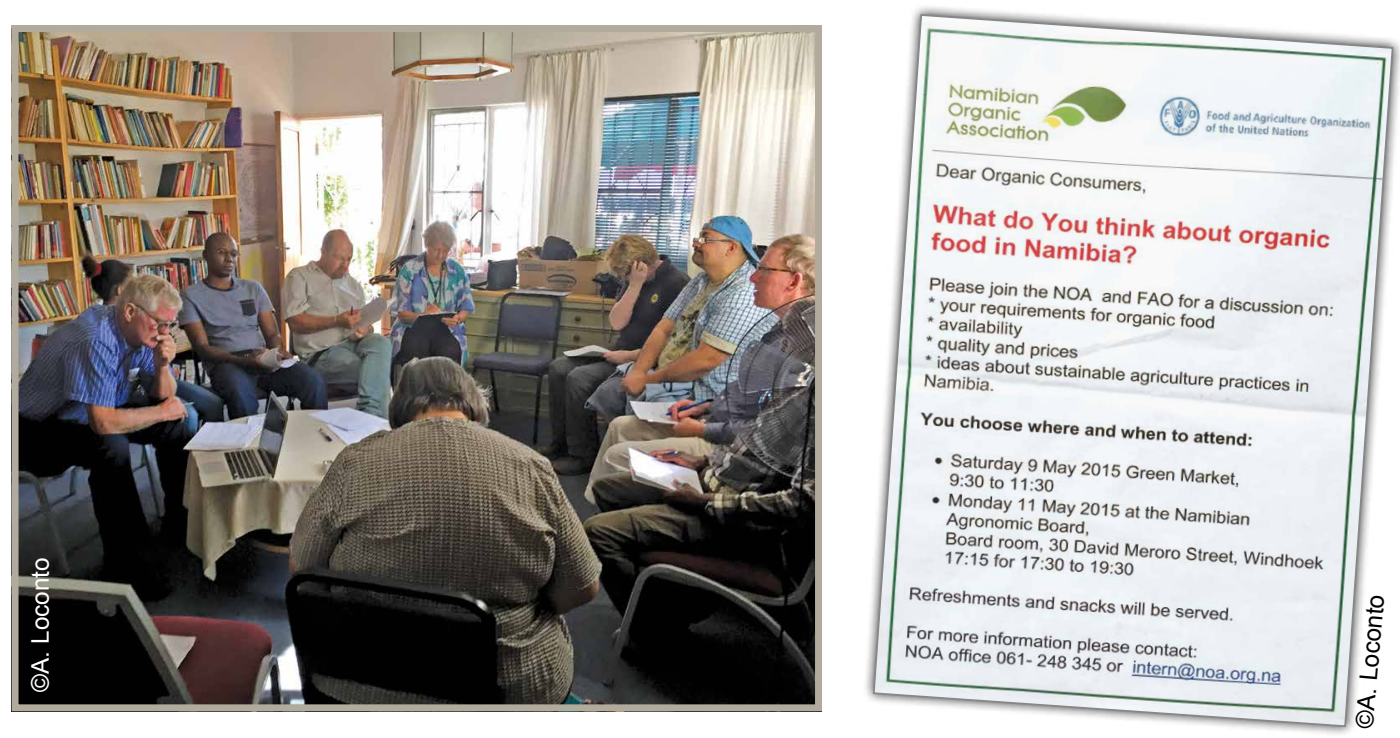


\subsection{Crear una plataforma de Internet}

Muchas iniciativas están utilizando Internet para establecer una estantería en línea donde productores individuales y grupos de productores pueden anunciar sus productos, y los consumidores pueden verlos y ordenarlos para su entrega o recogida. Estas plataformas en línea pueden ser parte de una iniciativa, una nueva puesta en marcha o parte de una red global de plataformas electrónicas.

\section{¿Ir solo o unirse a una red? (Benin)}

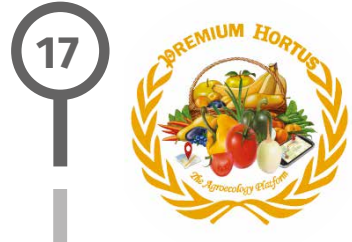

PREMIUM HORTUS es una plataforma tecnológica para la agroecología en Benin especializada en la producción orgánica, el comercio electrónico de productos agroecológicos y el apoyo a los productores. Disponible como aplicaciones web y móviles, y como una solución de pago en línea, el sitio PREMIUM HORTUS le permite suscribirse, elegir el contenido de su carrito de compras, pedir, pagar en línea y tener frutas, verduras, cócteles y productos orgánicos entregados de forma segura a su casa. Hay dos programas que ayudan a que este servicio sea más incluyente entre los hogares más pobres: CALIM+ es un crédito de alimentos que ayuda a los miembros con los pagos cuando se están escasos de efectivo; y CONSOM'Acteur es una aplicación que ayuda a los consumidores a rastrear sus hábitos alimenticios y sus necesidades de alimentos. PREMIUM HORTUS recogerá los excedentes de alimentos y los entregará a los necesitados.

PREMIUM HORTUS garantiza el acceso permanente de los productores agroecológicos a semillas naturales, biofertilizantes y biopesticidas específicos fuera de las granjas agroecológicas de Benin. Fortalece el profesionalismo y la resiliencia de los pequeños productores y granjas familiares a través de intercambios, generación de habilidades, apoyo técnico personalizado en la gestión de negocios ecológicos y soluciones tecnológicas limpias y adaptadas.

Fuente: Johannes Goudjanou, Premium Hortus.

Para saber más visite: http://premiumhortus.com.

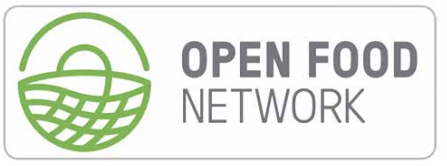

Open Food Network (OFN) es una red global colaborativa de organizaciones locales sin ánimo de lucro que han desarrollado conjuntamente software de código abierto y lo han puesto a disposición de los centros de alimentación de todo el mundo a través de plataformas en línea localizadas (como OFN UK, OFN Australia, Open Food France, Katuma, OFN Canada, etc.). La misión de esta comunidad es construir una infraestructura digital compartida (y conocimiento compartido) para permitir a los operadores de cadenas alimentarias cortas gestionar sus actividades, cooperar más eficientemente y construir soberanía alimentaria. Al igual que los consumidores y los productores se unen para crear centros de alimentación, en los centros 
de alimentación OFN se unen para crear infraestructura digital y compartir su uso.

En la práctica, la plataforma permite a los productores gestionar sus catálogos de productos y compartirlos con múltiples distribuidores (centros de alimentación). Los centros pueden conectarse con uno o varios productores para publicar sus productos en una tienda y organizar las ventas colectivas, y obtener datos agregados para organizar la logística y gestionar pedidos al por mayor o individuales.

En la OFN, un centro puede adoptar muchas formas diferentes, como:

- un productor que vende directamente a los consumidores a través de una tienda en línea;

- una ASC o un grupo de compra que organice compras colectivas regulares basadas en suscripción, y que pueda manejar múltiples grupos de subcompra;

- un empresario que compra alimentos de productores locales/orgánicos y organiza ventas a particulares, grupos, restaurantes y minoristas.

La plataforma también permite funciones de red y marketing, como la posibilidad de crear un "grupo" con los productores e identificar los centros de un ecosistema específico. Estos se pueden mostrar en un mapa, como el de la Biodynamic Association en el Reino Unido.

Fuente: Myriam Bouré, Open Food Network.

Para saber más visite:

https://openfoodnetwork.org.

\section{CONSEJO 12}

\section{Cómo encontrar mercados sostenibles}

- Asegúrese de que está familiarizado con los requisitos del mercado y con sus capacidades para cumplir con ellos antes de decidir dónde vender sus productos.

- Comprométase con los miembros de su iniciativa: consumidores, productores, intermediarios y otros actores interesados en la medida de lo posible. Son su mejor fuente de información sobre dónde encontrar mercados sostenibles.

- ¡Si no hay mercados sostenibles a su alrededor, créelos!

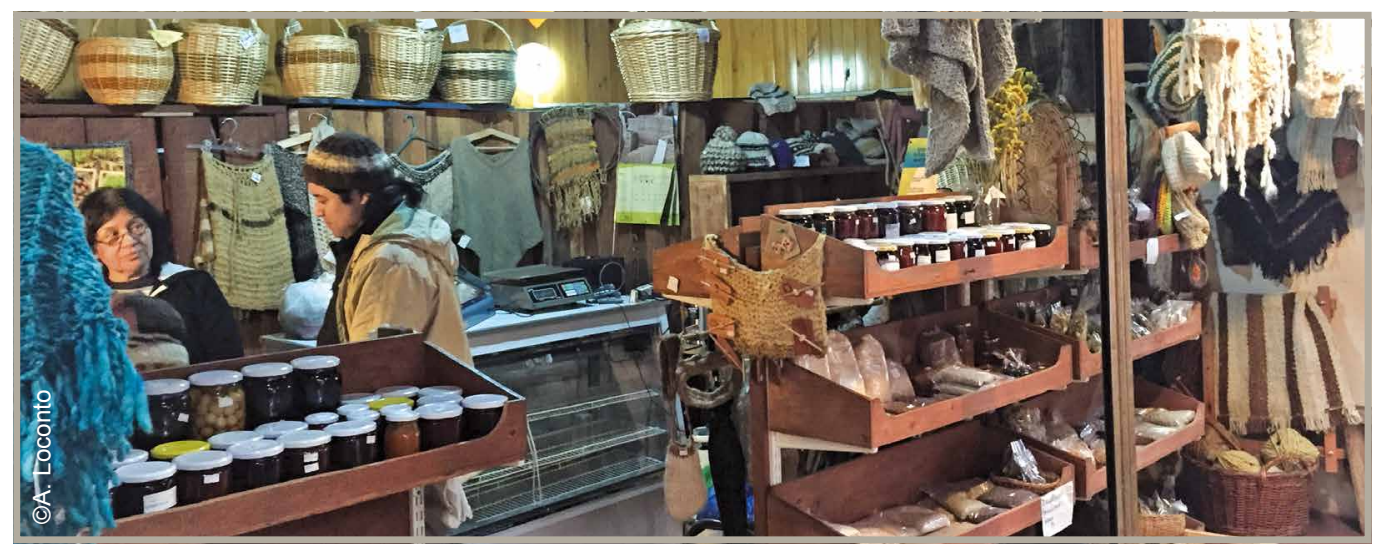




\section{LA AVENTURA DEL APRENDIZAJE, ¿DÓNDE SEGUIR?}

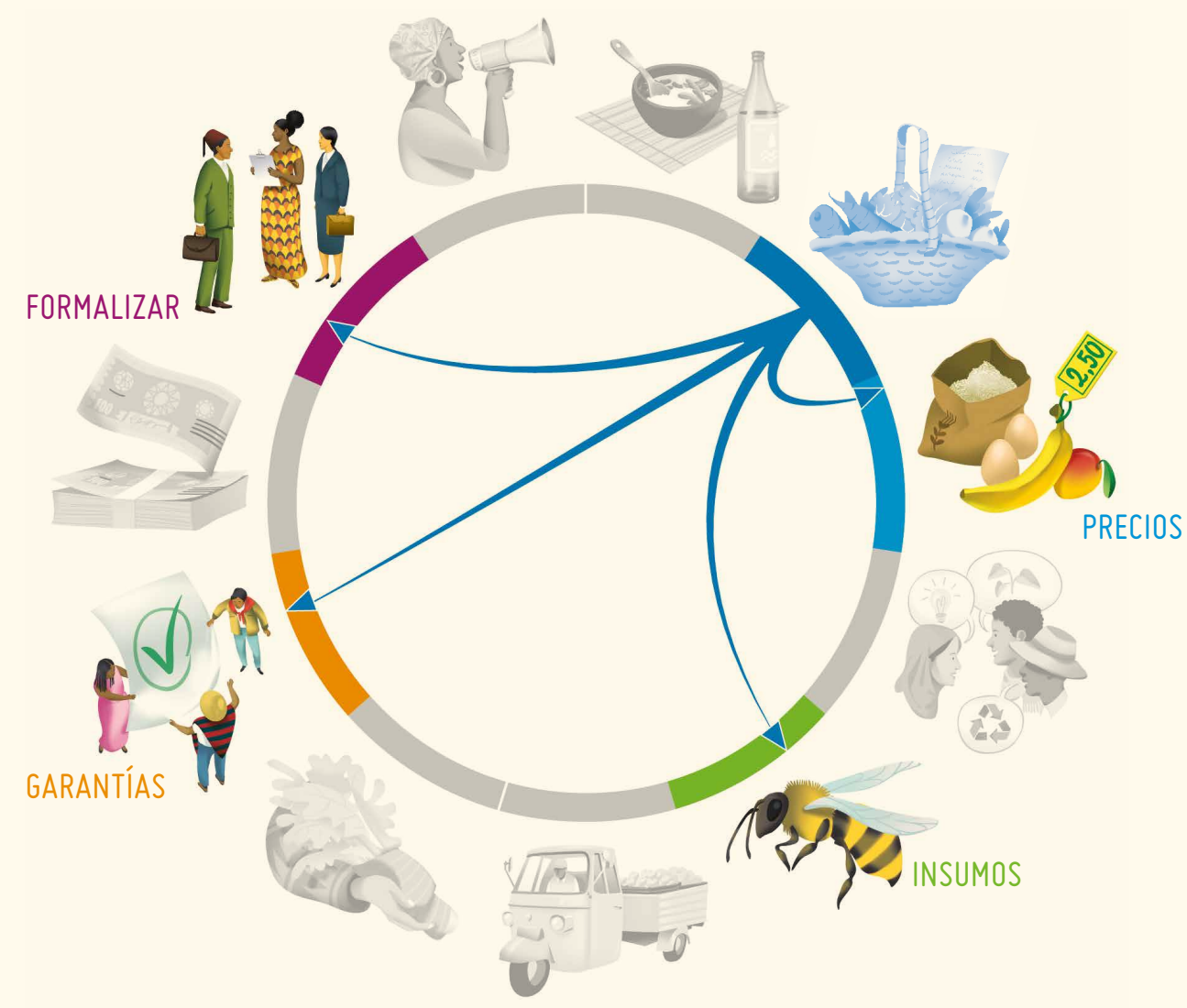

- ¿Quiere saber si una ASC es la opción correcta para la comercialización de sus productos? Vaya al Capítulo 10: Formalizar el trabajo colectivo.

- ¿Desea saber cómo acceder a los insumos necesarios para cumplir con los requisitos de su mercado? Vaya al Capítulo 5: Conocer y acceder a insumos sostenibles para averiguarlo.

- ¿Necesita aprender a cotizar sus productos para diferentes mercados? Vaya al Capítulo 3: Encontrar el precio "correcto".

- ¿Los clientes preguntan sobre sus prácticas sostenibles? Tal vez debería explicarles su sistema de garantía... El Capítullo 8: Garantías para la sostenibilidad, le guiará.

¿0 quizá tenga una idea mejor? Deje que ello le guíe al siguiente capítulo. 

3

量

ENCONTRAR EL

을

PRECIO “CORRECTO”

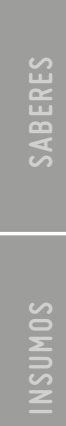

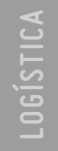

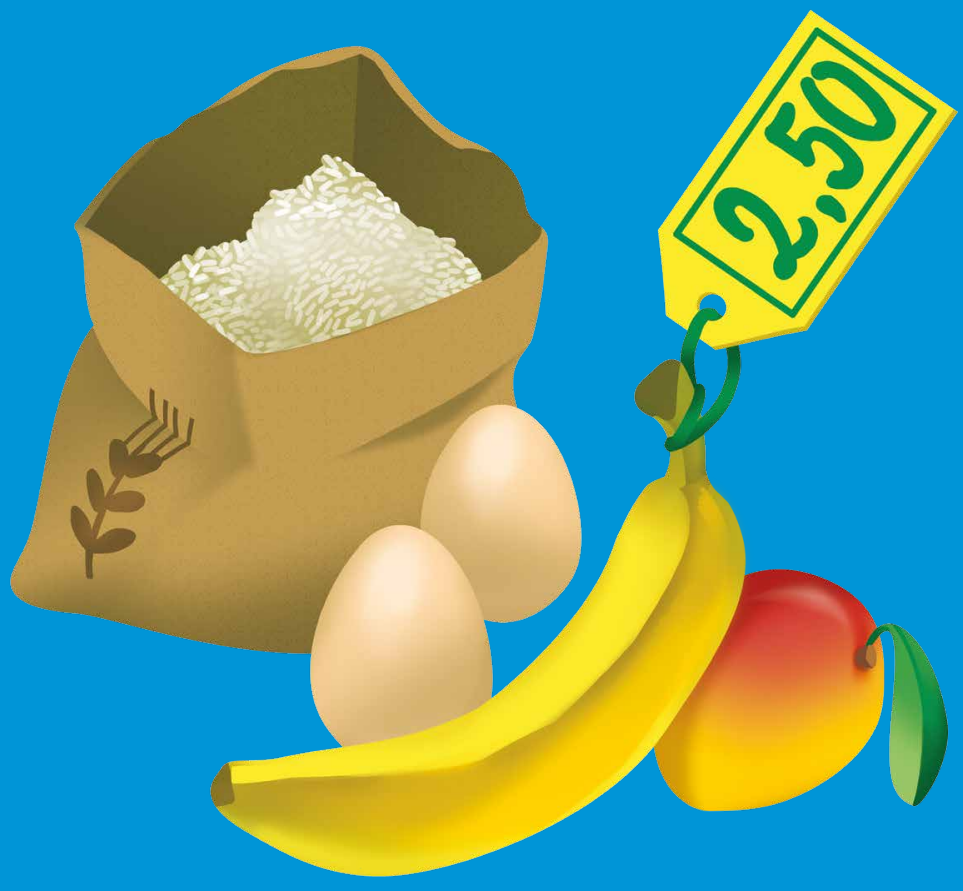

는
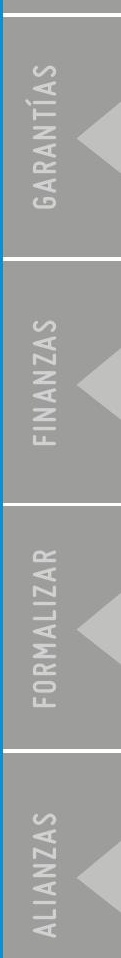


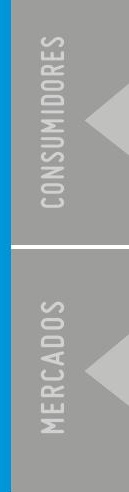

을
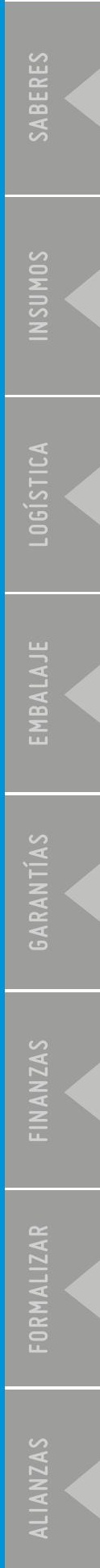


\section{1. ¿POR QUÉ ESTO ES IMPORTANTE?}

¿Cómo explicar el costo total de la producción sostenible, y cómo negociar los precios con diferentes tipos de compradores y consumidores? De hecho, la creación de mercados es un problema atemporal, y el cumplimiento de criterios de sostenibilidad en todos los aspectos del sistema alimentario hace que este equilibrio sea aún más dificil de lograr.

La verdadera contabilidad de costos, o simplemente, el conocimiento de los agricultores sobre los costos reales de la producción tiene como objetivo reequilibrar los cálculos de precios. Sin embargo, los consumidores también están acostumbrados a comprar alimentos baratos, lo que hace dificil renegociar los precios.

Por lo tanto, fijar el precio "correcto" para los alimentos, uno que sea justo y sostenible para todas las partes de la transacción, es uno de los retos económicos más relevantes de nuestros tiempos (Juliane y Shaz, 2015) y es fundamental para garantizar el verdadero valor de la agricultura.

En muchos países, la forma en que se establecen los precios de los alimentos puede tener efectos significativos en los medios de vida de los pequeños productores, cuestión que se debe típicamente a su participación débil o nula en los procesos de fijación de precios. A esto se suman los cambios en los mercados mundiales de los productos básicos, insumos y finanzas que afectan a los mercados nacionales y locales, donde los productores son los receptores de los precios, en lugar de los negociadores de los precios. Sin embargo, en los sistemas alimentarios sostenibles, se están implementando innovaciones de base para contrarrestar el comercio y poder de mercado tradicionales, proporcionando asi espacio para modelos participativos de acuerdos de precios.

En este capítulo, veremos tales innovaciones e intentaremos mostrar modelos pequeños e innovadores que cuestionen y cambien sistemáticamente el poder del mecanismo de los "precios de mercado" en favor de los pequeños agricultores.

\subsection{Costo vs precio}

Existe una distinción entre el costo de la producción y su precio. El primero comprende el costo de los insumos necesarios, como el tiempo, la mano de obra o el dinero, para producir una unidad de producción. Por ejemplo, en 2015, el costo de producción de un kilogramo de arroz en el estado de Tamil Nadu, en el sur de la India, era equivalente a un promedio de INR 15/ kg (TNAU, 2015). Sin embargo, el precio es lo que el productor obtiene del mercado, por ejemplo, la compra pública de arroz en Tamil Nadu en 2015 fue de INR 14.7/ kg (Kamaraj, 2015).

Para los pequeños agricultores de todo el mundo, siempre es difícil determinar el precio "correcto" para sus productos, que simultáneamente cubra sus costos, les permita obtener ganancias decentes e invertir en la próxima temporada agrícola, siendo sostenible en el tiempo. Sin embargo, los precios fijos generalmente no son representativos y no coinciden, ya que son determinados por intermediarios, con participación limitada o nula del productor en la negociación.

Dado que los productores tienden a incluir únicamente los costos de los insumos comprados en sus cálculos, el costo de producción está parcialmente subsidiado por ellos. Los costos laborales (incluso si se trata de su propia mano de obra) y los costos de transacción del mercado (por ejemplo, los costos de transporte al mercado) rara vez se incluyen. Las externalidades 
ambientales y sociales no suelen considerarse, y a menudo se excluyen los ahorros de costos que pueden resultar de la colaboración con otros agricultores o de la práctica de una economía de escala. En consecuencia, los pequeños agricultores se enfrentan a un desafio significativo en las negociaciones de precios de sus productos.

En los sistemas alimentarios sostenibles, la determinación de los precios que cubren los costos incurridos por los productores es un elemento integral de la sostenibilidad social y económica del sistema. Algunos intermediarios y consumidores buscan específicamente garantizar una compensación adecuada, mientras que otros no lo hacen.

\section{2. ¿Por qué es necesario "recalcular» el precio?}

Recalcular el precio de los productos agrícolas está motivado por la necesidad fundamental de tener en cuenta los costos y beneficios ocultos, como el daño ambiental, la restauración de los activos naturales o los servicios de los ecosistemas (los economistas llaman a estos "externalidades"), y los principales atributos de calidad que proporcionan a los productores una ventaja monetaria en el mercado. Estos pueden incluir: las particularidades de las semillas nativas, colores especiales, buen sabor, producción saludable, orgánica y local, y labor manual o artesanal, etc.

En comparación con los mecanismos convencionales de fijación de precios, la principal diferencia radica en la inclusión de los costos ocultos y en la garantía de que tanto los agricultores como los consumidores se benefician del intercambio. La determinación de precios justos y sostenibles es fundamental para que los actores revaloren el papel de la agricultura en la sociedad y creen sistemas alimentarios sostenibles.

Si bien existen fórmulas para ayudar a calcular estos precios, determinar el "justo" es fundamentalmente una cuestión de negociación empática y el uso de nuevos modelos de negocio que puedan calcular mejor los costos reales de producción y distribución, compartiendo uniformemente los beneficios entre los diversos actores del sistema alimentario.

\section{FÓRMULA DE EJEMPLO PARA CALCULAR LOS PRECIOS EN SISTEMAS ALIMENTARIOS SOSTENIBLES}

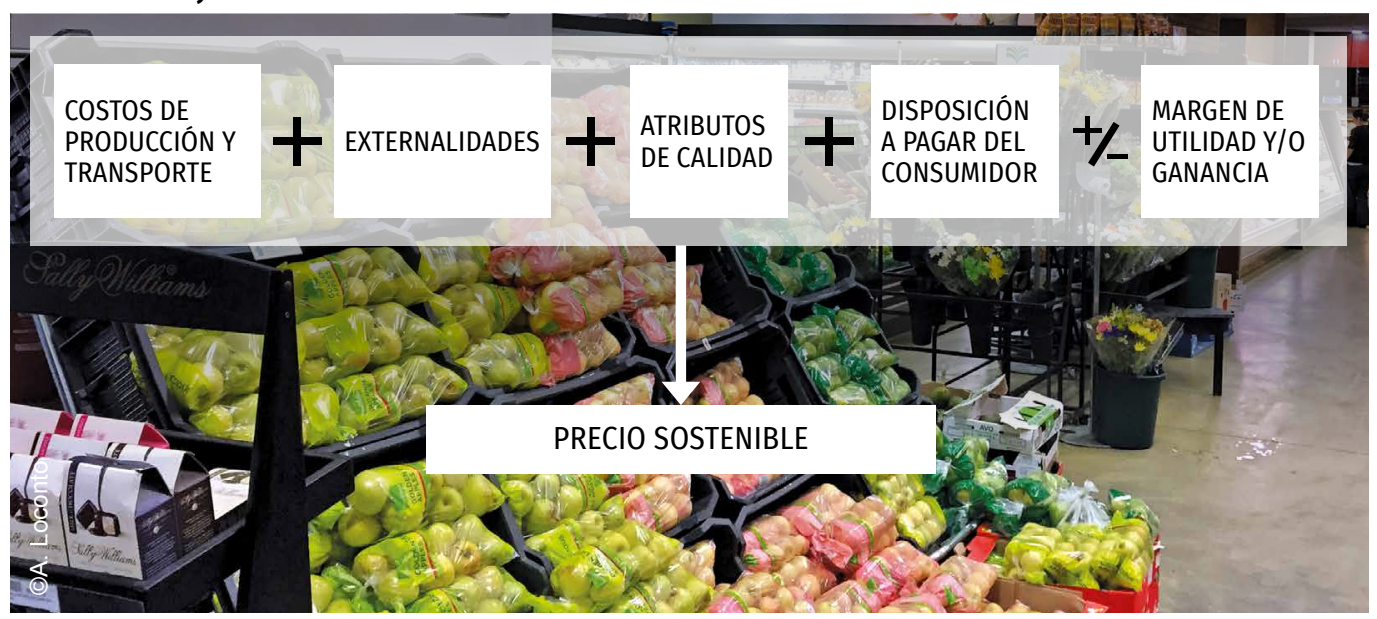




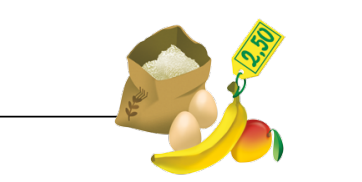

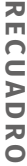

\section{Contabilidad de costos reales}

La contabilidad de costos reales también se conoce como de costo total, valor total o impacto total. Es una metodología para calcular el valor de los bienes no comerciales, como los activos ambientales y sociales, con el fin de analizar los costos y beneficios de las decisiones empresariales y/o políticas. Incluir externalidades negativas y positivas en un cálculo de costos puede ayudar a los productores a entender mejor cómo deben compensarse sus esfuerzos. La contabilidad de costos reales, cuando se utiliza para reevaluar los precios, debe considerar las tasas relacionadas con la determinación participativa de precios y/o los beneficios de los pagos por servicios de los ecosistemas. El aumento del conocimiento de los productores los capacita en las negociaciones de precios.

El Protocolo del Capital Natural creó un conjunto de herramientas que contiene elementos para recalcular el costo total de la producción:

https://naturalcapitalcoalition.org/wp-content/ uploads/2017/11/NCP-SEEA-Toolkit-Sep-2017IDEEA-Group-1.pdf.

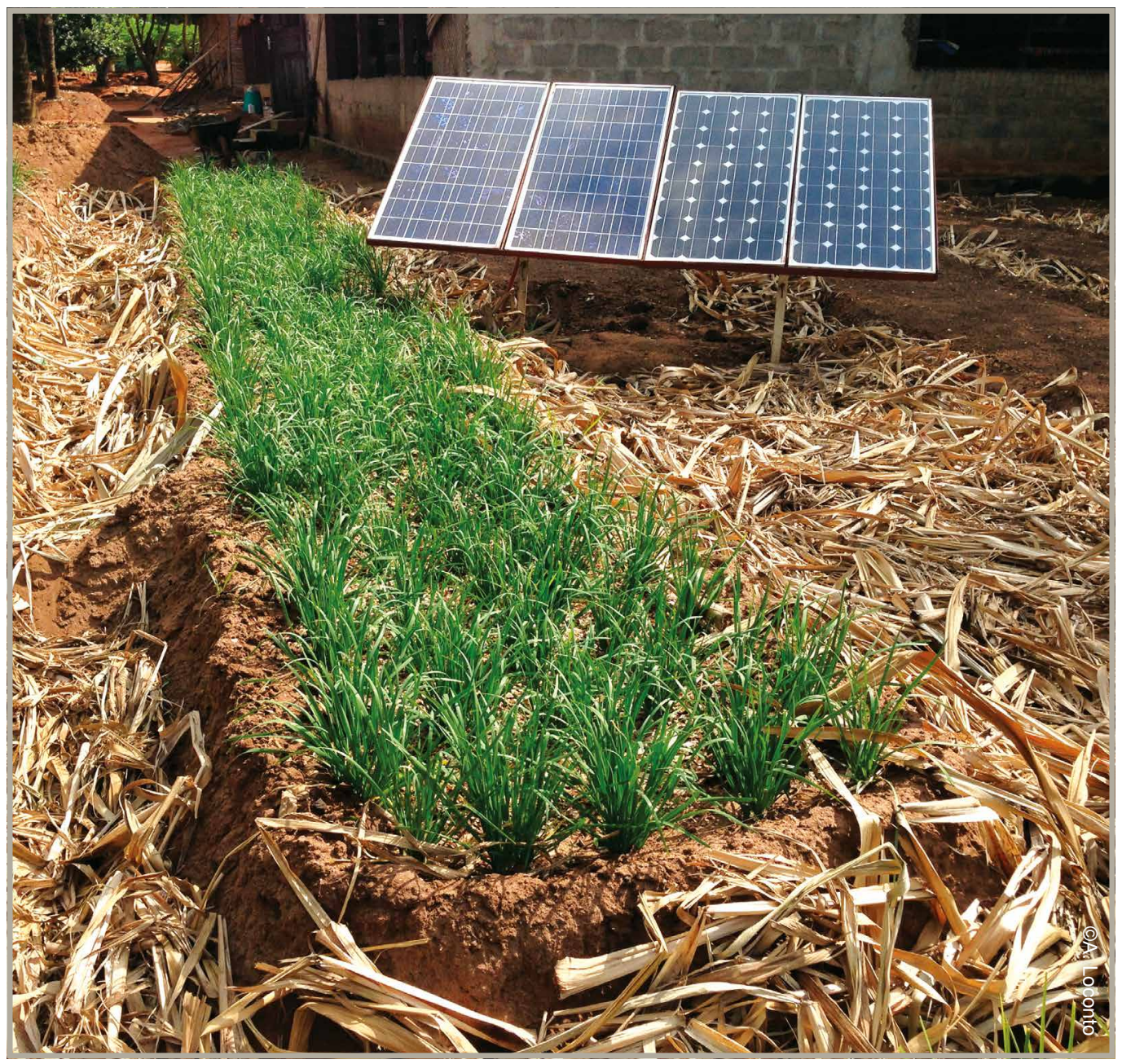




\section{2. ¿CÓMO GESTIONAR MECANISMOS DE FIJACIÓN DE PRECIOS PARTICIPATIVOS Y TRANSPARENTES?}

La mayoría de los métodos para crear mecanismos de fijación de precios participativos y transparentes son experimentales. Se generan cuando los consumidores son conscientes de los verdaderos costos de producción y están dispuestos a pagarlos, impulsados por el deseo de apoyar el precio real de sus alimentos, o en respuesta a la influencia de los productores a través de una negociación de precios.

Los mecanismos de fijación de precios son más eficaces cuando los actores entienden las situaciones y limitaciones de otros actores.

\subsection{Productores}

\subsubsection{El desafío}

En los sistemas alimentarios sostenibles, sólo unos pocos productores logran participar en los mecanismos de fijación de precios, lo que resulta en márgenes reducidos sobre el producto final vendido en el mercado. La distancia de los agricultores a los mercados y los mecanismos de negociación de precios desempeñan un papel importante en la capacidad de los productores para controlar los precios.

En los mercados locales, los productores suelen vender con relativa facilidad, debido a la interacción directa con los consumidores que facilita la comunicación sobre la equidad de precios. Los mercados distantes son más dificiles, tanto en términos de acceso como de transparencia, dado que normalmente se requieren intermediarios. La estacionalidad también puede afectar a los precios, ya que afecta directamente a la oferta del mercado. La temporada alta significa un exceso de oferta en el mercado, por lo que los precios pagados por los consumidores a los productores son más bajos.

Uno de los desafíos más graves que los agricultores enfrentan a menudo es el equilibrio entre el volumen vendido y el precio recibido. Basándose en la vida útil de los productos, los agricultores deben esperar a que los precios del mercado evolucionen, aferrándose a sus inventarios (liberando lentamente los productos) o vender inmediatamente (a menudo toda su producción) cuando los precios son bajos y la demanda es alta. Muchos agricultores deben hacer esta elección debido a la escasez de espacio de almacenamiento o a la necesidad de tener acceso inmediato a dinero en efectivo para los gastos diarios.

\subsection{2 ¿Cómo pueden los productores calcular los diversos componentes de un precio sostenible?}

La fijación de precios en los sistemas alimentarios sostenibles debería tener en cuenta la transparencia y la equidad. Además de los costos de producción, este es un proceso que debe tener en cuenta varios costos subyacentes, como los servicios de los ecosistemas y otros costos 
implícitos. Debe incluir un margen razonable para igualar los precios actuales en los sistemas alimentarios convencionales. Calcular la producción y los costos ocultos no son tareas simples, ya que exigen mucho conocimiento y habilidad. Sin embargo, existen formas fáciles de calcular los precios de los productos ya comercializados y nuevos. Los pasos que deben tomarse son:

1 Tome nota de las tareas diarias de la granja durante el proceso de producción para tener información sobre el tiempo, los costos y los insumos en la granja.

\section{CONSEJO 13}

Tome nota de las tareas diarias de la granja

El mantenimiento de los registros en la granja puede ser un proceso laborioso y lento, que requiere de anotaciones minuciosas, un listado por artículos y muchas decisiones contables. ¡Pero no tiene por qué serlo! Comience con lo simple y describa exactamente lo que usted hace en la granja. Por ejemplo:

> ¿Cuántas semillas compró?

¿Cuánto dinero gastó?

¿ ¿Cuándo plantó estas semillas?

¿Cuánta agua utilizó para regar estas plantas?

Al final de este proceso, estos registros proporcionarán la información necesaria para calcular con precisión los costos incurridos en la producción agrícola, dados los gastos registrados relacionados con el tiempo de trabajo y la compra de productos e insumos agrícolas.

\section{Enseñarles a los niños a mantener registros (Uganda)}

\section{9} FreshVeggie Ltd., un Sistema Participativo de Garantía (SPG en inglés) de Uganda, también practica este proceso de notación con los niños en su proyecto de Desarrollo de Pequeñas Empresas. A los niños en edad escolar se les dan pequeños proyectos (a menudo unos pocos patos) y se les asigna la tarea de criarlos para su eventual venta para financiar su escolarización. El mantenimiento de registros es extremadamente importante en su proceso de aprendizaje y fijación de precios, y al comenzar desde jóvenes, están bien preparados para las futuras realidades agrícolas de adultos.

Fuente: Julie Matovu, FreshVeggie.

\section{Determine la posición de su producto en términos de precio y calidad para dirigirse mejor a los mercados y consumidores que son más beneficiosos.}

Recuerde la regla de oro: un alto precio por baja calidad no es sostenible para los consumidores, mientras que un bajo precio por una alta calidad no es sostenible para los productores... justed tiene que encontrar el punto óptimo! 
3 Descubra y haga referencia al precio del producto vendido por los productores que están vendiendo en los mismos mercados a los que también desea dirigirse. Esto le permitirá tener una mejor comprensión del precio que puede esperar.

Si usted está introduciendo un nuevo producto, los atributos de novedad y calidad deben ser incluidos como un componente del precio. Para ello, confirme si los consumidores están dispuestos a pagar por el nuevo producto, ya que esto le ayudará a determinar el precio.

\section{CONSEJO 14}

Cómo entender la disposición de los consumidores a pagar

a. Para obtener comentarios sobre la calidad, y para determinar el precio que los consumidores están dispuestos a pagar por diferentes productos, usted puede presentar una gama de productos competitivos (incluyendo los suyos) a un pequeño grupo de posibles consumidores. Entonces ellos pueden juzgar cuál sería seleccionado primero, proporcionando retroalimentación sobre su elección. La posición, el precio o el paquete de sus productos se pueden ajustar en consecuencia.

b. En los mercados directos, permita a los clientes negociar sobre el precio, con la condición de que exista un margen de maniobra suficiente. Surgirá una tendencia en los precios que los consumidores ofrecen y acuerdan. Por ejemplo, si el consumidor se ofrece a comprar una mayor cantidad del producto a un precio unitario más bajo, esto se considera un negocio adecuado, dado que el productor puede liquidar sus inventarios.

\section{Si el producto es procesado, los costos de procesamiento deben ser incluidos.}

\section{CONSEJO 15}

La fijación de precios de los productos procesados requiere un método de cálculo mixto

Al vender un producto procesado, se deben tener en cuenta los siguientes elementos:

- Mezclar métodos que le permitan determinar los precios en función de los costos, pero también de los beneficios de la innovación, la saturación del mercado y la disposición a pagar de los consumidores.

- Esta mezcla debe definirse localmente en respuesta a las condiciones de cada mercado y a la experiencia e intuición del empresario o grupo de empresarios que lideran el proceso.

- Evalúe sus opciones de procesamiento y los costos asociados. Trate de encontrar empresas que puedan procesar y explicar todos los costos asociados con el procesamiento del producto. Esto puede ayudarle a determinar un precio justo, ya que no tiene que asumir todos los costos relacionados con la compra y el mantenimiento de los equipos requeridos.

- Pruebe el precio de su producto en el mercado para determinar el adecuado.

- Recuerde que el precio es un acuerdo comprador-vendedor, modificable en cualquier momento a medida que aparece nueva información. En consecuencia, la revisión de precios debe realizarse periódicamente o cuando se produce un evento en particular. 


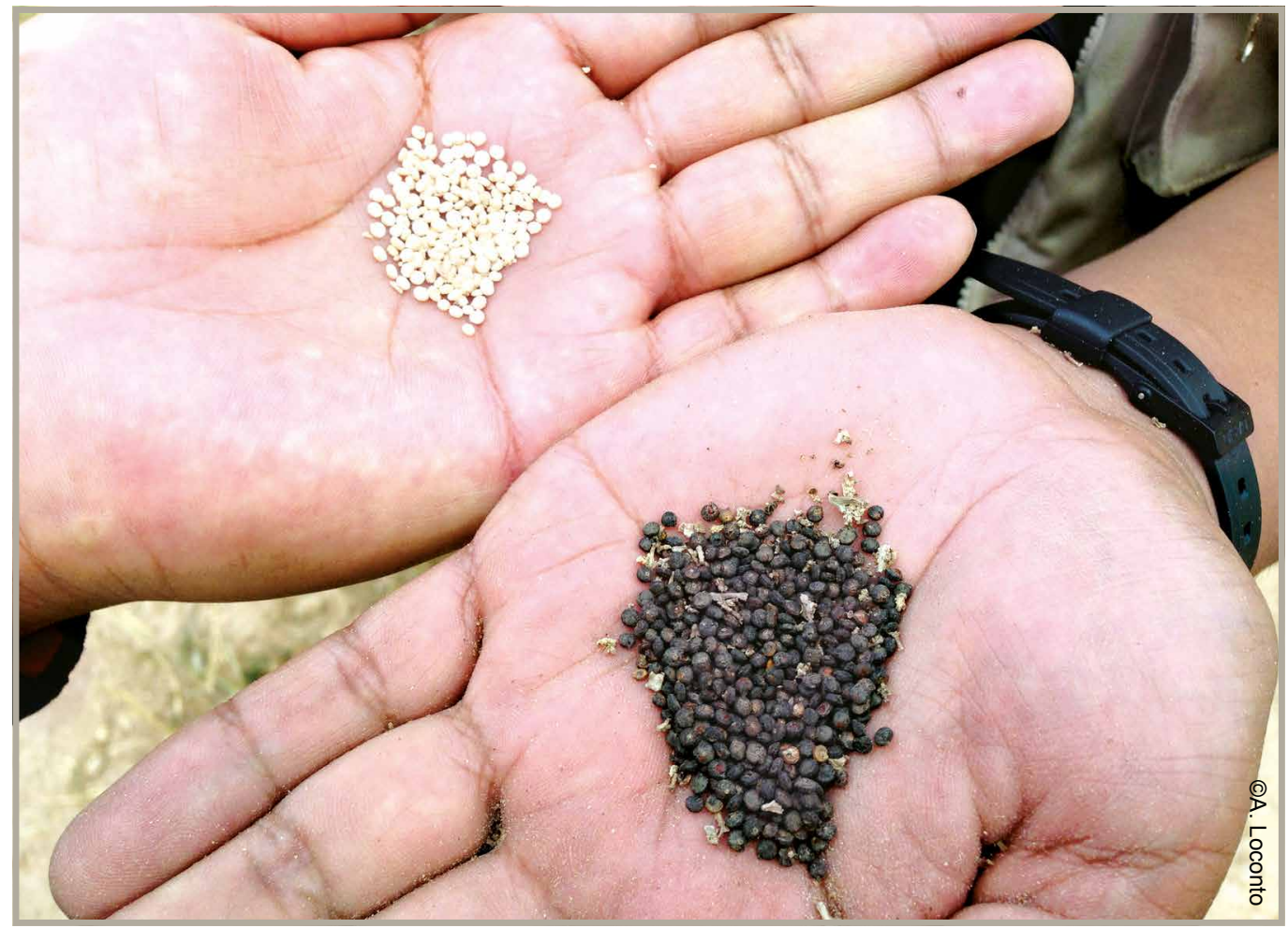

5 Establezca asociaciones con investigadores y proveedores de servicios que puedan ayudarle a entender los costos de producción ocultos para incluirlos en su cálculo de precios.

\section{2
0
0 \\ Familia de la Tierra, en Colombia, experimentó con la inclusión de externalidades y atributos} de calidad para definir el precio de las variedades de papa nativas. En colaboración con la Universidad Nacional de Colombia, se realizó un estudio para determinar las emisiones de $\mathrm{CO}_{2}$ en el marco del proyecto "Corredor Tecnológico Agroindustrial". El estudio reveló que la producción de
$9.000 \mathrm{~kg}$ de papa genera una emisión de aproximadamente $6.000 \mathrm{~kg}$ de $\mathrm{CO}_{2}$. Familia de la Tierra decidió ahorrar parte de los ingresos para impulsar la economía de la naturaleza (0.02 USD por paquete de $40 \mathrm{~g}$ de papas fritas) plantando 30 árboles que capturarán 6.000 $\mathrm{kg}$ de $\mathrm{CO}_{2}$ (200 kg cada uno) en su madurez. De esta manera, la iniciativa compensa una externalidad y la convierte en un atributo de producto positivo.

Fuente: Jaime Aguirre, Óscar Nieto y Familia de la Tierra. 
6 Una vez identificados y comprendidos los componentes de los precios, los productores pueden comenzar a negociar un precio justo y sostenible con otros actores del sistema alimentario. Recuerde que un productor por sí solo puede no ser capaz de calcular la disposición de los consumidores de pagar los costos de procesamiento o las externalidades. Los intermediarios transparentes o las organizaciones de productores pueden ayudar a los productores a llevar a cabo estas actividades, y esto debe tenerse en cuenta en el precio.

\section{Tres criterios a definir cuando una transacción es aceptable para los productores (India)}

\section{1}

Existen criterios mínimos comunes para facilitar las transacciones entre compradores y productores, especialmente para los pequeños agricultores. Estos criterios deben tenerse en cuenta al determinar los parámetros para cualquier transacción en un sistema alimentario sostenible. Para los pequeños agricultores de la India, y tal vez del resto del mundo, se aplican tres criterios principales:

a. El productor consigue vender todos los productos cultivados en una temporada.

b. El productor recibe el precio correcto para el producto de una manera que cubra su costo de insumos más una ganancia.

\section{c. El productor recibe el dinero de la transacción a su debido tiempo.}

Estos criterios son transaccionales, y se definen para atender la paridad de intercambio de productos por dinero u otro tipo de trueque. Un escenario ideal requiere que se cumplan los tres criterios anteriores para que el productor considere al precio como justo. Sin embargo, dadas las condiciones del mercado, lograr dos de estos tres elementos suele ser aceptable para la mayoría de los productores. En el caso de que esto no ocurra, el riesgo de los pequeños agricultores aumenta de forma múltiple, ya que tienen poca protección que les ayude a absorber las crisis del mercado y de los precios. Cualquier espacio de negociación con determinación de precios y transacción debe considerar estos simples criterios mientras se comunica con los pequeños agricultores.

Fuente: Ashish Gupta, Jaivik Haat.

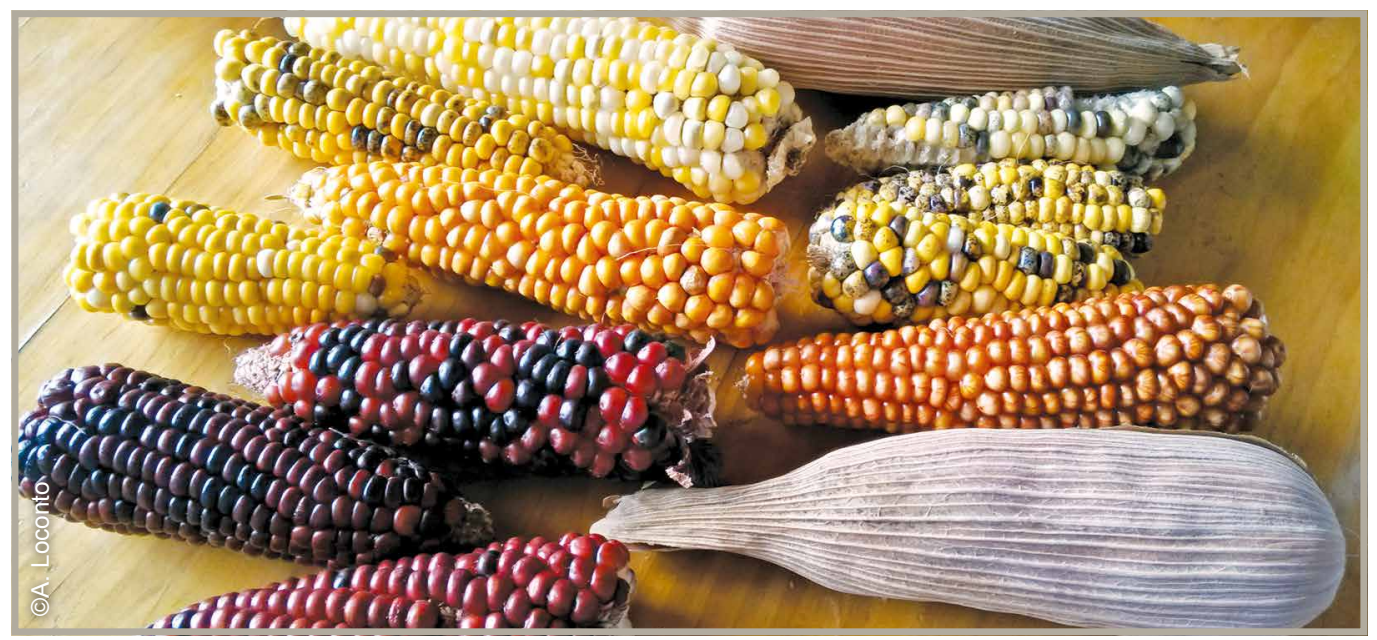


Por último, una vez que se haya negociado un precio sostenible con otros actores, los productores deberian tratar de estabilizar sus ingresos en la medida de lo posible para fomentar la confianza con los consumidores.

\section{CONSEJO 16}

Estabilizar los ingresos de los productores mediante la diversificación

a. Innovación permanente: El desarrollo de más productos agrícolas permite al productor mantener y mejorar los niveles de ganancia a través de un enfoque en los mercados locales, regionales y, en algunos casos, mundiales. Este tipo de innovación puede abordar cuestiones como: ¿Quién es mi consumidor objetivo? ¿Qué características debe incluir mi producto? ¿Qué otras características podrían incluir? ¿Qué alternativas se pueden ofrecer?

b. Diversificación de cultivos: La diversificación de los alimentos cultivados en la granja permite al agricultor y a la red de agricultores retener sus ingresos mediante una ganancia promedio. Cuando el precio de mercado de un producto cae, tal vez un producto diferente genere un mejor valor de ingresos y, por lo tanto, "equilibra" la ganancia.

c. Diversificación de los productos agrícolas mediante el empacado: El desarrollo de diferentes empaques innovadores y sostenibles permite a las granjas o redes de granjas tener una marca o símbolo común que se posiciona estratégicamente en un mercado. Este empaque único puede obtenerun mejor precio, que a menudo resulta en un mayor ingreso y beneficio para el productor.

d. Diversificación de los productos según su estado de maduración en el ciclo vegetativo: Las posibilidades de comercialización de productos frescos no solo se limitan a su componente espacial, es decir, cuántas plantas de qué variedades se plantan, sino que también pueden distribuirse a lo largo del tiempo y la maduración de su ciclo de crecimiento: germinación, crecimiento, floración, fructificación y fase de producción de semillas. Según el tiempo específico en el ciclo vegetativo, puede ser posible cosechar una versión "baby", una versión normal (estándar comercial), flores comestibles para cocina gourmet, e incluso semillas de la misma planta para la distribución local y regional.

e. Segmentación de precios y mercados: Fijar precios diferentes para diferentes grupos de consumidores, es decir, fijar el precio de acuerdo con la disposición (y capacidad) de pago del consumidor. Siguiendo esta estrategia, usted puede lograr el mejor precio posible de cada nicho o mercado. Si sus consumidores y listas de precios están bien definidos, su ingreso promedio será más estable en el mediano plazo.

\subsection{Consumidores}

\subsubsection{El desafío}

Los consumidores, al igual que los productores, son un componente clave de un sistema alimentario sostenible. A pesar de los desafios que plantea el establecimiento de nuevos sistemas de suministro y los altos precios iniciales, los consumidores de sistemas alimentarios sostenibles suelen apoyar a los miembros de las iniciativas. Su apoyo se deriva en parte de un deseo fundamental de garantizar la salud de su familia y el bienestar general del medio ambiente y de los agricultores. Hoy en día, el principal desafio para los consumidores es la disponibilidad de productos de calidad y precios justos. Dado que los costos de los productos producidos de forma ética y sostenible son a veces más altos, esta carga financiera puede recaer sobre los consumidores. 
Hay casos, como en los comités de fijación de precios, en los que los consumidores participan en el mecanismo de fijación de precios. Sin embargo, fuera de las iniciativas de las ASC, los consumidores generalmente están excluidos de tales discusiones. El reto es crear un sistema de suministro transparente en el que los productores y los consumidores comprendan el valor de los productos y tengan derecho a cuestionarlo, ya que los sistemas alimentarios sostenibles dependen de relaciones amistosas entre productores y consumidores.

\section{CONSEJO 17}

\section{Ayudar a los consumidores a conocer el precio "correcto"}

a. La transparencia y la confianza son claves. Informe a los consumidores y comparta su historia. En cada oportunidad, incluya entregas y transacciones de pago, comparta más sobre lo que hace como parte de un grupo de productores, sobre por qué usted es especial y cómo se distingue de los demás.

b. Cree actividades que promuevan la interacción entre el consumidor y el productor, como visitas de fin de semana en la granja para los consumidores. Anímelos a traer a sus hijos, para que participen en actividades de llenado de canastas, para que conozcan a los productores de sus productos favoritos, y para entender lo diferentes que son estos productos de los convencionales. Comparta la historia detrás de los precios establecidos.

\subsection{2. ¿Cómo pueden saber los consumidores el precio "correcto"?}

El conocimiento de los consumidores sobre el precio justo y la estacionalidad de los productos agrícolas es un aspecto clave para mantener y construir una base de mercado sólida. Los consumidores, al igual que los productores, deben participar en los procedimientos de fijación de precios.

Para ello, se pueden adoptar diferentes estrategias:

a. Invite a los consumidores a la granja (o planta procesadora) para tener una experiencia directa con ellos. Muéstreles cómo se cultiva el producto, mientras se crea una conexión con la calidad resultante de sus productos.

b. Cree comités de fijación de precios para negociar un precio justo con los consumidores. Tener un intermediario transparente entre productores y consumidores le ayudará a llevar a cabo este paso.

c. Asegúrese de que la información sobre las cualidades del producto se comunique en un lenguaje que sus consumidores entiendan. Algunos consumidores prefieren leer las etiquetas y reconocer las marcas, otros prefieren aprender sobre ellas directamente del productor, de los dueños de la tienda o de sus amigos.

d. Enséñeles a los consumidores cómo producir sus propios alimentos para promover la comprensión de los costos de producción.

e. Aliente a los consumidores a pedir información sobre precios a los intermediarios y a la fuente de los productos. Asimismo, motive a los intermediarios a que sean transparentes sobre sus costos y riesgos para que los productos estén disponibles en nombre de los productores.

f. Mantenga informados a los consumidores sobre los precios y los cambios de precios. 


\section{Enseñar a los consumidores cómo producir sus propios alimentos (Uganda)}

Debido a los desafíos asociados con la comprensión de los costos de producción por parte de los consumidores, y con el fin de satisfacer su creciente demanda de productos agrícolas de alta calidad, los miembros de FreshVeggies, junto con el apoyo de un consultor privado, han diseñado un paquete de huerta en casa para los consumidores locales. Por aproximadamente 57 dólares, el paquete básico

\section{Juls consults}

La agroempresa y el desarrollo sostenible de la comunidad

Estamos aquí para satisfacer las necesidades de nuestros clientes proporcionando soluciones prácticas a sus problemas de planificación y establecimiento de pequeñas fincas. Creamos la capacidad de las organizaciones comunitarias en materia de desarrollo sostenible y ofrecemos un servicio de asesoramiento agrícola.

Promovemos el desarrollo sostenible de la comunidad a través de servicios de agroindustria orgánica. Nuestros servicios incluyen la formación práctica en la producción de cultivos y ganado (aves de corral y pequeños rumiantes). Nuestro enfoque se basa en la promoción de alimentos sanos para el consumo familiar y comercial: desde los cultivos sanos en el huerto hasta la comida sana en el plato.

Nuestro paquete técnico básico de huerta:

- Un surtido de 160 - 220 plantas de semillero y semillas de siembra directa de varias verduras por mantenir las necesidades nutricionales de su familia ${ }^{\text {; }}$;

- 30 plantas de espinacas

- 30 plantas de brócoli

- 30 plantas de col verde/blanca/roja

- 10 plantas de tomate

- 30 plantas de cebolla [primavera/leek/rojo criollo].

- 30 plantas de lechuga (para ensaladas)

- 30 zanahorias

- 30 remolacha

- $5 \mathrm{~g}$ de hierbas mezcladas

- $10 \mathrm{~g}$ de semillas de ddodo/jjjobyo/Nakati

- 2 visitas prácticas a domicilio: una consulta de

planificación y una actividad de desarrollo de parcelas

- Una bandeja por semillas

- Una guía de jardinería de vegetales orgánicos

- Acompañamiento gratuito (a distancia) durante el año de cultivo.

1 La cosecha media prevista es de 90 a $100 \mathrm{~kg}$ de hortalizas frescas por temporada. incluye una variedad de plántulas/semillas vegetales (suficientes para producir alrededor de $100 \mathrm{~kg}$ de verduras variadas en un período de 90 días) y asesoramiento técnico in situ del equipo de FreshVeggie. Los consumidores pueden comprar este paquete y hacer que un experto de FreshVeggie vaya a establecer una huerta en su propio patio trasero. De esta manera, con algunos éxitos y fracasos en el proceso de crecimiento, los consumidores pueden aprender y apreciar los costos reales de los sistemas alimentarios sostenibles.

Fuente: Julie Matovu, FreshVeggies Ltd.

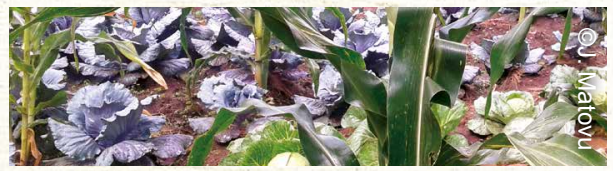

Costo del paquete técnico: UGX200.000= (sólo doscientos mil shillings) que incluye los costos de la encuesta y el transporte para las dos visitas a la finca. Se requiere un depósito inicial del $50 \%$ en el momento de la reserva, que debe ser confirmado al menos tres semanas antes de la sembra.

Juls Consults está asociada con la compañía Freshveggies PGS 2 .

DE LOS SUPLEMENTOS PERSONALIZADOS:

Podemos adaptar los suplementos a sus necesidades específicas. Por ejemplo :

- Bolsas de macetas

- Fertilizantes orgánicos certificados

- Entrega de bolsas de maceta listas para usar que contienen tierra esterilizada y/o tratada y fertilizantes orgánicos [el precio incluye : insumos, mano de obra, transporte].

- Insumos orgánicos adicionales

- Kit de irrigación por goteo

Nuestros contactos:

Ggombe B, Bukasa Parish, Wakiso District.

P.O.BOX 11133, Kampala.

Email: matovujuls@gmail.com

Tel.: Julie $0701636688 / 0772636688$ o George 07560473377

2 Freshveggies PGS es una red de pequeños agricultores orgánicos -principalmente mujeres- en las zonas periurbanas de Kampala (Uganda) La iniciativa tiene por objeto garantizar la producción agrícola sostenible entre los pequeños productores a objeto de aumentar los ingresos de los hogares y facilitar un acceso a alimentos sanos a los consumidores locales. Se trata de una innovación basada en el mercado que reúne a los agricultores con los consumidores locales para intercambiar conocimientos y mejorar sus aptitudes en materia de agricultura orgánica. Los Sistemas Participativos de Garantía (SPG) son sistemas de control de calidad adaptados al contexto local. FreshVeggies PGS cuenta con la participación activa de sus miembros para certificar a los productores. El sistema se basa en la confianza, las redes sociales y el intercambio de conocimientos. 
Estudios de mercado como medio para compartir información (Uganda)

23

En Freshveggies, los miembros realizan encuestas de minimercado con los clientes. A través de formularios sencillos y fáciles de rellenar enviados por correo electrónico o incluidos en la cesta de entrega a principios de cada año, Freshveggies SPG comparte sus precios o cualquier cambio de precio, introduce nuevos productos y ofrece a los clientes la oportunidad de solicitar nuevos productos. De esta forma, los clientes aprenden sobre los precios de los productos de una manera oportuna y personal.

Fuente: Julie, Matovu, FreshVeggies Ltd.

\subsection{Intermediarios transparentes}

\subsubsection{El reto}

Mientras que muchos sistemas alimentarios sostenibles tratan de eliminar a los intermediarios a través de las ventas directas y las cadenas de suministro cortas, los intermediarios regresan a menudo porque sus habilidades son necesarias. Ellos ayudan a facilitar los intercambios y a invertir en el almacenamiento y transporte que los productores y consumidores no pueden gestionar ni pagar.

El mayor desafio para los intermediarios es satisfacer las necesidades de los mercados, tanto para el productor como para el consumidor, incluso si o cuando estas éstas no son comparables. Los intermediarios transparentes suelen ser conscientes de cuestiones pertinentes, como la huella de carbono, la pérdida de la diversidad biológica autóctona debido a la preferencia por variedades de cultivos híbridos y otras aspectos relacionadas con la sostenibilidad. Por lo tanto, un sistema alimentario sostenible requiere intermediarios funcionales y transparentes que ayuden a los agricultores a canalizar sus productos hacia los mercados, al tiempo que se tienen en cuenta las preocupaciones relacionadas con la sostenibilidad de los consumidores y su deseo de utilizar cadenas de suministro cortas. Según los tipos de servicios ofrecidos tanto a los productores como a los consumidores, existen diferentes tipos de intermediarios transparentes. Además de las funciones de logística y agregación, los intermediarios pueden proporcionar un amplio conjunto de servicios para promover el intercambio de conocimientos y la acción colectiva en los sistemas alimentarios sostenibles. 


\section{Tres tipos diferentes de intermediarios transparentes (República de Corea e India)}

A continuación, se destacan tres modelos de intermediación transparente basados en el tamaño de su base de consumidores y los servicios ofrecidos.

\section{Modelo de gran tamaño: Cooperativa Hansalim, República de Corea}

Hansalim Cooperative crea un acceso transparente entre productores y consumidores al ofrecer equidad organizativa a ambas partes para que participen regularmente en muchas de las actividades de la cooperativa, incluyendo la determinación de precios. El lema de Hansalim es: "Hansalim va a la manera del productor", y proporciona acceso a la fijación de precios, para que el productor pueda continuar manteniendo la producción de manera segura y cómoda. Antes de la próxima temporada, los empleados, consumidores y productores de la cooperativa celebran reuniones anuales para determinar los precios. Dado que los bienes importados convencionales en República de Corea son susceptibles a las perturbaciones del mercado, la cooperativa tiene fondos

\section{Modelo de tamaño medio: Cooperativa Dharani FAM, India}

La cooperativa ayuda a los agricultores de SPG orgánicos a agregar y comercializar sus productos bajo la marca «Timbaktu Organic». La cooperativa proporciona a sus miembros las prácticas correctas de pesaje de sus productos y una prima de precio del $25 \%$ $30 \%$ sobre los precios de mercado existentes. Además, hay un $3 \%-7 \%$ adicional de incentivos anuales de retención para los productores. Junto con los agricultores, estos precios se fijan normalmente antes de que comience la temporada. A pesar de ofrecer estos márgenes, el precio general de los productos alimenticios sostenibles es aproximadamente un $20 \%$ menor que el de los productos de mercado

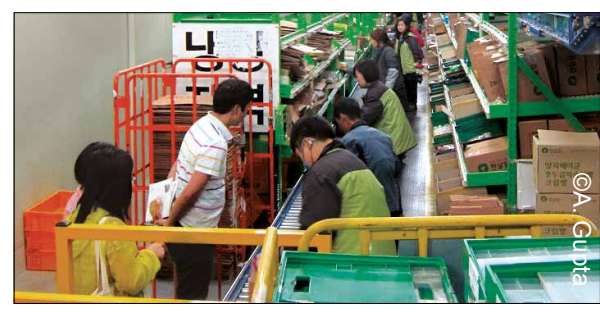

rotativos de estabilización para la producción y fondos de estabilización de precios, creando un "colchón" para los productores en caso de fuertes volatilidades de precios. En general, los precios se mantienen relativamente estables en el marco de Hansalim. Aproximadamente el $75 \%$ del precio final del mercado se paga a los productores. El volumen total de ventas de Hansalim en el mercado, según se informó en 2016, fue de USD 362 millones.

Fuente: Informe anual de Hansalim para 2016.

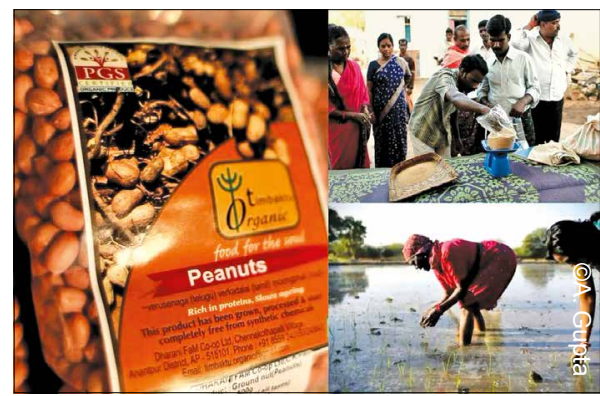

de grandes marcas. En todo momento, los agricultores tienen un acceso transparente a los mecanismos de adquisición, fijación de precios y comercialización. En 2016, el volumen general de ventas de mercado de Timbaktu Collective se registró en 310.000 dólares de EE. UU.

Fuente: Informe anual de 2016 de Timbaktu Collective. 


\section{Modelo pequeño: Jaivik Haat, India}

Jaivik Haat es una empresa social privada que gestiona un sistema de suministro de alimentos orgánicos/naturales al por menor en Nueva Delhi, India. Ofrece oportunidades de venta al por menor a agricultores pequeños y marginales que se rijan por prácticas agroecológicas, y especialmente a los agricultores certificados en SPG, así como otorgándoles un acceso transparente al mercado. Los márgenes operacionales son de alrededor del $35 \%$ del precio final del mercado. La fijación de precios se produce de dos maneras: en la primera, los productores (o sus grupos) fijan el precio considerando su costo de insumos, y Jaivik Haat agrega luego sus precios para gestionar la cadena de suministro. En la segunda, si los agricultores no pueden fijar los precios, Jaivik Haat compra sus productos por adelantado e intenta venderlos de contado al mejor precio posible de mercado en los mercados. Tras las ventas, el $60 \%-70 \%$ de los precios promedio finales regresan a los productores. En ambos modelos, los consumidores desempeñan un papel indirecto en la determinación de precios mediante un proceso de retroalimentación.

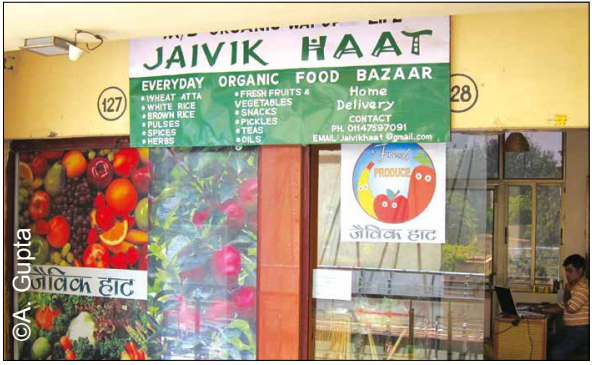

En el primer caso, si el productor fija los precios demasiado altos, no se logran cumplir los volúmenes de venta. Por lo tanto, el precio de la producción puede reducirse para asegurar que se vendan los volúmenes necesarios. Así, el mercado abierto ayuda a determinar el precio a través de aprender haciendo. En el segundo caso, Jaivik Haat intenta negociar el mejor precio de mercado posible en función de los costos de oportunidad. Por lo tanto, el mercado y los consumidores ayudan a negociar un costo real basado en transacciones reales, en lugar de en estimaciones predeterminadas establecidas por terceros.

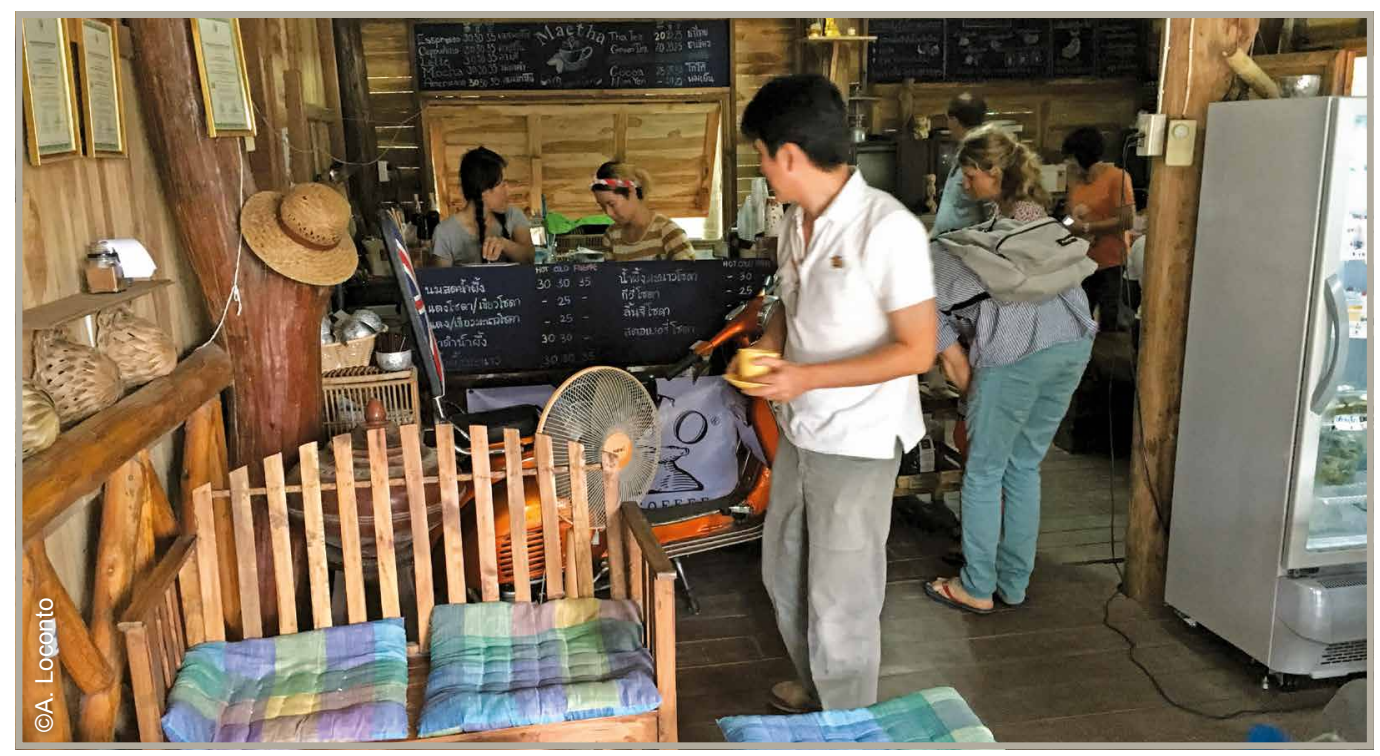




\subsection{2. ¿Cómo pueden los intermediarios transparentes facilitar la negociación entre otros actores del sistema?}

Dado que los intermediarios transparentes desempeñan un papel crucial en la conexión efectiva entre productores y consumidores, necesitan fijar precios que satisfagan a todos los miembros de la cadena de valor.

En cuanto a los productores, los intermediarios transparentes deben comprender en primer lugar la estructura de costos de los productores y los precios fijados por los competidores en su área de mercado (o incluso los precios proyectados en futuros mercados).

A continuación, para fijar precios sostenibles, los intermediarios transparentes pueden facilitar un proceso de negociación entre productores y consumidores (o con otros actores del sistema alimentario). Hay una variedad de maneras a través de las cuales puede lograrse este proceso:

\section{1) Comités de fijación de precios}

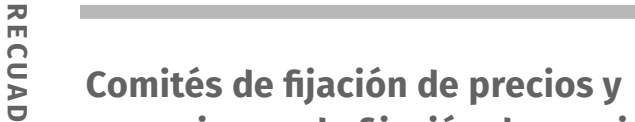 mecanismos de fijación de precios en ASC \\ Un precio justo y equitativo es fundamental para un emprendimiento ASC. Los modelos de precios pueden variar en función de la pertenencia al grupo, la geografía o el fundamento filosófico. Tres ejemplos estratégicos de diversos miembros de URGENCI demuestran las posibilidades:}

a. Costos reales de los productos agrícolas: Evaluar todo el presupuesto agrícola de la ASC para la temporada de producción. Incluir todos los costos, como los relacionados con la producción (es decir, semillas, herramientas e insumos), mano de obra, depreciación de maquinaria, entre otros. Dividir la cifra de costo total entre el número de miembros de la ASC. Por ejemplo, si el costo total de producción para la temporada es de USD 1.000, y usted tiene 20 miembros, cada miembro debe pagar USD 50 por participación. De esta manera, se puede cotizar cada participación de miembro.

b. Contribuciones deliberadas: En este modelo de precios, los precios son responsabilidad directa de los miembros como grupo. El agricultor evalúa todo el presupuesto de la granja ASC y presenta esta cifra a los miembros. Los miembros entonces escriben secretamente cuánto pueden pagar individualmente para la temporada. El agricultor suma estas cantidades, y si la suma cumple con el presupuesto, se fijan los precios. Si el importe total no se ajusta a las necesidades presupuestales, los miembros vuelven a hacer una oferta de precios hasta que se alcanze el presupuesto.

c. Precios de valor de mercado: La referencia a los precios de mercado de los agricultores es quizás el método más común. Determine su precio objetivo, es decir, el precio que la gente está dispuesta a pagar por los esquemas de canasta vegetariana. A continuación, establezca la cuota en función del precio de los artículos individuales, en los mercados campesinos locales o en cadenas de venta directa o de suministro cortas similares, hasta alcanzar el precio objetivo. Por ejemplo, la gente está lista para pagar hasta 15 USD por una entrega semanal; entonces usted puede establecer la cuota en base a los precios del mercado.

Fuente: Folleto Be Part of ASC de 2016. 


\section{Investigación de mercado participativo}

$\begin{array}{ll}\stackrel{\text { J }}{\text { Č }} & \\ \text { Investigación de Mercado } \\ \text { D } & \text { Participativo (IMP) (Uganda) }\end{array}$

Trabajando dentro de su esquema MVMAM (Medios de Vida Mejorados por Acceso a Mercados), FreshVeggies Ltd., con sede en Uganda, conecta directamente a productores y consumidores en su programación de IMP dirigida, lo que conduce a resultados concretos en la fijación de precios. Los miembros de FreshVeggies entrevistan a consumidores potenciales en los mercados locales, sus hogares y sitios de trabajo. En este proceso, se recopila información sobre qué productos son más interesantes para ellos, y se solicitan futuros clientes para estos productos. Dependiendo del número de participantes de FreshVeggies, y de las distancias necesarias para viajar para hablar con los consumidores potenciales, la IMP puede tardar entre dos y cinco días.

- Día uno: Los participantes son introducidos al proceso de la IMP, las preguntas a incluir en la IMP son finalizadas, y las preguntas sobre el proceso son contestadas.
Días dos y tres: La IMP se ejecuta in situ en mercados locales/hogares/sitios de trabajo, y se recopila y se anota la información.

- Días cuatro y cinco: La información recopilada de la IMP se compila y sintetiza, se organiza un ejercicio de retroalimentación con posibles clientes, se discuten los precios y se hacen acuerdos de compra.

De esta manera, los productores pueden establecer relaciones directas con los consumidores potenciales y, al hacerlo, pueden discutir los costos asociados con la producción de productos agrícolas de alta calidad. Los consumidores adquieren conocimientos sobre el proceso agrícola de gran intensidad de mano de obra y, como tal, suelen estar más comprometidos con el apoyo financiero a estos productores.

Fuente: Julie Matovu, FreshVeggies Ltd., Uganda.

Figura 3: Ejemplo de una plantilla con los resultados de una investigación de Mercado Participativo de un SPG

\begin{tabular}{|c|c|c|c|c|c|c|c|}
\hline \multicolumn{8}{|c|}{$\begin{array}{l}\text { Resumen de la información generada a pi } \\
\text { actividad de la IMP. }\end{array}$} \\
\hline \multicolumn{8}{|c|}{ Producto: por ejemplo, tomates orgánicos } \\
\hline $\begin{array}{l}\text { Ubicación } \\
\text { del hogar/ } \\
\text { lugar de } \\
\text { trabajo/ } \\
\text { espacio de } \\
\text { mercado } \\
\end{array}$ & $\begin{array}{l}\text { Calidad/ } \\
\text { Tipo/ } \\
\text { Tamaño } \\
\text { requerido }\end{array}$ & $\begin{array}{l}\text { Cantidad } \\
\text { requerida }\end{array}$ & $\begin{array}{l}\text { Frecuencia } \\
\text { de } \\
\text { entrega y } \\
\text { empaque } \\
\text { especial } \\
\text { requeridos }\end{array}$ & $\begin{array}{l}\text { Otras } \\
\text { fuentes } \\
\text { conocidas } \\
\text { del } \\
\text { producto } \\
\text { requerido }\end{array}$ & $\begin{array}{c}\text { Precio/ } \\
\text { Rango } \\
\text { de } \\
\text { precios }\end{array}$ & $\begin{array}{l}\text { Condiciones } \\
\text { de pago }\end{array}$ & $\begin{array}{c}\text { El } \\
\text { encuestado } \\
\text { acepta las } \\
\text { ventas por } \\
\text { SPG } \\
\text { (Sí/No) }\end{array}$ \\
\hline & & & & & & & \\
\hline & & & & & & & \\
\hline & & & & & & & \\
\hline
\end{tabular}




\section{Relación de reparto de precios en el sector del té (República Unida de Tanzanía)}

En República Unida de Tanzanía, el té es producido tanto por grandes fincas como por pequeños agricultores. El sector inmobiliario es propietario de la mayoría de las fábricas de procesamiento, mientras que los pequeños agricultores son considerados cultivadores subcontratados, que solo poseen sus pequeñas huertas administradas por la familia. Tras una larga batalla por una estructura de precios justa para los cultivadores subcontratados, se tomó la decisión de utilizar el costo de producción a lo largo de la cadena de suministro con proporciones compartidas (basadas en la teoría económica de la productividad marginal). Esta analiza los beneficios maximizando la cantidad de insumos (es decir, los servicios como un factor de producción) adquiridos por una empresa en la producción de productos.

El modelo de costo de producción se considera un enfoque justo y viable para el sector del té tanzaniano. Esencialmente, todos los costos de producción pertinentes se utilizan para determinar la relación de reparto del precio de mercado del té vendido. El proceso se resume en la siguiente figura, que describe la fórmula simple que combina el costo de producción de los pequeños productores y las fábricas para obtener el costo del cultivo, elaboración y venta de té. Este enfoque se puede examinar desde ambos lados, el lado de insumos (GL) o el lado del producto (MT). No obstante, para crear una base común para calcular el precio, se utilizan medidas de GL.

Sobre la base de los resultados de esta fórmula, se llega a un acuerdo sobre las respectivas cuotas de los cultivadores subcontratados y de los procesadores a partir de los precios finales alcanzados en la subasta. Estos precios incluyen cualquier ganancia obtenida, a ser compartida entre los productores y los procesadores. Dado que los precios finales del té están muy determinados por los atributos de calidad, esta fórmula y enfoque une a todos los actores dentro de la cadena de valor para asegurar que el producto final enviado a la subasta se adhiere al más alto estándar de calidad y, en consecuencia, el mejor precio. Fuente: Emmanuel Simbua, TRIT.

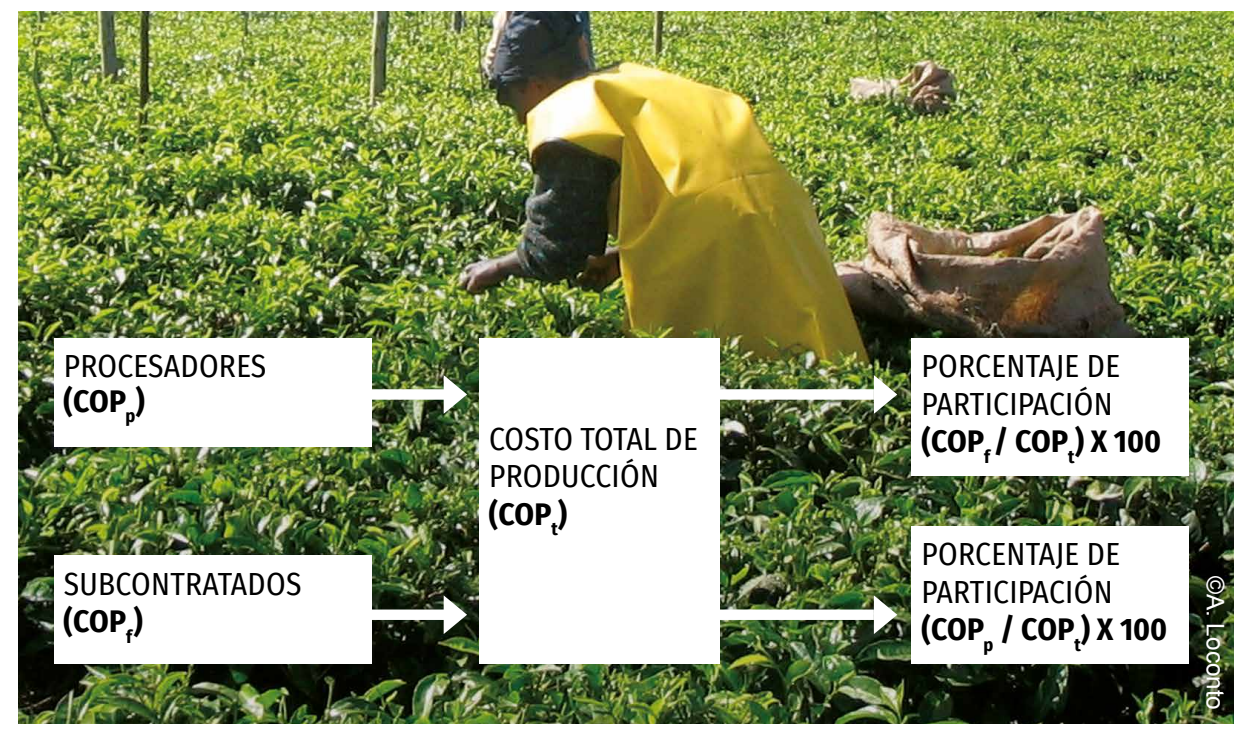




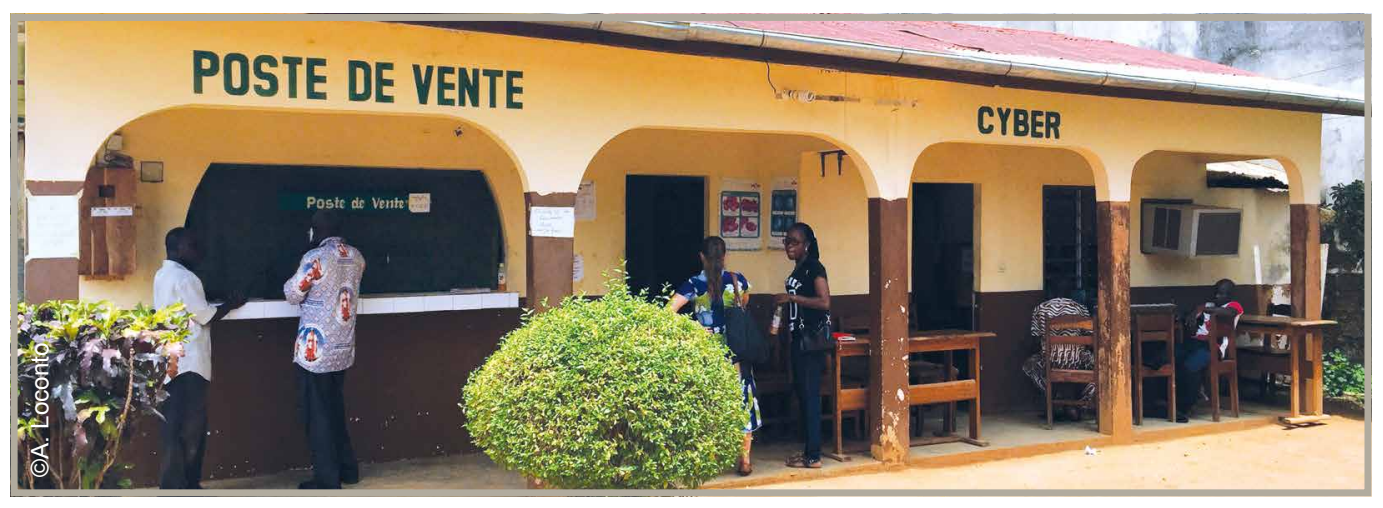

\subsection{3. ¿Cómo pueden los intermediarios transparentes establecer un margen justo para sus actividades?}

El papel de los intermediarios transparentes es establecer precios de mercado que tengan en cuenta las necesidades de los productores y de los consumidores. En general, la remuneración razonable para un intermediario transparente es de alrededor del $30 \%$ del precio de venta, permitiendo así que el intermediario transparente logre cubrir financieramente sus funciones básicas, es decir, logística y agregación, y para remunerar su trabajo, mientras que alrededor del $70 \%$ del precio de venta se le da al productor. Así pues, se garantiza a los agricultores una cuota justa de los precios de mercado, y se proporciona a los consumidores información transparente sobre los costos de funcionamiento de la cadena de suministro.

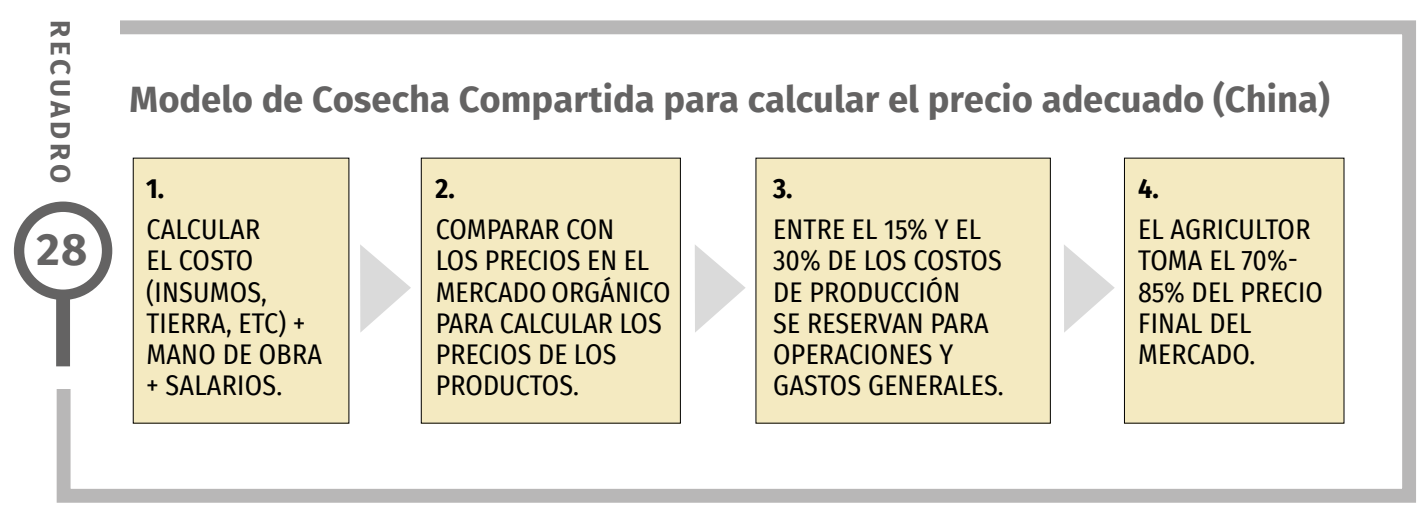

\subsection{Generadores de políticas}

Determinar quién debe absorber el costo real de la producción sostenible de alimentos es complicado. Algunos sugieren que los gobiernos y los generadores de políticas deberían pagar por los servicios prestados por los ecosistemas en lugar de hacer que los consumidores paguen un precio más alto por los productos finales. Aparte de estos tipos de pagos, los generadores de políticas pueden influir en la fijación de precios adoptando dos estrategias diferentes: 
1 Los encargados de formular políticas pueden desempeñar el papel de un intermediario transparente, y facilitar el flujo de información sobre los precios, tanto para los productores como para los consumidores. En algunos casos, en los que la negociación entre los actores del sistema alimentario es particularmente dificil, o cuando los productores sostenibles son especialmente vulnerables, los generadores de políticas también pueden fijar precios mínimos.

\section{El Gobierno como intermediario transparente (India)}

En la India, la adquisición de productos de mercado convencionales a partir de mercados abiertos es un ejemplo de una función de "intermediario transparente". Los precios de una serie de productos básicos se fijan por adelantado como "Precio Mínimo de Sustentación" (MSP por sus siglas en inglés) por un organismo del Gobierno central: la Comisión de Costos y Precios Agrícolas (CACP sigla en inglés); http://cacp.dacnet. nic.in/). La CACP tiene un modelo sólido para calcular los costos acumulados para los agricultores, cubriendo alrededor de 27 cultivos, incluyendo arroz, trigo, leguminosas y cultivos comerciales como yute y caña de azúcar. El objetivo del Gobierno es actuar como herramienta de apoyo a los agricultores para garantizar el control de precios, funcionando como comprador directo de productos de los agricultores. En caso de volatilidad de los precios en el mercado abierto, el Gobierno también emite bonificaciones periódicas sobre y por encima de los precios calculados.

El cálculo básico del MSP se basa en diversos factores, entre ellos los costos de insumos de los agricultores, la paridad de precios, los precios históricos y la demanda y la oferta, entre otros. Por lo tanto, la metodología de cálculo CACP se compone de varios costos:

Costo A1 = Costo de cultivo, incluyendo insumos, mano de obra, depreciación, impuestos, intereses y varios.

Costo A2 = A1 + alquiler pagado por arrendamiento de tierras

Costo B1 = A2 + interés sobre el valor de activos de capital fijos (excluyendo la tierra)

Costo B2 = B1 + valor de alquiler de la tierra propia y el alquiler pagado por arriendo de tierra Costo $\mathrm{C} 1=\mathrm{B} 1+$ valor implícito del trabajo familiar

Costo $\mathrm{C} 2=$ B2 + valor implícito del trabajo familiar

Costo $\mathrm{C}^{*}$ = costo $\mathrm{C} 2+$ valor adicional basado en mano de obra a los precios de mercado

Costo final C3 $=$ costo $\mathrm{C} 2 *+10 \%$ de $\mathrm{C} 2 *$ (hacia los costos administrativos por agricultor)

Si bien el concepto de este plan es ampliamente apreciado en la India, las realidades para implementarlo dependen de factores de mercado, de déficits gubernamentales y del clima político. Sobre la base de estos factores, los responsables de la formulación de políticas eligen una de las fórmulas anteriores.
El uso de este método para calcular el precio tiene un impacto significativo en la determinación de los precios de mercado abierto. Sin embargo, éste ignora las externalidades ambientales intrínsecas a la agricultura sostenible. Puede haber argumentos para incluirlas en el futuro.

Fuente: Ashish Gupta, Jaivik Haat, India. 
2 Los generadores de políticas pueden crear un mercado específico para los productos sostenibles mediante la contratación pública, ofreciendo así precios superiores a los productores sostenibles y un punto de mercado seguro.

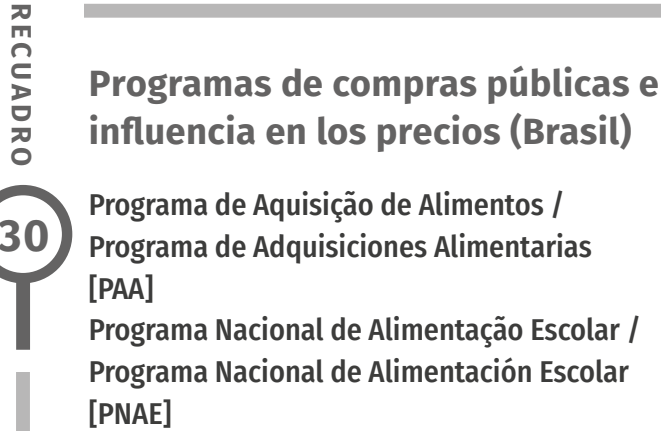

El alcance de los programas públicos de adquisición institucional podría ser amplio, dado que los alimentos suelen suministrarse a las escuelas públicas, los organismos de asistencia alimentaria, las prisiones y los hospitales. En 2003, Brasil implementó uno de los primeros Programas Institucionales nacionales de Adquisición de Alimentos (PAA) mediante una relación directa entre la demanda estructurada de pequeños agricultores y una estrategia nacional de seguridad alimentaria. Si bien la mayoría de los sistemas gubernamentales de fijación de precios requieren que se presenten al menos tres ofertas para su examen, el Gobierno de Brasil decidió renunciar a este proceso estableciendo el requisito de que «los alimentos debían ser producidos por los familias agricultoras; los precios no deberían ser más altos que los precios de referencia en los mercados regionales; $y$ se debe respetar un límite financiero de adquisiciones establecido por año para cada unidad agrícola familiar". (Swensson, 2015, 16)
El PAAMG (Grupo de Gestión del Programa de Compra de Alimentos) es responsable de establecer los criterios para definir el precio de referencia del PAA, y que actualmente son los siguientes:

a. El precio de referencia para todos los productos se define por el promedio de tres encuestas de precios realizadas en mercados mayoristas locales/regionales en los últimos 12 meses.

b. Otras agencias pueden utilizar los precios de referencia definidos por la Companhia Nacional de Abastecimento (CONAB) para agilizar el proceso.

c. El precio de referencia de los productos orgánicos puede aumentarse hasta un $30 \%$ en relación con el precio de referencia de los productos convencionales.

d. El precio de referencia sigue siendo válido durante 12 meses.

De esta manera, el Gobierno es responsable de establecer un precio de referencia justo para todos los productos. A su vez, los agricultores pueden fijar sus precios en relación con esta medida externa para poder optar a la contratación institucional. 
A pesar del acuerdo general de que es necesario reforzar y apoyar la sostenibilidad de los sistemas alimentarios, los encargados de formular políticas siguen apoyando principalmente a la agricultura convencional como parte de las prácticas heredadas, a saber, subsidios a los insumos y proyectos de modernización. Estos tipos de incentivos y subsidios tienen efectos perversos en los precios del mercado de alimentos, lo que hace que los alimentos sostenibles parezcan mucho más caros de lo que realmente son. Hay mucho que los generadores de políticas pueden hacer para remediar esta situación, empezando por una mejor comprensión de los verdaderos costos de los alimentos.

http://www.fao.org/nr/sustainability/full-cost-accounting/en.

\section{CONSEJO 18}

\section{Cómo encontrar un precio sostenible}

- Ningún actor tiene la información necesaria para fijar un precio justo y sostenible. La transparencia puede ayudar a todos a estar más informados.

- La empatía en las negociaciones es clave. Imaginarse en los zapatos del otro puede ayudar a determinar los precios.

- Los comités de precios y la negociación colectiva, con o sin la ayuda de un intermediario transparente, pueden dar lugar a precios más justos.

- Los precios sostenibles cubren todos los costos de producción, los volúmenes producidos y las calidades deseadas. Además, pueden ser pagados de manera oportuna y pueden ser sostenidos con el tiempo.

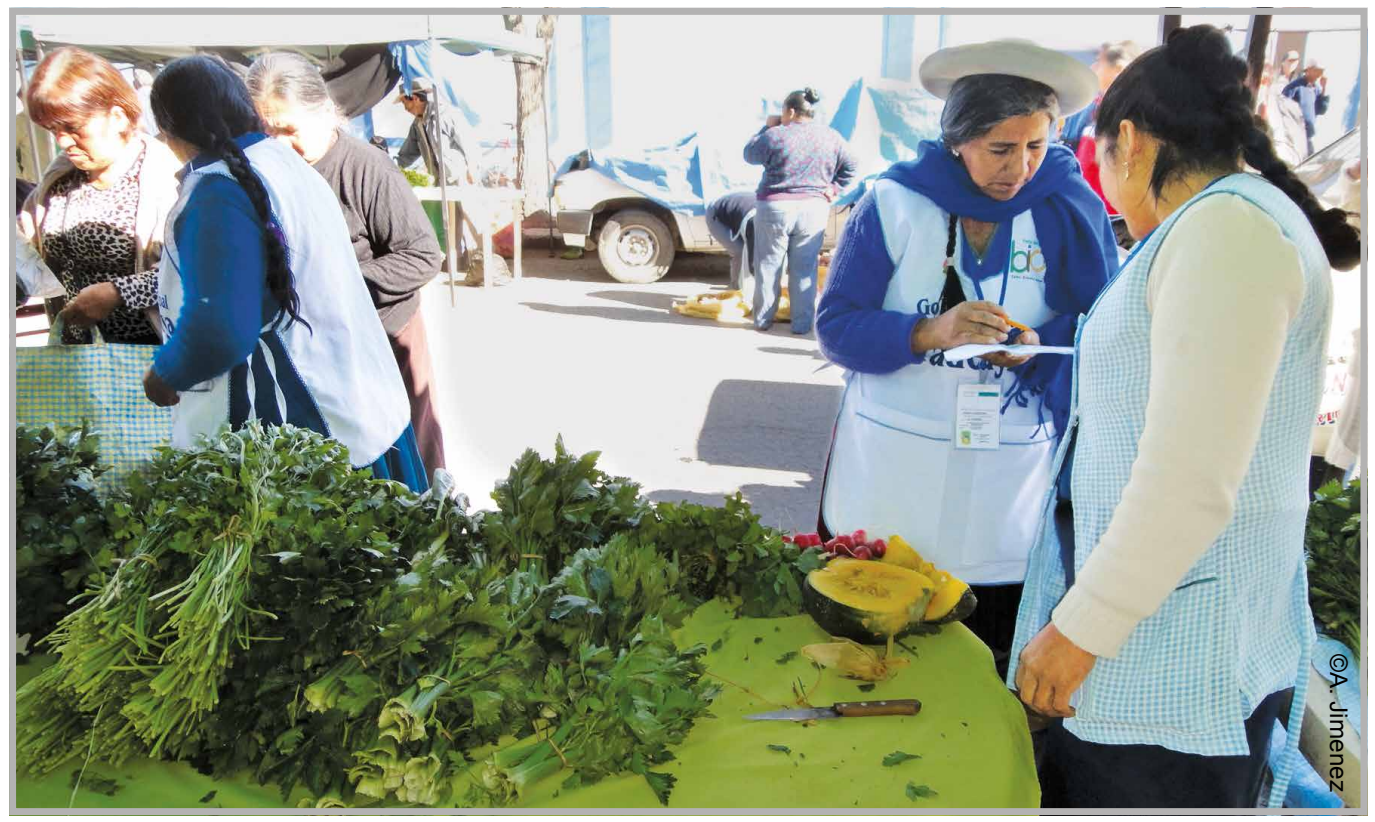




\section{LA AVENTURA DEL APRENDIZAJE, ¿DÓNDE SEGUIR?}

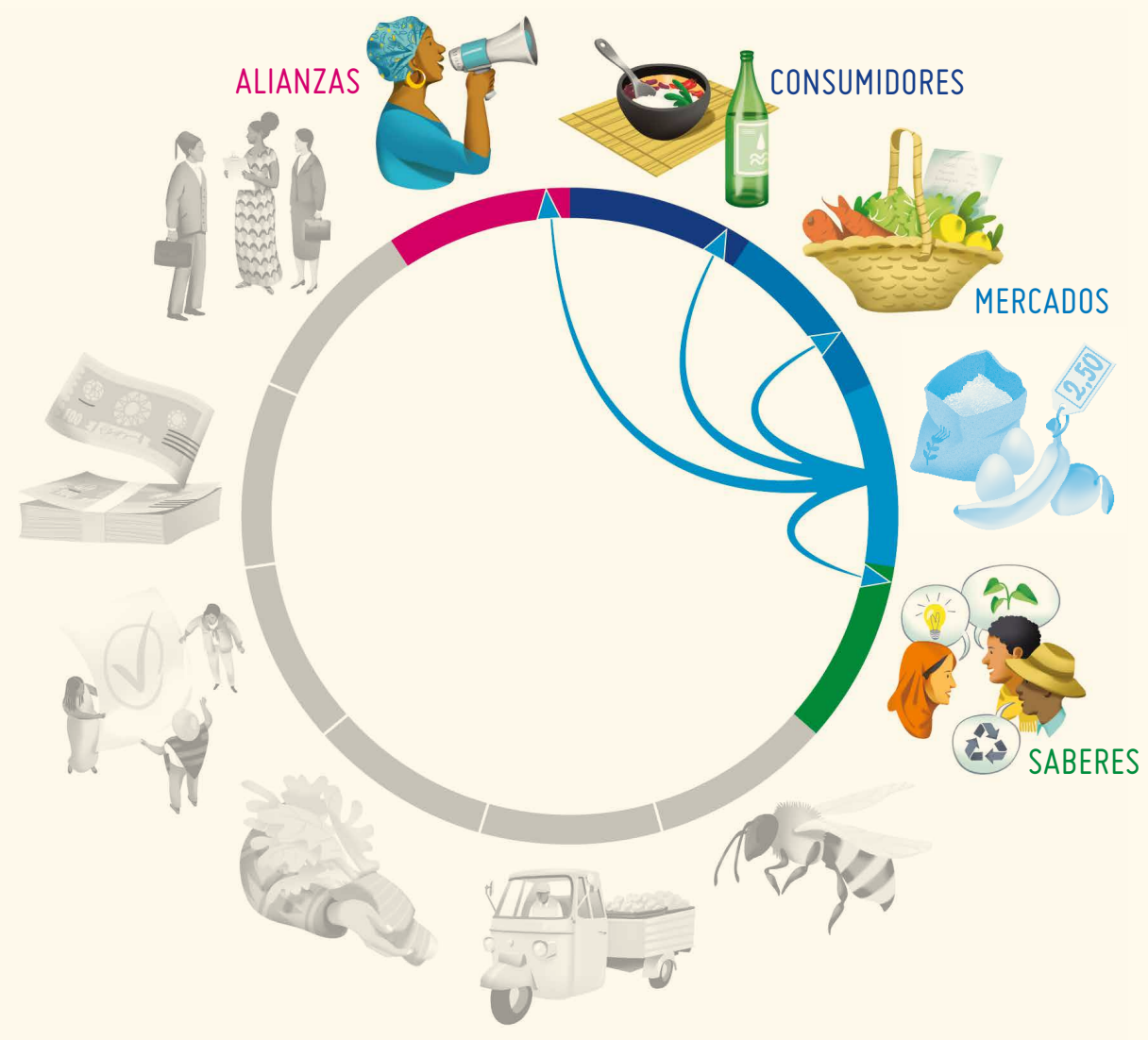

- ¿Le gustó conocer sobre algunas de las asociaciones innovadoras creadas para determinar los precios? Capítulo 11: Alianzas y promoción ofrece más información sobre este tema.

- Para obtener más información sobre cómo organizar una visita de los consumidores a la granja, consulte el Capítulo 2: Conocer sus mercados.

- ¿Quiere establecer un Comité de fijación de precios, pero no sabe dónde encontrar consumidores? Intente leer el Capítulo 1: Atraer a los consumidores y mantenerlos comprometidos.

- ¿Quiere saber más sobre la producción sostenible para poder calcular mejor sus precios? Continúe con el Capítulo 4: Compartir y cocrear conocimientos para una producción sostenible.

O puede aventurarse en otro capítulo que despertó su interés... 

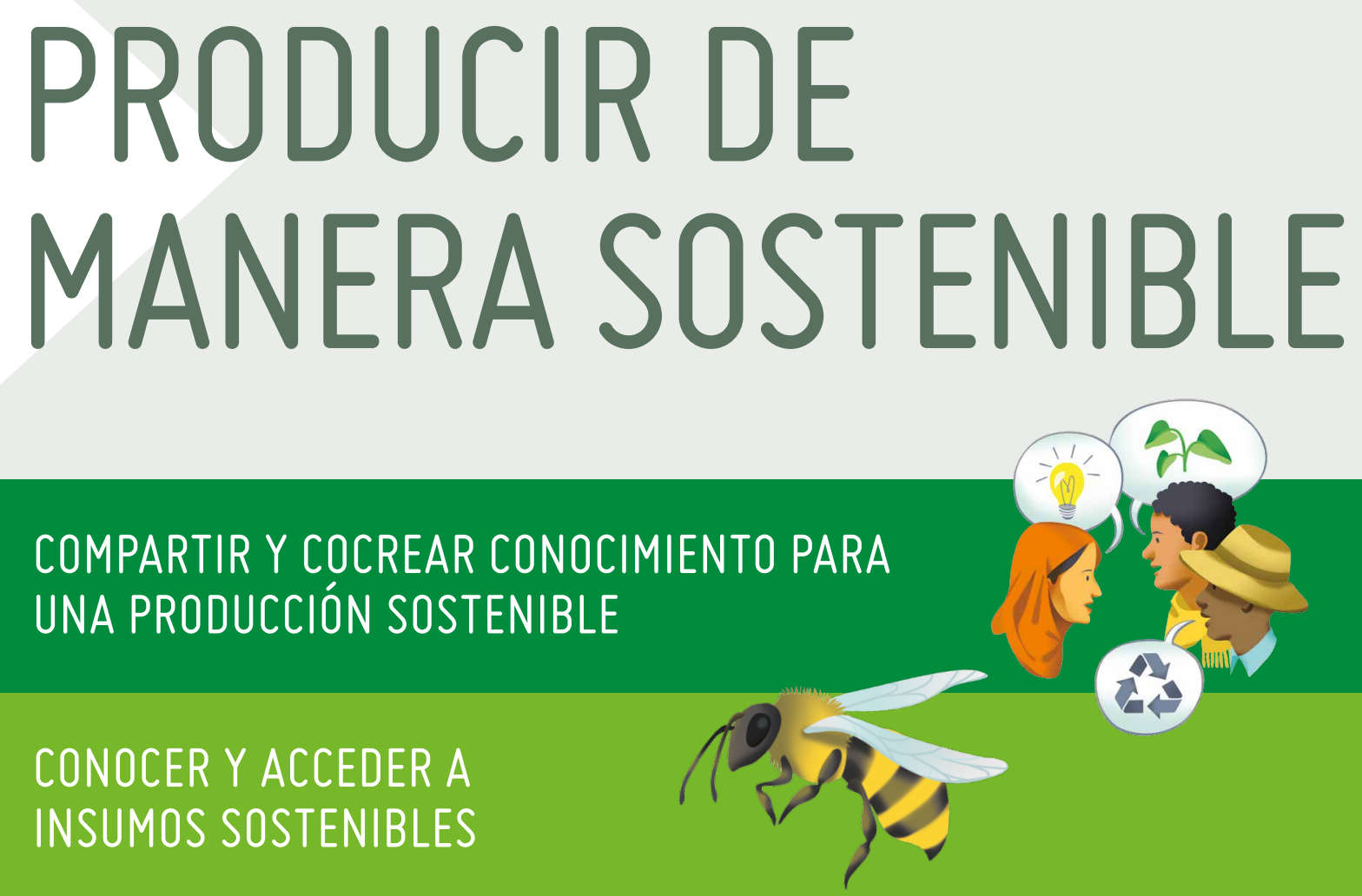

En el siguiente grupo de capítulos, exploramos sobre la producción de los sistemas alimentarios sostenibles.

Sin embargo, no vamos a entrar en detalles sobre las prácticas de producción sostenible (este tipo de información es muy específica para el contexto y no es el propósito de este manual). Algunas herramientas en línea pueden ayudarle a encontrar esta información:

- www.fao.org/sustainability/frameworks-approaches/en.

- www.fao.org/agroecology.

- www.ifoam.bio/en/organic-30/organic-food-system-program.

- www.ifoam.bio/sites/default/files/organic_food_system_in_practice_ feb2017web.pdf.

En cambio, el manual se centra en dos aspectos de la organización de sistemas de producción sostenibles: cómo compartir y cocrear conocimiento sobre la producción sostenible, y cómo acceder y gestionar insumos sostenibles.

Ambos temas comprenden muchas innovaciones, y compartimos algunas ideas de las experiencias de los autores que pueden ayudar a guiar su travesía. 

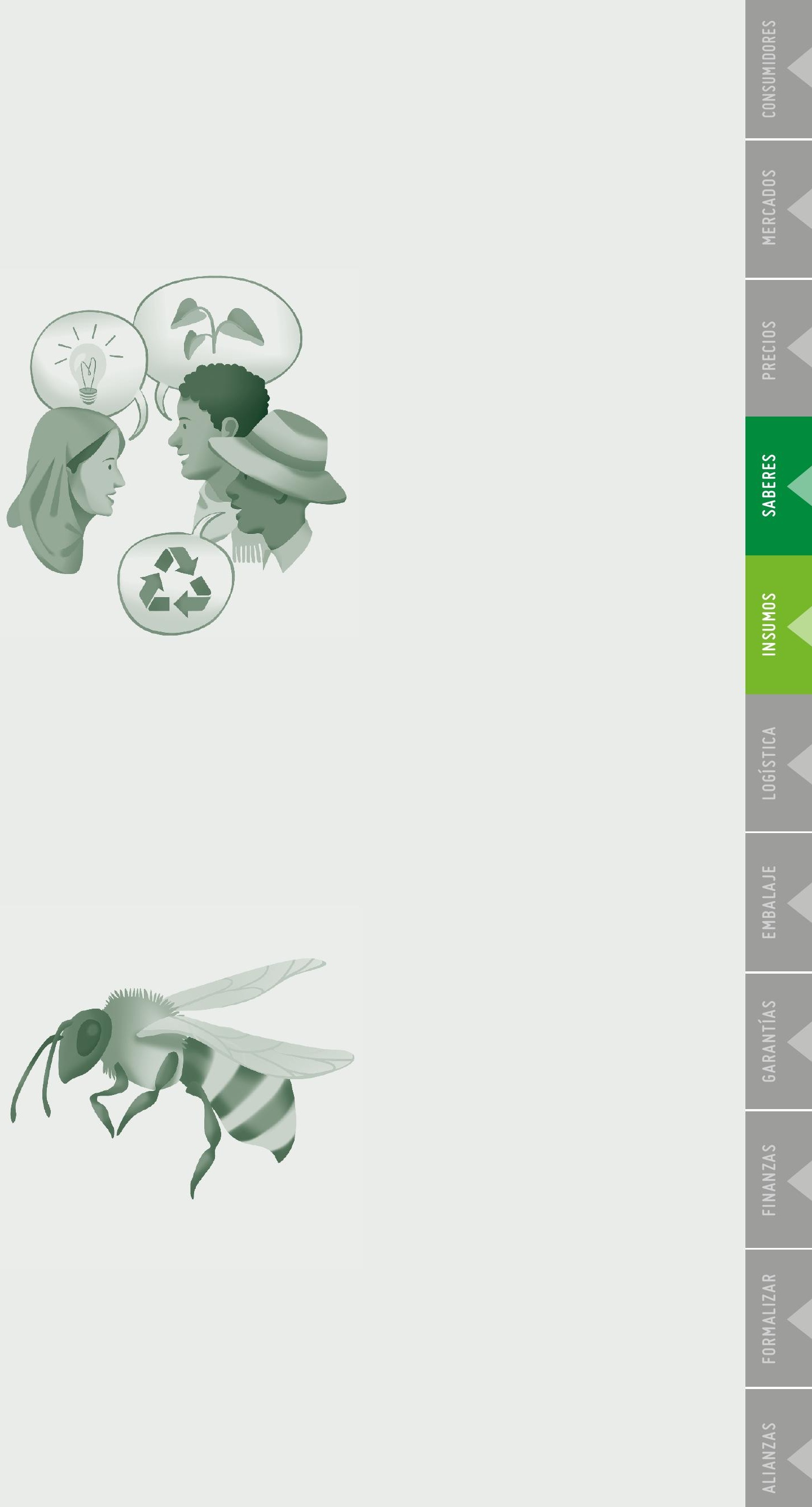
यू
음
产
亭

3

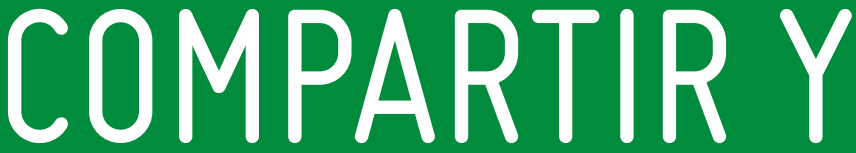

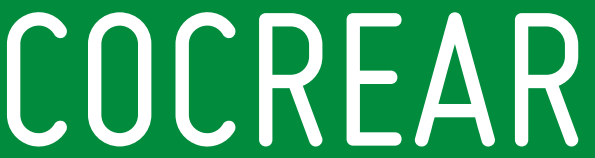

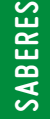

CONOCIMIENTO

PARA

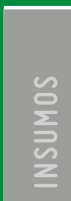

UNA PRODUCCIÓN

SOSTENIBLE

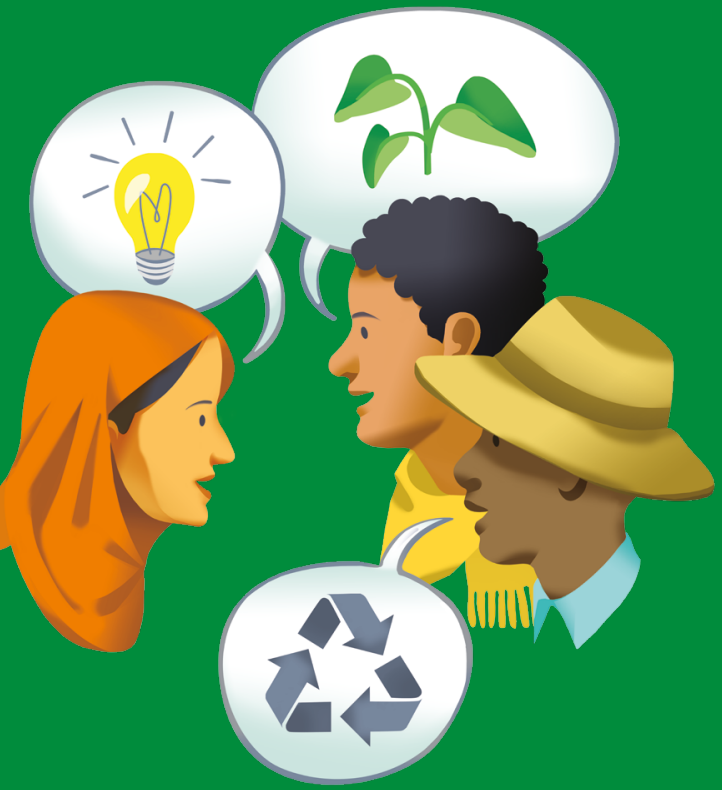




\section{1. ¿POR QUÉ ESTO ES IMPORTANTE?}

La producción sostenible requiere que los productores tengan acceso a una amplia variedad de información y conocimientos sobre los ciclos naturales, las intervenciones humanas y las interacciones entre sistemas.

Un aspecto clave de la sostenibilidad es ofrecer igualdad de oportunidades para innovar y compartir conocimientos con las generaciones actuales y futuras. Todos los actores deben saber lo que significa «producir de manera sostenible»: esto creará una mayor conciencia en todo el sistema alimentario. Sin embargo, el desarrollo de mecanismos para la cocreación y el intercambio de conocimiento requiere de un sentido de creatividad, de una capacidad de colaboración y de saber con quién trabajar.

Este capítulo trata sobre "cómo» funcionan los enfoques innovadores para compartir y cocrear conocimiento, y «cómo» diferentes tipos de actores se han organizado (tanto formal como informalmente) para hacerlo.

\section{CONSEJO 19}

Saber cuándo son más apropiados los enfoques formales e informales.

La creación y el intercambio de conocimientos formales (asociaciones legalmente enmarcadas, conocimientos institucionalizados, programas recurrentes) es más apropiada cuando es necesario mejorar continuamente las capacidades y los conocimientos a lo largo del tiempo. Los enfoques informales son más sencillos.

\section{2. ¿CÓMO ENFOCAR EL CONOCIMIENTO PARA LA PRODUCCIÓN SOSTENIBLE?}

Existen dos enfoques particularmente interesantes que se adaptan mejor para compartir y cocrear conocimientos para la producción sostenible:

1. Aprender haciendo enfatiza la práctica como una manera de adquirir conocimiento y saber hacer. Incluye una variedad de métodos, tales como visitas de intercambio de agricultor a agricultor, acciones de investigación e investigación participativa. Este enfoque educativo se utiliza en una variedad de entornos, y hace hincapié en que el conocimiento debe ser una actividad aplicada, porque el aprendizaje sobre la agricultura sostenible deriva de sus propias experiencias y prácticas.

2. La experimentación dirigida por los agricultores se centra más profundamente en los agricultores como vectores clave de la innovación. Existen diversas combinaciones de plataformas de innovación dirigidas por los agricultores: plataformas de agricultores y actores públicos, plataformas de agricultores y de la sociedad civil, plataformas de agricultores y el sector privado, plataformas de innovación de múltiples actores y escuelas de campo para agricultores. La experimentación dirigida por los agricultores es un tipo de investigación iniciada y llevada a cabo por los agricultores en sus propios campos, y puede iniciarse al interior de los grupos de agricultores existentes. Este enfoque permite a los agricultores identificar opciones tecnológicas adecuadas a las condiciones agroecológicas/orgánicas y socioeconómicas locales. 


\section{CONSEJO 20}

Reflexione sobre la sostenibilidad de sus prácticas agrícolas

Reconocer el grado de sostenibilidad de su actividad es un primer paso importante para identificar las lagunas de conocimiento. El proceso de autoevaluación, que puede ser tan simple como comparar su rutina diaria con los estándares de prácticas sostenibles de interés, le ayudará a entender y comunicar mejor el lenguaje de la sostenibilidad. También le permitirá tomar decisiones más informadas, y puede ser necesario si busca la certificación.

Comience por mirar el material que recibió de su capacitación o cualquier estándar que esté tratando de seguir. También puede utilizar algunas herramientas reconocidas internacionalmente como guía, las cuales se enumeran a continuación.

- Directrices del SAFA (FAO): Los indicadores de sostenibilidad de la FAO fueron elaborados por profesionales y expertos en análisis a fin de proporcionar un panorama crítico para la evaluación de la producción sostenible.

Para saber más visite:

www.fao.org/nr/sustainability/evaluaciones-de-la-sostenibilidad-safa/es.

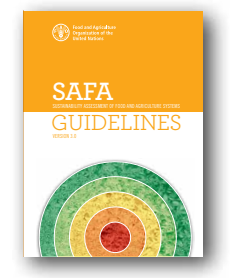

- SHARP (FAO): La Autoevaluación y Valoración Holística de la Resiliencia Climática de Agricultores y Pastores (SHARP por sus siglas en inglés) se desarrolló para atender las necesidades de los pequeños agricultores y pastores, para evaluar su resiliencia climática a nivel de hogares y comunidades individuales.

Para saber más, visite:

www.fao.org/in-action/sharp/es.

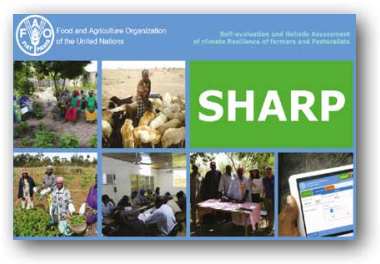

- Guía de Mejores Prácticas para la Agricultura y las Cadenas de Valor (IFOAM): La Guía de Mejores Prácticas para la Agricultura y las Cadenas de Valor tiene como objetivo dirigir, guiar e inspirar a la gente a trabajar en cooperación a través de la agricultura sostenible. Aspira a empoderar a las personas y las organizaciones para mejorar su propio desempeño y prácticas, calidad de vida y el bienestar de sus comunidades. Para saber más visite: www.ifoam.bio/sites/default/files/best_practice_guideline_v1.0_ratified_withcover.pdf.
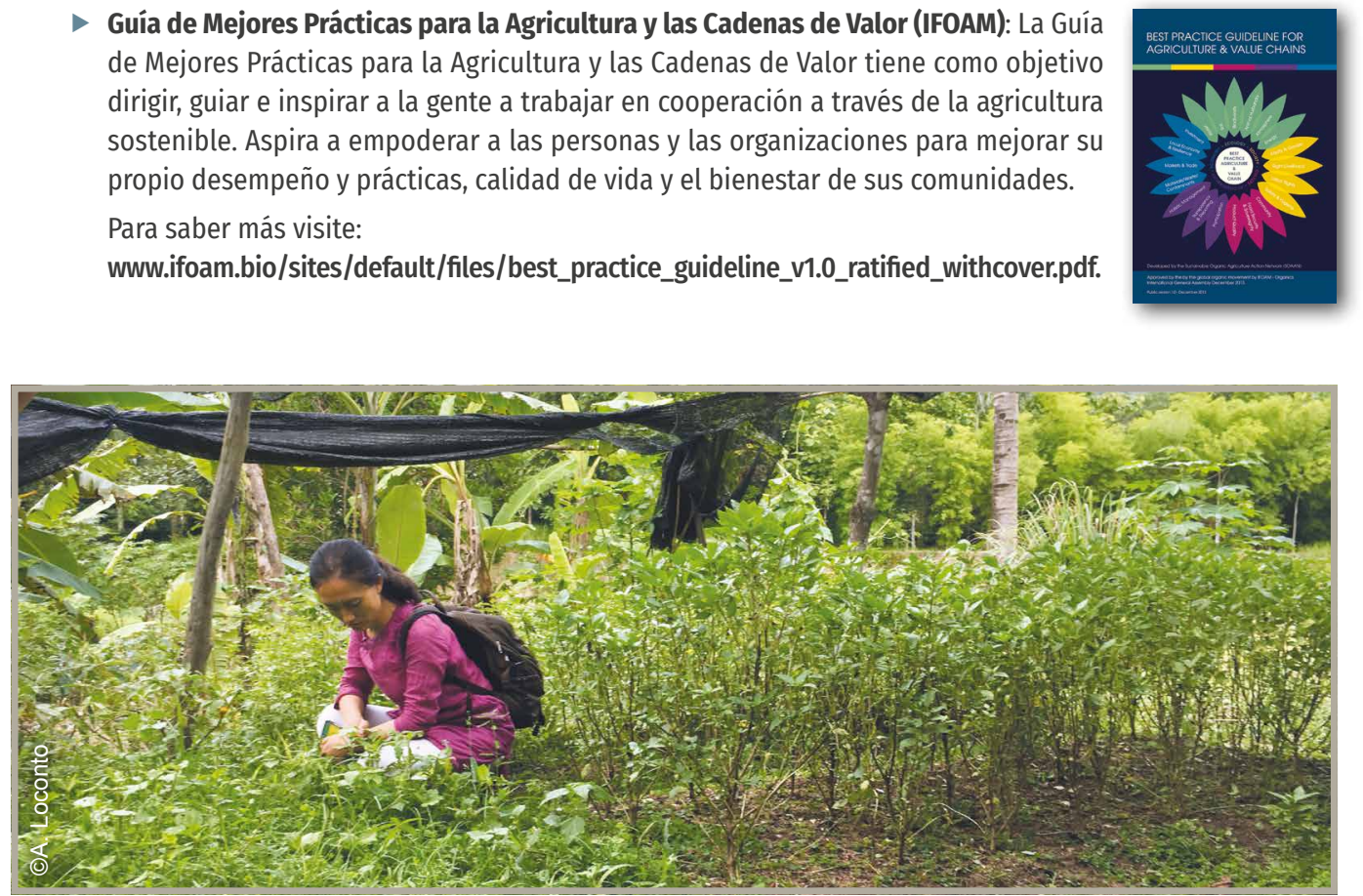


\section{DIFERENTES MECANISMOS PARA DIFERENTES PROPÓSITOS}

\subsection{Visitas de intercambio de agricultor a agricultor}

Las visitas de intercambio son útiles para compartir conocimientos con otros productores que practican la agricultura sostenible. Pueden ser formales y recurrentes, como actividades que aseguran un flujo continuo de información entre los miembros. Además, pueden ser ad hoc, es decir, organizadas en torno a un tema actual o cuando se necesita una información específica.

Recuerde que las visitas de intercambio se pueden utilizar de manera eficaz para compartir conocimientos cuando las relaciones entre los agricultores se basan en la confianza.

Si los agricultores confian unos en otros, no se preocuparán de la apropiación de conocimientos, y será más fácil acceder a la información pertinente.

\section{El programa TRIT para} intercambios de agricultores (República Unida de Tanzanía)

El Instituto de Investigación del Té de la República Unida de Tanzanía (TRIT por sus siglas en inglés) realiza visitas de intercambio de agricultores como parte de un programa más amplio de transferencia de tecnología para apoyar el intercambio de conocimientos entre los pequeños productores de té. Por lo general, la actividad se planifica de tal manera que agricultores más expertos en tecnología acogen a aquellos que están rezagados en cuestiones similares. El supuesto fundamental subyacente es que es más probable que se adopte una tecnología, que ya está siendo utilizada con éxito, por los agricultores, que si la misma tecnología es promovida por un funcionario de extensión o cualquier otro agente externo.

Las formas de llevar a cabo esas visitas de intercambio pueden dividirse en dos categorías: visitas de intercambio interno entre pueblos (dentro del mismo distrito) y visitas de intercambio externo entre distritos.

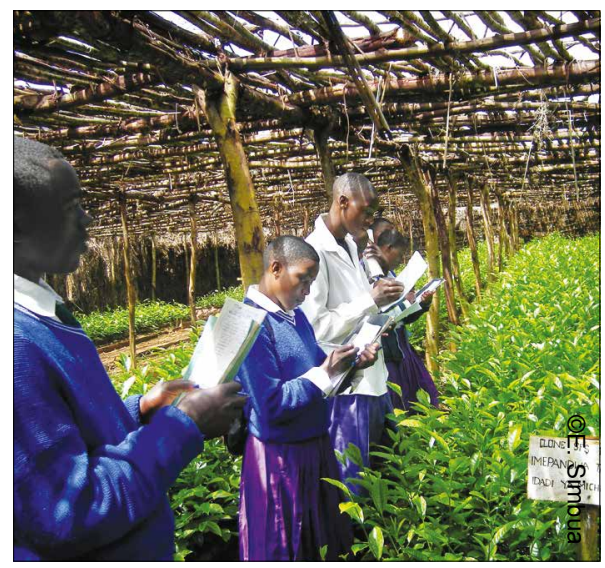

- Las visitas a otros lugares o distritos geográficos tienden a ser más atractivas para los agricultores. Además de los temas objetivo enseñados, los agricultores también están expuestos y aprenden sobre nuevos entornos, nuevas personas que pueden compartir diferentes culturas y nuevos alimentos. En conjunto, estos factores fomentan una experiencia de unión entre los agricultores y crean una atmósfera de aprendizaje positiva. 
- Las visitas de intercambio interno son sencillas y eficaces para temas muy específicos relacionados con la producción o la adición de valor. Pueden ser breves y permitir a los agricultores intercambiar sus experiencias más libremente, dado que trabajan en el mismo entorno agroecológico. Si bien no recrean plenamente la «experiencia turística», sí ofrecen oportunidades para el enlace y la creación de redes de grupos.

Existen importantes disposiciones logísticas que deben tenerse en cuenta al organizar dichas visitas de intercambio:

1. Número de participantes: El número de participantes debe ser manejable para permitir una participación fluida e inclusiva. Con base en la experiencia con el TRIT, tener un grupo de 20-30 participantes fue ideal, ya que encajan en un miniván, viajanjuntos y continuan sus discusiones e interacciones a lo largo de todo el viaje.

2. Duración de la visita: Las visitas de intercambio deben ser cortas y efectivas, desde varias horas en un solo día para visitas de intercambio interno, hasta entre 1 a 3 días para visitas interregionales. Las visitas que duran más de tres días tienden a aburrir a los participantes.
3. Apoyo logístico: El TRIT apoya a los participantes con gastos de sostenimiento para atender sus estadías nocturnas. Para las visitas cortas de un día, se ofrecen refrigerios para crear un ambiente favorable para discutir e intercambiar ideas. El TRIT posee dos minivanes de 30 puestos, que se usan generalmente para transportar a los participantes a varias ubicaciones.

La experiencia pasada con visitas de intercambio institucionalizadas indica que el enfoque es muy eficaz para proporcionar plataformas donde compartir experiencias. Durante estas visitas, los agricultores anfitriones están orgullosos y honrados de dar la bienvenida a los visitantes y quieren impresionarlos. Igualmente cierto es el sentimiento recíproco de los visitantes, expresando gratitud a sus anfitriones. Los visitantes estarán ansiosos por adoptar el papel de anfitriones, y típicamente estarán bien preparados para compartir sus prácticas. Estos programas tienen una deficiencia clave, en la medida en que es poco probable que duren sin una institución facilitadora como el TRIT.

\subsection{Escuelas de campo para agricultores}

Las Escuelas de Campo para Agricultores (ECA) han demostrado ser una herramienta eficaz para compartir conocimientos entre los agricultores mediante la promoción de la experimentación práctica y directa (enfoque dirigido a los agricultores). Se centran en la adaptación local de las prácticas y tecnologías existentes. Este instrumento es particularmente pertinente para promover la transición a la agricultura sostenible. A través de las ECA, se pueden fomentar comunidades de práctica, que pueden convertirse en iniciativas innovadoras si los participantes deciden participar en otras actividades, como el procesamiento o la comercialización de productos sostenibles. 


\section{CONSEJO 21}

\section{Cree una ECA}

1. Realice una sesión de Capacitación de Capacitadores $(\mathrm{CdC})$ sobre cómo facilitar una ECA.

- Cada facilitador debe preparar un informe de capacitación, que entregará a la dirección de su organización y a sus colegas.

2. Asegúrese de que el facilitador despierte el interés sobre la ECA, a fin de informar y obtener el apoyo de la gente para implementarlo.

- Esta actividad suele ocurrir durante una reunión o una asamblea de pueblo convocada, y está abierta a todos los productores interesados.

- Se proporciona información sobre la historia, los objetivos, los resultados técnicos y las condiciones de implementación de la ECA. Los participantes comparten sus experiencias, discuten sus principales desafíos y hablan sobre la implementación de la ECA. El facilitador documenta y recopila esta información.

3. Seleccione el terreno de la ECA.

- El terreno debe seleccionarse al menos un mes antes de la capacitación, y en consulta con organizaciones de agricultores u organizaciones comunitarias.

- Los terrenos seleccionados deben tener en cuenta las limitaciones de la zona (posibles conflictos de tierras, daños a los animales, inundaciones, etc); deben ser lo más seguros posibles y ser fácilmente accesibles.

4. Realice el Diagnóstico Comunitario Participativo de Restricciones y Oportunidades, una encuesta sobre las prácticas y los problemas de los productores. La encuesta ayudará a definir el contenido de la capacitación.

- Por lo menos un mes antes del inicio del calendario agrícola, el facilitador lo llevará a cabo de manera participativa a través de entrevistas con productores y actores locales.

5. La selección de los participantes influye en gran medida en el éxito de la capacitación y en el impacto del programa.

- Se pueden utilizar los siguientes criterios para guiar la selección de los participantes: un productor del cultivo en estudio, un voluntario, estar abierto a la innovación, capacidad para participar regularmente en sesiones de capacitación, aceptar la difusión de los conocimientos obtenidos de otros productores y aceptar visitas a su terreno.

6. Preparar y facilitar las sesiones de capacitación.

- Definir un programa de capacitación basado en los resultados obtenidos de las encuestas básicas. Dentro del programa se pueden incluir temas agronómicos y otros temas específicos (como la dinámica de grupo, el conocimiento sobre insectos, la producción de compost, etc). Esto debería alentar a los productores a responder a las preocupaciones expresadas por otros productores.

- Preparar materiales de capacitación, recursos visuales, etc.

- Estimular la autorreflexión y la interacción entre los agricultores y la experimentación directa.

- Crear un buen entorno de aprendizaje mediante la gestión eficaz de los debates y la garantía de que los hombres y las mujeres, los jóvenes y los adultos mayores participen por igual.

- Realizar una evaluación de los resultados en temporada y al final de temporada.

7. Organizar una ceremonia de clausura y entregar certificados. Esta es una manera de sensibilizar e informar a la comunidad sobre los resultados de la ECA en términos del nivel de conocimiento de los participantes y de la mejora de la producción.

Fuente: http://www.fao.org/3/a-i4411e.pdf y http://www.fao.org/3/a-i3948f.pdf. 


\section{Granjas incubadoras (Francia)}

En Francia, existe una tendencia creciente entre los pequeños agricultores para crear granjas incubadoras. La recientemente establecida red nacional de incubadoras (Réseau national d'espace test agricoles, Reneta) es una clara indicación de este desarrollo.

Entre los ejemplos más exitosos están las incubadoras "Champs des possibles". Fueron creadas por la red local de ASC en la región de París, para satisfacer la necesidad de aumentar el número de nuevos participantes en los sistemas agrícolas de cadena corta. Como se indica en Peter Volz et al (2017, p.34):

Las granjas incubadoras proporcionan acceso a la tierra y a los equipos, asesoría y personería jurídica a los nuevos productores durante un período de prueba. El objetivo es ayudarles a adquirir nuevas habilidades y confianza, probar las prácticas agrícolas, construir una base de consumidores y desarrollar su red profesional antes de empezar a trabajar en su propia granja. Esta es una dimensión clave para cerrar la brecha entre la capacitación y la entrada de futuros agricultores a la agricultura, quienes a menudo carecen de experiencia práctica.

Desde su creación en 2009, “Champs des possibles" ha incubado a 40 futuros agricultores, y ha ayudado a instalar a 14 nuevos agricultores. También se ha expandido a nuevos sitios de prueba, y ha lanzado una mayor cooperación con una asociación local de agricultura orgánica, con un fondo nacional de tierras basado en la comunidad llamado Terre de Liens, y con la red ASC. El objetivo era establecer una plataforma informal para promover a los nuevos agricultores de la zona. Todos ellos consideraron que era necesario cooperar entre las diferentes organizaciones de expertos: una que proporcionaba capacitación y asesoramiento sobre habilidades agronómicas, otra sobre sistemas de distribución y conexiones comunitarias, una tercera sobre agricultura experimental, y una última sobre la búsqueda y la obtención de tierras. Así pues, la cooperación entre todas estas estructuras era necesaria para proporcionar un conjunto amplio y coherente de actividades. El propósito es ayudar a los futuros agricultores a pasar «de los planes iniciales a la agricultura real, asegurando cada paso de su camino de entrada a la agricultura» (Peter Volz et al, 2017, pág. 36).

Fuente: Jocelyn Parot, URGENCI.

Para saber más, visite:

http://www.accesstoland.eu/IMG/pdf/reneta_ overview_farmincubators_france_en.pdf. http://www.terredeliens-iledefrance.org/lepole-abiosol.

http://www.leschampsdespossibles.fr.

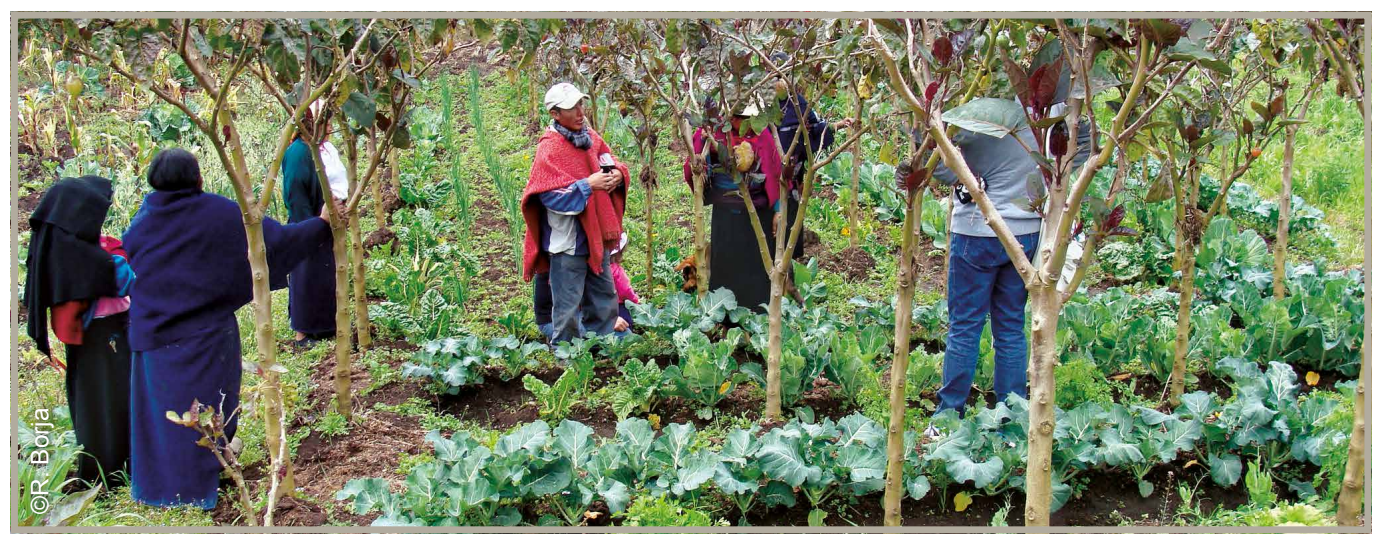




\subsection{Investigación participativa e investigación-acción}

La investigación participativa y la investigación-acción pueden ser estrategias poderosas para llenar las brechas de conocimiento de los agricultores, y para fomentar el aprendizaje y la comprensión colectivas entre los diferentes actores en un sistema alimentario dado.

- En la investigación participativa, el investigador y los participantes coconstruyen preguntas de investigación con los participantes. La recopilación y el análisis de datos se realizan mediante la participación del investigador en las actividades del proyecto.

- Aunque la investigación-acción no siempre se basa en preguntas de investigación coconstruidas, el propósito es llevar a cabo investigaciones que influyan en el cambio durante el proyecto a través de la participación de los asociados.

\section{Investigación-acción para promover las prácticas agroecológicas (Ecuador)}

EkoRural es una ONG ecuatoriana que promueve innovaciones sociotécnicas en áreas rurales a través de un enfoque endógeno y centrado en la gente. Dado el enfoque de EkoRural en facilitar nuevas relaciones entre productores y consumidores, en 2010 se inició un proceso de intensificación agroecológica al vincular una organización campesina de Tzimbuto (Asociación Nueva generación) con consumidores urbanos pertenecientes a la organización Canasta Comunitaria Utopía ubicada en Riobamba. Se adoptó un enfoque de investigación-acción, mediante el cual los participantes registraron y analizaron críticamente los productos, prácticas, relaciones, flujos y normas que surgieron del proceso, a fin de encontrar soluciones comunes. El proceso de investigación-acción se llevó a cabo de la siguiente manera:

1. Documentar y analizar las expectativas: Ekorural, como organismo experimentado en procesos de investigación-acción y enfocada en personas, documentó la oferta de la organización campesina Asociación Nueva Generación, y analizó las expectativas de ambos miembros: de Canasta Comunitaria Utopía y Asociación Nueva Generación.

2. Compartir expectativas: Se organizaron reuniones en las que expertos de EkoRural facilitaron el intercambio de expectativas entre los miembros de las dos organizaciones, creando así un espacio para la comprensión y el acuerdo mutuos. Además, los agricultores participaron en eventos de intercambio y aprendizaje para familiarizarse con la dinámica de Canasta Comunitaria Utopía. Los consumidores de Canasta Comunitaria Utopía visitaron a agricultores de Asociación Nueva Generación para sensibilizarse sobre la realidad rural y la importancia del consumo local.

3. Establecimiento del esquema de entrega: El modelo comenzó en 2010, aunque los consumidores notaron algunos problemas en la calidad de los productos entregados, cultivando así una frágil alianza. Los productores carecían de experiencia en la producción agroecológica y la comercialización directa, y tenían dificultades para coordinar y organizar la cosecha, el control de calidad y la entrega de los productos. 
4. Superar las brechas existentes mediante el diálogo: Durante los dos primeros años del proyecto, EkoRural concedió un subsidio de transporte a los agricultores de Tzimbuto para visitar a Canasta Comunitaria Utopía. La asociación Nueva generación decidió volver a concentrarse en la importancia de los productos de calidad, así como en cumplir con la cantidad acordada y la diversificación de los productos.

5. Realineación: Para respetar el acuerdo con Canasta Comunitaria Utopía, EkoRural apoyó a los miembros de la Asociación Nueva Generación en la modificación de sus prácticas agricolas para reflejar mejor y apoyar la agricultura agroecológica andina. Se introdujeron nuevas especies y variedades nativas, plantaciones escalonadas, la rotación de cultivos y la planificación agrícola mediante visitas de intercambio de agricultor a agricultor, ampliando así la selección de productos agroecológicos. También se mejoraron los sistemas de entrega y control de calidad.

6. Fomento de la retroalimentación continua: EkoRural facilitó reuniones periódicas para permitir a los miembros de las dos organizaciones compartir continuamente sus experiencias y preocupaciones, manteniendo así flujos de información y retroalimentación. Después de cada evento, los consumidores lo evaluaron y se invitó

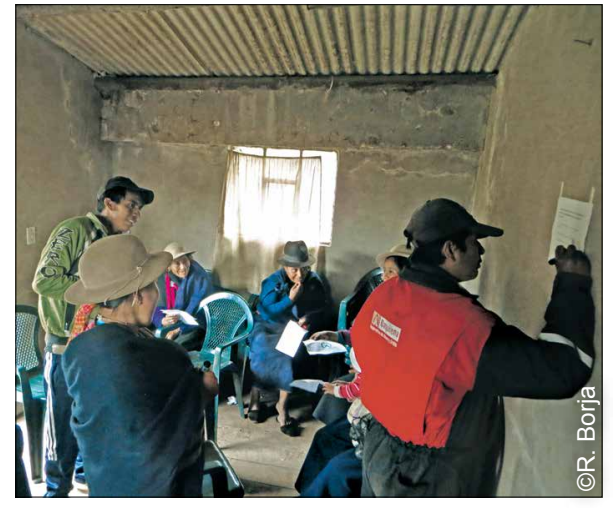

a los representantes de los productores a estas sesiones de evaluación. Además, los representantes de los productores fueron invitados sistemáticamente a las asambleas generales de Canasta Comunitaria Utopía, proporcionando así un espacio para que los productores expresaran sus percepciones de la relación, y para que discutieran cuestiones de precios y acuerdos de colaboración.

Dado el enfoque adoptado, se creó una forma innovadora de interacción en la que los productores y los consumidores comparten valores y metas, determinan mutuamente precios justos, y pasan de una relación basada en la maximización de las ganancias a una basada en valores de reciprocidad y confianza.

Fuente: Ross Mary Borja, Fundación Ekorural.

\subsection{Innovación interactiva}

Una innovación interactiva es una configuración de múltiples actores establecida para facilitar y emprender diversas actividades en torno a los desafios y las oportunidades identificadas en los sistemas alimentarios sostenibles. No existe una estructura fija para una innovación interactiva y los actores pueden ser diferentes. Además de la participación de la sociedad civil y los agricultores, estos tipos de innovaciones suelen incluir también a actores públicos y/o privados. 


\section{Alianza sociedad civil-sector público para promover el concepto de Ecosalud (Colombia)}

En 1994, el Gobierno de Colombia creó un marco jurídico para garantizar la participación ciudadana y comunitaria en la planificación, gestión y evaluación de los planes de salud pública. Como parte de este marco jurídico, se crearon comités comunitarios de participación en salud pública (COPACO) a nivel municipal, proporcionando así un espacio para la discusión y consulta. En el municipio de Sumapaz, del Distrito de Bogotá, el Hospital Nazareth, en concertación con el COPACO local, solicitó y obtuvo apoyo financiero del Secretario de Salud Pública del Distrito para crear el Centro para el Desarrollo del Potencial Humano (CDPH). Dado que el Hospital Nazareth es el único hospital rural del distrito, el centro está diseñado para responder a las necesidades específicas de salud de la población rural a través de un enfoque ecosistémico de la salud humana llamado "Ecosalud". El CDPH consta de dos componentes principales: Parque Temático Chaquen y Programa de Ecoterapia.

1. Parque Temático Chaquen es una estrategia innovadora para abordar las causas de los problemas de salud en las zonas rurales: condiciones de trabajo inseguras, prácticas agrícolas inadecuadas, dietas inadecuadas, poblaciones dispersas, bajos ingresos y una relación hostil con el medio ambiente. Las actividades del parque se organizan en diferentes dimensiones:

- Disponibilidad de alimentos y acceso: ambos han aumentado para las familias que interactúan con el parque. A través de la diversificación, la recuperación y conservación de especies nutritivas ancestrales cultivadas y diseminadas en el parque y distribuidas a las familias, se fomenta la diversificación de las dietas.
- Consumo y uso biológico: se refuerzan los conocimientos de los consumidores sobre dietas saludables y alimentos saludables para lograr un estado adecuado de salud y nutrición.

- Seguridad y calidad de los alimentos: los agricultores reciben incentivos para eliminar el uso de plaguicidas a fin de producir alimentos con mayor valor biológico y crear condiciones de trabajo más saludables en el campo.

- Hábitat saludable: los agricultores son capacitados y entrenados para adoptar sistemas de producción limpios, y las Buenas Prácticas Agrícolas (BPA) son demostradas a los visitantes del parque.

- Entorno de trabajo seguro y saludable: se promueve un entorno de trabajo saludable mediante acciones $y$ capacitación tanto a nivel comunitario como individual, así como en los sectores formal e informal.

2. El Programa de Ecoterapia es una terapia de rehabilitación innovadora para las poblaciones vulnerables. Implementa técnicas y estrategias de intervención para volver a crear roles sociales significativos y valorados, lo que conduce a mayores oportunidades de empleo e inclusión social. Alrededor de 100 personas que vivían en la calle y sufrían diversas enfermedades mentales en Bogotá están incluidas en el Programa de Ecoterapia, ofreciendo un enfoque diferente para el mejoramiento de la salud. Reciben atención hortícola, ecológica, médica, psicológica y psiquiátrica para verificar, identificar, describir y contrarrestar su enfermedad.

Fuente: Andrea Moya, Claudia Helena Prieto, Parque Temático en Salud Pública Chaquen Subred integrada de preocupación de Servicios de Salud Sur. 


\section{Asociaciones entre agricultores e investigadores (Kenya)}

Los agricultores son una fuente rica de conocimientos y prácticas indígenas. Sin embargo, su experiencia ha sido históricamente infravalorada, y ha habido una convergencia limitada entre la innovación informal y los sistemas formales de investigación y desarrollo. El modelo dominante de apoyo a los agricultores ha sido un enfoque de "transferencia de tecnología" de arriba hacia abajo, mediante el cual los científicos determinan las prioridades de investigación, generan tecnología y, con la ayuda de especialistas, la transmiten a los extensionistas que luego la transfieren a los agricultores. Este enfoque excluye a los agricultores del desarrollo y la difusión de nuevas tecnologías.

En consecuencia, los agricultores rara vez adoptan estas tecnologías, que a menudo consideran irrelevantes y que desprecian sus circunstancias sociales, económicas y ambientales. Se ha reconocido cada vez más que los agricultores tienen conocimientos y experiencia valiosos para contribuir al proceso de investigación y desarrollo agrícola, y que, como usuarios finales de la tecnología, deben participar activamente en todas las etapas del proceso.
PELUM Kenya y Jomo Kenyatta University of Agriculture (JKUAT) se ha asociado para ser parte de un proceso interactivo en el que participan la comunidad y actores afines con diferentes conocimientos y habilidades, para validar, adoptar y ampliar las innovaciones de los agricultores. El apoyo científico a las innovaciones aumenta la capacidad de conocimiento de los agricultores, mientras que la participación de investigadores y agricultores aumenta la confianza de los agricultores en su capacidad para adaptar las tecnologías a sus propias explotaciones agrícolas. La asociación mejoró los enfoques dirigidos por los agricultores, mediante los cuales ellos también se involucraron en procesos formales de investigación.

La asociación pretende salvar la brecha entre los agricultores y los investigadores, facilitar los enfoques de investigación dirigidos por los agricultores, y proporcionar una vía para que los agricultores accedan a los resultados de la investigación y las innovaciones técnicas de otros agricultores en JKUAT. PELUM construyó su programa basado en lo que aprendieron del modelo MASIPAG, que ha estado funcionando en Filipinas durante muchos años.

Fuente: Carmen Cabling, Quezon PGS.

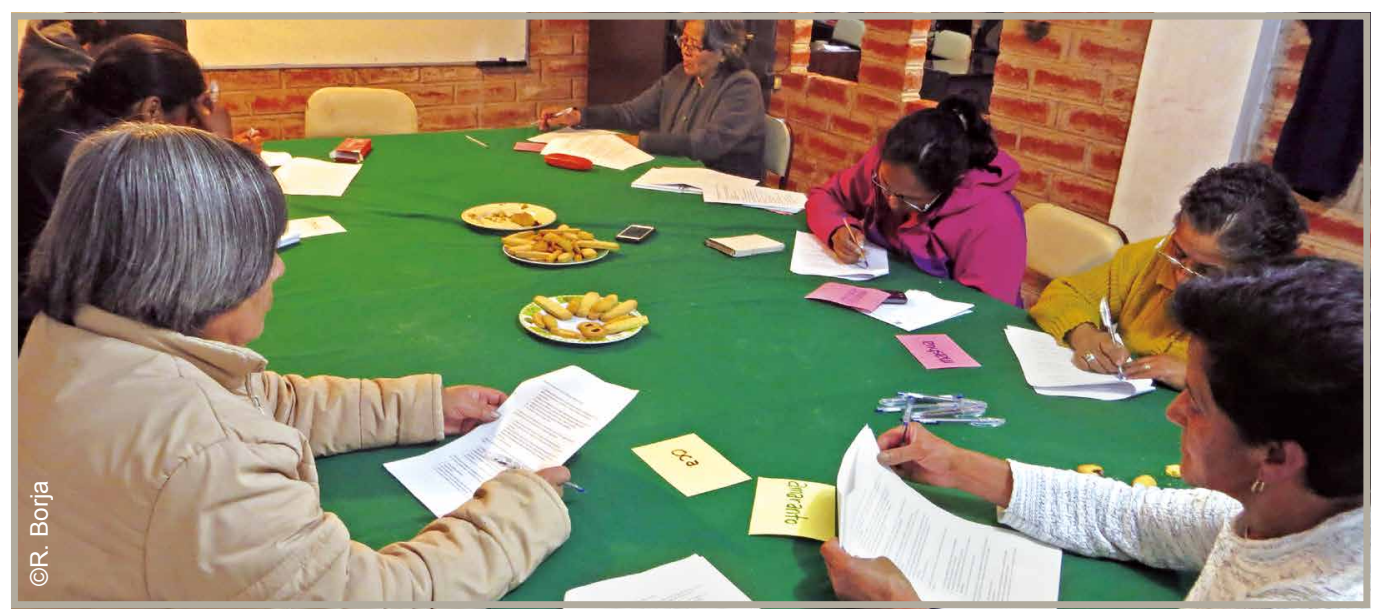




\subsection{Pautas dirigidas por ciudadanos}

A escala mundial, las autoridades públicas están empezando a reconocer la ineficacia del asesoramiento de arriba hacia abajo, como un enfoque que no integra sistemáticamente la sostenibilidad en sus soluciones propuestas a los productores. En cambio, se están haciendo más esfuerzos para mejorar la participación ciudadana a través de la planificación y acciones innovadoras a nivel local. Los líderes locales, que median en las relaciones entre las comunidades y las instituciones públicas, desempeñan un papel fundamental en este tipo de acuerdos, y pueden ser activos clave para abordar los desafios de la sostenibilidad con soluciones innovadoras.

\section{Yachachiqs (Perú)}

Según el Censo Nacional Agropecuario (2012), en Perú el 10\% de los agricultores no tienen acceso a servicios de capacitación, asesoramiento 0 asistencia técnica. A la luz de esta brecha, las ONG trabajan para desarrollar las habilidades y capacidades de los líderes comunitarios. Hoy en día, estos agricultores y líderes comunitarios se han integrado en los servicios de extensión para el desarrollo rural y se llaman "Yachachiq" (el que enseña, el maestro). Uno de los primeros proyectos de desarrollo rural que incluyó a los campesinos como agentes de extensión fue PRODERM (1986-1991), seguido de otros proyectos que adoptaron un enfoque similar durante las décadas de 1990 y 2000. Los extensionistas se centran en la inclusión de los dirigentes campesinos en el proceso de intercambio de conocimientos, lo que se convierte en un factor de potenciación local. De hecho, las comunidades que participaban en estos proyectos podrian cocrear el nuevo sistema de extensión. Actualmente, el MIDIS (Ministerio de
Desarrollo e Inclusión Social) implementa el programa Haku Wiñay (Mi Granja Empresarial) conjuntamente con los Yachachiqs en 40.000 hogares de 19 regiones del Perú. En 2017, tenían un presupuesto anual de 200 millones de soles (aproximadamente USD 60 millones), siendo el programa más pequeño dentro del MIDIS (representando el 4\%-5\% del presupuesto anual total). Se desarrolla con los siguientes principios clave:

- fortalecimiento de los sistemas de producción familiar;

- mejoramiento de la vivienda saludable;

- promoción de negocios rurales inclusivos; y

- aumento de la educación financiera.

Fuente: Patricia Flores, IFOAM Organics International.

Para saber más, visite: http://intranet.foncodes.gob.pe/haku2016/ index.php/blog/yachachiqs. 


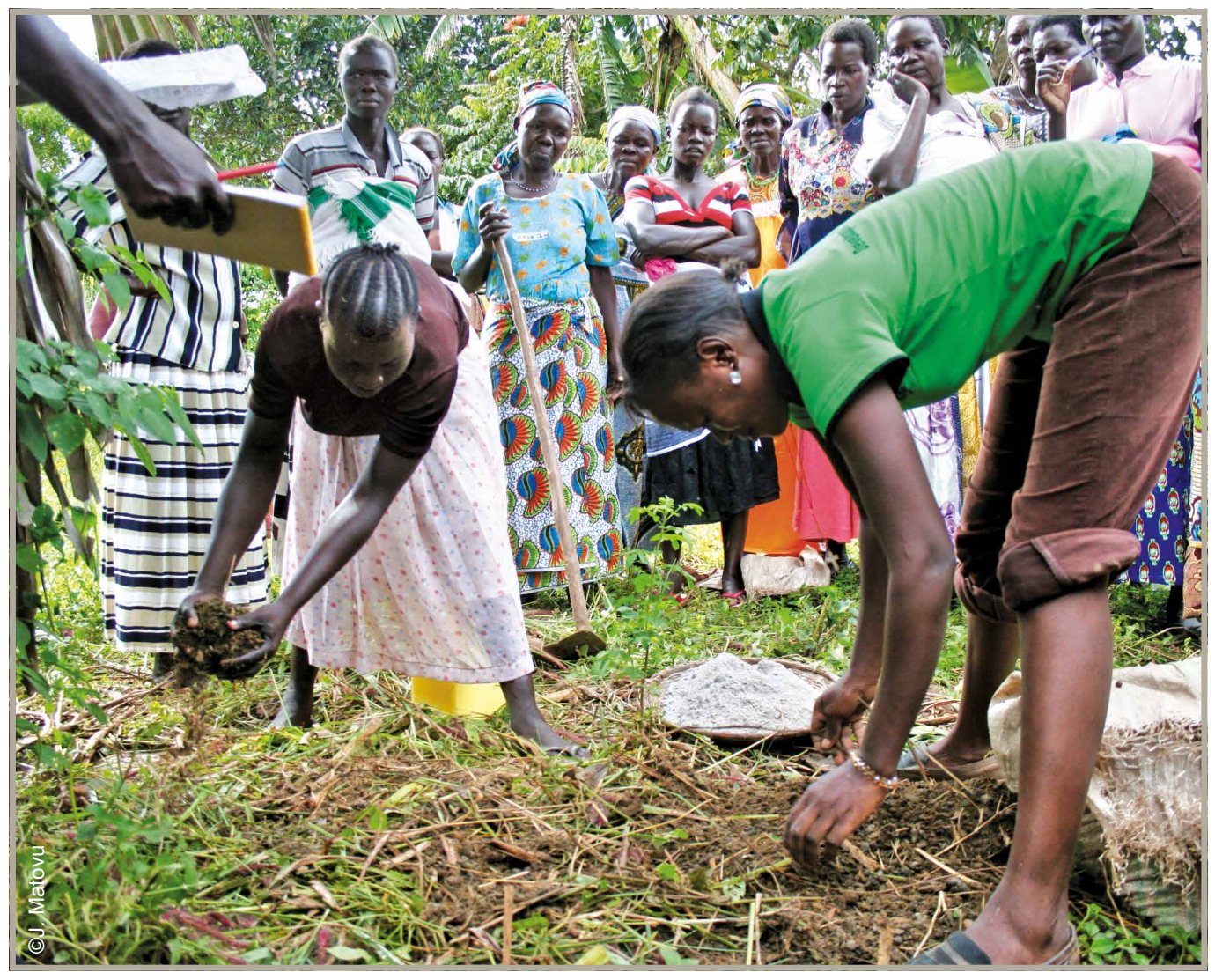

\section{䛔 \\ $\sum_{D}$ Escuela para la formación de \\ 깅 líres en seguridad y soberanía alimentaria y nutricional \\ 37 (Colombia)}

La Escuela de Gestión de Soberanía Alimentaria y Seguridad Alimentaria y Nutricional en Colombia promueve el empoderamiento de la comunidad, haciendo hincapié en sus tres conceptos fundamentales: soberanía alimentaria y seguridad alimentaria y nutricional. La escuela incentiva el intercambio de conocimientos, y fortalece a la sociedad civil, al permitir la participación de la comunidad en la formulación, implementación y monitoreo de las políticas públicas de alimentación. El proceso comenzó en algunas áreas urbanas alrededor de Bogotá, donde los líderes locales fueron identificados y capacitados sobre cómo reconocer y abordar las necesidades territoriales, y cómo utilizar los recursos locales de manera más eficiente. La capacitación de líderes también permite que las comunidades locales participen plenamente en la realización de los planes de desarrollo territorial propuestos por los gobiernos locales. Cada sesión de capacitación sigue un enfoque participativo centrado en el aprendizaje por actividades, que permite a los participantes aprender mientras desarrollan sus propias propuestas de políticas.

Fuente: Andrea Moya, Claudia Helena Prieto Parque Temático en Salud Pública Chaquen, Subred Integrada de Prestación de Servicios de Salud. 


\section{4. ¿QUÉ MECANISMO ES ADECUADO PARA USTED?}

Dado que los sistemas alimentarios sostenibles cambian constantemente y generan nuevos desafios y oportunidades, compartir conocimientos y experiencias debe ser una actividad continua. La comunicación entre los actores del sistema alimentario sobre las prácticas de producción sostenible también puede crear oportunidades para resolver otros desafios.

D

Identifique cuál es su necesidad principal de conocimiento, y experimente con algunas estrategias diferentes.

¿Quiere iniciar una iniciativa sostenible y no tiene mucha información sobre las prácticas agrícolas sostenibles?

¿Quiere fomentar un sentido de comunidad entre los agricultores?

¿Quiere mejorar el entendimiento mutuo entre los diferentes actores dentro de su sistema?

¿Quiere llenar una brecha de conocimiento a través de un enfoque ascendente que garantice el aprendizaje colectivo?

¿Desea difundir el conocimiento sobre prácticas agrícolas sostenibles entre los actores de su sistema?

$¿$ Desea aprovechar las oportunidades existentes para vincular la agricultura sostenible con la provisión de bienes públicos?

¿Desea integrar a las comunidades locales en los procesos de toma de decisiones sobre el desarrollo del sistema alimentario?
- Visitas de intercambio de agricultor a agricultor

- ECA

- Visitas de intercambio de agricultor a agricultor

- Pautas dirigidas por ciudadanos

- Investigación participativa e investigación-acción

- Investigación participativa e investigación-acción

- Innovación interactiva

- Innovación interactiva

- Pautas dirigidas por ciudadanos

El trabajo conjunto con múltiples actores es fundamental para el éxito de estos enfoques. Le sugerimos que identifique a los actores que complementen su experiencia y que estén dispuestos a embarcarse en la nueva travesía con usted. No solo piense en sus miembros, invite a

Recuerde: ¡si no pregunta, nunca lo sabrá! otros aliados potenciales en su comunidad local.

\section{CONSEJO 22}

\section{Compartir y cocrear conocimiento}

- Autoevalúe sus prácticas para comunicar mejor a los demás lo que está haciendo.

- Saber cómo acceder al conocimiento sobre la producción sostenible cuando lo necesita es la mitad de la batalla.

- Hay múltiples métodos para cocrear conocimiento y aprendizaje. Entienda por qué está buscando cierta información y elija el mecanismo adecuado para usted.

- La investigación o la experimentación colectiva es una manera de cocrear el conocimiento, y de asegurar que el contenido aprendido también sea conservado. 


\section{LA AVENTURA DEL APRENDIZAJE, ¿DÓNDE SEGUIR?}

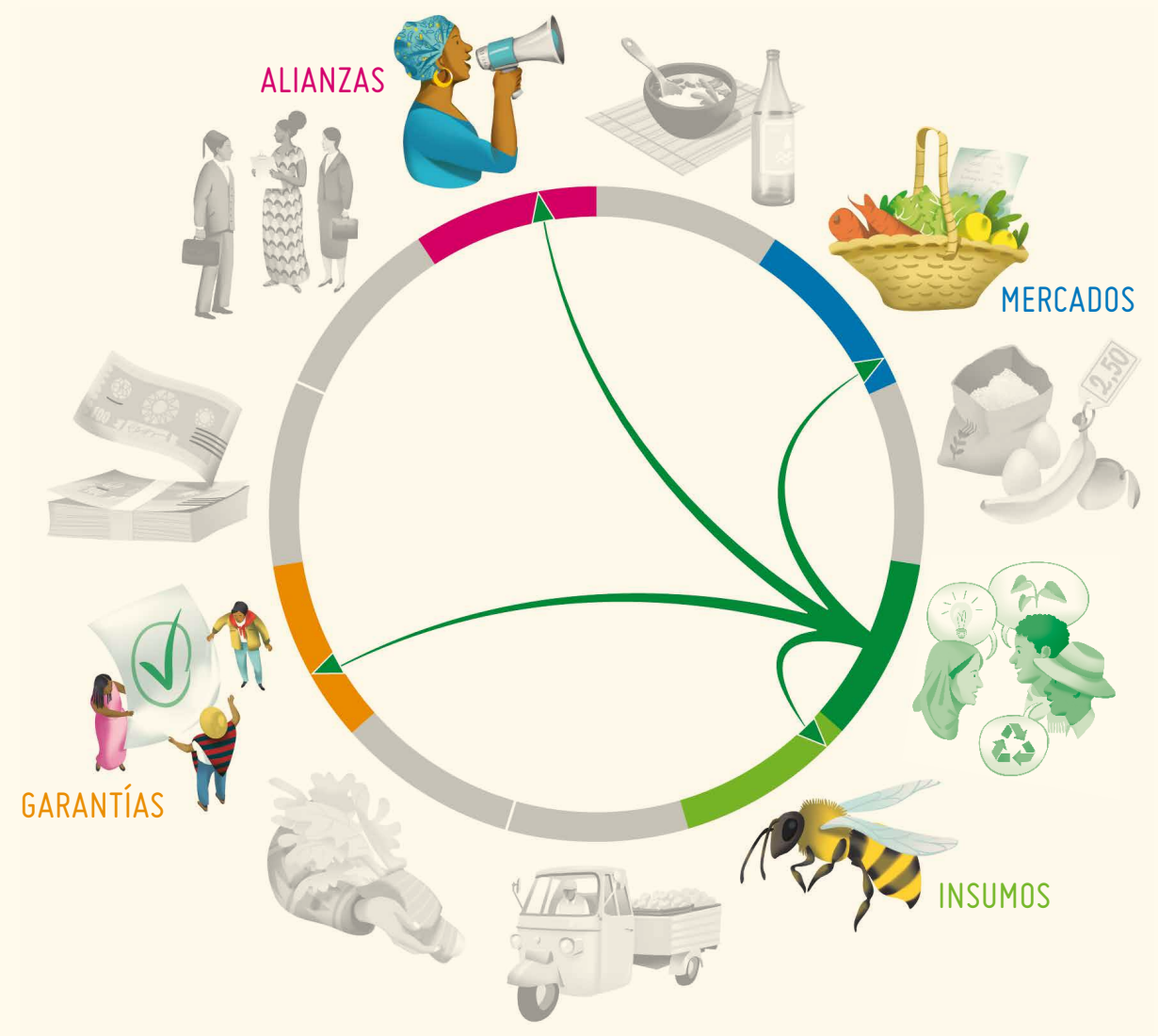

- ¿Ha identificado a un aliado con el que trabaja de forma eficiente y desea encontrar soluciones a largo plazo? Intente leer el Capítulo 11: Alianzas y promoción.

- ¿Ha realizado una autoevaluación y ha pensado en obtener una certificación? Vaya al Capítulo 8: Garantías para la sostenibilidad.

¿Ha introducido un nuevo cultivo en su rotación y quiere venderlo? Consulte el Capítulo 2: Conocer sus mercados.

- ¿Necesita saber más sobre los insumos para la producción sostenible? Continúe con el Capítulo 5: Conocer y acceder a insumos sostenibles.

¿0 tal vez necesita otra información? Pruebe con otro capítulo...

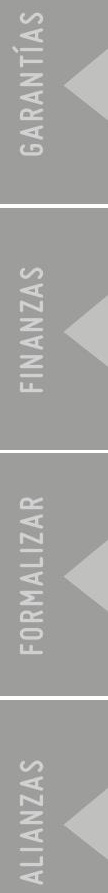


5

CONOCER Y ACCEDER
A INSUMOS SOSTENIBLES

लिखिए 

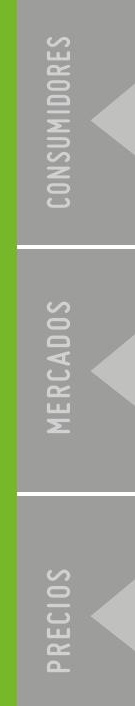

h
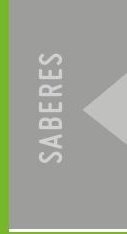

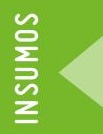

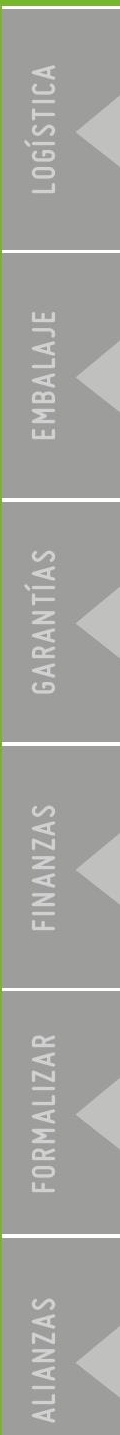




\section{1. ¿POR QUÉ ESTO ES IMPORTANTE?}

Los sistemas alimentarios sostenibles deben ser sostenibles en todas las actividades, desde la producción de alimentos hasta el consumo, incluyendo los materiales utilizados para producir alimentos. De hecho, una serie de cuestiones plantean desafíos específicos a los productores cuando tratan de asegurar que sus insumos (tanto materiales como servicios) sean sostenibles, como:

- la falta de insumos no sintéticos en muchas zonas rurales;

- la presencia de productos falsificados o productos ineficaces, sin forma de responsabilizar a las empresas;

- precios más altos, erráticos y no regulados;

- riesgo de posible contaminación por OGM;

- ingredientes activos y no activos altamente tóxicos de los productos utilizados en los campos de los vecinos;

- evidente desaparición de tecnología indígena útil, especialmente en la conservación de semillas;

- espacio limitado para operar redes alternativas para intercambios de semillas e insumos fuera de los mercados convencionales;

- falta de investigación sobre muchos insumos sostenibles y soluciones ecológicas para el control de plagas y enfermedades; $y$

- la falta de integridad, transparencia y honestidad de algunos extensionistas e intermediarios responsables de proporcionar asesoramiento sobre insumos y su uso sostenible.

El acceso a insumos que son sinérgicos con la agricultura sostenible suele ser un desafío, por dos razones:

a. Deben ser producidos en la granja, requiriendo tiempo y recursos que pueden no estar suficientemente disponibles en su granja.

b. Deben comprarse o intercambiarse con otros, pero los proveedores locales de insumos no siempre llevan opciones sostenibles y es posible que aún no se establezcan redes locales de intercambio.

En las etapas de planificación de la producción sostenible, debe determinarse claramente el acceso y la gestión del uso de insumos sostenibles. Estos insumos deben ser considerados en relación con otras actividades en su sistema agrícola y alimentario. 


\section{QUÉ INSUMOS NECESITA PARA CULTIVAR ALIMENTOS SOSTENIBLES}

Los insumos son materiales y servicios (incluidos los servicios sociales y de ecosistemas) necesarios para producir alimentos y otros productos agrícolas. Los insumos sostenibles pueden considerarse como los recursos y servicios necesarios para la agricultura ecológica, y que contribuyen a la sostenibilidad del agroecosistema y del sistema alimentario en general.

Se dividen en seis categorías:

Cuadro 4: Tipos de insumos

\begin{tabular}{l|l}
\hline Tipos de insumos & Ejemplos \\
\hline $\begin{array}{l}\text { ¿Quién necesita aportar su } \\
\text { tiempo y conocimiento a la } \\
\text { producción? }\end{array}$ & $\begin{array}{l}\text { Conocimientos y habilidades de los agricultores, mano de obra adicional } \\
\text { (familiar, contratado, compartido, etc.), servicios veterinarios, servicios de } \\
\text { albañiles y servicios de extensión. }\end{array}$ \\
\hline $\begin{array}{l}\text { ¿Qué se necesita cultivar, } \\
\text { recoger o reciclar? }\end{array}$ & $\begin{array}{l}\text { Alimentación animal, estiércol animal, forraje recolectado o cosechado, plantas } \\
\text { medicinales, razas de animales, semillas, materiales de plantación, plantas para } \\
\text { cultivos intercalados y plantas como repelentes de insectos. }\end{array}$ \\
\hline $\begin{array}{l}\text { ¿Qué herramientas se } \\
\text { necesitan para producir de } \\
\text { manera sostenible? }\end{array}$ & $\begin{array}{l}\text { Herramientas de siembra (por ejemplo, labradores, tractores, tracción animal, } \\
\text { fertilizantes y estiércol), herramientas de cosecha (por ejemplo, cestas, redes, } \\
\text { máquinas de corte), herramientas de protección (por ejemplo, ropa protectora } \\
\text { y bioinsecticidas), materiales de construcción para estructuras agricolas (por } \\
\text { ejemplo, cemento, techos y madera). }\end{array}$ \\
\hline $\begin{array}{l}\text { ¿Qué tipo de tierra es } \\
\text { accesible? }\end{array}$ & $\begin{array}{l}\text { Parcelas comunitarias, terrenos alquilados, tierras de propiedad individual, } \\
\text { tierras pastorales comunales, tejados, tierras contratadas, estanques naturales o } \\
\text { artificiales y tierras costeras. }\end{array}$ \\
\hline $\begin{array}{l}\text { ¿ué servicios y condiciones } \\
\text { ecológicas y biológicas se } \\
\text { necesitan? }\end{array}$ & $\begin{array}{l}\text { Factores ambientales apropiados (humedad, temperatura), microorganismos } \\
\text { autóctonos, flora y fauna del suelo, polinizadores, agua, micro y macronutrientes } \\
\text { de los ciclos naturales, energía/electricidad, integración animal en el sistema de } \\
\text { producción de fertilizantes naturales, aireación del suelo, etc. }\end{array}$ \\
\hline $\begin{array}{l}\text { ¿Qué se necesita para } \\
\text { comunicarse con otros sobre } \\
\text { las actividades de la granja? }\end{array}$ & $\begin{array}{l}\text { Servicios de certificación, servicios de registro agrícola, servicios de } \\
\text { comunicación y servicios de mercadeo. }\end{array}$ \\
\hline
\end{tabular}

\section{¿Producción en la granja o fuera de la granja?}

Los insumos necesarios para la producción sostenible pueden obtenerse de la propia granja o externamente (fuera de la granja). Producir sus propios insumos es a menudo la forma más rentable y sostenible de acceder a los servicios ecológicos y biológicos. Al reciclar nutrientes dentro de la granja o agroecosistema, se puede reducir la pérdida de nutrientes que a veces ocurre con el uso de insumos externos.

Sin embargo, a veces se da el caso de que su granja no tiene todos los nutrientes, la tecnología o la mano de obra necesarios para alcanzar la productividad deseada. En todo el mundo, están surgiendo modelos de negocios alternativos que ofrecen formas interesantes de acceder a los insumos: nuevas empresas centradas en proporcionar nuevas tecnologías o servicios directamente a los agricultores, y sistemas de intercambio donde las comunidades organizan nuevos tipos de colaboración para compartir insumos, tecnologías y mano de obra. 


\section{3. ¿CUÁN SOSTENIBLES SON SUS INSUMOS Y CÓMO HACERLOS MÁS SOSTENIBLES?}

Así como la sostenibilidad de su sistema de producción puede ser autoevaluada, también pueden serlo sus insumos. Para empezar, tome nota de los insumos necesarios para cada una de las categorías mencionadas, como comenzar a cosechar, rehabilitar las tierras abandonadas o para convertir un sistema convencional en uno sostenible.

Después de enumerar todos los posibles insumos en las categorías anteriores, considere evaluar cuál de estos planea tener, cuales tiene actualmente o cuales le faltan. Un buen ejercicio es pensar en la sostenibilidad de cada insumo y compararla con su estado deseable. Por último, escriba las acciones prácticas para la transición hacia una solución más sostenible para acceder a los insumos.

El siguiente cuadro se puede utilizar como plantilla inicial:

\section{Cuadro 5: Plantilla para categorizar insumos}

\begin{tabular}{|c|c|c|c|}
\hline \multirow{2}{*}{$\begin{array}{l}\text { Categorias de } \\
\text { insumos } \\
\text { Insumo }\end{array}$} & \multicolumn{2}{|c|}{ Características de los insumos } & \multirow{2}{*}{\begin{tabular}{|l} 
Recomendaciones \\
$\begin{array}{l}\text { Acción necesaria para avanzar } \\
\text { hacia la sostenibilidad }\end{array}$ \\
\end{tabular}} \\
\hline & $\begin{array}{l}\text { Sostenible } \\
\text { (deseable) }\end{array}$ & $\begin{array}{l}\text { No sostenible } \\
\text { (indeseable) }\end{array}$ & \\
\hline Semillas & $\begin{array}{l}\text { Altas tasas de germinación } \\
\text { pueden ser guardadas y } \\
\text { resembradas; perfil de } \\
\text { calidad deseado (sabor, } \\
\text { color, tamaño), fácil acceso }\end{array}$ & $\begin{array}{l}\text { Baja germinación, no } \\
\text { reproducibles, no se } \\
\text { les puede guardar y } \\
\text { resembrar, perfil de } \\
\text { calidad deseado, alto } \\
\text { costo, difícil accesibilidad }\end{array}$ & $\begin{array}{l}\text { Colaborar con otros agricultores } \\
\text { para crear un intercambio } \\
\text { de semillas; negociar una } \\
\text { disponibilidad de semillas de } \\
\text { mayor calidad con el proveedor } \\
\text { local, establecer vínculos con } \\
\text { distribuidores de semillas } \\
\text { certificados }\end{array}$ \\
\hline Fertilizante & $\begin{array}{l}\text { Los animales y el abono } \\
\text { integrados en un sistema } \\
\text { de producción mixta } \\
\text { que puede soportar } \\
\text { suficientemente un } \\
\text { microbioma sano del suelo }\end{array}$ & $\begin{array}{l}\text { Aplicaciones excesivas } \\
\text { de fertilizantes sintéticos } \\
\text { comprados y estiércol } \\
\text { animal o compost } \\
\text { inaccesibles }\end{array}$ & $\begin{array}{l}\text { Introducir los animales en el } \\
\text { sistema de producción, comenzar } \\
\text { a compostar los residuos de la } \\
\text { cocina y la granja, colaborar con } \\
\text { otros agricultores para acceder } \\
\text { a fertilizantes que se apliquen } \\
\text { de una manera que equilibren el } \\
\text { microbioma }\end{array}$ \\
\hline Tierra & $\begin{array}{l}\text { Proteger los derechos de } \\
\text { propiedad o uso y realizar } \\
\text { cambios para ahora y en } \\
\text { el futuro }\end{array}$ & $\begin{array}{l}\text { No hay acceso } \\
\text { garantizado, amenazas de } \\
\text { seguridad, no se puede } \\
\text { llegar fácilmente, no es } \\
\text { del tamaño o la calidad } \\
\text { adecuada para cultivar }\end{array}$ & $\begin{array}{l}\text { Si está ocupando la tierra, trate } \\
\text { de registrarla a su nombre. Si } \\
\text { es factible, compre los terrenos } \\
\text { alquilados o asegúrese de que } \\
\text { el contrato de alquiler cubra al } \\
\text { menos tres temporadas. Hable con } \\
\text { la comunidad para establecer un } \\
\text { sistema seguro para el cultivo o el } \\
\text { uso de tierras comunales de una } \\
\text { de manera sostenible }\end{array}$ \\
\hline $\begin{array}{l}\text { Ahora inténtelo } \\
\text { usted... }\end{array}$ & & & \\
\hline
\end{tabular}




\section{OPCIONES POSIBLES: EVALUAR DIFERENTES FORMAS DE OBTENER INSUMOS}

Una vez que sepa qué insumos necesita, es fundamental determinar cómo acceder a ellos de forma sostenible en la granja. En esta sección se ofrecen ejemplos de formas innovadoras de obtener una serie de insumos.

Aunque un enfoque puede tener éxito en una situación particular, no significa que pueda aplicarse a todas las situaciones. En nuestra experiencia, muchas soluciones para mejorar la fuente y la gestión de los insumos comienzan con buenas intenciones, pero presentan muchos problemas para los pequeños agricultores una vez que se aplican. Una de las principales preocupaciones radica en evaluar si el costo del insumo superará la ganancia potencial de producción, o si la(s) forma(s) en que usted accede o administra el(los) insumo(s) encajará en su cronograma habitual. A medida que desarrolle su estrategia de abastecimiento, piense cuidadosamente en los "pros y contras" de cada innovación.

\subsection{Tiempo o mano de obra}

\subsubsection{Compartir la mano de obra en lugar de pagarla: bancos de tiempo}

Mantener una granja sostenible es un esfuerzo de equipo, por lo que compartir la mano de obra es un activo valioso. Participar en un sistema que proporciona ayuda de los agricultores/estudiantes de fuera de la granja ha demostrado ser útil para sostener una granja a pequeña escala.

\section{Mano de obra compartida (India)}

En un gran número de aldeas de Himachal Pradesh, India, se utiliza un sistema nformal de distribución de la mano de obra llamado "Jawari". Es un sistema autónomo de autofuncionamiento en una comunidad cerrada, basado en las redes interpersonales existentes y fundamentadas en la confianza. Un pequeño agricultor puede llamar a un Jawari para completar cualquier trabajo dentro o fuera de la granja (como la construcción de un nuevo establo). A cambio, los pequeños agricultores se ven obligados a responder a las llamadas de otros pequeños agricultores para compartir la mano de obra. En este sistema social no hay intercambio monetario, y funciona sobre la base de la reciprocidad y la confianza. Los pequeños agricultores acogen a los trabajadores como huéspedes, atendiendo sus necesidades de alimentación y alojamiento.

Pro

+ Cuando el flujo de dinero en efectivo es limitado se puede solicitar mano de obra adicional.

\section{Contra}

- Acoger trabajadores pueden ser un desafío personal/social.

Fuente: Ashish Gupta, Jaivik Haat. 


\subsection{Insumos materiales para la producción}

\subsubsection{Fertilizantes de fuera de la granja}

Han surgido nuevos modelos de negocio para satisfacer las necesidades de fertilizantes cuando éstos exceden las capacidades de las granjas para producirlos a su interior.

\section{Fertilizantes saludables derivados} de residuos de restaurantes (Colorado, USA)

WasteFarmers es un negocio en Arvada, Colorado certificado por B Corp, que se especializa en la fabricación de fertilizantes saludables para la tierra a partir de residuos recogidos de restaurantes, negocios y colegios. Estos fertilizantes orgánicos se transportan a una "Cervecería de Microbios", donde se compostan y luego se venden a los agricultores. La Cervecería de Microbios y la granja en donde se encuentra sirven como un espacio educativo, y ofrecen visitas anuales a miles de personas de forma gratuita. Sus empleados son recompensados con tiempo pagado en la granja y oportunidades educativas. Las B Corps son entidades con ánimo de lucro, certificadas por la organización sin ánimo de lucro B Lab, para cumplir con rigurosos estándares de desempeño social y ambiental, responsabilidad y transparencia.

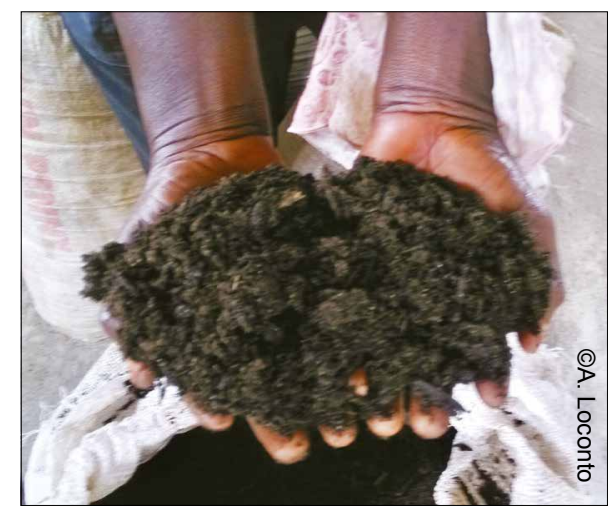

Pro

+ A los pequeños agricultores les resulta difícil crear y gestionar grandes cantidades de compost, incluso si hay biomasa disponible, dado que la mano de obra requerida es exigente. Muy pocas herramientas son asequibles y utilizables por los agricultores. Las empresas que producen grandes cantidades de fertilizantes orgánicos son una solución viable para reducir los residuos urbanos e industriales y para aumentar el uso de compost orgánicos.

+ Crea empleos adicionales en áreas rurales y urbanas.

+ El modelo de empresa responsable y las condiciones laborales ofrecen un modelo comercial equitativo para la sostenibilidad.

\section{Contra}

- Para transportar los desechos y los fertilizantes se necesitan inversiones importantes en infraestructura (por ejemplo, carreteras y grandes plantas de procesamiento).

- Es necesaria la colaboración con los actores públicos para autorizar la compra o donación de residuos que puedan recogerse en edificios públicos y rellenos sanitarios.

Fuente: https://www.wastefarmers.com.

Para saber más, visite: https://www.wastefarmers.com. http://www.bcorporation.net/community/ waste-farmers. 


\subsubsection{Generación de energía en la granja}

Hay una serie de nuevas tecnologías a pequeña escala que están surgiendo para convertir los residuos agrícolas en energía.
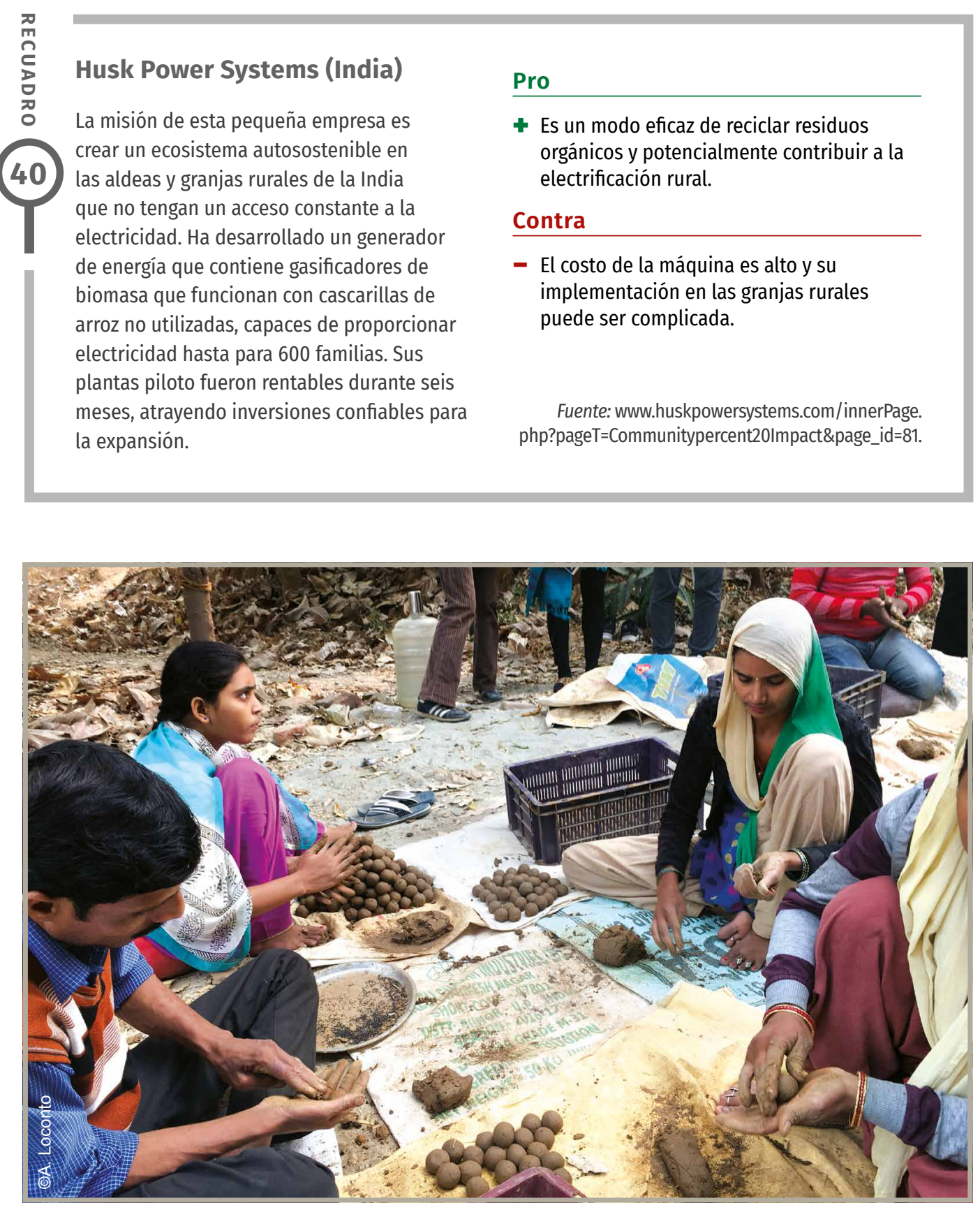


\subsubsection{Intercambios de semillas}

En muchos países, los sistemas formales de distribución de semillas certificadas son dominantes, ya que proporcionan constantemente información sobre la calidad y el uso de las semillas. Sin embargo, muchas variedades que contribuyen a dietas tradicionales (y diversificadas), que resisten a ciertas plagas o sequías, o que se conservan en la granja, no se incluyen en estos sistemas. En todo el mundo se utilizan formas tradicionales de intercambio de semillas y técnicas innovadoras de bancos de semillas.

\section{Seed Mothers (India)}

En Odisha, India, se lanzó una iniciativa para responder al efecto insostenible de los kits de semillas convencionales (semillas certificadas, fertilizantes químicos y pesticidas, pequeñas bombas de riego, máquinas poscosecha y herramientas agrícolas), como lo experimentó una comunidad local de pequeños agricultores.

Un grupo de mujeres tribales conocidas como "madres de semillas" son expertas en la identificación, recolección y multiplicación de semillas. Su sistema consiste en cartografiar la biodiversidad de las pequeñas explotaciones agrícolas de la aldea, e identificar las semillas que son apropiadas para cada granja, garantizando la biodiversidad de los cultivos, multiplicando las semillas, compartiéndolas con otros agricultores, siguiendo procedimientos para la selección de semillas en línea pura. El modelo multiplicativo requiere que las familias cultiven entre 13 y 467 variedades de semillas, incluyendo mijo, legumbres, verduras, arroz con cáscara y tubérculos, todos identificados y guardados por el grupo. Se organizan ferias regulares de intercambio y distribución de semillas con las madres, que ofrecen asesoramiento a los agricultores en cuanto a la elección de semillas, métodos de almacenamiento y manejo de cultivos. Las madres de semillas tratan las semillas como tratarían a sus propios hijos. Como resultado, un total de 5321 hogares han enriquecido sus huertas de patio trasero, produciendo alimentos que están disponibles durante un período de 6 a 11 meses por año. El proyecto pone en duda los supuestos de la agricultura convencional, y fomenta nuevas técnicas de reproducción, orgánicas y participativas.

\section{Pro}

+ La diversidad de variedades aumenta la biodiversidad y la resiliencia del agroecosistema.

+ El intercambio de semillas, en lugar de pagar por ellas, reduce los costos de insumos de los agricultores.

+ Las semillas cultivadas y la variedad de cultivos aumentan la disponibilidad de alimentos durante todo el año, lo que tiene un efecto positivo en la seguridad alimentaria.

\section{Contra}

- Los bancos comunitarios de semillas y los sistemas de intercambio deben estar muy atentos a la calidad de las semillas. Es importante que cada comunidad tenga a alguien bien informado y capaz de mantener la calidad de la semilla.

Fuente: Organization for Rural Reconstruction \& Integrated Social Service Activities (ORRISSA).

Para saber más, visite:

http://www.fao.org/3/a-bl924e.pdf. 


\section{CONSEJO 23}

Cómo crear su propio banco de semillas

- Consulte este manual del facilitador: www.fao.org/fileadmin/user_upload/fao_ilo/pdf/Other_docs/FAO/ Community_Seed_Banks.pdf.
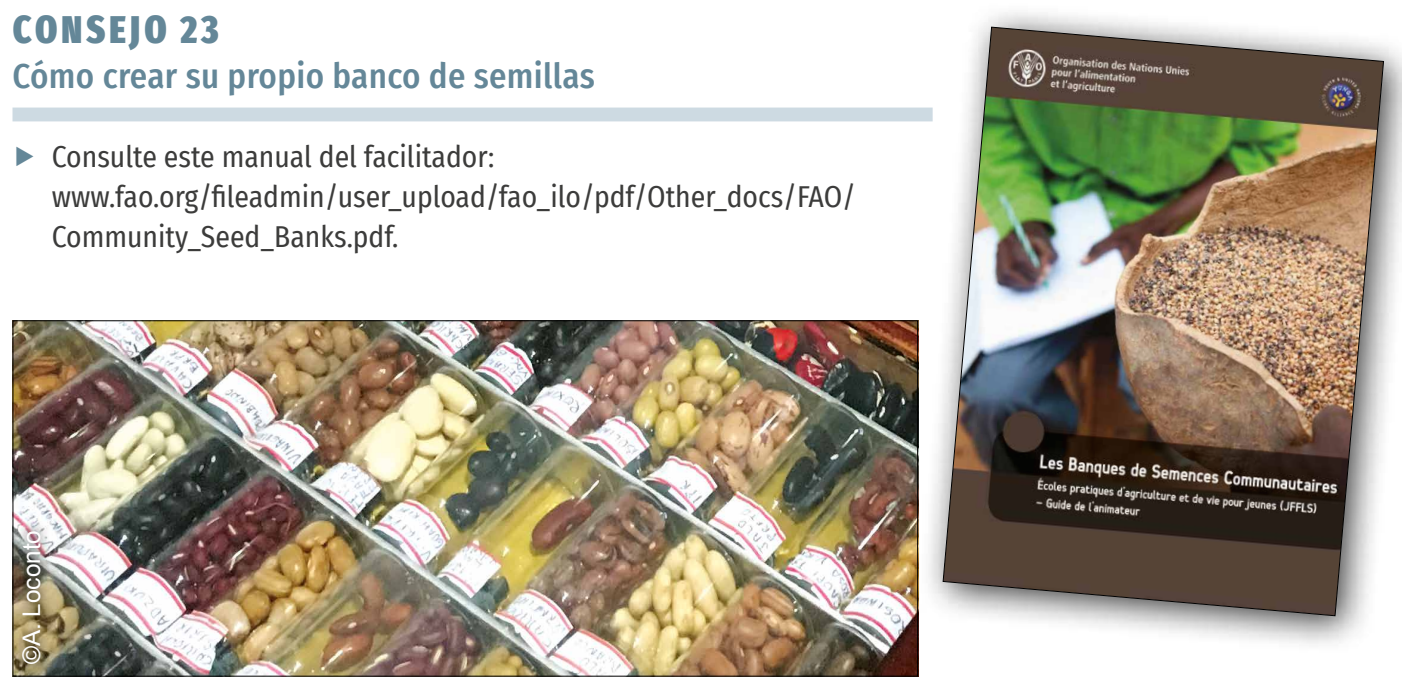

\section{Farm (Kenya)}

Una clave para la agricultura sostenible es el acceso a los mercados vecinos para el inventario, las semillas y las ideas agrícolas. M-farm es un emprendimiento que tiene como objetivo conectar a los pequeños agricultores con sus mercados circundantes, proporcionándoles información sobre los precios en tiempo real. Esta aplicación para smartphone ("app") proporciona información sobre precios de productos en cinco mercados en: Nairobi, Kisumu, Eldoret y Kitale. La app también permite a los agricultores comprar semillas utilizando M-Pesa (el sistema de transferencia de dinero basado en teléfonos celulares de Kenya).

Pro

+ M-farm ayuda a los agricultores a comprar y vender cosechas de manera más eficiente, lo que permite que su práctica agrícola sea más sostenible a largo plazo. Además, la aplicación para smartphone proporciona una valiosa herramienta de comunicación.

\section{Contra}

- Dado que este emprendimiento es relativamente nuevo, la prueba de su sostenibilidad es limitada. Existen muchas aplicaciones similares a M-Farm, y es difícil medir su impacto en la vida diaria de los pequeños agricultores sin aumentar sus costos de insumos. Si bien estas innovaciones son positivas, es fundamental examinar las que funcionan sin aumentar los costos de insumos de los pequeños agricultores.

- El acceso a un smartphone e Internet es obligatorio. La aplicación también está vinculada a M-Pesa, por lo que uno ya debe haberse registrado para ese servicio.

Fuente: Sitio web de M-Farm: https://www.mfarm.co.ke.

Para saber más, visite: https://www.mfarm.co.ke. 


\subsection{Herramientas y máquinas}

Es dificil ser sostenible si todos los aspectos de la producción y el procesamiento se realizan manualmente. Numerosas herramientas y máquinas han ayudado significativamente a mecanizar algunos procesos de producción. A menudo, los problemas a los que se enfrentan los pequeños agricultores están vinculados a las dificultades para acceder al tamaño adecuado de las herramientas. Para que las herramientas sean más accesibles, las siguientes sugerencias pueden ser útiles:

- Crear herramientas y máquinas administradas por la comunidad, compartidas por todos los miembros para reducir el costo de producción.

- Capacitar a los artesanos locales para reparar o modificar el equipo para que se adapte al medio ambiente.

- Crear piezas de repuesto esenciales para los vehículos motorizados o maquinaria que puedan ser de propiedad colectiva de la cooperativa.

- Crear una tienda local de alquiler de equipos, que pueda alquilar maquinaria a pequeña escala u otras herramientas.

- Crear empresas de servicios agrícolas que puedan ser contratadas para arar, remover maleza, inspeccionar o cosechar.

\subsubsection{Tracción animal}

Si su parcela se encuentra en zonas y tierras altas predominantemente semihúmedas/semiáridas, los métodos/insumos de tracción animal pueden ser una inversión valiosa. Sin embargo, la tracción animal es cada vez menos deseable, debido al aumento de la mecanización y las diversas complicaciones asociadas con la salud animal, la capacitación y la adquisición de herramientas adecuadas. Algunas de las ventajas asociadas con este insumo son:

- Cuando se utiliza correctamente, puede aumentar la productividad.

- Es una tecnología de bajo costo y segura para el medio ambiente.

- Se puede comprar localmente.

- No requiere cambios drásticos en los sistemas agrícolas.

- Es muy eficaz para los pequeños agricultores.

- El estiércol producido por el animal es una gran manera de fertilizar el suelo en el campo.

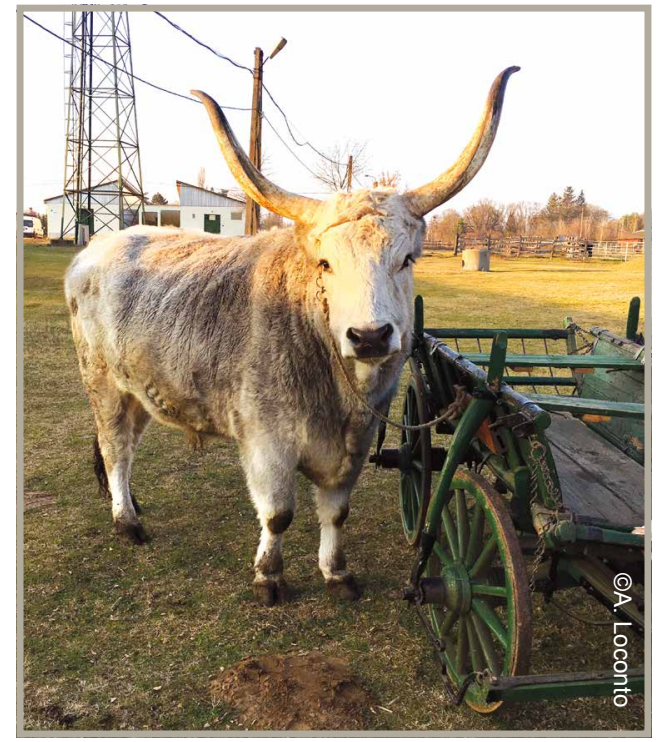




\section{Anicytor, tracción de energía} verde para herramientas agrícolas (Etiopia)

Las herramientas tradicionales no cierran la brecha de conocimientos técnicos/ de ingeniería de los agricultores: todos los agricultores tienen necesidades tecnológicas. El cambio climático tiene repercusiones mundiales, y paisajes enteros están siendo destruidos debido al uso inadecuado de herramientas agrícolas tradicionales y la expansión de tierras agricolas. Para resolver los problemas antes mencionados, el "jalado" de animales se transforma en "pedaleo" animal, lo que da como resultado una tecnología muy eficaz, basada en la energía verde, y que requiere de mucha mano de obra, para los países en desarrollo. Los animales tienen patas potentes: Las patas delanteras son impulsadas por la inercia y la relación de masa corporal, mientras que las patas traseras son más altas y musculares, generando la fuerza necesaria. A medida que el animal camina y pisa, esta energía potencial se transformará en energía cinética. Por lo tanto, al fijar palancas y engranajes a las piernas del animal, el movimiento hacia atrás y hacia adelante/ energía cinética cambiará a una rotación completa (360 grados). Esto significa un motor mecánico que puede mover ruedas y otros instrumentos agrícolas montados, de ahí el nombre científico de "Anicytor": Tractor animal de pedaleo/ciclismo. La innovación es compatible para su uso por cualquier animal de cuatro patas y por los seres humanos. Su tamaño/altura es ajustable al tamaño específico del animal y al propósito de su uso.

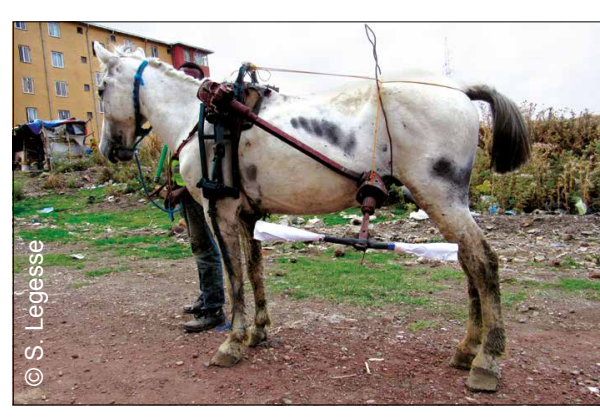

\section{Pro}

+ Dado que no consume combustible, y puede estar compuesto de materiales disponibles localmente, la tecnología puede reducir considerablemente los residuos y la contaminación. Se puede utilizar para la limpieza de las calles.

+ Puede fabricarse con materiales disponibles localmente para reemplazar tractores importados.

+ Dado que la mayoría de los agricultores de los países en desarrollo tienen necesidades tecnológicas, son usuarios objetivo de esta nueva tecnología agrícola.

+ Las oportunidades de empleo se crean haciendo que la agricultura sea interesante y más fácil para la juventud rural, y en la construcción de sus diversas piezas de repuesto, en el montaje, la venta al por mayor, la venta minorista y la prestación de servicios mediante la herramienta.

\section{Contra}

- Necesidad de garantizar que los animales sean tratados adecuadamente cuando lo están usando.

Fuente: Sitotaw Legesse, Sitotaw y Yeshi Engineering Share Cop, Etiopía.

Para saber más, visite: https://agriprofocus.com/profile/sitotaw. legesse.22606. 


\subsubsection{Herramientas manuales para pequeños agricultores}

Los pequeños agricultores trabajan predominantemente de forma manual. Con el tiempo, se han desarrollado herramientas e instrumentos agrícolas para reducir el trabajo pesado, especialmente para las agricultoras. Por ejemplo, en el cultivo del arroz, el trasplante y el desyerbe es una parte esencial del sistema de cultivo. Las mujeres experimentan graves dificultades durante ambos procesos. En las montañas, donde la tierra se trabaja en terrazas y la superficie de tierra adecuada para el cultivo no es uniforme, los desafíos son aún más pronunciados. Por lo tanto, es importante que las herramientas apropiadas - diseñadas ergonómicamente, eficientes en producción y ligeras para transportar - estén disponibles a precios asequibles para los pequeños agricultores.

44

Una empresa en el este de la India elabora herramientas exclusivas para agricultores pequeños y marginales. Hay una serie de herreros y diseñadores de herramientas locales que trabajan a varios niveles locales en todo el país, aunque solo unos pocos utilizan innovaciones de herramientas manuales e innovadoras. La empresa pone a su disposición sus herramientas y sus diseños de forma gratuita. También anima a los artesanos locales a adaptar las herramientas a las condiciones locales, haciendo las herramientas completamente de código abierto. A menudo ocurre que las herramientas diseñadas para condiciones de suelo de arcilla pesada no son adecuadas para suelos arenosos, por lo que el entorno agrícola local debe ser considerado. Entre las herramientas más populares hechas por esta empresa se encuentran las vinculadas al cultivo de arroz como el Cono y el Paddy Weeder, que suelen utilizar los agricultores al aplicar ciertas técnicas, como el sistema de intensificación del arroz. Además, también se utilizan herramientas, como sembradoras múltiples, desmalezadoras de tierras secas y azadones de ruedas con accesorios. Las herramientas son eficaces y asequibles y también se pueden personalizar según las necesidades locales.

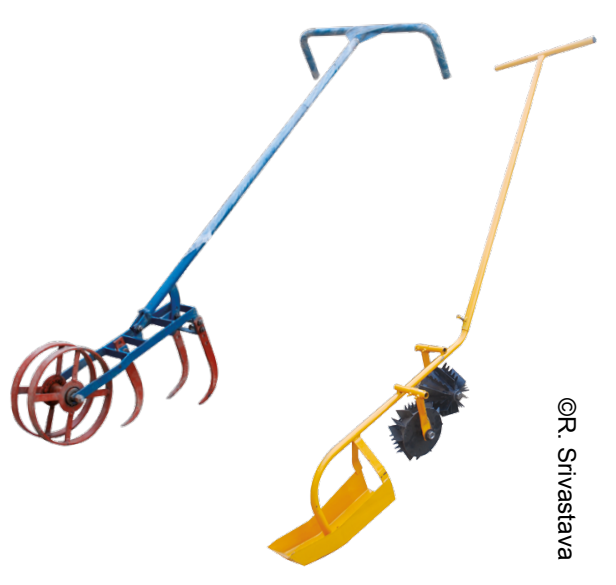

Pro

+ Las herramientas son de código abierto y fácilmente adaptables.

+ Su peso ligero las hace más fáciles de usar por las mujeres.

+ Pueden mecanizar la producción a un costo relativamente bajo.

\section{Contra}

- Todavía son herramientas manuales, lo que significa que se necesita algo de trabajo.

Fuente: Ashish Gupta, Jaivik Haat. 


\section{CONSEJO 24}

Obtener herramientas y/o máquinas sostenibles

- Pruebe la tecnología usted mismo y proponga una opción factible.

- Inicie un proceso participativo que permita a los miembros de la comunidad proponer soluciones.

- Adquiera herramientas en el mercado, aunque esto puede aumentar el riesgo asociado con la calidad, la disponibilidad y el costo.

- Busque tecnologías que se ajusten a sus condiciones climáticas cambiantes y a las implicaciones de los insumos después de la cosecha.

\subsection{Mejora de los servicios biológicos y ecosistémicos}

\subsubsection{Biocarbón para ayudar a construir materia orgánica del suelo}

Aunque es un proceso lento, añadir biocarbón al suelo ayuda a acumular su materia orgánica, lo que resulta en un suelo más fértil y resistente al clima.

\section{Wanakaset Network (Tailandia)}

Un miembro de la Red Wanakaset, P. Yai, destila aceites esenciales de hierbas y frutas.

A medida que los miembros de Wanakaset practican la agrosilvicultura, obtienen una gran cantidad de ramas y palos. P. Yai utiliza una estufa que convierte eficientemente esta biomasa en calor para calentar los tanques de destilación durante las varias horas que se requieren para capturar los aceites esenciales, produciendo muy poco humo.

Green Net procesa marañones orgánicos; primero, al vapor (para abrir las cáscaras), y luego secándolas. Las cáscaras se utilizan para alimentar un horno de biomasa que genera calor y vapor para este proceso, reduciendo así en gran medida la necesidad y el uso de gas natural o electricidad. Algunos molinos de arroz modernos generan energía a partir de la cáscara de arroz. Estas cáscaras se convierten en carbón/ceniza y es utilizada para mejorar el suelo (como biocarbón), o vendida a los fabricantes de chips de computador por su silicio de alta calidad.

\section{Pro}

+ Uso fiable de residuos.

+ Un medio eficiente de reciclar nutrientes de vuelta a los ecosistemas.

+ Fácil de usar para los agricultores, siendo un buen equipo para tener en un sistema agrícola.

\section{Contra}

- Todavía son herramientas manuales, lo que significa que se necesita algo 1. Las estufas de biocarbón más grandes y eficientes pueden ser inaccesibles para los pequeños agricultores debido a las condiciones de costo y mantenimiento. No obstante, muchos agricultores de pequeña escala están produciendo y utilizando con éxito el biocarbón en diferentes formas. En el sudeste asiático, las unidades comunes construidas en casa producen carbón vegetal (usado como combustible), vinagre de madera (usado como biopesticida), y biocarbón (pedacitos pequeños) usado en compost y tierra para materas. de trabajo.

Fuente: Michael Commons, GreenNet. 


\subsubsection{Servicios integrados de manejo de plagas}

Controlar las amenazas externas a los cultivos como plagas, maleza y la sequía es un gran reto. Sin embargo, para evitar el uso de pesticidas y herbicidas, un sistema integrado que "combate la naturaleza con la naturaleza" puede ser una solución viable.

\section{Dudutech (Kenya)}

Dudutech es una empresa que suministra a los agricultores insectos y hongos beneficiosos

para reducir su uso de insecticidas y pesticidas que son típicamente insostenibles y generan estrés en los cultivos. Los paquetes distribuidos contienen ciertos bioinsumos (hongos beneficiosos, insectos, bacterias) que combaten las amenazas externas perjudiciales para los cultivos de manera mutuamente beneficiosa para las plantas y los insectos/ hongos. Un ejemplo de un bioinsumo para combatir la sequía es la micorriza, un hongo que forma una relación simbiótica con las plantas, intercambiando agua y fertilizantes por savia vegetal y azúcares. La micorriza aumenta drásticamente el volumen de raíz efectivo de la planta, reduciendo su estrés y permitiendo que siga creciendo en tiempos de sequía. Dudutech suministra más de 17 agentes de control biológico diferentes, y proporciona paquetes de bioinsumos a los agricultores de Kenya y Sudáfrica.

\section{Pro}

+ Esta empresa ofrece empleo a más de 100 trabajadores calificados en una zona rural agrícola de Kenya.

+ La capacidad de contratar a un experto en Manejo Integrado de Plagas (MIP) para prestar servicios a la granja, proporciona a los agricultores acceso a los conocimientos sobre MIP que puede que aún no tengan.
+ El sitio web de la empresa es muy útil, hace sugerencias sobre qué paquete utilizar para problemas específicos. Por ejemplo, para un caso de mildiú polvoriento, el sitio web aconseja al agricultor que utilice "TRICHOTECH", que es un paquete distribuido por Dudutech para combatir este tipo de mildiú. Este tipo de programa integrado de manejo de cultivos tiene un enfoque holístico que puede tener éxito a largo plazo.

\section{Contra}

- Estos paquetes pueden ser demasiado inasequibles para los pequeños agricultores, ya que la mayoría de los clientes son grandes terratenientes.

- La venta de microorganismos incubados en laboratorios o fábricas significa que hay poco control sobre la calidad del producto final. Las concentraciones microbianas son propensas a tener una vida útil más corta y una menor eficacia a largo plazo. Además, la concentración garantizada por los fabricantes no tiene en cuenta las condiciones locales del suelo, la humedad y los métodos de aplicación de los agricultores. Así pues, en la mayoría de los casos, dado que los productos se aplican utilizando estimaciones medias, sus efectos reales son difíciles de medir.

Fuente: Allison Loconto, INRAE.

Para saber más, visite:

http://www.dudutech.com. 


\subsubsection{Servicios de gestión del ciclo del agua}

Con los efectos del cambio climático, la gestión del ciclo del agua se está volviendo cada vez más dificil. El riego a gran escala a menudo no es factible en muchas zonas del mundo, por lo que los agricultores han optado por soluciones alternativas e innovadoras para recuperar el agua y redirigir su ciclo natural para uso agrícola.

\section{Dos ejemplos de gestión del agua} (Zimbabue, India y República Unida de Tanzanía)

1. Pozos Phiri (Zimbabue): En las zonas propensas a la sequía, una práctica tradicional es construir pozos subterráneos con piedras que puedan filtrar el agua de lluvia y aumentar la capacidad de retención del suelo. En la década de 1960, un tal señor Phiri comenzó a descubrir este sistema practicándolo en su granja con una serie de pozos ubicados en diferentes puntos de esta. El resultado ha sido la resistencia a la sequía a largo plazo.

Para saber más, visite: https://youtu.be/cXLD0akTmrl. https://youtu.be/ieqYZaTOJwA.

2. Bombas de gravedad (India/República Unida de Tanzanía): Las regiones montañosas y de las tierras altas también pueden sufrir escasez de agua debido al flujo de agua natural y descendente dirigido por la gravedad. En la India, los ingenieros tecnológicos de pequeña escala comenzaron a utilizar la gravedad colocando una bomba en un arroyo en el fondo de una colina. La fuerza de la caída de agua choca con el mecanismo de la bomba, que es lo suficientemente resistente para propulsar el agua de vuelta a la colina a través de un tubo que llega a la granja. Esta tecnología también se utiliza activamente en las tierras altas de la República Unida de Tanzanía.

Fuente: Allison Loconto, INRAE.
Pro

+ Estas tecnologías de captura de agua de lluvia pueden ayudar a los agricultores a crear un sistema de riego a pequeña escala y de bajo costo.

+ Los diseños de bomba hidráulica de pistón (la bomba de gravedad más conocida) se pueden encontrar fácilmente en Internet.

\section{Contra}

- Las bombas de gravedad requieren cascada y flujo, lo que significa que no funcionan bien en áreas planas o durante largas temporadas secas.

- Los pozos Phiri requieren mantenimiento. No puede construirlos una vez y olvidarse de ellos; la nueva tierra que cae en ellos necesita ser removida.

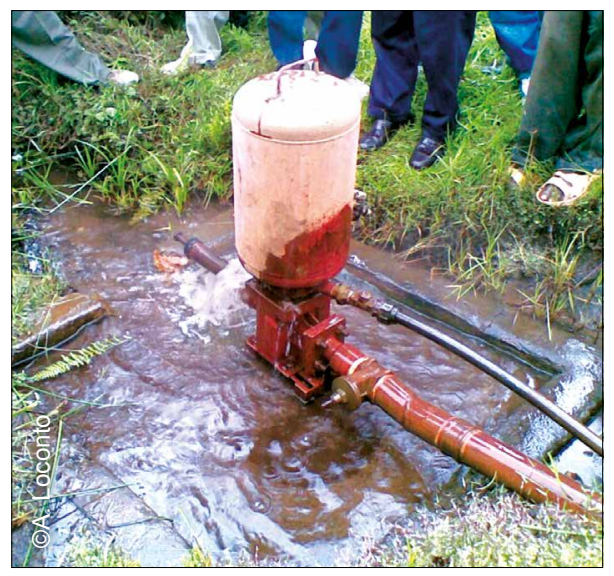




\subsubsection{Insumos de apoyo a la polinización}

En la producción agrícola mundial, los polinizadores proporcionan un servicio esencial al ecosistema. Las interacciones complejas entre especies polinizadoras como abejas, aves, mariposas y murciélagos con especies vegetales son un ciclo valioso que se debe mantener en una granja sostenible. Los agricultores deben mantenerse informados sobre los sistemas de polinización y obtener polinizadores para sus cultivos y agroecosistemas específicos. Por ejemplo, el principal polinizador para los granos de café es la abeja.

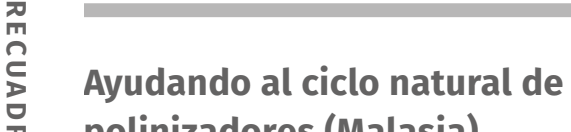 polinizadores (Malasia)}

Participar en el comercio de polinizadores puede alentar y sostener ciclos naturales de polinización en su granja. Implica el transporte de material vivo a los ecosistemas donde normalmente están ausentes. A su vez, esto ayudará a establecer un sistema de polinización que pueda aumentar los rendimientos de los cultivos del campo de forma "gratuita". Por ejemplo, el gorgojo, un escarabajo específico responsable de la polinización de la palma de aceite, se introdujo en África y Malasia, donde la palma de aceite es un cultivo importante. La polinización se realizó manualmente antes de su introducción, y los rendimientos de los cultivos han aumentado considerablemente desde entonces.

\section{Pro}

+ Los servicios de polinización son un "insumo agrícola" esencial que garantiza la producción de cultivos.

+ La mejora de la densidad y la diversidad de los polinizadores repercute directa y positivamente en los rendimientos de los cultivos.

\section{Contra}

- La introducción de nuevas especies siempre conlleva el riesgo de que éstas puedan convertirse en invasoras y desestabilizar el ecosistema. La introducción de nuevos insectos (incluso si son beneficiosos) requiere de un cuidado y atención particulares. Comience buscando especies locales que puedan desempeñar el mismo papel.

\section{Para saber más, visite:} http://www.fao.org/pollination/en.

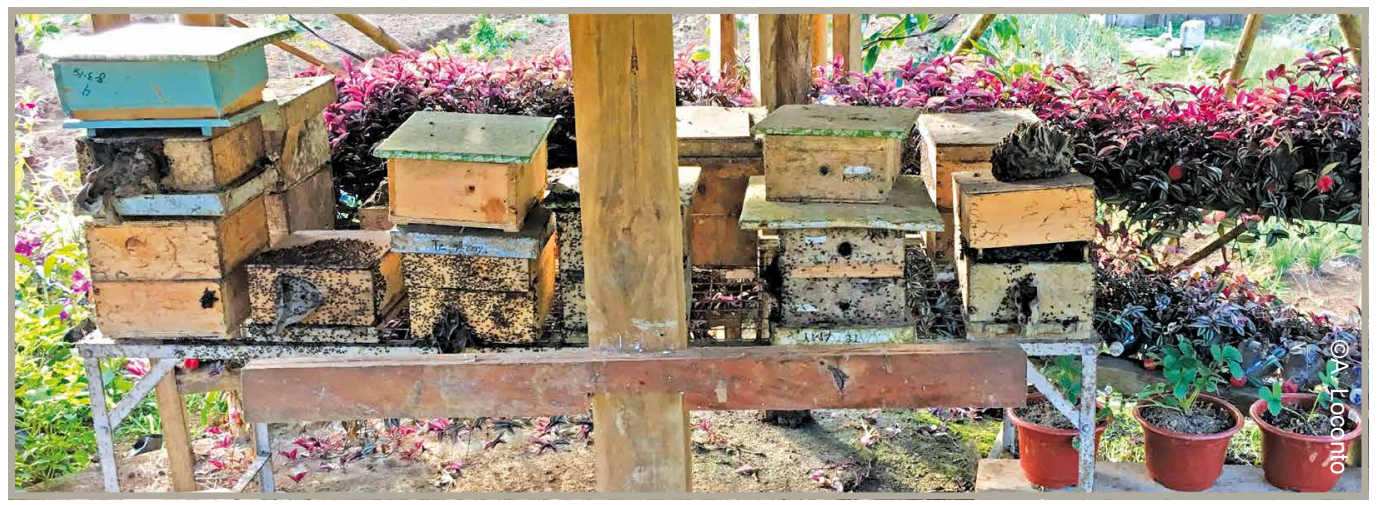




\section{5. ¿CÓMO MANEJA SUS INSUMOS?}

Una vez que entienda sus necesidades de insumos y el alcance de las técnicas o tecnologías emergentes, comience a reflexionar sobre la accesibilidad. ¿Cómo está accediendo actualmente a sus insumos? ¿Cómo gestiona su uso? ¿Cuáles son las opciones alternativas?

\section{LISTA DE VERIFICACIÓN}

Responder a las siguientes preguntas de diagnóstico le ayudará a identificar prácticas que pueden y no pueden ser sostenibles en el tiempo.

1. ¿Cómo está manejando su suelo?

a. ¿Está al día con los pagos, títulos de propiedad o contactos?

b. ¿Tiene que colaborar o negociar con otra persona para garantizar que su uso de la tierra sea sostenible?

2. ¿Cómo está manejando su ciclo de agua?

a. ¿Tiene una fonte natural o tiene que pagar por el acesso?

b. ¿Tiene que colaborar o negociar con otra persona para garantizar que su uso del agua sea sostenible?

3. ¿Cómo está gestionando sus ciclos de nutrientes?

a. ¿Está utilizando fertilizantes sintéticos o biológicos?

b. ¿Los compra, los haces usted mismo, o los intercambia con otros agricultores?

4. ¿Cómo maneja las plagas y las enfermedades?

a. ¿Utiliza productos fitosanitarios sintéticos o biológicos?

b. ¿Los compra, los hace usted mismo, o los intercambia con otros agricultores?

5. ¿Cómo gestiona la mano de obra agrícola?

a. ¿Está usando su propio trabajo (o mano de obra familiar), o contrata a otros?

b. ¿Remunera el trabajo familiar?

c. Si contrata trabajadores, ¿los vincula usted mismo o depende de otros?

d. ¿Está ofreciendo una remuneración justa para sus trabajadores?

6. ¿Cómo gestiona su tecnología y máquinas?

a. ¿Construye sus propias tecnologías/máquinas en la granja o las adquiere externamente?

b. ¿Usted compra, alquila o comparte su tecnología?

c. ¿Cómo mantiene sus máquinas? 
Una vez que usted reflexione sobre estas preguntas, intente llenar la siguiente matriz para determinar por qué usted está abasteciendo sus insumos de personas/lugares específicos.

Cuadro 6: Matriz de origen de insumos

\begin{tabular}{l|l|l|l|l|l}
\hline $\begin{array}{l}\text { Nombre } \\
\text { del } \\
\text { insumo }\end{array}$ & $\begin{array}{l}\text { ¿De dónde } \\
\text { obtiene el } \\
\text { insumo? }\end{array}$ & $\begin{array}{l}\text { ¿Qué porcentaje } \\
\text { es local? }\end{array}$ & $\begin{array}{l}\text { Beneficios } \\
\text { recibidos }\end{array}$ & $\begin{array}{l}\text { Desafios } \\
\text { enfrentados }\end{array}$ & Alternativas sostenibles \\
\hline Urea & $\begin{array}{l}\text { Proveedor de } \\
\text { insumo }\end{array}$ & 100 & $\begin{array}{l}\text { Barato, fácil } \\
\text { acceso }\end{array}$ & $\begin{array}{l}\text { Nitratos } \\
\text { lixiviados } \\
\text { en fuentes } \\
\text { de agua, } \\
\text { disminución } \\
\text { en la salud } \\
\text { del suelo }\end{array}$ & $\begin{array}{l}\text { Comience a reducir el } \\
\text { uso de insumos externos, } \\
\text { primero aplicando estiércol } \\
\text { de ganado, luego probando } \\
\text { si necesita nutrientes } \\
\text { adicionales. Si no tiene } \\
\text { ganado en la granja, vea si } \\
\text { hay una granja de ganado } \\
\text { en su área. }\end{array}$ \\
\hline $\begin{array}{l}\text { Ahora } \\
\text { inténtelo } \\
\text { usted... }\end{array}$ & & & & & \\
\hline
\end{tabular}

\section{CONSEJO 25}

\section{Gestionar y acceder a insumos sostenibles}

- Los insumos en la agricultura sostenible no son sólo adiciones materiales al sistema; también incluyen la tierra, el ecosistema y los servicios humanos que aseguran la producción.

- La opción más sostenible es mantener todos los ciclos naturales dentro de la granja. Si eso no es factible, intente establecer intercambios para reducir los costos de insumos.

- Existen muchas tecnologías adecuadas disponibles que se adaptan a la producción sostenible; el código abierto ayuda a fomentar la experimentación y la innovación.

- Los modelos empresariales innovadores pueden garantizar que el tiempo y la mano de obra, insumos fundamentales en los sistemas sostenibles, sean justos y sostenibles.

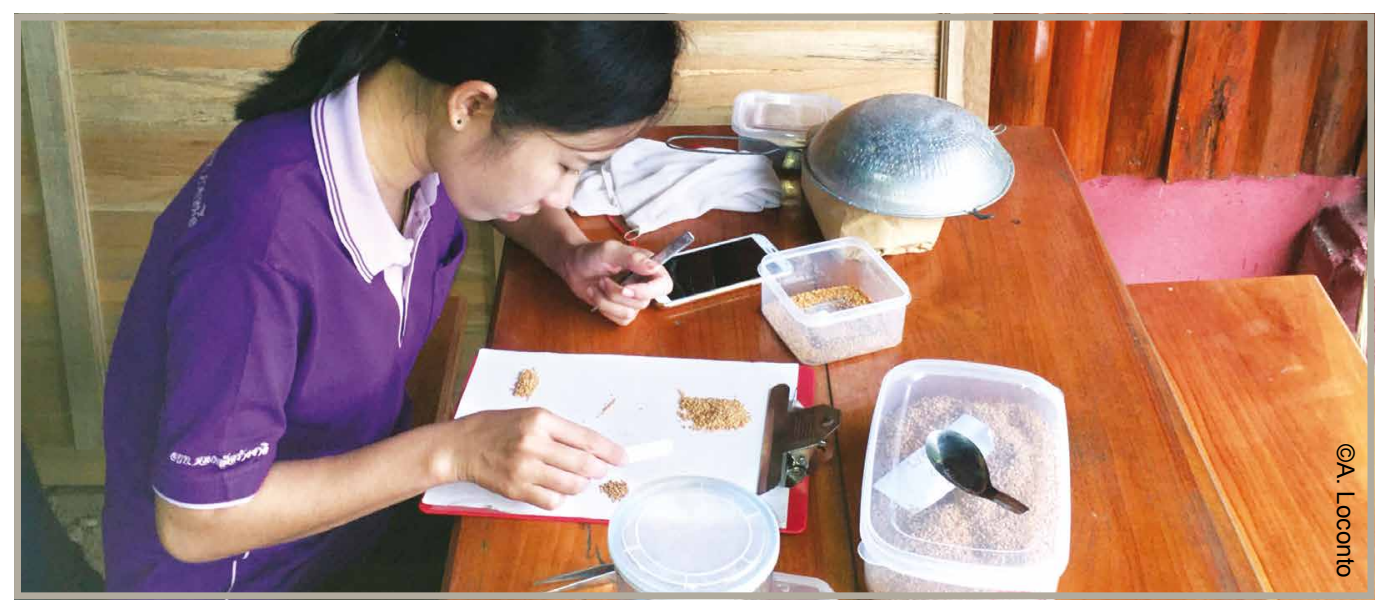




\section{LA AVENTURA DEL APRENDIZAJE, ¿DÓNDE SEGUIR?}

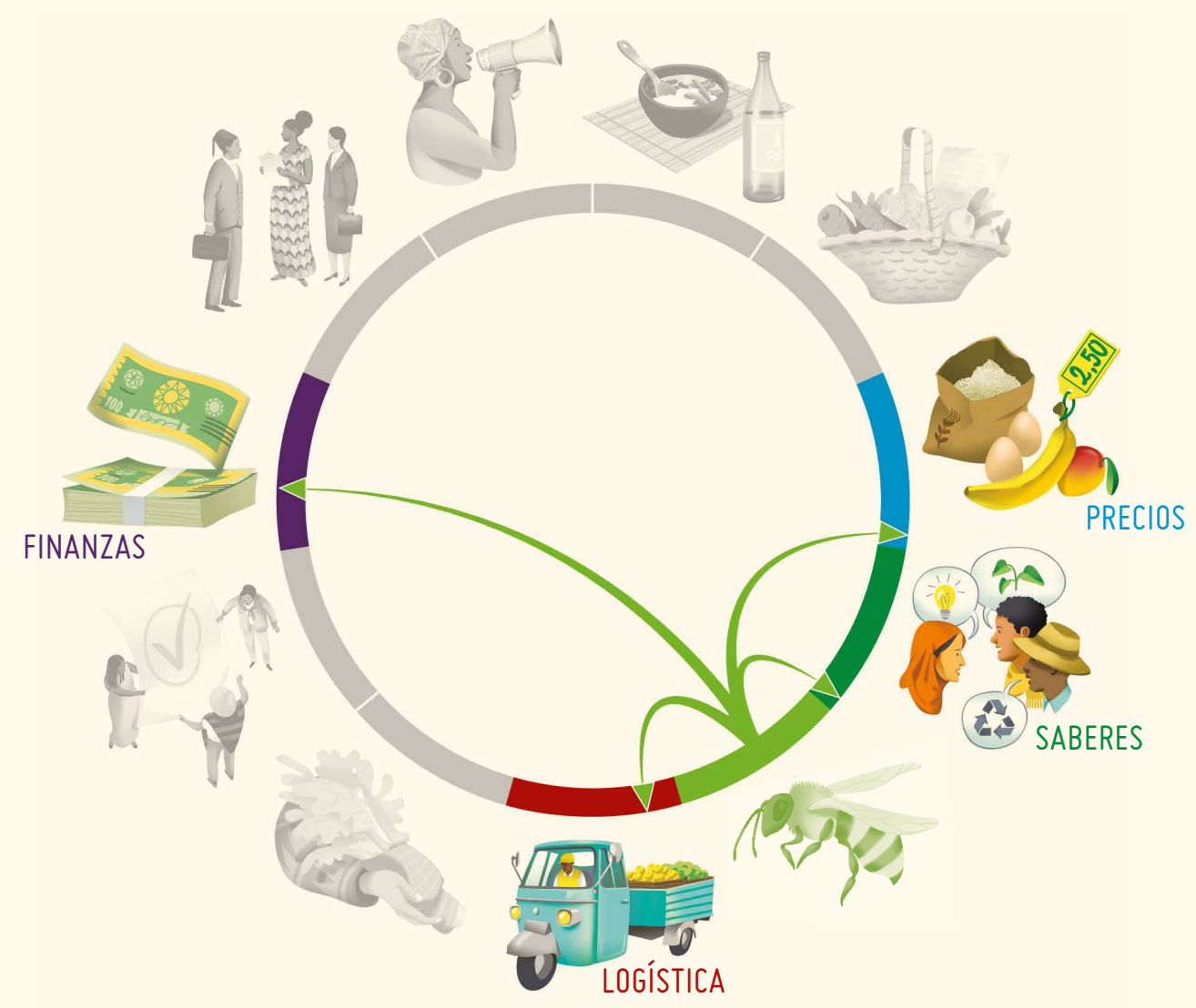

- ¿Creyó que el conocimiento, como insumo, fue excluido del análisis? No se preocupe, éste se trató en el Capítulo 4: Compartir y cocrear conocimientos para una producción sostenible.

- Si no puede producir todos sus insumos en la granja, es posible que tenga que comprarlos. ¿Necesita ideas sobre mecanismos de financiación innovadores? Vaya al Capítulo 9: Financiamento innovador.

- ¿Quiere tratar de reciclar residuos orgánicos fuera de la granja a biogás o compost? Lea el Capítulo 6: Manténgase conectado a través de la logística.

- ¿Está produciendo más insumos materiales de los que puede utilizar y quiere venderlos a otros agricultores? Capítulo 3: Encontrar el precio "correcto" puede ofrecer una idea útil.

0 visite otro capítulo... ¡depende de usted! 


\section{COMERCIALIZACIÓN DE PRODUCTOS}

MANTÉNGASE CONECTADO A TRAVÉS DE LA LOGISTICA

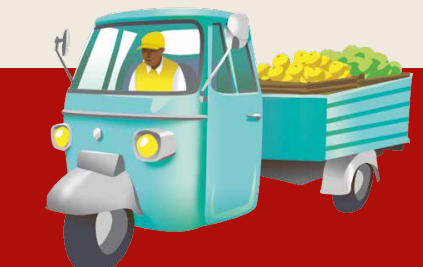

EMBALAJE SOSTENIBLE

GARANTÍAS PARA
LA SOSTENIBILIDAD

En este grupo de capítulos, exploramos cómo navegar a través de las actividades intermedias que aseguran que los alimentos producidos de manera sostenible lleguen a los consumidores.

Nos centramos en la logística, el ambalaje y las garantías; todos ellos añaden valor a los productos sostenibles, pero también deberían ser sostenibles.

Si estos son algunos elementos que usted requiere, intente comenzar su aventura aquí. 



\section{1. ¿POR QUÉ ESTO ES IMPORTANTE?}

Si bien puede tener un gran producto que llegue a sus clientes (ya sean consumidores o procesadores) en buen estado, con los estándares de calidad acordados y en el tiempo de entrega, la logística es el elemento clave para construir relaciones de mercado sólidas y sostenibles.

Los requisitos son los mismos para la gestión de subproductos derivados de la agricultura sostenible, que luego deben ser transformados en productos secundarios de valor agregado.

Por último, los residuos deben gestionarse. Los desechos orgánicos se pueden convertir en insumos agrícolas o se pueden utilizar como fuente de energía (biogás). Los residuos no orgánicos son reutilizables siempre que sea posible (por ejemplo, botellas de vidrio), o reciclables si se dispone de la infraestructura local.

Una logística bien estructurada y consistente es sustancialmente valiosa para los compradores y distribuidores que buscan asegurar un suministro constante a los consumidores. Además, la logística también es beneficiosa para los productores, ya que la racionalización de los obstáculos logísticos dentro de un sistema de producción sostenible genera un mayor valor agregado, reduce los costos y fomenta la sostenibilidad general.

Sin embargo, la gestión logística es difícil, iy la sincronía es fundamental! Entre los principales problemas, cabe mencionar la definición de las necesidades logísticas y la reducción al mínimo de los costos necesarios para satisfacer esas necesidades. ¿Qué significa esto?

El siguiente cálculo le ayudará a determinar la logística:

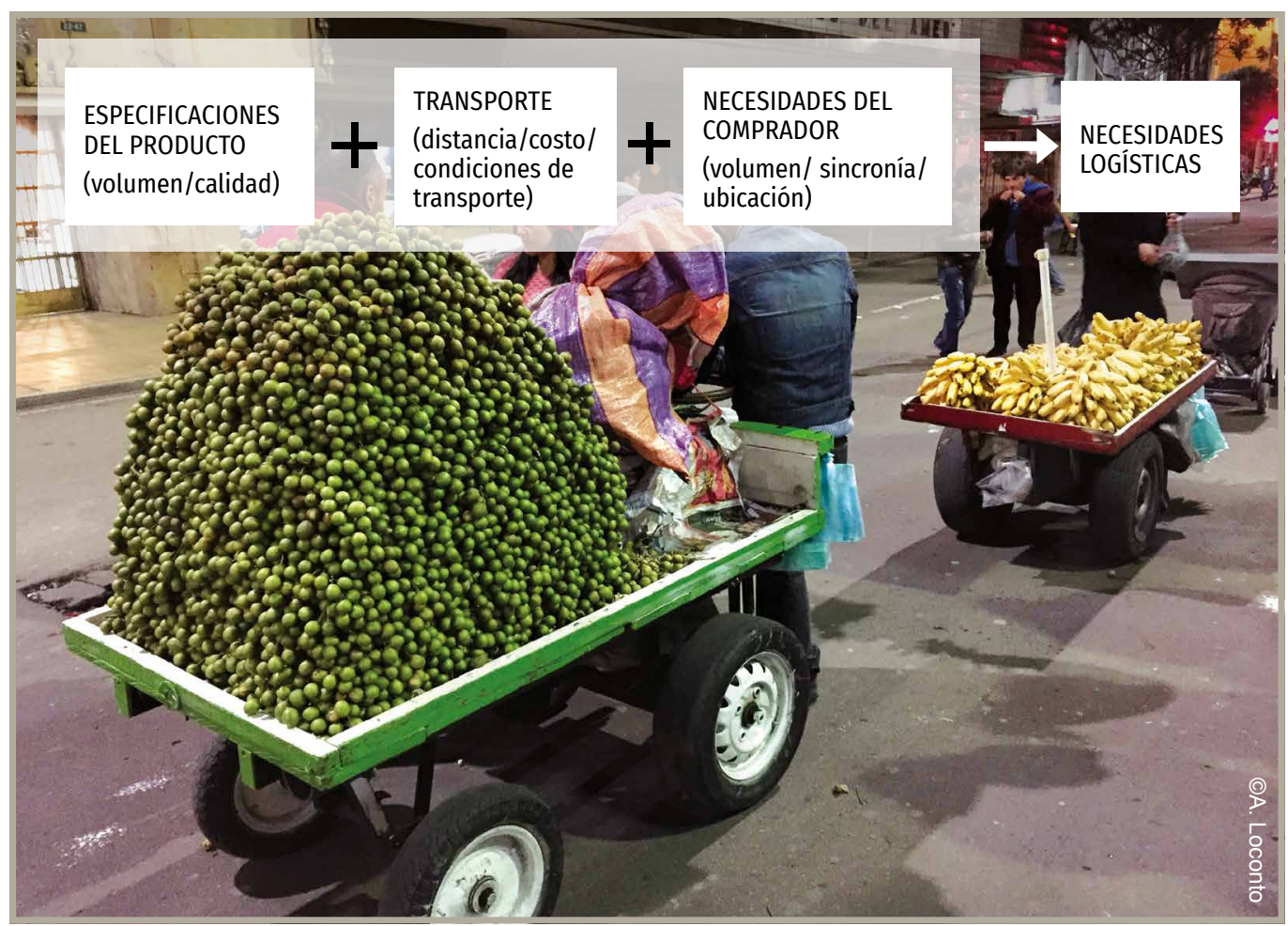


Basándose en los productos que tiene, pregúntese:
1. ¿Son?
¿Con quiénes está intercambiando?
¿Qué está buscando su comprador?
1. ¿Perecederos?
2. ¿Para
consumidores
individuales
o clientes
mayoristas?
1. ¿A qué distancia están?
2. ¿Ofrecen transporte, o usted necesita organizarlo?
1. ¿Tiene la cantidad y calidad adecuadas?
2. ¿Cuándo necesitan ellos los productos? ¿Tienen un horario flexible?
3. ¿Cuáles son las condiciones de transporte? Por ejemplo, ¿necesita almacenamiento en frío o tipos especiales de cajas?
3. ¿Puede llegar fácilmente a su ubicación utilizando el transporte normal?

Si usted ha respondido a estas preguntas, entonces está listo para crear un plan de logística simple.

\section{2. ¿CÓMO EMPEZAR CON UN PLAN DE LOGÍSTICA?}

La logística empresarial normalmente cubre todo el ciclo del producto, desde la producción (y/o el procesamiento) hasta la venta. Por lo tanto, pueden incluirse actividades relacionadas con la compra, almacenamiento, inventario y/o transporte. Para ser sostenible, el plan logístico también debe tener en cuenta los flujos circulares de subproductos y los flujos atrasados de desechos.

La ejecución suele estar determinada por el contexto local, por el capital humano (por ejemplo, cultura, habilidades y costos) y por el entorno

Recuerde: ¡un plan que es difícil de ejecutar es un mal plan! empresarial y jurídico. Por lo tanto, no existe un único plan para todas las situaciones, y los planes deben optimizarse y revisarse periódicamente.

Para empezar con un plan de logística, comience rellenando, paso a paso, el siguiente cuadro con sus propios productos.

\begin{tabular}{|c|c|c|c|}
\hline Los pasos & Arroz & Vegetales & $\begin{array}{l}\text { Mi producto } \\
\text { (llene esto en } \\
\text { usted mismo) }\end{array}$ \\
\hline $\begin{array}{l}\text { (a) Comience con el } \\
\text { diagrama de flujo de } \\
\text { producción/operación } \\
\text { que indica todos los } \\
\text { pasos operativos, las } \\
\text { personas involucradas } \\
\text { y las tareas principales. }\end{array}$ & $\begin{array}{l}\text { Cultivo y cosecha de arroz } \\
\text { recolección de arroz } \\
\text { almacenamiento de arroz } \\
\text { molienda }>\text { empacado } \\
\text { entrega a los consumidores }\end{array}$ & $\begin{array}{l}\text { Cultivo y cosecha de vegetales } \\
\text { centro de recogida } \\
\text { almacenamiento }>\text { lavado y } \\
\text { corte } \triangleright \text { empacado }>\text { entrega } \\
\text { a los consumidores }\end{array}$ & \\
\hline
\end{tabular}




\begin{tabular}{|c|c|c|}
\hline $\begin{array}{l}\text { (b) Llene el número } \\
\text { de personas, espacio, } \\
\text { tiempo, equipo y costos } \\
\text { unitarios necesarios } \\
\text { para cada paso. }\end{array}$ & $\begin{array}{l}\text { - La molienda es realizada } \\
\text { por un contratista } \\
\text { privado, que requiere un } \\
\text { mínimo de } 5 \text { toneladas } \\
\text { de arroz, produciendo } \\
\text { aproximadamente } 3.5 \\
\text { toneladas de arroz molido. } \\
\text { - El camión puede transportar } \\
\text { un máximo de } 1 \text { tonelada } \\
\text { (establecido por la } \\
\text { normativa local). } \\
\text { - La tarifa del camión es de } \\
\text { USD } 200 \text { por trayecto. } \\
\text { - Al empacar arroz en la } \\
\text { empresa, el espacio puede } \\
\text { almacenar alrededor de } 2 \\
\text { toneladas. }\end{array}$ & $\begin{array}{l}\text { - Recibir } 100 \text { kg de verduras el } \\
\text { jueves por la tarde. } \\
\text { - Se necesitan diez personas } \\
\text { para hacer el corte y } \\
\text { empacado, con costos de } \\
\text { USD } 2 \text { por hora. } \\
\text { - Se necesitan cuatro horas } \\
\text { para el corte y el empacado } \\
\text { - Se necesitan dos horas } \\
\text { para la entrega a los } \\
\text { consumidores. } \\
\text { - Los compradores } \\
\text { (consumidores) quieren } \\
\text { recoger las verduras a las } \\
\text { 17:00 horas en la ciudad. }\end{array}$ \\
\hline $\begin{array}{l}\text { (c) Asegúrese de que la } \\
\text { logística tenga sentido, } \\
\text { pregúntese a sí mismo: } \\
\text { "¿encaja todo?" }\end{array}$ & $\begin{array}{l}\text { - Uno de los camiones está } \\
\text { medio lleno, por lo tanto, los } \\
\text { costos son más altos. } \\
\text { - No hay suficiente espacio } \\
\text { para almacenar el arroz } \\
\text { molido. }\end{array}$ & $\begin{array}{l}\text { - La entrega no se pudo hacer } \\
\text { a tiempo el jueves. }\end{array}$ \\
\hline $\begin{array}{l}\text { (d) Considere otras } \\
\text { opciones y sus } \\
\text { implicaciones, confirme } \\
\text { la viabilidad de una } \\
\text { nueva configuración } \\
\text { logística. }\end{array}$ & $\begin{array}{l}\text { - Opción 1: negociar con el } \\
\text { molino de arroz para reducir } \\
\text { el mínimo a } 2.8 \text { toneladas de } \\
\text { arroz (1.9 toneladas de arroz } \\
\text { molido), pero los costos de } \\
\text { molienda serían más altos. } \\
\text { - Opción 2: encontrar espacio } \\
\text { de almacenamiento } \\
\text { adicional por } 1.9 \text { toneladas } \\
\text { cerca de la empresa, pero } \\
\text { usted necesita pagar el } \\
\text { alquiler y los costos de } \\
\text { mano de obra para cargar y } \\
\text { descargar dos veces, y luego } \\
\text { aumentar el volumen de } \\
\text { molienda a 5.6 toneladas } \\
\text { (resultando en } 3.9 \text { toneladas } \\
\text { de arroz molido). }\end{array}$ & $\begin{array}{l}\text { - Opción 1: pedirles a los } \\
\text { agricultores que entreguen } \\
\text { antes, a las 10:00 horas del } \\
\text { jueves por la mañana; los } \\
\text { agricultores deben comenzar } \\
\text { a cosechar a las 05:00 horas. } \\
\text { - Opción 2: aumentar el } \\
\text { número de trabajadores a 20, } \\
\text { reduciendo así a la mitad el } \\
\text { tiempo asignado al corte y } \\
\text { al empaque, pero los costos } \\
\text { laborales aumentan; } \\
\text { - Opción 3: pedir a los } \\
\text { agricultores que cosechen } \\
\text { el miércoles por la noche y } \\
\text { entregar en el mismo día, } \\
\text { pero se necesitaría tener } \\
\text { almacenamiento en frío de } \\
\text { un día para otro. }\end{array}$ \\
\hline $\begin{array}{l}\text { (e) Cualquier cosa } \\
\text { que pueda salir mal, } \\
\text { saldrá mal. Por lo } \\
\text { tanto, su cálculo debe } \\
\text { incluir un margen } \\
\text { de error, o factor de } \\
\text { seguridad, o un plan de } \\
\text { contingencia. }\end{array}$ & $\begin{array}{l}\text { - El espacio de } \\
\text { almacenamiento debe ser } \\
\text { un } 10 \% \text { más grande de lo } \\
\text { planeado para permitir } \\
\text { flexibilidad. }\end{array}$ & $\begin{array}{l}\text { - Al pedir verduras de los } \\
\text { agricultores, debe agregar } \\
\text { un } 5 \%-10 \% \text { más de lo que } \\
\text { realmente se necesita. }\end{array}$ \\
\hline
\end{tabular}

A menudo se supone que el producto determina la logística, pero esto no siempre es cierto. En algunos casos, la logística (principalmente los costos y la distancia al mercado) determina a los productos. Asegúrese de considerar esto a medida que desarrolla su plan. 


\section{3. ¿QUIÉN GESTIONA LA LOGISTICA?}

Algunos productores establecieron una estantería en su granja para vender directamente a los consumidores. En algunos modelos, en particular para ciertas frutas, los clientes son invitados a la granja a cosechar sus propios productos a un precio más bajo (autoservicio). Sin embargo, la mayoría de las veces, los agricultores necesitan transportar productos a otro lugar, como un mercado de agricultores, un hotel, un restaurante, una escuela, un centro de distribución de supermercados, un punto de recogida de una ASC, la casa de un comprador o a un almacén para seguirlos transportando a través del país o al extranjero.

Este proceso requiere de logística y de un intermediario transparente. Si bien existen intermediarios inescrupulosos, en particular en las cadenas de suministro no organizadas, los intermediarios transparentes desempeñan un papel importante en la recogida y entrega de los productos de los agricultores a sus mercados; un servicio que, sin embargo, incluye gastos generales (transporte/ almacenamiento/ reempacado) y riesgos potenciales (pérdidas/ daños/ imposibilidad de vender). Los agricultores pueden recibir un precio más bajo si involucran a un intermediario. No obstante, el precio del productor no suele incluir los costos logísticos de transporte, almacenamiento o riesgo.

Un camino posible es que la iniciativa desarrolle las habilidades, y encuentre el equipo para gestionar esto de manera autónoma (para convertirse en el intermediario transparente), pero a menudo no es la mejor opción ni la más fácil. Para volúmenes pequeños, usar su propio camión puede costar más que pagarle a una compañía de logística para que le transporte sus productos. Los compradores a granel, e incluso los grupos de consumidores interesados, pueden tener el equipo y la capacidad de recoger los productos de la granja, lo que ahorra esta inversión y desafío. Mientras, los agricultores puedan producir en una calidad y volúmenes consistentes que se ajusten a las necesidades de los compradores y, en particular, si tienen productos ecológicos exclusivos, estarán en una posición más sólida para negociar y obtener ganancias justas por lo que ofrecen.

\section{Encontrándose en el medio,} convirtiendo la desventaja en ventaja (República Democrática

\section{(49) Popular Lao)}

Xaobaan es una empresa pequeña y socialmente comprometida con base en Vientiane, República Democrática Popular Lao, que produce yogur natural y productos lácteos de alta calidad. Tratando de integrar a grupos más marginados, la gerente, la señora Nongnut Foppes Ayamuang, vinculó a miembros de la comunidad de sordos, que actualmente manejan toda la logística diaria y entregan productos a diferentes puntos de distribución, a menudo en motocicleta. Cuando se trabaja en zonas ruidosas, su audición limitada y su capacidad para comunicarse a través del lenguaje de signos es una ventaja. Los servicios de mensajería para teléfonos móviles les permiten comunicarse fácilmente con otras personas que no hablan el lenguaje de señas. Lo que podría haber sido considerado un impedimento laboral, se considera estratégicamente beneficioso para sus operaciones.

Fuente: Michael Commons, Earthnet Foundation, Tailandia. 


\section{PROBLEMAS LOGÍSTICOS}

\subsection{Almacenamiento}

Una norma básica para la logística es "menos trabajo, menos problemas". Es ideal elegir un plan de logistica que no requiera de almacenamiento.

Sin embargo, el almacenamiento es esencial para los insumos (por ejemplo, semillas, plántulas y fertilizantes orgánicos), las materias primas (por ejemplo, arroz con cáscara), los productos semiprocesados (arroz molido, pero sin empacar) y los productos acabados (por ejemplo, arroz empacado listo para vender a los consumidores). A veces, se opera a nivel comunitario con un depósito de almacenamiento público, aunque a menudo es manejado por un intermediario o grupo de productores. ¡Tenga en cuenta las opciones disponibles en su área local!

A continuación, se enumeran los factores que se deben tener en cuenta al gestionar el almacenamiento:

- Cantidad: Además de la necesidad de tener suficiente área de almacenamiento para albergar su volumen de producción, algunos productos, especialmente las materias primas y los productos semiprocesados, pueden perder peso cuando se almacenan debido a plagas, pérdida de humedad y deterioro con el tiempo. Tenga en cuenta estos elementos cuando establezca el espacio de almacenamiento para minimizar las pérdidas.

- Calidad: Diferentes productos requieren diferentes condiciones de almacenamiento. Por ejemplo, ciertas verduras pueden necesitar temperaturas y niveles de humedad particulares, mientras que otros productos (por ejemplo, café, té) absorben la fragancia y el olor del entorno. La buena gestión del almacenamiento debe tener en cuenta las características individuales del producto.

- Inventario: Hay algunos elementos a considerar cuando se piensa en el inventario, tales como:

- la regla de "primero en entrar, primero en salir";

- ¿quién está autorizado para sacar los productos del almacenamiento?

- ¿quién controla el control del inventario? A menudo, el inventario se ignora completamente o se regula en exceso. Encuentre un nivel adecuado de funcionamiento.

Costos: Para ser sostenibles, las empresas requieren reducir los costos de mantenimiento mediante la eficiencia y la eficacia. Los costos de almacenamiento pueden incluir varios puntos. Considere algunos ejemplos de costos de almacenamiento:

- los costos iniciales de inversión, es decir, la compra y la construcción de las instalaciones de almacenamiento;

- costos de depreciación (especialmente para fines contables);

- costos de mantenimiento, es decir, para la reparación de techos, paredes y/o maquinaria.

- electricidad y servicios, por ejemplo, el almacenamiento en frío necesita un aire acondicionado funcionando 24 horas, los 7 días de la semana y 365 días al año,

- limpieza regular,

- servicios de control de plagas,

- estanterías o bastidores,

- mano de obra para descarga, y

- personal de control de inventario. 


\subsection{Elaboración artesanal 0 a pequeña escala}

Una regla básica que no se aplica a la logística es " a más procesamiento, menos problemas".

Existe una diferencia entre el transporte de productos frescos y productos semiprocesados o totalmente procesados. Al procesar algunos productos en la granja o en los puntos de recogida locales, puede ampliar la vida útil de estos y transportarlos a distancias más largas. Estos tipos de actividades de valor agregado también pueden generar precios más altos para los productores. El procesamiento puede depender de equipos industriales o modernos, aunque requeriría de una gran inversión de capital inicial. El procesamiento tradicional o artesanal puede ser igual de eficaz si se cumplen las normas de higiene y seguridad alimentaria. El procesamiento artesanal también puede ofrecer oportunidades de comercialización, ya que usted puede reclamar el atributo de "hecho a mano", "tradicional" o "artesanal" que algunos consumidores prefieren.

\section{Elaboración de arroz parbolizado en el Centro Songhai (Benin)}

50

El Songhai Centre de Benin, un centro de formación y producción juvenil está organizado como eje y portavoz de innovación, que permite el procesamiento de productos a través de su red. En un eje central de Porto Novo, el moderno equipo de procesamiento embotella agua de manantial y jugo de fruta, $y$ produce y envasa palomitas de maíz, galletas y pasabocas salados. Una panadería en el lugar prepara pan y pasteles, un humero cura las carnes, y los molinos procesan aceite de soya y arroz empacado.

Este eje central obtiene sus materias primas de su propia granja y criadero de peces, y de los cinco satélites regionales que se encuentran en diferentes áreas agroecológicas. Cada satélite, que también es un centro de capacitación, bien se autoabastece de productos, o los obtiene de sus exestudiantes, que ahora tienen sus propias granjas en la vecindad. Los agricultores llevan sus productos a centros regionales, donde se procesan como mangos secos y pasta de mango. Los residuos de harina de los molinos se mezcla con otros materiales para producir alimento para ganado. Utilizando métodos artesanales, estos centros producen jugos de frutas y pasabocas, una parte de los cuales se vende en el estand de la misma granja.
Songhai organiza un programa de formación de técnicos en su Departamento de Maquinaria. Los técnicos desarrollan y fabrican todo tipo de máquinas adaptadas a las necesidades locales y a diversos productos (arroz, aceite de palma, jugo de fruta, aceite de semilla de palma, gari [de tubérculos de yuca], alimentación animal y secado, entre otros). Estas máquinas también están disponibles para la venta a un precio reducido y asequible, por lo que son adquiribles por otras personas que desean impulsar su producción y sistemas de procesamiento primario. Para el procesamiento de arroz, Songhai posee camiones que viajan entre los satélites y el centro, recogiendo productos crudos y entregándolos procesados. El arroz, por ejemplo, se transporta desde los satélites a Porto Novo para que sea parbolizado, secado al sol y luego empacado utilizando bolsas estandarizadas y etiquetadas, que son vendidas en el país o exportadas. El parbolizado es fácilmente procesable, sin la necesidad de maquinaria moderna, y el precio en el mercado final es considerablemente más alto debido a su menor tiempo de cocción.

Fuente: Allison Loconto, INRAE y Belvue Akpatcho, Centre Songhai, Benin http://www.songhai.org/index.php/en/homeen/16-songhai/191-biotransformation-en. 


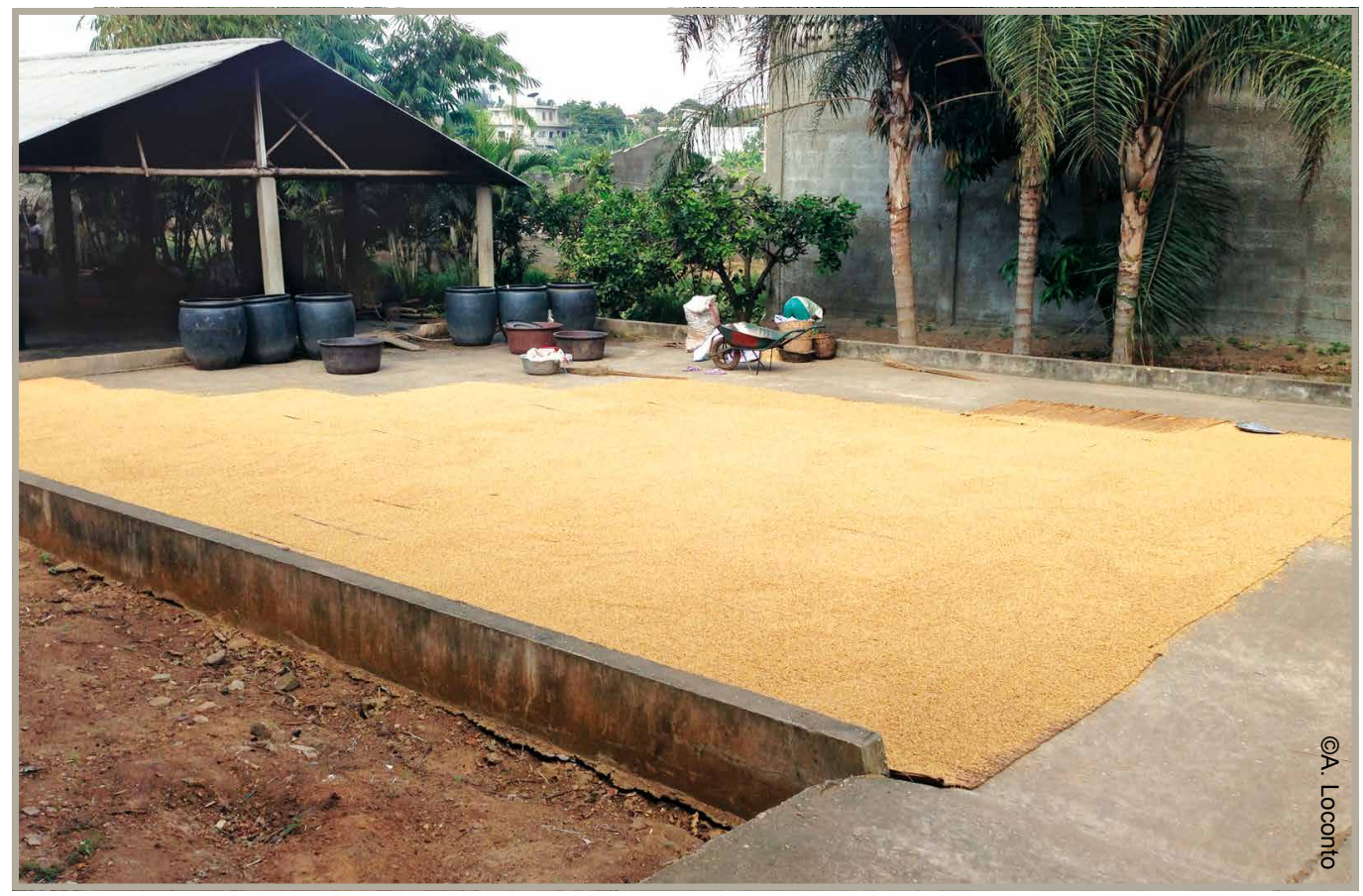

\subsection{Transporte y entrega}

Una vez más, se aplica la regla básica para la logística: "menos transporte, menos problemas".

Además, los factores que influyen en la gestión del transporte son similares a otros problemas logísticos, ya que se trata de una forma de almacenamiento temporal. Otros factores a considerar son el camión, el conductor y el tráfico.

Para un emprendimiento, a menudo es mejor utilizar servicios especializados de entrega y transporte tanto como sea posible. No se necesita una inversión inicial, y los costos suelen ser más bajos para pequeñas cantidades. Una vez que las cantidades aumentan, se necesitan opciones más sostenibles.

Al considerar la sostenibilidad absoluta (a lo largo del ciclo de vida del producto y a lo largo de todo el sistema alimentario), elija servicios de entrega que requieran menos energía fósil, por ejemplo, con una preferencia por orden: bicicleta, tren, barco, vehículos eléctricos o híbridos, o camión. Trate de compartir el transporte tanto como sea posible para maximizar el espacio y reducir el número de viajes necesarios (por ejemplo, compartir el automóvil o un espacio de carga en los camiones). Asegúrese de que sus decisiones también tengan en cuenta su ubicación final en el mercado. Cuando esta opción no es factible, se hace necesario disponer de los medios de transporte propios. En esta situación, calcular adecuadamente los costos de transporte y su huella de carbono asociada es fundamental para el éxito empresarial. 
Ecovida es una red de 4.500 familias que venden productos agroecológicos en cuatro estados del sur de Brasil. Su red de distribución abarca más de $1.600 \mathrm{~km}$. Semanalmente, los agricultores llevan sus productos a un centro (núcleo) administrado por un agricultor. Cada administrador de núcleo envía un mensaje a través de WhatsApp a los demás administradores, informándoles de las cantidades presentes de productos y de los pedidos entrantes. Por ejemplo, un centro tiene $10 \mathrm{~kg}$ de naranjas y $20 \mathrm{~kg}$ de bergamotas, y busca $5 \mathrm{~kg}$ de plátanos, $1 \mathrm{~kg}$ de marañones y $10 \mathrm{~kg}$ de arroz. Otro administrador de centro puede tener $15 \mathrm{~kg}$ de arroz y $10 \mathrm{~kg}$ de marañones, y necesita $5 \mathrm{~kg}$ tanto de naranjas, bergamotas y plátanos.

Los pedidos se realizan y la ruta del camión se determina en consecuencia, deteniéndose primero en el centro 1 para recoger las naranjas, el centro 2 para recoger el arroz y los plátanos y dejar las naranjas, y el centro 3 para recoger/dejar otros productos. En el camino de vuelta, los plátanos, las nueces y el arroz se entregarán al centro 1.

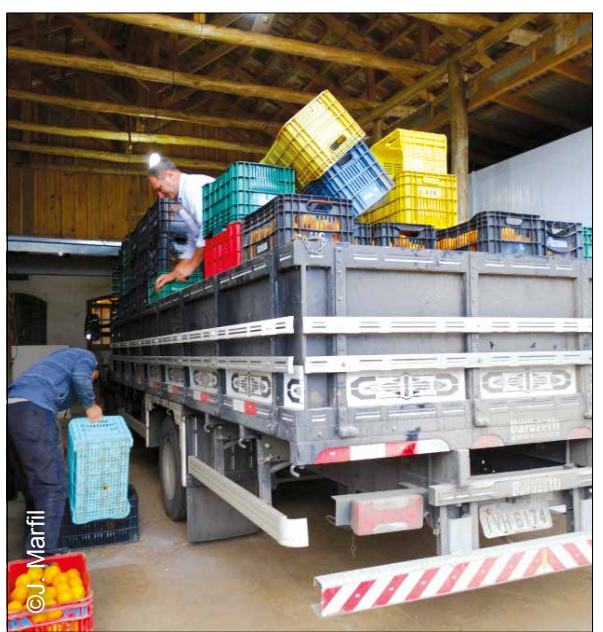

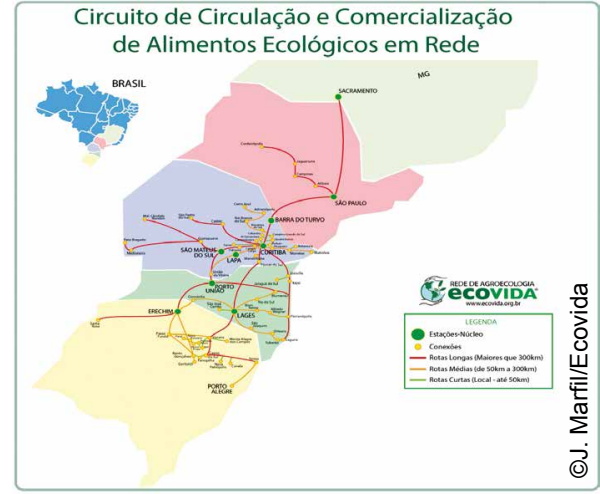

Todos los camiones deben ser propiedad de un agricultor-miembro de Ecovida, no hay distribuidores externos para manejar el transporte.

Los precios también se negocian para todos los productos comercializados semanalmente. También se añaden los costos fijos de transporte: BRL $0.30 / \mathrm{kg}$ para trayectos cortos y BRL $0.60 / \mathrm{kg}$ para trayectos largos (por ejemplo, Curitiba a São Paulo).

Fuente: José Antonio da Silva Marfil, Ecovida, Brasil.

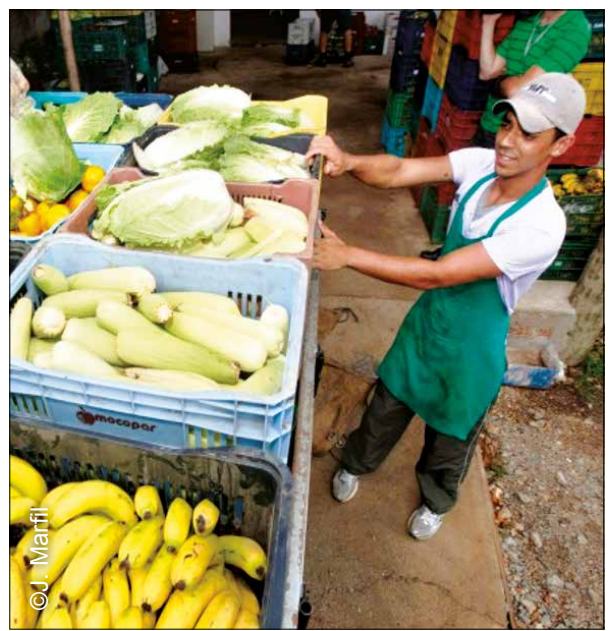


Cuadro 7: Tipología de diferentes sistemas de distribución

\begin{tabular}{|c|c|c|c|}
\hline Sistema de entrega & Ejemplos & Beneficios & Retos \\
\hline PRODUCTORES & $\begin{array}{l}\text { Mercados } \\
\text { campesinos }\end{array}$ & $\begin{array}{l}\text { Permite a los } \\
\text { consumidores conocer a } \\
\text { sus productores. } \\
\text { No hay intermediarios en } \\
\text { la cadena de suministro. } \\
\text { Más cantidad y variedad } \\
\text { disponible para los } \\
\text { consumidores. } \\
\text { El almacenamiento puede } \\
\text { estar incluido o no. }\end{array}$ & $\begin{array}{l}\text { No hay garantía de } \\
\text { que se venderá lo que } \\
\text { el productor trae al } \\
\text { mercado. } \\
\text { Tanto los productores } \\
\text { como los consumidores } \\
\text { tienen que utilizar su } \\
\text { propio transporte, lo que } \\
\text { significa costos más altos. }\end{array}$ \\
\hline PRODUCTORES & $\begin{array}{l}\text { Tiendas } \\
\text { cooperativas, } \\
\text { tiendas de } \\
\text { agricultores, } \\
\text { descargue de } \\
\text { ASC, asambleas } \\
\text { de alimentos; } \\
\text { grupos de } \\
\text { compra } \\
\text { colectiva, } \\
\text { modelos de } \\
\text { canastas }\end{array}$ & $\begin{array}{l}\text { Pueden ser un punto de } \\
\text { salida regular útil para los } \\
\text { productores locales. } \\
\text { Más cantidad y variedad } \\
\text { disponible para los } \\
\text { consumidores. } \\
\text { Los agricultores pueden } \\
\text { organizarse para } \\
\text { minimizar los costos de } \\
\text { transporte en el punto de } \\
\text { recolección. } \\
\text { La entrega de cajas } \\
\text { a los consumidores } \\
\text { puede organizarse para } \\
\text { minimizar costos. } \\
\text { El almacenamiento puede } \\
\text { o no estar incluido en este } \\
\text { modelo. }\end{array}$ & $\begin{array}{l}\text { El almacenamiento } \\
\text { mínimo debe incluirse en } \\
\text { este modelo. } \\
\text { La gestión del tiempo } \\
\text { puede ser difícil, ya que } \\
\text { depende de la afluencia } \\
\text { de consumidores. } \\
\text { El suministro es } \\
\text { estacional, por lo que } \\
\text { puede ser difícil proveer } \\
\text { a los consumidores } \\
\text { regulares de manera } \\
\text { segura y consistente. } \\
\text { La demanda puede ser } \\
\text { muy baja durante algunos } \\
\text { períodos del año (por } \\
\text { ejemplo, durante las } \\
\text { vacaciones de verano). }\end{array}$ \\
\hline PRODUCTORES & $\begin{array}{l}\text { Ventas a la } \\
\text { entrada de } \\
\text { la granja, } \\
\text { Participaciones } \\
\text { de la granja en } \\
\text { una ASC }\end{array}$ & $\begin{array}{l}\text { Dirigidas por agricultores. } \\
\text { Consumidores locales. } \\
\text { No hay costos de } \\
\text { transporte para los } \\
\text { agricultores. } \\
\text { No se requiere } \\
\text { almacenamiento. }\end{array}$ & $\begin{array}{l}\text { Dado el suministro } \\
\text { irregular y estacional } \\
\text { puede ser difícil asegurar } \\
\text { consumidores regulares. }\end{array}$ \\
\hline
\end{tabular}

Fuente: M. Vicovaro, FAO y los autores. 


\subsection{Convertir pérdidas y residuos en subproductos e insumos para la producción o procesamiento}

Una gestión bien planificada y creativa de los subproductos puede convertirlos en productos altamente valorados, evitando así los posibles residuos. El consejo más importante para el manejo de subproductos es "nunca dejar de innovar".

Al igual que los productos principales, los subproductos necesitan un enfoque creativo para agregar valor y mejorar los retornos. Los subproductos se pueden utilizar para desarrollar soluciones de envasado/empacadoinnovadoras, pueden procesarse en nuevos productos o simplemente venderse a diferentes mercados. Entienda y encuentre los mercados adecuados para los subproductos, considerando que a menudo pueden ser diferentes y requerir de trabajo adicional como organizar reuniones entre agricultores, procesadores, intermediarios y consumidores.

Si desea un enfoque integral en cuanto a la sostenibilidad medioambiental, debe reducir sus residuos y reciclar los residuos no reducibles. Los residuos orgánicos son compostables como futuros insumos agrícolas, o utilizables como una fuente de energía para el biogás. En tanto, los residuos no orgánicos son reutilizables (por ejemplo, botellas de vidrio), o reciclables en nuevos productos.

\section{CONSEJO 26}

\section{Gestionar los residuos de forma eficiente}

1. Los residuos pueden reducirse mediante una buena producción o un diseño y control de procesos. Averigüe dónde se generan la mayoría de los residuos y busque alternativas que puedan ayudar a reducirlos. A veces esto implica un cambio sistémico basado en maquinaria, mientras que, en otras ocasiones, puede simplemente requerir un cambio de comportamiento. Implemente primero la alternativa fácil o de bajo costo y compruebe los resultados antes de decidir invertir en soluciones más costosas.

2. Reciclaje de materiales orgánicos a través de animales. Muchas formas de desechos orgánicos son un buen alimento para pollos, cabras, cerdos, peces o lombrices de tierra (es decir, vermicompostaje). Gran parte de los desechos orgánicos que no pueden ser consumidos por los animales pueden ser "consumidos" (utilizados como sustrato) por hongos.

3. Reciclaje de materiales orgánicos a través de compostaje. Esto puede ser compostaje simple (compostaje a cielo abierto) o compostaje vía un digestor de biogás. Los materiales compostados pueden usarse en la producción de la granja, para ayudar a cerrar los ciclos de nutrientes, o venderse a jardineros urbanos (esto podría ser una buena actividad promocional para su negocio).

4. Reciclando materiales no compostables (papel, botellas de vidrio, bolsas de plástico, etc.) con servicios públicos de basuras donde sea posible. Una oportunidad de negocio adicional podría ser invertir en máquinas de reciclaje de plástico o vidrio, iy ofrecer estos servicios a las empresas locales y/o el gobierno! 


\section{La basura de la feria se convierte en fertilizante en la capital (Brasil)}

La ciudad de São Mateus, la capital del estado de Espirito Santo en el suroeste de Brasil, introdujo un plan para recoger residuos orgánicos de sus 900 mercados semanales y compostarlos localmente. Cada año, los rellenos sanitarios serán liberados de aproximadamente 62.000 toneladas de basura. La ciudad estableció cuatro plantas de compostaje, cada una costando aproximadamente USD 140 por mes para operar. Esta es una cantidad equivalente a los gastos del Municipio por enterrar en el relleno sanitario la basura recolectada en los mercados. Estas plantas ofrecen varias soluciones de recolección y tratamiento de residuos, y venden sus materiales de compostaje a los pequeños agricultores. En el proceso, la producción de basura se reduce, la vida de los rellenos sanitarios se prolonga y los costos de limpieza de los mercados se reducen en alrededor de un $30 \%$. Si bien estos ahorros en el mercado callejero de Ursa Minor se deben a la reducción de la mano de obra, dos de sus ocho limpiadores callejeros han sido reentrenados como agentes ambientales que acompañan la recolección de basura, su transporte a la planta de compostaje, y su recomposición en troncos de compost (es decir, los residuos orgánicos se mezclan con el aserrín para convertirse en compost).

Fuente: José Antonio da Silva Marfil, Ecovida, Brasil.

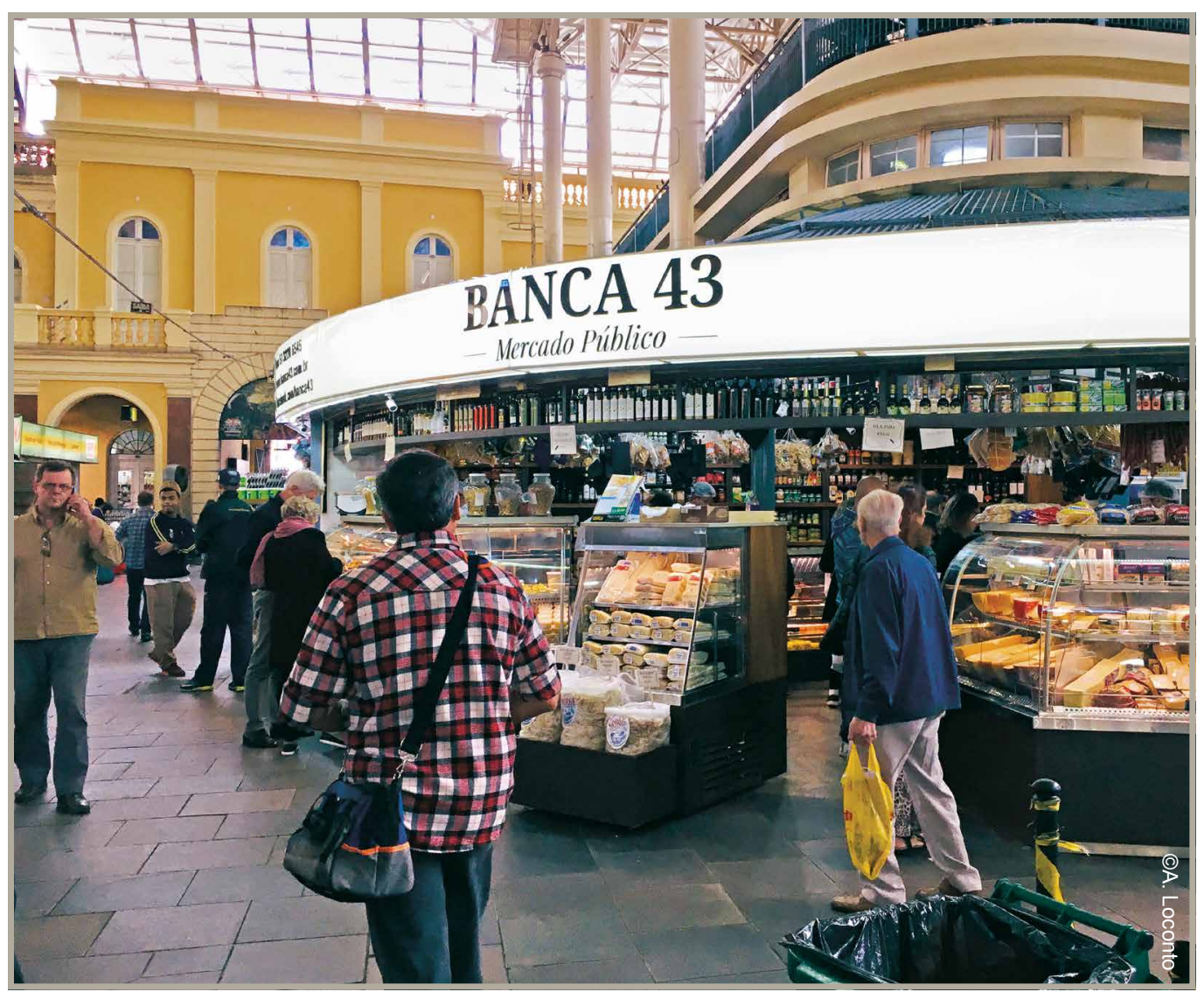




\section{USAR EL PLAN LOGÍSTICO PARA CUMPLIR CON LOS ESTÁNDARES}

\subsection{Trazabilidad}

La trazabilidad es un proceso que utiliza documentación y etiquetado de productos para permitir a los usuarios finales determinar la ruta del producto desde la comunidad. Por lo general, es un requisito para obtener la certificación de inocuidad y sostenibilidad de los alimentos. Un sistema de trazabilidad ayuda a identificar el origen de los brotes de contaminación alimentaria y es necesario para implementar retiradas de productos.
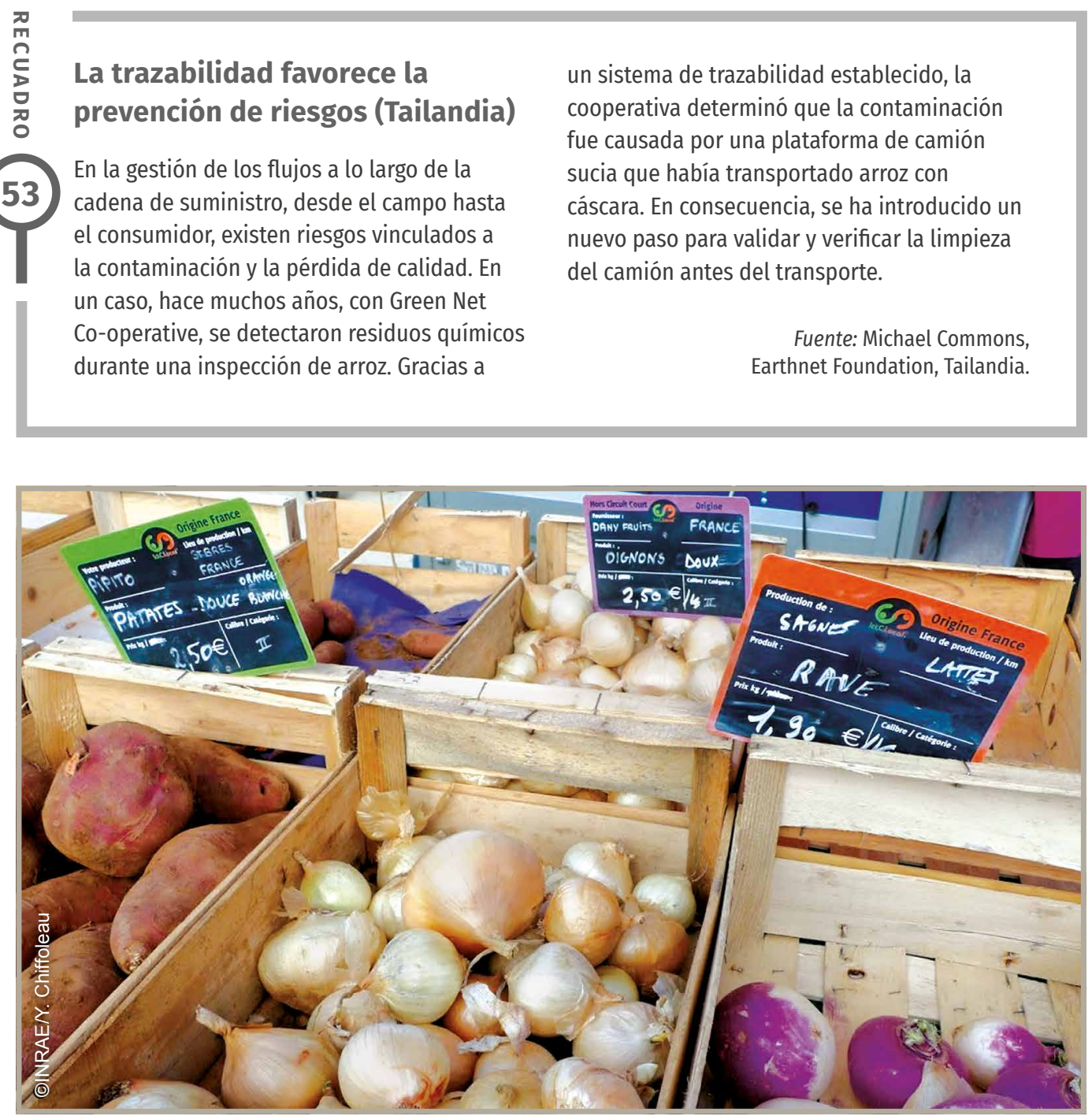
Trazabilidad mediante una simple identificación y distinción codificada por colores (República

\section{Unida de Tanzanía)}

La Wakulima Tea Company (WATCO) estableció un sistema de pesaje digital con un programa diseñado para separar a los agricultores certificados por Rainforest Alliance y a los no certificados en los puntos de recogida del pueblo. A cada agricultor se le asigna un número con los prefijos $00=$ no certificado y 01=certificado. Después del pesaje, la hoja certificada se carga en bolsas verdes o de otro color, mientras que la no certificada se carga en bolsas amarillas. Durante el transporte, las bolsas no certificadas se cargan en el nivel inferior del vehículo y las certificadas en el nivel superior. La descarga en la fábrica comienza con la hoja certificada (el nivel superior) y termina con las bolsas no certificadas. Por lo tanto, estas últimos son las últimas en ser puestas en canales de marchitamiento respectivamente etiquetados (y numerados). Durante el procesamiento, comienzan con tés certificados hasta que terminan. A continuación, limpian a fondo el área de procesamiento y esperan 45 minutos antes de empezar a procesar tés no certificados. Esta separación de té certificado y no certificado es fundamental para la forma en que el estándar incentiva la adopción de prácticas sostenibles. Esencialmente, los

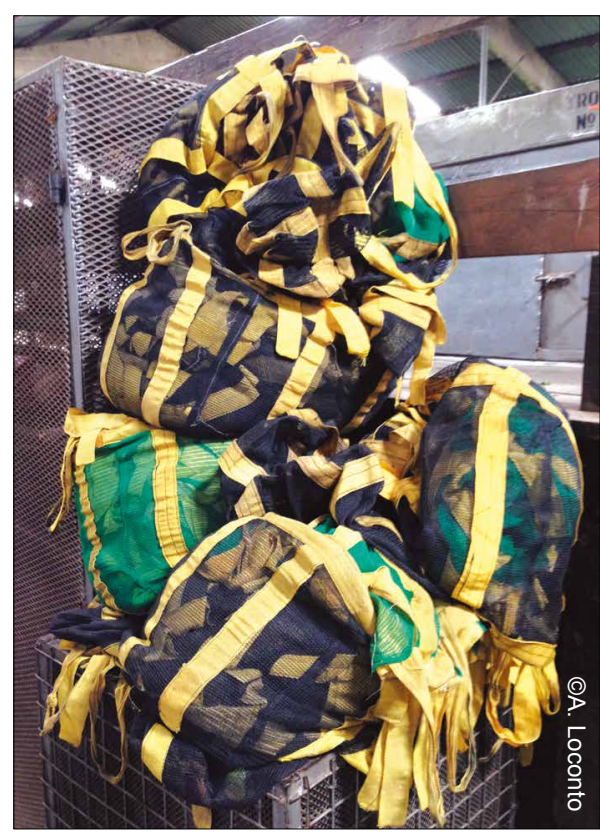

agricultores cuyo té ha sido colocado en bolsas amarillas han cuestionado su división, ya que el color brillante es notado por todos en el punto de recogida. Además, se atribuyen diferentes precios a las bolsas de diferentes colores, lo que anima a los agricultores no certificados a preguntar cómo pueden certificarse, con el fin de disminuir el sentimiento de exclusión.

Fuente: Allison Loconto, INRAE y Emmanuel Simbua, TRIT, República Unida de Tanzanía.

\subsection{Reducción del riesgo de contaminación}

Existe el riesgo de contaminación de los alimentos en toda la cadena de valor. El riesgo suele ser bajo en las granjas sostenibles, dado el uso de buenas prácticas. Sin embargo, este riesgo es proporcionalmente mayor fuera de la granja, cuando los productos viajan distancias más largas para llegar a los consumidores. Todos los agentes de la cadena alimentaria deben garantizar que no se produzca tal contaminación. En mercados distantes, estas buenas prácticas se aplican a través de un proceso, como por ejemplo un rastreo documental por Certificado de Transacción, que rastrea los productos a medida que se mueven de actor a actor. Este rastro documental es entonces comprobado por un tercero que prueba el producto para identificar toxinas o bacterias. 
Sin embargo, en la práctica, cada lote de mercancías no puede ser inspeccionado debido al gran volumen de transacciones, que incurren en costos, que pueden resultar en un precio final al consumidor más alto.

Otros métodos son dignos de exploración. Una vez que un sistema de garantía confirma la sostenibilidad de la fuente del producto, el producto final puede ser probado para detectar residuos (es decir, la vigilancia del mercado), aunque esto es generalmente costoso. Si existe un alto nivel de confianza entre los actores involucrados en la iniciativa (principalmente productores y consumidores), el costo de las pruebas podría reducirse realizando muestras aleatorias de prueba de manera participativa, compartiendo los costos entre los miembros de la iniciativa.

\section{Pruebas de contaminación participativas (India)}

\section{5}

En la India, en varias partes de la campaña

BhoomikA y del Mercado de Agricultores

Orgánicos de Delhi, se invita a los consumidores

finales a seleccionar periódicamente muestras aleatorias de frutas, verduras y otros granos, mientras que un representante del laboratorio selecciona simultáneamente una muestra. Todas las muestras se colocan en bolsas selladas, y el informe de la prueba se hace público voluntariamente. La inclusión de este mecanismo de transparencia acoge con satisfacción los comentarios y sugerencias de todos los agentes, para mejorar la transparencia y evitar al mismo tiempo altos costos de cumplimiento. También se invita a los consumidores finales a participar en los SPG utilizados para certificar a las granjas, y algunos consumidores también visitan las granjas para fomentar la confianza. Hasta la fecha, no se han encontrado residuos en el protocolo de ensayo. En caso de detectarse, los actores son responsables de hacer públicos estos informes, de tomar medidas correctivas, y de reembolsar a los consumidores. Si un productor incurre en una pérdida, una simple disculpa a veces ayuda mucho a mantener la transparencia y la confianza. Estos modelos también podrían explorarse para cadenas de suministro largas con el fin de reducir los riesgos de contaminación. Sin embargo, como regla general, la gente tiende a confiar en aquellos que conocen más que en empresas desconocidas.

Fuente: Ashish Gupta, Jaivik Haat.
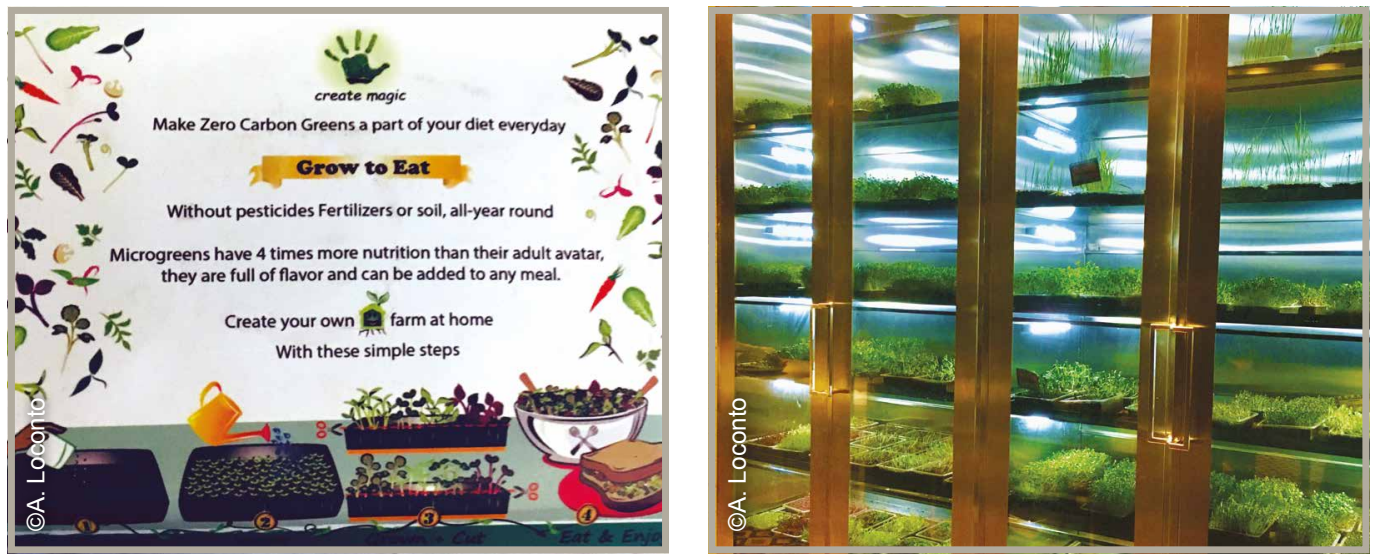


\subsection{Inquietudes y regulaciones sobre inocuidad alimentaria}

Aunque todos los sistemas están regidos por normas de inocuidad alimentaria, en un sistema alimentario sostenible, se necesitan medidas cuidadosas para garantizar que no se produzca contaminación a través de alimentos convencionales. Desde la producción hasta el consumo, las directrices reglamentarias especifican las normas de segregación física de los alimentos. Sin embargo, las normas de inocuidad evolucionan con el tiempo, por lo que es importante mantenerse actualizado.

\section{Participación en la} reglamentación de la inocuidad de los alimentos (India)

56

Una buena manera de mantener informados a los productores y consumidores es asegurar su representación en los procesos de revisión regulatoria participativa. En la India, la Autoridad de Normas y Seguridad Alimentaria

(FSSAI) invita a representantes de varias organizaciones de la sociedad civil (OSC) a revisar las normas de regulación orgánica. A través de este procedimiento, se enviaron borradores de regulaciones, y las OSC tuvieron múltiples discusiones con el regulador. Se aceptaron muchos cambios significativos en el proceso, como el reconocimiento de los Sistemas Participativos de Garantía (SPG) como una forma válida de certificación, la armonización de diversos mecanismos de cumplimiento bajo una regulación unificada para los alimentos orgánicos, y la creación de un logotipo oficial "Jaivik Bharat". El regulador también lanzó un portal llamado "Portal de Integridad de Bases de Datos Orgánicas de la India", para que los consumidores rastreen los alimentos de los certificadores (tanto de terceros como de los SPG). El reglamento también incluye algunos elementos clave destinados a aumentar la competitividad de los productores locales:

1. Los pequeños agricultores que venden directamente a los consumidores quedaron exentos de la regulación, y todavía pueden vender sus productos como "orgánicos" en las ventas directas.

2. Las regulaciones de importación de alimentos fueron más estrictas, para asegurar que los alimentos importados y procesados no se vendan en los mercados indios si estos están disponibles por los productores locales.

Fuente: Ashish Gupta, Jaivik Haat.

\section{CONSEJO 27}

\section{Gestionar la logística}

- El tiempo es clave: ser puntual y aparecer en el lugar adecuado en el momento adecuado puede ahorrar dinero, reducir los residuos y garantizar la calidad.

- La elaboración de productos en la granja, o en las instalaciones locales de recogida y almacenamiento, puede aumentar los ingresos de los productores y reducir los costos de transporte.

- La trazabilidad es fundamental para garantizar que su comida sea segura para comer, pero no tiene que ser compleja. Se trata esencialmente de documentar quién entregó qué y cuándo.

- Incluso en logística, compartir responsabilidades puede ayudar a fortalecer la confianza entre productores y consumidores, ayudando a hacer los sistemas sostenibles a largo plazo. 


\section{LA AVENTURA DEL APRENDIZAJE, ¿DÓNDE SEGUIR?}

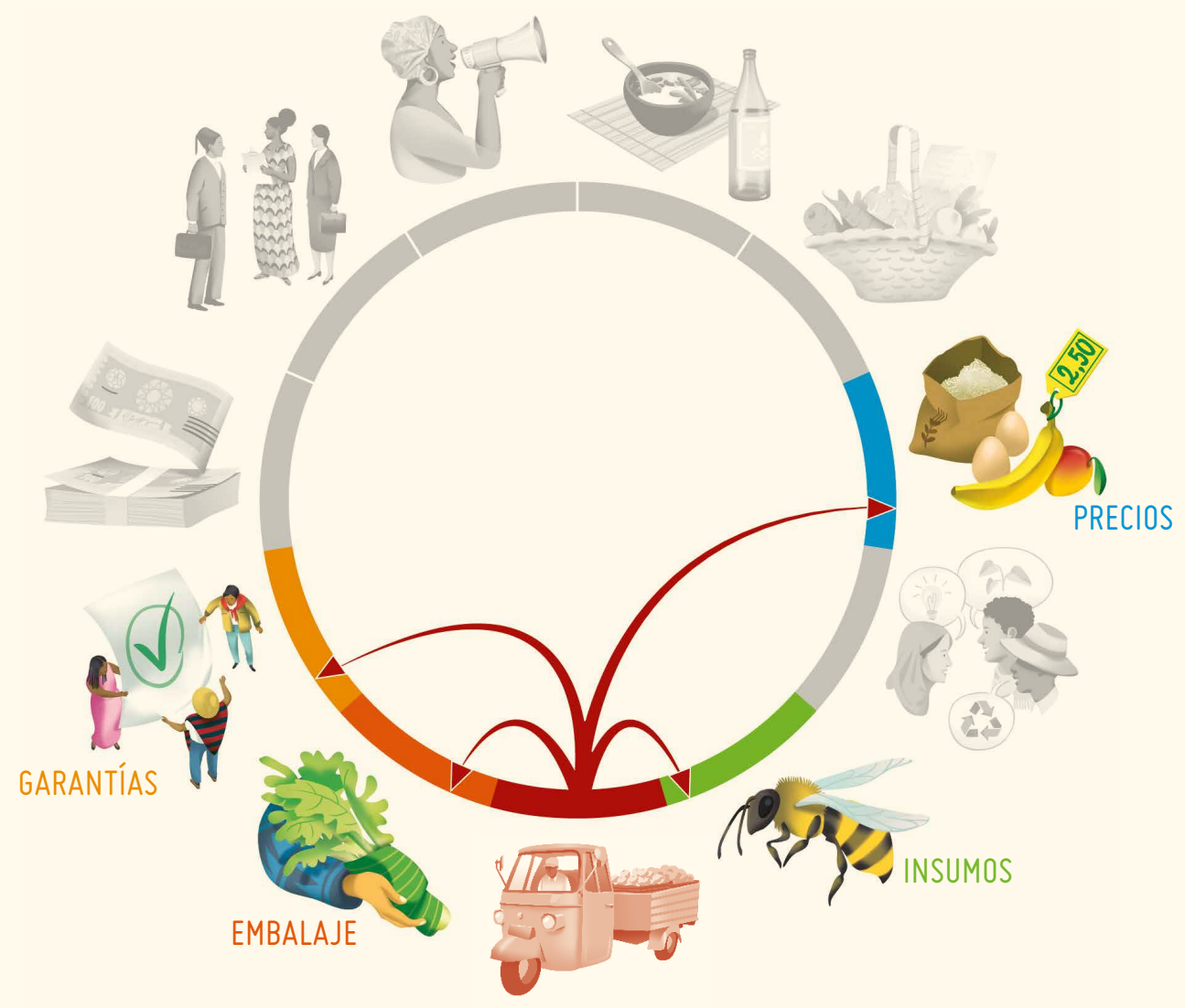

- ¿Necesita garantizar la trazabilidad como parte de un requisito de certificación, pero no está satisfecho con el procedimiento de certificación? Vaya al Capítulo 8: Garantías para la sostenibilidad para conocer otras formas de garantía.

- ¿Quiere saber más sobre intermediarios transparentes y cómo podrían apoyar su iniciativa? Consulte el Capítulo 3: Encontrar el precio "correcto".

- ¿Qué pasa con los residuos orgánicos... puede intentar convertirlos en compost? Aprenda cómo en el Capítulo 5: Conocer y acceder a insumos sostenibles.

- ¿Es seguro reutilizar los residuos no orgánicos para el empacado? Continúe con el Capítulo 7: Embalaje sostenible, para descubrirlo.

O pase a otro capitulo... ¡idepende de usted! 


\section{EMBALAJE SOSTENIBLE}

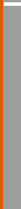

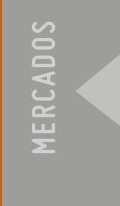

co

$\tilde{0}$
$\frac{\tilde{U}}{\alpha}$
$\frac{1}{\alpha}$
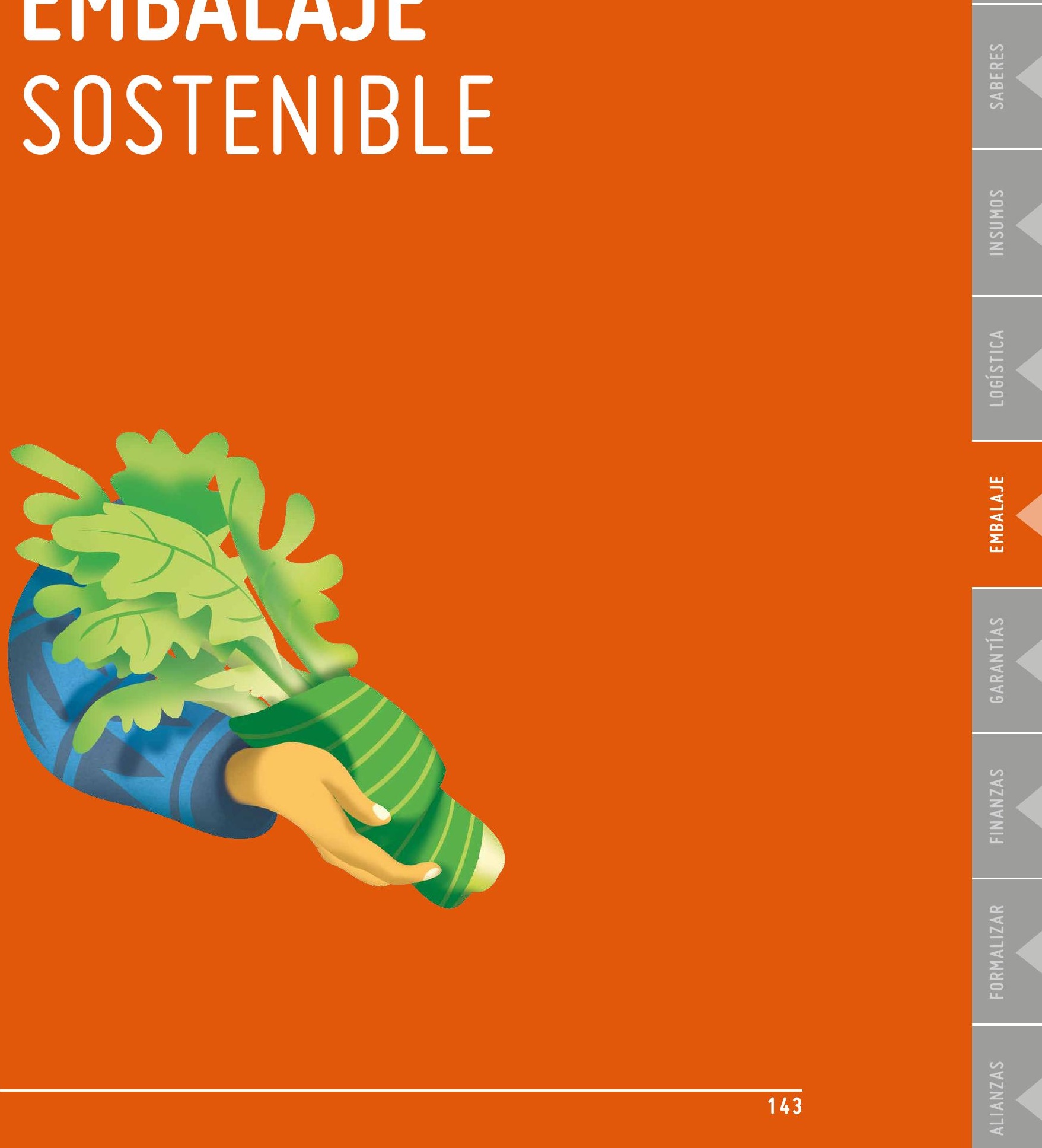

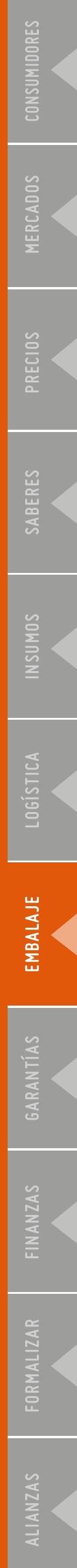


\section{1. ¿POR QUÉ ESTO ES IMPORTANTE?}

En un sistema alimentario sostenible, el embalaje tiene dos funciones principales:

1. conservar su producto; $y$

2. comunicar su valor a los consumidores.

Estas dos funciones generan más valor, tanto para los productores como para los consumidores, ya que el empaque puede proporcionar una marca reconocible. Un empacado consistente proporciona estabilidad a lo largo del tiempo, en la medida en que los consumidores aprenderán a identificar los productos de la iniciativa sin perder tiempo leyendo las etiquetas o buscando productos similares.

\section{Reducir, reutilizar, reciclar (China)}

"Reducir, reutilizar, reciclar" son los tres mensajes de la estrategia de empaquetado de Shared Harvest Farm. Shared Harvest es una granja de ASC con cerca de 800 miembrosfamilias en Beijing. Ellos entregan los alimentos puerta a puerta cada semana. En primer lugar, para la mayoría de sus productos, como las verduras, sólo utilizan paja para agruparlas, y muy pocas bolsas de plástico. En segundo lugar, trabajan con una empresa logistica local que recoge cajas y otros materiales de embalaje para devolverlas a la granja para su reutilización. Al mismo tiempo, promueven los beneficios de reducir los envases insostenibles para sus consumidores a través de las redes sociales, y utilizan materiales reciclables siempre que sea posible.
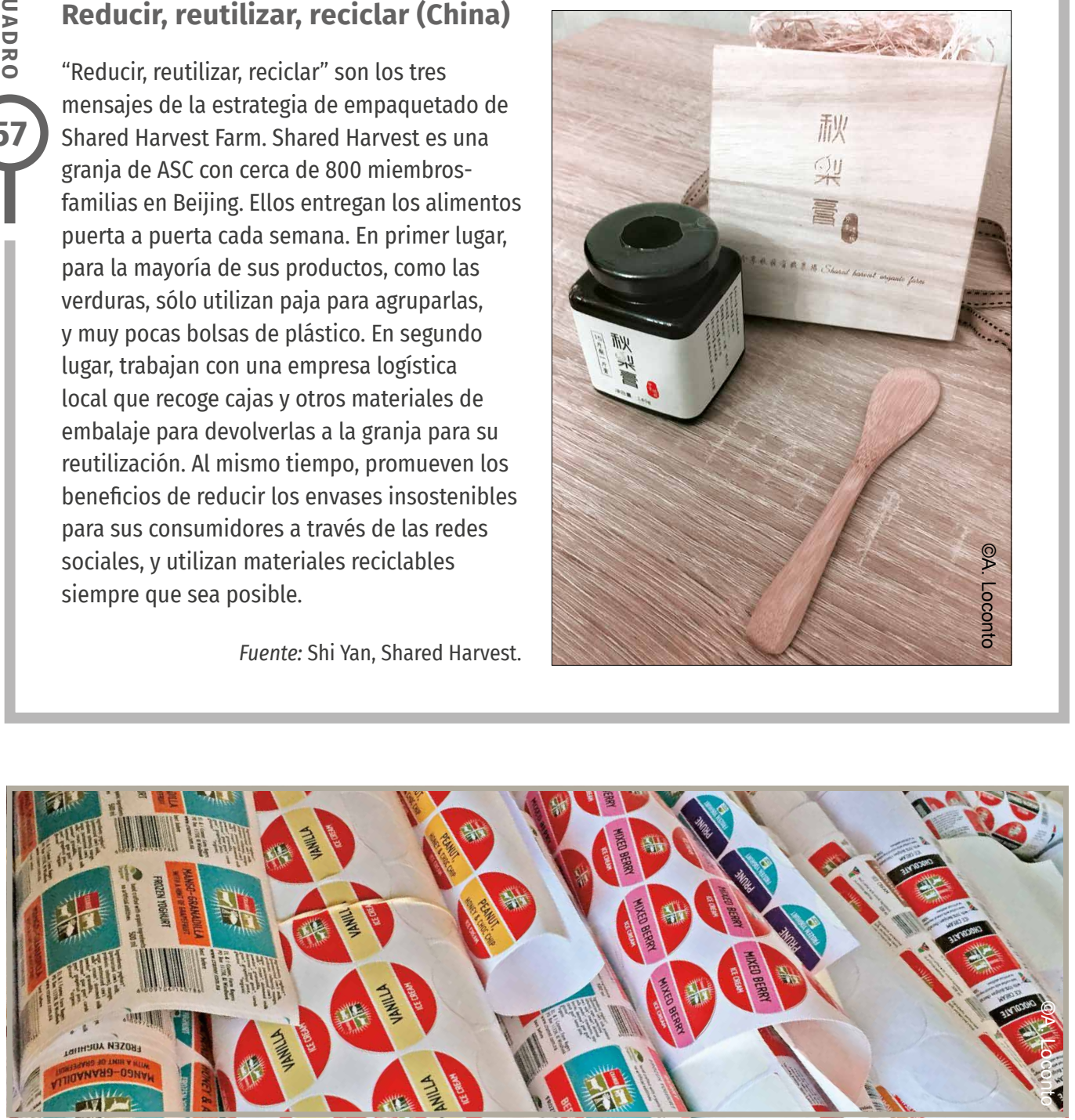


\section{2. ¿CÓMO DETERMINAR El EMBALAJE dE SUS PRODUCTOS?}

Cuando usted está decidiendo cómo empaquetar su producto de forma sostenible, existen dos cuestiones principales que debe tener en cuenta:

1. Lo perecedero del producto que desea vender y la finalidad del paquete, es decir, venderles el producto a los consumidores finales, o transportarlo a otra planta de transformación o punto de venta.

2. El material que proporciona soluciones de embalaje sostenibles. Cuando se trata de materiales de embalaje, también es importante tener en cuenta la sostenibilidad medioambiental. Para ello, puede explorar dos estrategias: materiales de embalaje biodegradables (por ejemplo, paquetes de fibra natural), o materiales reutilizables o totalmente reciclables (por ejemplo, vidrio). Se debe evitar el embalaje de plástico.

Cuadro 8: Ejemplos de diferentes opciones de embalaje según las diferentes características del producto

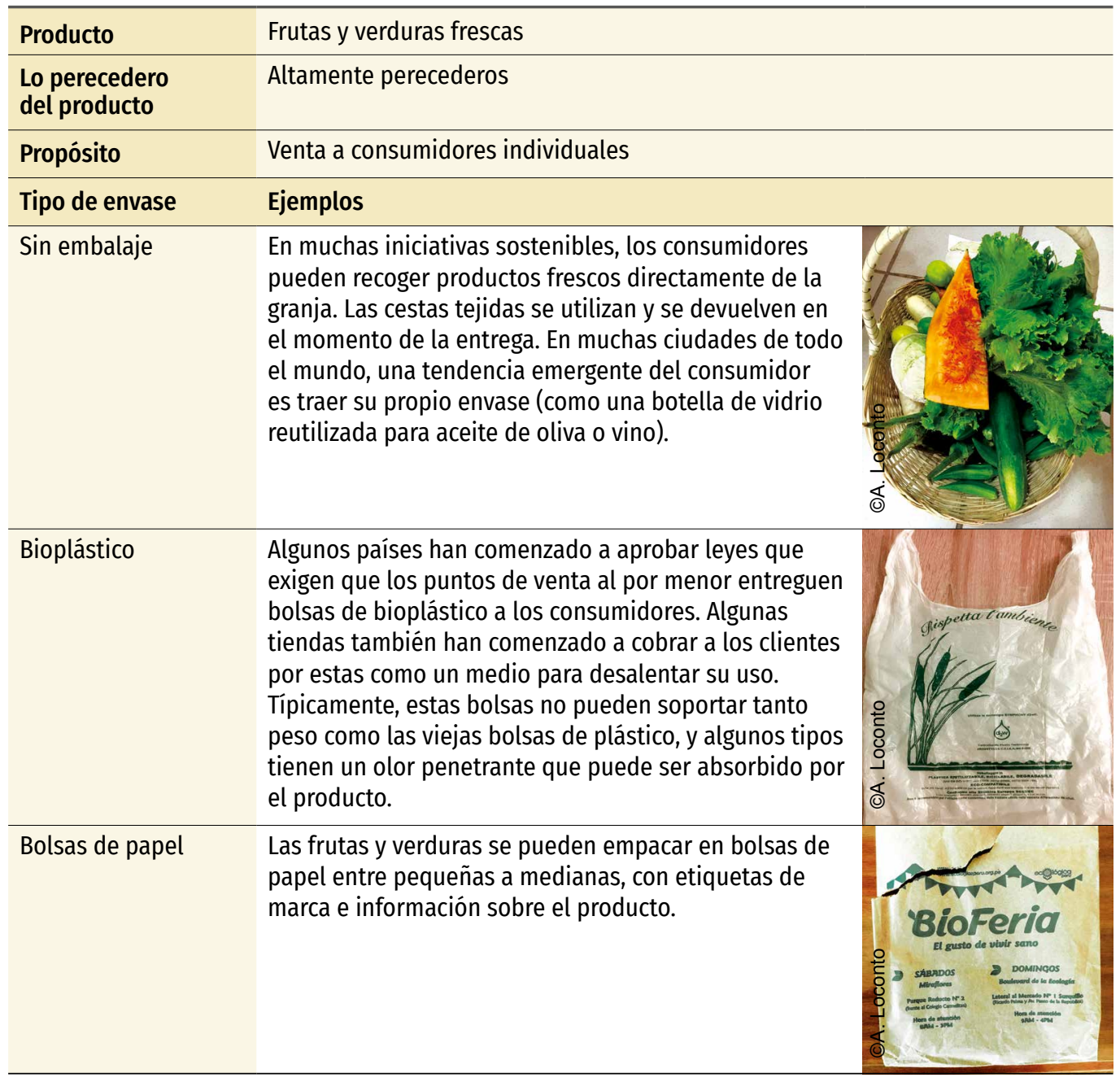




\begin{tabular}{|c|c|}
\hline Producto & Frutas y verduras frescas \\
\hline $\begin{array}{l}\text { Lo perecedero } \\
\text { del producto }\end{array}$ & Altamente perecederos \\
\hline Propósito & Transporte a puntos de venta o procesamiento \\
\hline Tipo de envase & Ejemplos \\
\hline Cartón para fresas & $\begin{array}{l}\text { Para productos altamente perecederos como las } \\
\text { fresas las cajas de cartón pueden ayudar a reducir } \\
\text { el uso de plástico. También tienden a absorber } \\
\text { la humedad, por lo que es mejor ordenarlas con } \\
\text { sus hojas. En el caso de las fresas, esto ayuda a } \\
\text { conservar el producto durante más tiempo y evita su } \\
\text { deterioro. Para las fresas cultivadas orgánicamente, } \\
\text { se utilizan las hojas de la misma plantación de } \\
\text { fresas. Sin embargo, este método está prohibido en } \\
\text { la producción convencional. }\end{array}$ \\
\hline $\begin{array}{l}\text { Cestas tejidas con } \\
\text { hojas de palmera }\end{array}$ & $\begin{array}{l}\text { Los paquetes/cestas son biodegradables, fácilmente } \\
\text { reciclables y extremadamente baratos. } \\
\text { Los productos presentados de esta manera son } \\
\text { estéticamente atractivos para los consumidores. }\end{array}$ \\
\hline Cajas apilables & $\begin{array}{l}\text { Este tipo de caja es reutilizable, maximiza el espacio } \\
\text { disponible, y previene las magulladuras durante } \\
\text { el transporte. Algunas marcas están hechas de } \\
\text { bioplásticos resistentes (como por ejemplo almidón } \\
\text { de maíz). }\end{array}$ \\
\hline
\end{tabular}

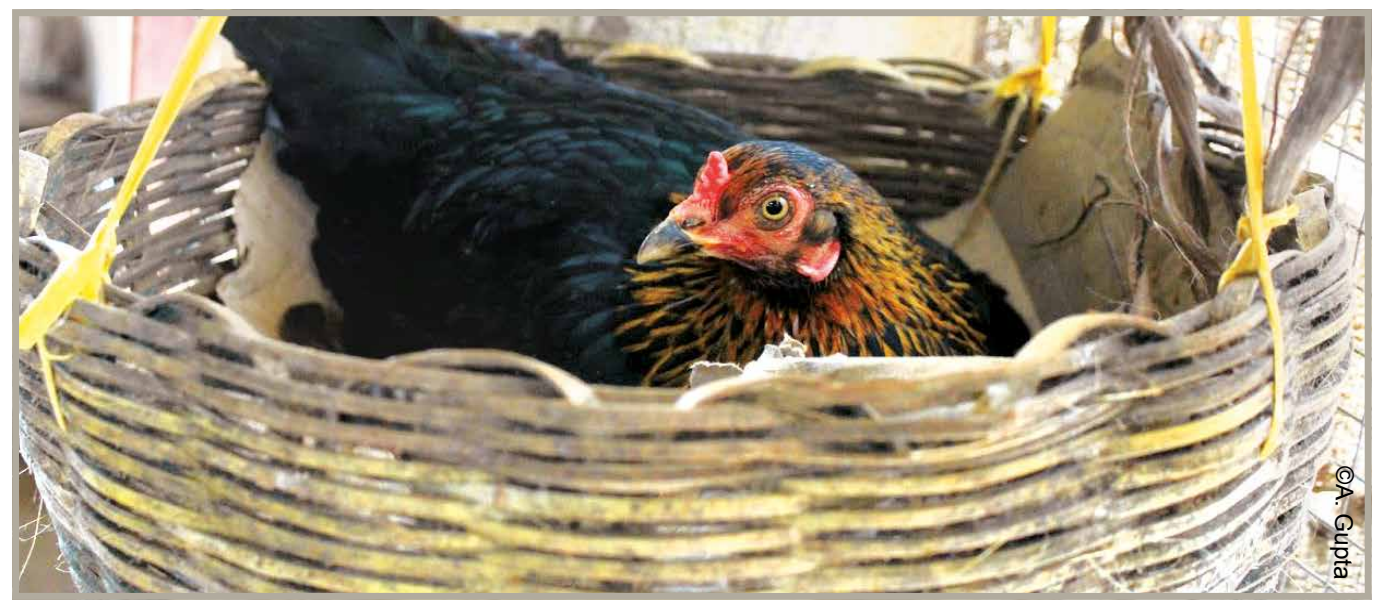




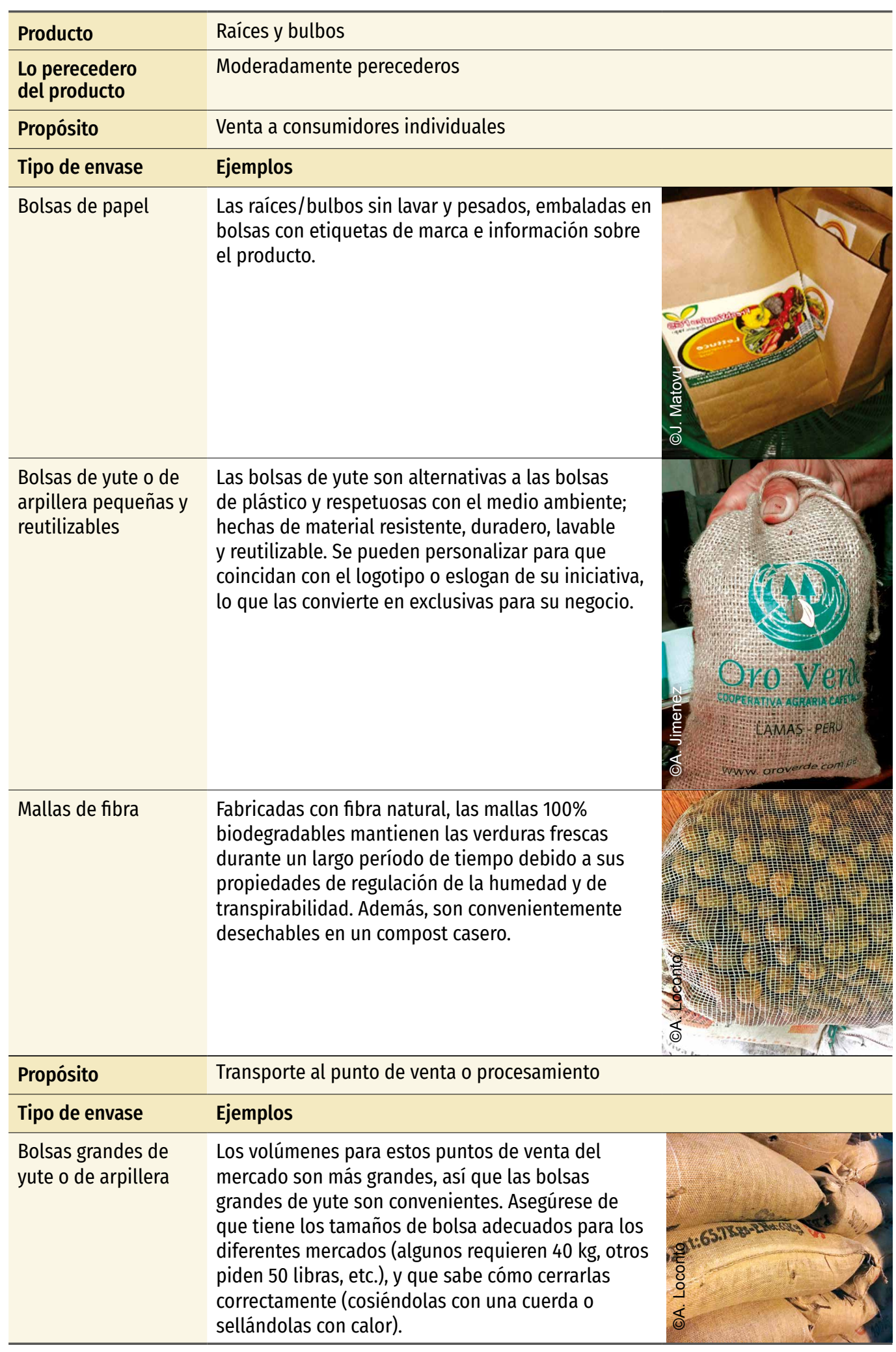




\begin{tabular}{ll}
\hline Producto & Líquidos y mermeladas \\
\hline $\begin{array}{l}\text { Lo perecedero } \\
\text { del producto }\end{array}$ & Entre medianamente a bajamente perecederos \\
\hline Propósito & Venta a consumidores individuales \\
\hline Tipo de envase & $\begin{array}{l}\text { Ejemplos } \\
\text { productores de Sumapaz, Colombia, conserva las } \\
\text { propiedades nutricionales del producto. El vidrio } \\
\text { es una solución de embalaje adecuada, porque } \\
\text { cumple con los estándares de higiene y ofrece una } \\
\text { estética limpia. }\end{array}$ \\
\hline jarras de vidrio &
\end{tabular}

\section{Envasado en un proyecto de pesca} artesanal orgánica (Tailandia)

El Organic Artisan Fisheries Project, bajo la Fundación Earth Net, tiene como objetivo conectar a los pescadores tradicionales de pequeña escala, que respetan la práctica sostenible en diferentes provincias del sur de Tailandia, con los consumidores de Bangkok. Con cantidades demasiado pequeñas para invertir en un camión frigorífico, los peces se envasaron en cajas reutilizables aisladas con espuma para preservar su calidad y frescura durante el transporte. Aunque hay muchos servicios logísticos, el colectivo no estaba dispuesto a transportar mariscos junto con otras cargas. Afortunadamente, algunos buses turísticos públicos circulan regularmente hacia y desde Bangkok a otros lugares, y acordaron transportar las cajas de espuma en sus contenedores de carga, para ser recogidas de la estación de autobuses y transportadas al mercado por el personal del proyecto.

Fuente: Michael Commons, Fundación Earthnet.

\section{Paquetes de fibra natural} para entrega en el hogar en FreshVeggies (Uganda)

En el sistema de entrega de FreshVeggies, las cestas están hechas de hojas de palma no teñidas y fibra de plátano seca, y son tejidas a mano en múltiples capas para garantizar la resistencia y durabilidad de la cesta. Las canastas, que provienen localmente de una iniciativa de mujeres, apoyan los ingresos de los hogares de base y el uso sostenible de los humedales (las palmas crecen en pantanos/humedales). Estas cestas naturales son atractivas, reutilizables, seguras para transportar verduras frescas y otros alimentos, asequibles y respetuosas con el medio ambiente. Además, conservan la frescura, permitiendo la evapotranspiración natural de las verduras. Las bolsas de plástico, por otro lado, sofocan los productos y reducen su vida útil, y tienen un impacto negativo en el medio ambiente a lo largo de su ciclo de vida.

Fuente: Julie Matovu, FreshVeggies Ltd., Uganda. 


\section{DISENAR LOS PAQUETES ADECUADOS}

\subsection{El diseño}

El diseño del embalaje actúa como la "cara" del producto, y debe destacarse en comparación con otros productos de la misma categoría. Además, muestra información relevante y características del producto que hacen que este sea más atractivo.

El embalaje es también una forma de comunicar a los consumidores los valores de su iniciativa y los de sus productos (ecológicos, innovadores, solidarios, hechos a mano, producidos localmente, etc).

Recuerde que el diseño es esencial para desarrollar productos y generar valor.

\section{CONSEJO 28}

\section{Desarrollar un diseño atractivo}

1. Piense en la ergonomía del producto (fácil/difícil de abrir, fácil de manejar, fácil de transportar, tiene la relación peso/tamaño adecuada, etc).

2. Hable directamente con sus consumidores a lo largo de la fase de diseño. Piense en cómo su embalaje encarna el mensaje visual principal que desea comunicar (salud, producción local, ecológico, etc) y las maneras de hacerlo (color/imágenes/texto/relación entre los diferentes elementos del envase, etc.).
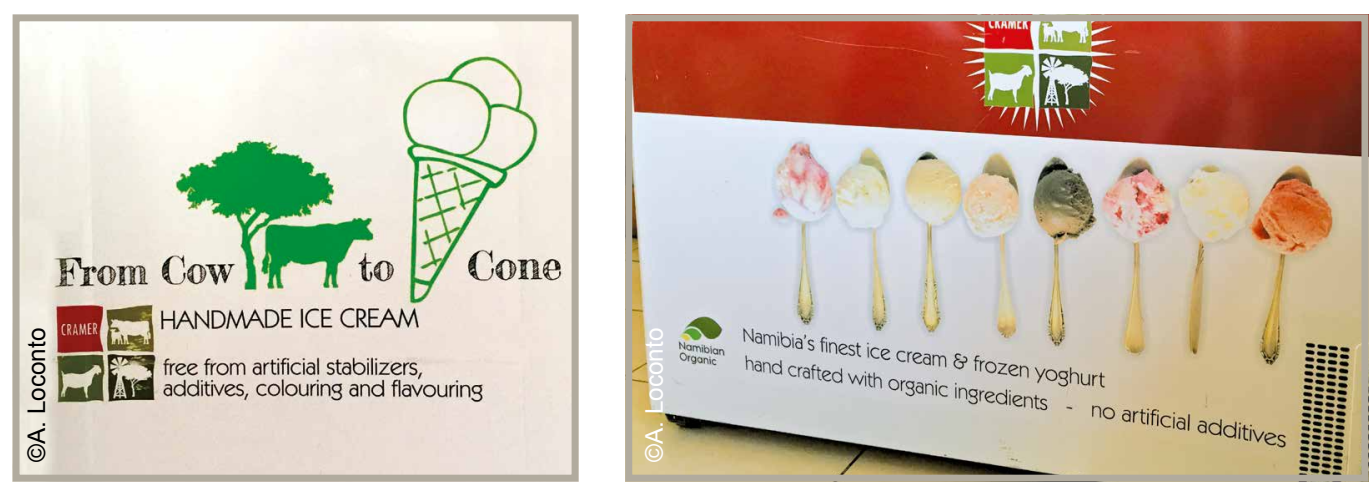


\section{¿Cómo diseñar un paquete} original y atractivo? (Colombia)

\section{0}

En el caso de las patatas fritas "Ancestrales", hechas de variedades indigenas de papa, Familia de la Tierra comenzó a desarrollar su producto identificando el concepto principal que querían compartir con los clientes, para promover la preservación del ecosistema Páramo y la cultura campesina tradicional. Ancestrales fue desarrollada como una marca que captura estos valores.

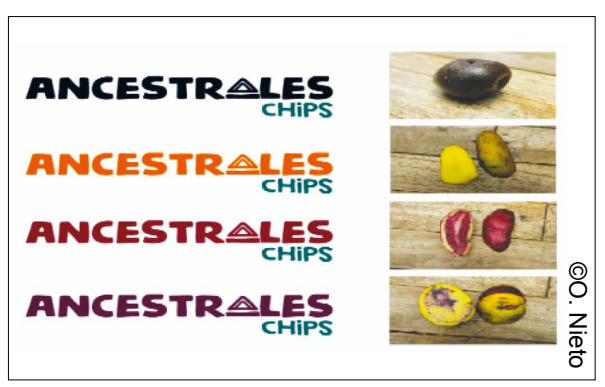

Posteriormente, con la ayuda de un equipo de diseño, se desarrolló el embalaje. Las texturas de la papa fueron reproducidas a través de acuarelas, luego digitalizadas e incorporadas en el diseño final.
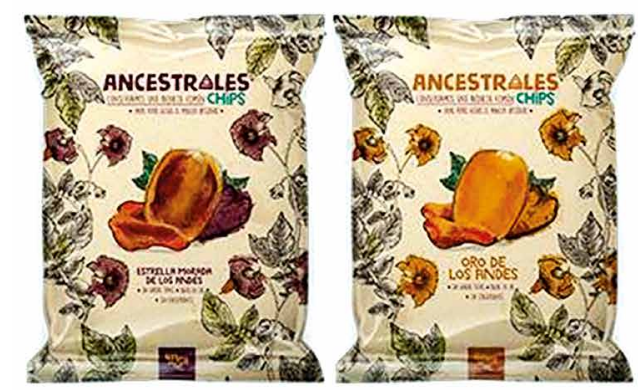
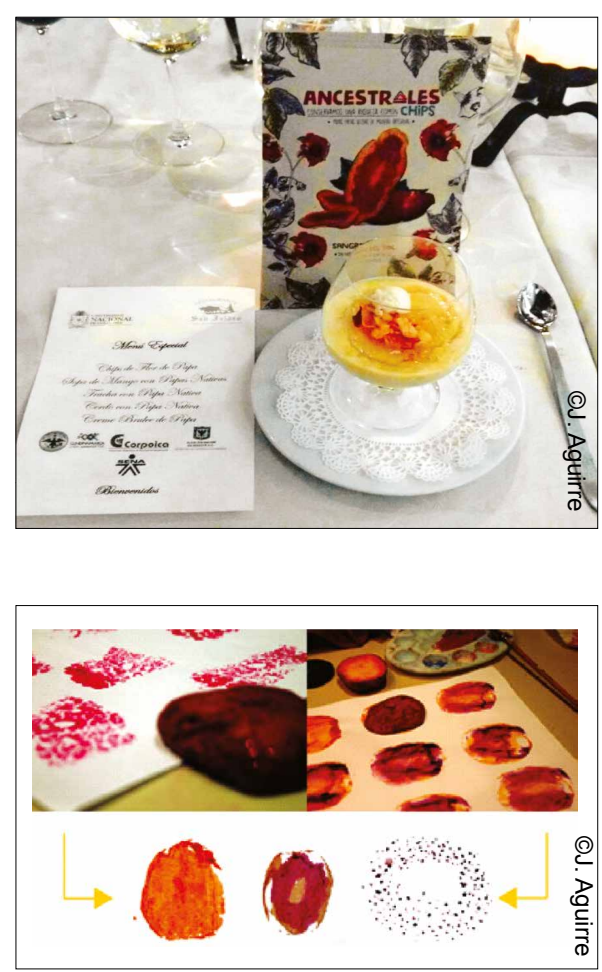

En el último paso, se finalizó el logotipo de la marca y se reunieron todos los elementos para completar el paquete del producto.

Fuente: Jaime Aguirre, Óscar Nieto, FDT.

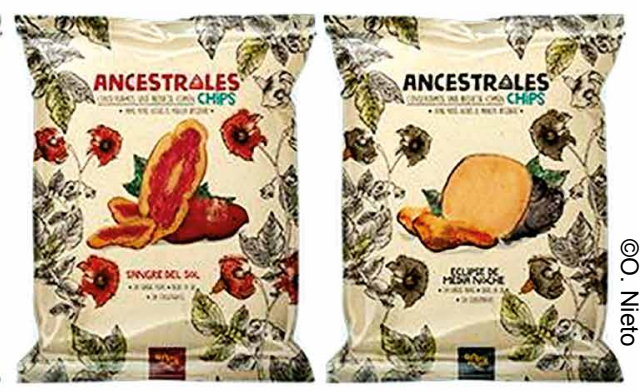




\subsection{Tamaño}

El tamaño del envase también es fundamental para garantizar el atractivo, la ergonomía y el consumo sostenible de sus productos (es decir, la reducción de los desechos de alimentos y el tamaño de las porciones nutricionalmente adecuadas). Considere al consumidor final para determinar el tamaño apropiado. Por ejemplo, si el producto está destinado a niños (o a un consumidor individual en lugar de a una familia), se prefiere un tamaño pequeño para evitar los desechos.

Cuadro 9: Ejemplos de diferentes tamaños de envase para diferentes consumidores

\begin{tabular}{|c|c|c|}
\hline Producto & $\begin{array}{l}\text { Consumidores objetivo } \\
\text { (y punto de mercado) }\end{array}$ & Tamaño \\
\hline \multirow{3}{*}{$\begin{array}{l}\text { Caña } \\
\text { de azúcar } \\
\text { fresca }\end{array}$} & $\begin{array}{l}\text { Consumidores individuales } \\
\text { (minoristas de alimentación, puntos } \\
\text { de mercados de alimentos abiertos) }\end{array}$ & $\begin{array}{l}\text { Paquetes de 10-12 plantas enteras de caña de } \\
\text { azúcar atadas con cuerdas de sisal/fibra. }\end{array}$ \\
\hline & $\begin{array}{l}\text { Niños (mercados campesinos y } \\
\text { ventas en granjas) }\end{array}$ & Tallos simples, cortados. \\
\hline & $\begin{array}{l}\text { Familias } \\
\text { (Modelos de canastas) }\end{array}$ & $\begin{array}{l}\text { Pelada, pesada en kilogramos (por ejemplo, } 0.5 \mathrm{~kg} \text {, } \\
4 \mathrm{~kg} \text { ), y embalada en una bolsa de papel forrada } \\
\text { con una bolsa de polietileno de grado alimentario. }\end{array}$ \\
\hline
\end{tabular}

\subsection{El procesamiento del material de embalaje}

A menudo se requieren inversiones significativas en el equipo necesario para el empaque de los productos, asi como para el desarrollo de los materiales de embalaje. Se necesitan máquinas específicas para cada proceso, así como de personal calificado que esté familiarizado con su uso. A menudo, el costo del embalaje es una de las principales razones por las que los pequeños agricultores prefieren no hacerlo ellos mismos. Sin embargo, existen muchas técnicas artesanales para procesar, almacenar y envasar productos (por ejemplo, enlatar las mermeladas en el hogar), y hay una tendencia creciente a utilizar la tecnología de "tamaño reducido" que ofrece nuevas posibilidades. Por lo tanto, puede decidir desarrollar un paquete atractivo y sencillo, o subcontratar el procesamiento a una empresa especializada.

\section{CONSEJO 29}

Desarrollar un embalaje atractivo y sencillo

Los envases atractivos no requieren necesariamente una gran inversión. Con una impresora (color) y un poco de atención al diseño, puede crear una marca visualmente atractiva y proporcionar toda la información necesaria. Para los productos con un tamaño y un paquete comunes, como los paquetes de semillas vegetales, puede ser útil diseñar un paquete impreso estándar y pegar pequeñas etiquetas adhesivas para describir la variedad, el peso y otra información específica. Las hojas de etiquetas blancas (y a color) en tamaño de impresora A4 son fáciles de encontrar. Como alternativa, se puede utilizar papel reciclado. Esta es una opción mucho más factible hasta que grandes volúmenes hagan que la impresión especializada valga la pena. La escritura pulida, o el uso de un sello de marca de goma, pueden agregar carácter a un producto y promover su naturaleza artesanal. 


\section{Externalización de la impresión (Colombia)}

Para imprimir y preparar los paquetes de papas fritas "Ancestrales", Familia de la Tierra firmó un contrato con una empresa privada local. La empresa propuso imprimir un mínimo de 48.000 bolsas de plástico para crear la plantilla de diseño. Sin embargo, después de la negociación, los cuatro paquetes diferentes (ver imagen) se ajustaron en una sola hoja de impresión, obteniendo así 12.000 paquetes para cada tipo de papas fritas. Se estima que los costos de embalaje pueden variar de COP 200 a COP 105 por bolsa (equivalente a unos USD 0.03), ahorrando asi una cantidad significativa de dinero. Para "Ancestrales", se invirtió una suma inicial de 2.400 dólares para

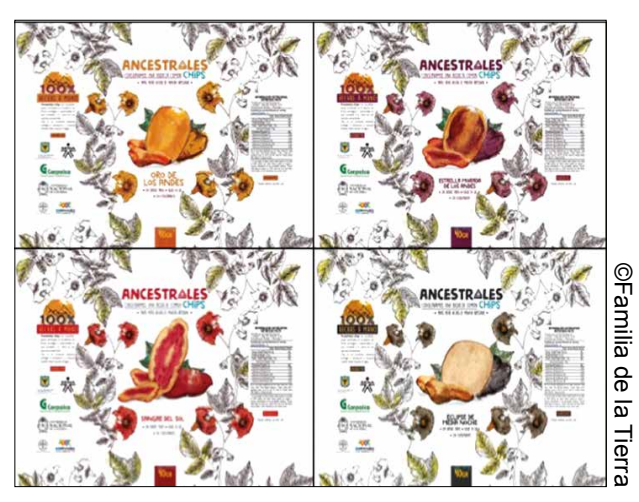

el diseño de las plantillas, para el corte de moldes y para la impresión. El segundo ciclo de impresión cuesta aproximadamente USD 1.700.

Fuente: Jaime Aguirre, Óscar Nieto, FDT.

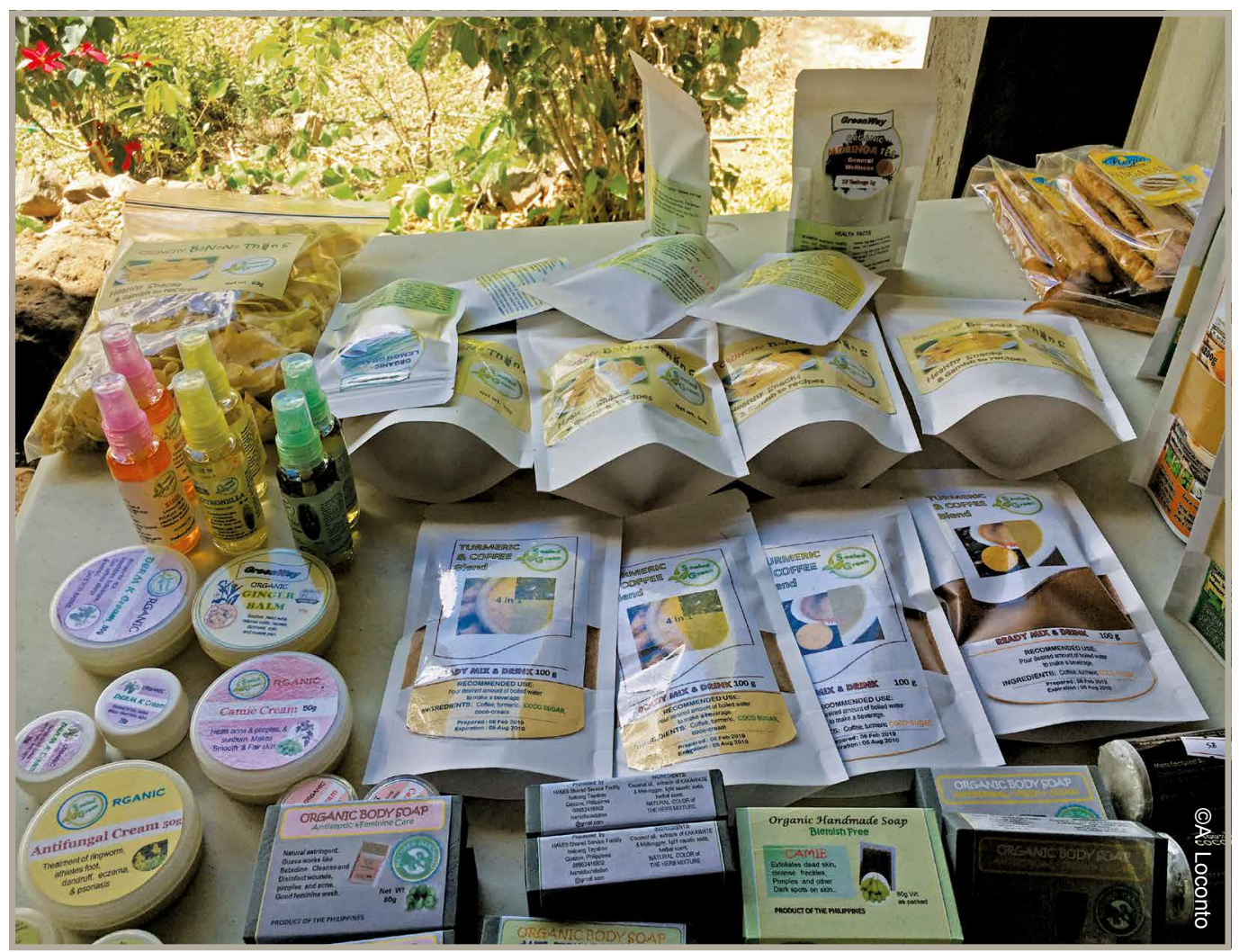




\section{4. ¿CÓMO PUEDE ETIQUETAR SUS PAQUETES?}

Las imágenes y los mensajes escritos que aparecen en los paquetes tienen dos propósitos: comunicar la información legalmente requerida sobre el producto, asi como sus valores y cualidades.

\subsection{Los aspectos legales del embalaje}

Aunque las regulaciones de embalaje difieren de un país a otro, la siguiente información es típicamente requerida: el nombre del producto, una lista de ingredientes, peso, valores nutricionales, información de contacto del productor o de la empresa, el lugar de origen, número de lote, fecha de producción y vencimiento, pautas de preservación e instrucciones de uso.

\section{Información obligatoria sobre el etiquetado (Colombia)}

La información que debe incluirse en las etiquetas de los productos se especifica en las leyes nacionales de etiquetado. En Colombia, la siguiente información es obligatoria: 1) las propiedades nutricionales; $y$ 2) los ingredientes enumerados, de la cantidad más grande a la más pequeña. El acceso a esta información, especialmente sobre los valores nutricionales, no siempre es una tarea fácil para los pequeños agricultores. La manera más precisa de obtener este tipo de información es hacer que sus productos sean probados en un laboratorio acreditado. Si esta no es una opción viable, se pueden obtener copias de las tablas de composición de los alimentos de las autoridades nacionales de inocuidad de los alimentos y nutrición. Algunas herramientas web también pueden crear etiquetas de valor nutricional para productos basados en recetas estándar. Antes de usar estos valores, es mejor validar los propios. A continuación, se muestran algunas herramientas útiles:

- El directorio internacional de la tabla/base de datos de composición de alimentos (INFOOD) contiene todos los cuadros oficiales de composición nutricional de los productos alimenticios medidos, y se ha actualizado constantemente desde 1988. Hay enlaces a bases de datos regionales que contienen información sobre alimentos específicos para las regiones.

http://www.fao.org/infoods/infoods/ tables-and-databases/en.

- Wolphram Alpha es un ejemplo de una herramienta gratuita en la que, al introducir su producto, se obtienen sus valores nutricionales, incluso si los valores proporcionados son para "productos estándar" y que puedan existir diferencias con estos valores según las características específicas del producto. https://www.wolframalpha.com/examples/ society-and-culture/food-and-nutrition.

- Recipal es una herramienta donde, por una pequeña suma, usted puede obtener los valores nutricionales de su producto/ recetas, así como guías útiles para diseñar su propia etiqueta. https://www.recipal.com.

Fuente: Jaime Aguirre, Óscar Nieto, Familia de la Tierra, Colombia. 


\subsection{Los aspectos de mercadeo del embalaje}

Puede incluir información adicional no obligatoria en el paquete para que sea más atractivo para los consumidores. Esto puede incluir:

- etiquetas ambientales y/o sociales que se otorgan a los agricultores que cumplen con criterios específicos de producción o comercio (por ejemplo, orgánicos, comercio justo, verificados como no OGM); estas etiquetas son fácilmente reconocidas por muchos consumidores que las equiparan con la sostenibilidad y el comercio ético;

- su marca, que ayuda a los consumidores a distinguir sus productos de los de sus competidores,

- reivindicaciones sobre los valores nutricionales específicos de su producto (por ejemplo: bajo en o sin grasa, alto en fibra, bajo en o sin azúcar, sin grasas trans, etc.);

- reivindicaciones sobre los beneficios para la salud de su producto (por ejemplo, "el yacón ayuda a regular los niveles de azúcar en la sangre, lo cual es bueno para tratar la diabetes"). Advertencia: Algunos países regulan estrictamente las reivindicaciones de propiedades saludables de los productos, así que verifique las normas de su país y las del país al que desea exportar (por ejemplo, la UE tiene leyes de etiquetado muy estrictas sobre las reivindicaciones de propiedades saludables), y/o

- una narración personal sobre quién es usted, cómo vive, cómo cultiva o produce el producto; el texto suele ir acompañado de una imagen del agricultor o productor (al compartir la historia detrás del producto, el consumidor puede sentirse como si le conociera).

Tenga mucho cuidado con las afirmaciones de marketing que haga sobre sus productos, ya que algunos de ellas están regulados por las leyes de alimentos. Las reivindicaciones sobre los beneficios de salud tienden a ser estrictamente reguladas, y usted puede ser sancionado por hacer declaraciones falsas.

\section{CONSEJO 30}

\section{Empaquetar productos sostenibles que venden}

- Aunque el embalaje desempeña un papel importante en la conservación de los productos, también es muy importante para la comunicación de valor.

- Para satisfacer mejor las necesidades de los intermediarios y consumidores, se pueden utilizar diferentes formas de envasado en diferentes etapas de la cadena de suministro. Algunos tipos de materiales de embalaje son incluso reutilizables.

- La adopción de envases sostenibles desde el punto de vista medioambiental puede reducir los costos (especialmente si se utilizan materiales reciclados), reducir el impacto medioambiental y los residuos, siendo estéticamente agradable.

- El espacio para las etiquetas de un producto empaquetado es limitado: ¡elija lo que comunica con prudencia! 


\section{LA AVENTURA DEL APRENDIZAJE, ¿DÓNDE SEGUIR?}

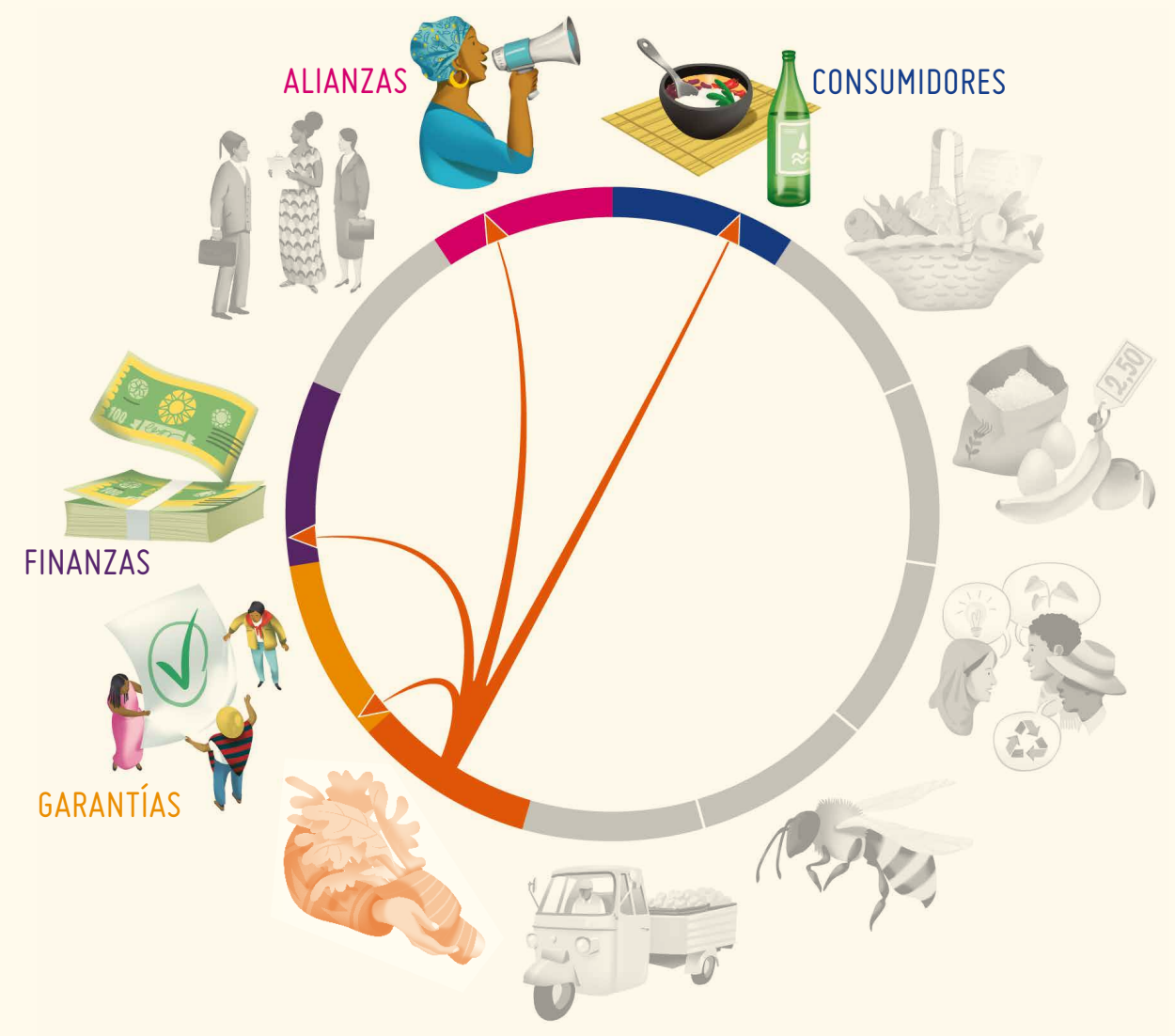

¿Quiere saber qué valores incluir en su paquete? Vaya al Capítulo 1: Atraer a los consumidores y mantenerlos comprometidos.

- ¿Está pensando en colaborar con una imprenta profesional para diseñar su embalaje? Vaya al Capítulo 11: Alianzas y promoción.

- ¿Desea invertir en tecnología de procesamiento y envasado, pero no tiene fondos suficientes? Vaya al Capítulo 9: Financiamento innovador, para explorar algunas ideas.

- ¿Quiere incluir etiquetas de sostenibilidad como «orgánico» en su paquete? En primer lugar, asegúrese de que puede garantizar ese estándar de calidad... el Capítulo 8: Garantías para la sostenibilidad, le dirá más sobre esto.

0 puede que quiera leer otro capítulo... justed es quien más sabe! 



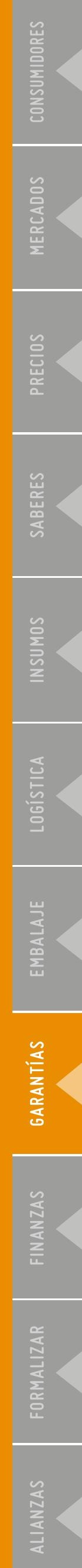




\section{1. ¿POR QUÉ ESTO ES IMPORTANTE?}

Dado que la agricultura sostenible no es practicada por todos los productores, es fundamental diferenciar entre ellos.

Los productores, intermediarios y consumidores utilizan un sistema de garantía para validar que los alimentos intercambiados que se producen de manera sostenible.

\section{2. ¿QUÉ ES UNA GARANTÍA?}

Una garantía es una promesa de que algo se ha hecho y se hará. Puede ser tan simple como una promesa verbal de cumplir con la práctica sostenible (una garantía informal), o tan complejo como una afirmación formal, certificada por terceros, de que un producto, persona o proceso cumple con ciertos estándares de sostenibilidad o calidad preestablecidos.

Es necesaria una garantía para fomentar la confianza de los consumidores. Esta asegura la consistencia en la calidad del producto, protege a los consumidores contra el fraude, y confirma que el producto cumple con las prácticas de producción sostenible.

Un sistema de garantía es la provisión sistemática de una garantía. Por lo general, sigue un estándar de producción y reglas operativas escritas. A los productores o procesadores se les suele conceder un certificado que demuestra su sostenibilidad. Existen diversas formas de garantizar que se sigan las prácticas sostenibles.

\subsection{Autodeclaración}

En este tipo de garantía, los productores se certifican a sí mismos. Una autodeclaración se asocia con varios grados de formalidad. Puede ser una garantía simple e informal expresada verbalmente a los consumidores, como la "garantía de devolución de dinero" (si los consumidores no están satisfechos con un producto, el vendedor promete reembolsarles). Un tipo más formal de autodeclaración consiste en completar un formulario escrito de autoevaluación o una promesa presentada al intermediario transparente o comprador. El beneficio de este tipo de garantía es que crea confianza entre los productores y los consumidores que se reúnen y se comunican regularmente. Sin embargo, la información falsa también es común y difícil de detectar cuando los productores y los compradores rara vez se encuentran cara a cara.

\section{Pros}

+ sin costo o a costo bajo;

+ La mayoría de los formularios son fáciles de rellenar;

+ no hay auditorías externas.

\section{Contras}

- la información falsa es común;

- algunos formularios son difíciles de rellenar;

- normalmente, no se permiten etiquetas en el paquete. 


\subsection{Auditoría de los actores}

En este tipo de garantía, también llamada certificación de segunda parte, la evaluación es implementada por un intermediario transparente o un procesador interesado en la auditoría de productores. Los ejemplos incluyen un procesador que audita a los proveedores de sus agricultores, o una organización que certifica a sus miembros, en cuyo caso el proceso se conoce como Sistema de Control Interno (SCI).

\section{Pros}

+ bajo costo,

+ los formularios suelen ser rellenados por la segunda parte, no por los agricultores,

+ sin auditorías externas,

+ a veces los agricultores pueden poseer sus propios certificados,

+ los productores a veces pueden aplicar una etiqueta en el envase.

\section{Contras}

- no se visitan todas las granjas,

- se pueden producir informes falsos,

- la inspección aleatoria (en virtud de un SCI) abre el riesgo al abuso e incumplimiento

- los certificados son a menudo utilizados internamente por el comprador o cooperativa/ asociación, y no pueden ser utilizados para otros mercados

\subsection{Sistema de inspección, certificación y acreditación}

Este sistema de garantía, también llamado certificación de terceros, es el más formal, ya que requiere múltiples niveles de control. La evaluación es realizada por un organismo externo acreditado por el Gobierno, sin intereses financieros o comerciales en la granja u organización evaluada.

Pros

+ es la única garantía reconocida por la regulación pública (excepto en algunos países),

+ requisito de exportación (para acceder a los mercados de EE.UU., la UE, Japón, China y Canadá, entre otros),

+ algunas certificaciones son aceptadas en múltiples mercados,

+ las cooperativas de agricultores pueden utilizar internamente un $\mathrm{SCl}$ de una segunda parte, $\mathrm{y}$ hacer que su SCl sea auditada por un tercero;

+ los productores suelen aplicar una etiqueta en el envase.

\section{Contras}

- muy costoso,

- se requiere mucha documentación,

- no se permite la participación,

- sin control social,

- los certificados se conceden al grupo (SCI), ONG o empresa exportadora, no a agricultores individuales,

- las normas se revisan sistemáticamente y a veces se relajan para facilitar el proceso de certificación,

- la inspección aleatoria (en virtud de la SCI) abre el riesgo el abuso y al incumplimiento;

- los agricultores pagan a los certificadores directamente por la auditoría (a veces se compran certificados), creando un conflicto de intereses inherente. 


\subsection{Sistemas híbridos}

Existen múltiples sistemas que "mezclan" diferentes formas de garantía. Por ejemplo, se puede combinar la declaración propia y la certificación de terceros, como en el caso de determinadas mesas redondas sobre productos básicos del sector privado. Los agricultores rellenan formularios sobre su rendimiento, y se selecciona aleatoriamente una muestra representativa de las granjas para que sea auditada por un tercero certificador. Las garantías de segunda y tercera parte también pueden combinarse, como en el caso de Rainforest Alliance. En todos los sistemas, las garantías informales a menudo juegan un papel.

Pros

+ Estos sistemas mixtos son a menudo adoptados por marcas privadas, por lo que hay grandes mercados para productos tropicales individuales (por ejemplo, té, café, aceite de palma, soya, cacao).

* La mezcla de diferentes formas de garantía puede ayudar a evitar el fraude, que es común en los sistemas que dependen de un solo tipo de garantía.

+ Los sistemas mixtos implican una mayor colaboración, por lo que la posibilidad de utilizar algunos informes para más de un sistema de garantía puede reducir la carga administrativa de los productores.

\section{Contras}

- Persisten algunos retos en la certificación de segundas y de terceras partes, en particular los relacionados con los costos y la documentación.

- Las múltiples formas de garantía generan mucha burocracia y mecanismos de retroalimentación lentos.

- Algunos consumidores consideran la mezcla de garantías como una estrategia corporativa para reducir el rigor de las auditorías de terceros, entendidas como las más sólidas. Esto puede reducir la confianza de los consumidores.

\section{Rainforest Alliance (República Unida de Tanzanía)}

Rainforest Alliance utiliza tanto la certificación de segundas como la de terceras partes para designar su etiqueta de "rana verde". Las granjas son evaluadas anualmente por el equipo de verificación de Rainforest Alliance, y son auditadas por un certificador acreditado cada tres años. Las auditorías de terceros de Rainforest Alliance consisten principalmente en auditorías de documentos (para asegurar que se estén informando sobre los planes de mejora), así como algunas visitas físicas ocasionales a la granja para tratar los principales incumplimientos. Cada tres años, el auditor externo visita la granja, decide renovar o revocar el certificado, y envía el informe a Rainforest Alliance. Basándose en este informe y en sus propias auditorías, Rainforest Alliance decide si la granja será certificada para el siguiente período de tres años.

Fuente: Allison Loconto, INRAE.

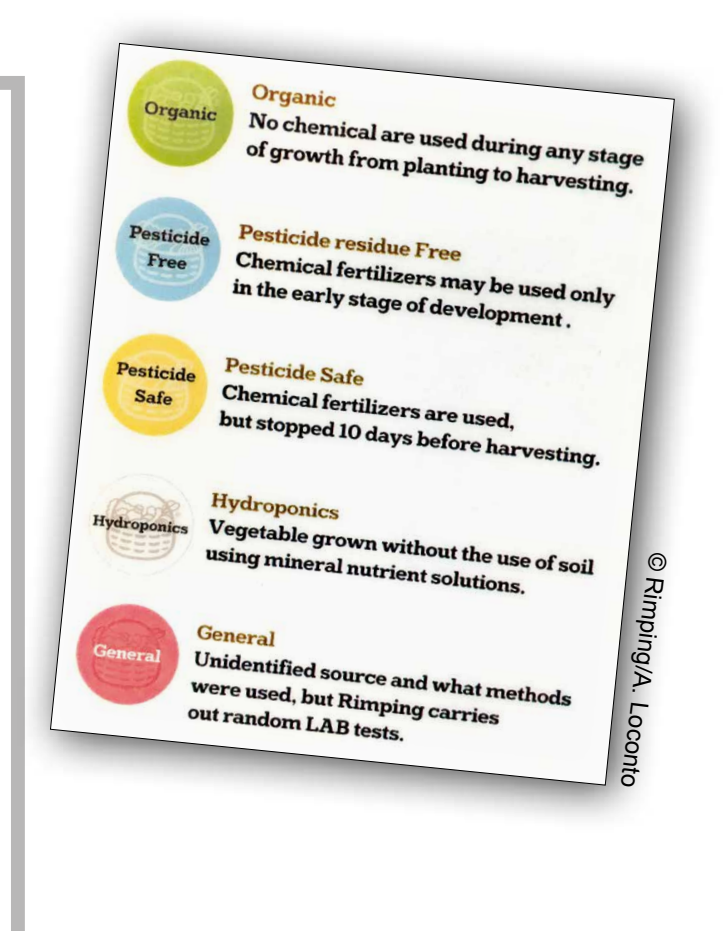




\subsubsection{Sistema Participativo de Garantía (SPG)}

Los SPG utilizan elementos tanto de autodeclaración como de certificación de segunda parte, y son esencialmente sistemas de garantía de calidad enfocados localmente que certifican a productores basados en la participación activa de agricultores, consumidores y otros actores locales. Los agricultores se comprometen a seguir las normas orgánicas, y un grupo de actores (generalmente compuesto únicamente por agricultores, o una mezcla de agricultores, consumidores y un agrónomo) realizan visitas de campo a intervalos regulares de tiempo - pueden ser mensuales, bianuales o anuales. Se establece un Comité de SPG con representantes de todos los grupos de interesados, que revisa el informe y determina si la certificación debe concederse o no. Estos grupos pueden trabajar de manera autónoma para garantizar el cumplimiento de las etiquetas privadas, o pueden asociarse con agencias públicas para garantizar el cumplimiento de las normas orgánicas nacionales.

\section{Pros}

+ bajo costo,

+ proporciona acceso, información e intercambio de conocimientos,

+ todos los actores participan; los consumidores participan en el proceso de garantía de productos, lo que refuerza el apoyo a la producción;

+ proporciona acceso al mercado debido a un contacto más estrecho en cadenas de suministro más cortas;

+ los grandes intermediarios, hoteles y restaurantes pueden entender los procesos que experimentan los productores, $y$ tienden a ser más favorables a la producción.

+ apoya el mercado y economías locales;

+ promueve la transparencia,

+ promueve el empoderamiento de los agricultores,

+ promueve el control social,

+ reglas predeterminadas para el incumplimiento

+ Desarrollado de acuerdo con las condiciones y necesidades de los pequeños agricultores

+ método de certificación no jerárquico

\section{Contras}

- no reconocido por algunos reguladores públicos,

- los productores probablemente no conozcan los $S P G$, a menos que una $0 \mathrm{NG} /$ investigador les comente acerca de esta,

- falta de información nacional e internacional sobre los SPG,

- requiere mucho tiempo y requiere esfuerzos (por parte de productores, consumidores y otros actores) para desarrollar un mecanismo verdaderamente participativo,

- se necesita un apoyo financiero considerable para apoyar otras actividades para los agricultores, es decir: capacitación sostenida, actualizaciones de tecnologías y avances en la aceptación mundial de los SPG (cuando el apoyo de las ONG es limitado);

- falta frecuente de participación activa de los consumidores (a menos que cuente con el apoyo de las ONG o del Gobierno). 
$x$
m
2
0
0
0 certificación de multiactores, que garantiza a los consumidores que todos los productos vendidos en el mercado campesino semanal cumplen con las normas orgánicas. Los pasos implicados en su proceso de certificación son:

1. Autorevisión: el agricultor está capacitado en estándares orgánicos, reglas y procesos de SPG antes de presentar una solicitud a un revisor de pares que determina si la granja está calificada para la inspección.

2. El revisor par realiza una inspección de la granja y presenta un informe al comité de revisión.
3. El revisor del comité evalúa el informe y toma una decisión:

a. si se aprueba, el comité remite la decisión al comité de gestión de Quezon PGS de expedir el certificado.

b. si se rechaza, el informe vuelve al revisor par, que notifica al agricultor y al comité de gestión de Quezon PGS. En este caso, el grupo de agricultores puede hacer correcciones y someterse a otra visita de revisión por pares en seis meses.

4. El Comité de gestión de Quezon PGS emite la certificación.

5. El par revisor entrega la certificación al agricultor.

Fuente: Carmen Cabling, Quezon PGS, Filipinas.

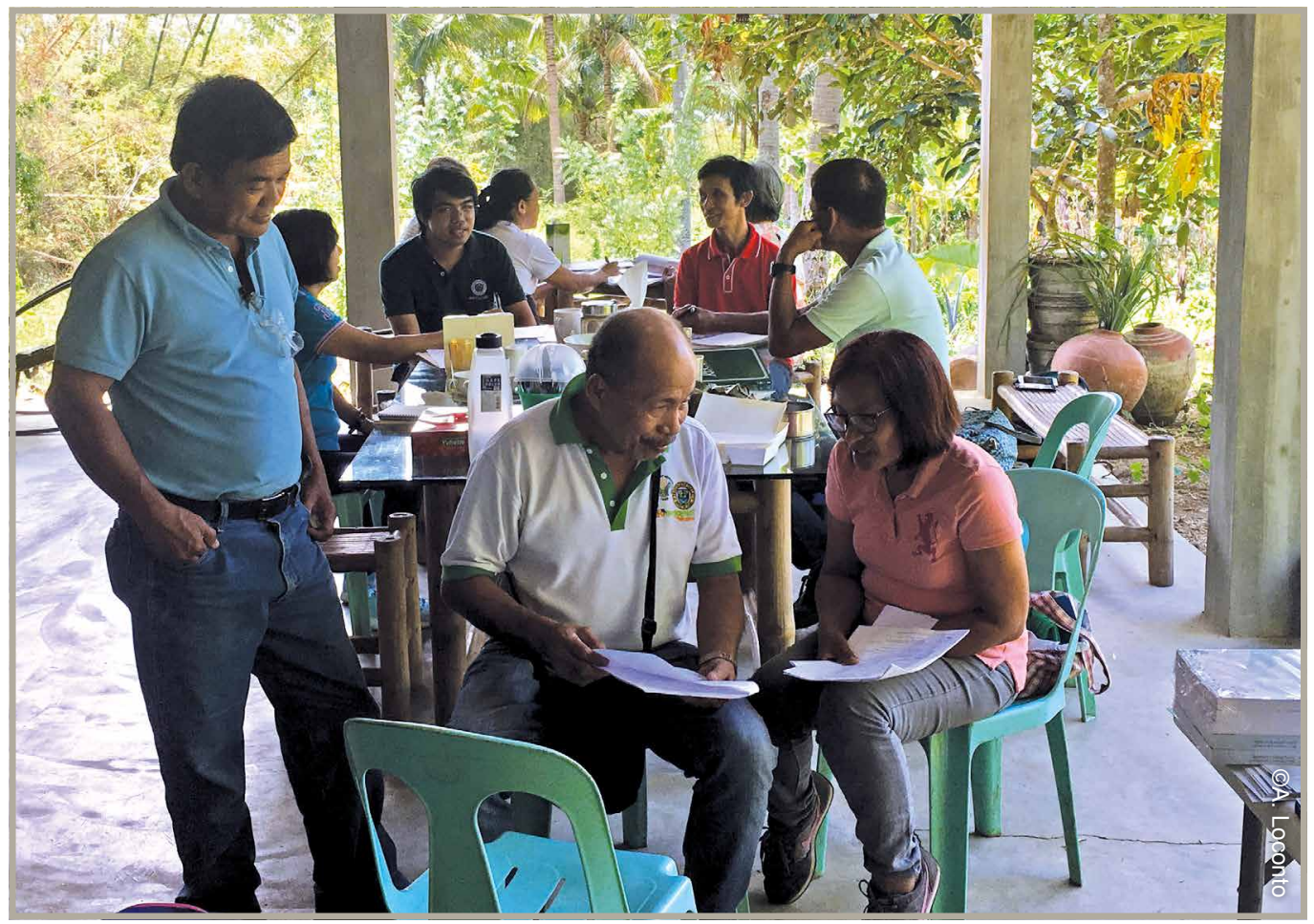




\section{ELEGIR SU SISTEMA DE GARANTÍA}

Antes de elegir el sistema de garantía más adecuado, es útil recopilar información sobre los sistemas de certificación que operan en su área para tomar la mejor decisión.

\section{CONSEJO 31}

Recopile información sobre los sistemas de garantía de su zona

a. ¿Qué iniciativas están adoptando sistemas de certificación para los productos producidos de manera sostenible?

b. ¿Cuál es el perfil organizativo de la iniciativa?

c. ¿Está la iniciativa legalmente registrada?

d. ¿Cuántos sistemas o productos agrícolas han sido certificados?

e. ¿Cuáles son las cuotas de participación?

f. ¿Se ofrecen servicios adicionales a los miembros a través del sistema de certificación?

g. ¿En qué mercados venden sus productos?

Para saber dónde funcionan los diferentes sistemas de garantía, consulte:

- El ITC Standards Map (http://www.standardsmap.org/)

- El Ecolabel Index (http://www.ecolabelindex.com/)

- El IFOAM PGS Map (https://pgs.ifoam.bio/)

Una vez que haya recopilado suficiente información sobre qué sistemas existen ya, comience a pensar en las garantías que corresponden a sus mercados objetivo y determine el costo de cada opción.

\section{1. ¿Cómo se construye la confianza en cada sistema de garantía, y en qué mercado es más eficaz esta confianza?}

Los mercados suelen definir el tipo de sistema de garantía utilizado en los procesos de certificación. Los diferentes mercados, y los consumidores que los componen, exigen diferentes tipos de garantías; esto suele estar relacionado con la forma en que se construye la confianza dentro del sistema de garantías. Por ejemplo, en los mercados barriales, las autodeclaraciones podrían bastar, ya que productores y consumidores se conocen entre sí. Mientras tanto, para mercados distantes, como los de exportación, en los que es imposible que consumidores y productores se reúnan, se puede aceptar un SPG y se puede exigir una certificación de terceros. 
Cuadro 10: ¿Cómo se construye la confianza en diferentes sistemas de garantía?

\begin{tabular}{|c|c|c|}
\hline $\begin{array}{l}\text { ¿Cuál sistema de } \\
\text { garantía? }\end{array}$ & ¿Cómo se construye la confianza? & ¿Qué mercado? \\
\hline Autodeclaración & $\begin{array}{l}\text { La confianza se basa en interacciones } \\
\text { directas y repetidas entre productores y } \\
\text { consumidores. }\end{array}$ & $\begin{array}{l}\text { Mercados barriales y locales con } \\
\text { relaciones directas entre productores } \\
\text { y consumidores. }\end{array}$ \\
\hline $\begin{array}{l}\text { Auditoría de } \\
\text { los actores }\end{array}$ & $\begin{array}{l}\text { La confianza se basa en interacciones } \\
\text { directas y repetidas entre el intermediario } \\
\text { o procesador transparente y los } \\
\text { consumidores. }\end{array}$ & $\begin{array}{l}\text { Mercados locales o nacionales } \\
\text { con relaciones directas entre } \\
\text { intermediarios o intermediarios } \\
\text { transparentes y consumidores. } \\
\end{array}$ \\
\hline $\begin{array}{l}\text { Auditoría de } \\
\text { terceros }\end{array}$ & $\begin{array}{l}\text { La confianza se basa en la independencia } \\
\text { del organismo de certificación y en la } \\
\text { acreditación de las autoridades públicas. }\end{array}$ & $\begin{array}{l}\text { Mercados nacionales e } \\
\text { internacionales en los que los } \\
\text { consumidores tienen pocas } \\
\text { posibilidades de conocer } \\
\text { directamente a los operadores de } \\
\text { sistemas alimentarios sostenibles; } \\
\text { la confianza se construye a través de } \\
\text { certificadores profesionales. }\end{array}$ \\
\hline $\begin{array}{l}\text { Sistemas } \\
\text { Participativos de } \\
\text { Garantía }\end{array}$ & $\begin{array}{l}\text { La confianza se basa en la participación } \\
\text { directa de todos los actores, lo que } \\
\text { significa que los consumidores confian } \\
\text { en este sistema ya sea porque participan } \\
\text { activamente en el proceso de certificación } \\
\text { o porque tienen relaciones directas con } \\
\text { otros actores que participan en el sistema } \\
\text { de garantía (productores, intermediarios } \\
\text { transparentes u otros consumidores). }\end{array}$ & $\begin{array}{l}\text { Mercados locales y nacionales con } \\
\text { relaciones directas entre los actores. }\end{array}$ \\
\hline ¿otros? & $\ldots$ & $\ldots$ \\
\hline
\end{tabular}

\section{Supermercados SPAR/SUPERSPAR} (Namibia)

SUPERSPAR, una filial de la franquicia

holandesa SPAR, es una cadena de supermercados en Namibia. En su tienda de Maerua, SUPERSPAR ha introducido la "Nuez de la Salud", una sección del supermercado que ofrece una gama de productos orgánicos, desde productos frescos hasta productos procesados y cosméticos.

En su sitio web, SUPERSPAR anuncia que "nuestras hierbas y verduras orgánicas producidas localmente se cultivan bajo estrictas regulaciones de la Asociación
Orgánica de Namibia (NOA) y por lo tanto están acreditadas como orgánicas. Disfrute de una variedad de verduras frescas, ensaladas completas o hierbas intensas".

Las normas privadas de la NOA comprenden las únicas regulaciones nacionales para los alimentos orgánicos debido a la falta de un organismo público de regulación orgánica. Las normas NOA utilizan un SPG para garantizar su calidad orgánica, demostrando que es posible que los supermercados respeten formas alternativas de garantía.

Fuente: Manjo Krige,

Movimiento de Agricultura Orgánica de Namibia, http://www.weckevoigtsspar.com/in-store/health-nut. 


\section{2. ¿Cuánto cuesta?}

Las tasas y las estructuras de tasas varían según el tipo de sistema de garantía buscado y el área de operación. Mientras que la autodeclaración y la certificación de una segunda parte son generalmente baratas o no costosas en absoluto, la certificación de una tercera parte requiere honorarios. Lamentablemente, las tasas no están reguladas, y los certificadores no están obligados a publicarlas o anunciarlas. Determinar los costos requiere un poco de investigación:

1. En primer lugar, navegar por los sitios web de las organizaciones de normalización para determinar cuáles están presentes en su área; y en segundo lugar, revisar los sitios web de los certificadores para averiguar si sus honorarios han sido publicados;

2. Luego, debe ponerse en contacto con sus oficinas locales para obtener un costo estimado de certificación. Usted puede darse una vuelta y comparar honorarios si hay varios certificadores en su área.

Cuadro 11: ¿Cómo se comparan los costos entre los sistemas de garantía?

\begin{tabular}{|c|c|c|}
\hline $\begin{array}{l}\text { ¿Cuál sistema de } \\
\text { garantía? }\end{array}$ & ¿Cuáles son las tarifas? & ¿Cuál es la estructura de tarifas? \\
\hline Autodeclaración & $\begin{array}{l}\text { No se requieren tarifas para este } \\
\text { sistema de certificación. }\end{array}$ & N.D. \\
\hline Auditoría de los actores & $\begin{array}{l}\text { No se requieren tarifas o estas son } \\
\text { muy limitadas para este sistema de } \\
\text { certificación. }\end{array}$ & $\begin{array}{l}\text { La estructura de tarifas puede variar } \\
\text { mucho dependiendo del auditor. La } \\
\text { estructura de tarifas de este sistema } \\
\text { puede calcularse en función de } \\
\text { todo el sistema agrícola o solo para } \\
\text { productos individuales. }\end{array}$ \\
\hline Auditoría de terceros & $\begin{array}{l}\text { Se requiere de honorarios para este } \\
\text { tipo de certificación y pueden ser } \\
\text { bastante altos. A veces hay tarifas } \\
\text { especiales para grupos de pequeños } \\
\text { agricultores. }\end{array}$ & $\begin{array}{l}\text { La mayoría de los terceros } \\
\text { certificadores calculan sus tarifas en } \\
\text { función del número de productos que } \\
\text { se certificarán en la granja, el número } \\
\text { de normas necesarias (por ejemplo, la } \\
\text { UE, Orgánica, NOP y Soil Association } \\
\text { pueden evaluarse durante la misma } \\
\text { auditoría), el tamaño de la granja y el } \\
\text { número de días de trabajo esperados } \\
\text { necesarios para llevar a cabo la } \\
\text { certificación. }\end{array}$ \\
\hline $\begin{array}{l}\text { Sistemas Participativos } \\
\text { de Garantía }\end{array}$ & $\begin{array}{l}\text { Las tarifas son acordadas por los } \\
\text { grupos SPG. No todos los SPG cobran } \\
\text { una tarifa. }\end{array}$ & $\begin{array}{l}\text { En el SPG, las tasas están destinadas } \\
\text { a cubrir la certificación de todo el } \\
\text { sistema agrícola, independientemente } \\
\text { del número de productos que } \\
\text { produzca. Si hay tasas, suelen ser } \\
\text { nominales, para cubrir los gastos de } \\
\text { transporte de las visitas a la granja. }\end{array}$ \\
\hline Otros & $\ldots$. & $\ldots .$. \\
\hline
\end{tabular}




\section{Certificación Fairtrade (FloCert)}

FloCert, el organismo de certificación de Fairtrade International, utiliza una calculadora de tarifas de certificación fácil de usar en su sitio web. Utilizando un cuestionario de selección múltiple, la plataforma de FloCert formula las siguientes preguntas sobre:

1. su tipo de organización (por ejemplo, pequeño productor),

2. el tipo de tarifa que desea calcular (inicial 0 anual),

3. el tipo de "grado" al que pertenecen sus miembros:

a. Primer grado, es decir, una pequeña organización de productores cuyos miembros son exclusivamente pequeños agricultores individuales.

b. Segundo grado, esto es, una pequeña organización de productores cuyos miembros son organizaciones de primer grado. c. Tercer grado, es decir, una pequeña organización de productores cuyos miembros son organizaciones de segundo grado.

4. el número de miembros en su organización,

5. el número de productos que usted tiene,

6. el número de instalaciones de procesamiento que posee; $y$

a. el número de obras en cada instalación.

7. el número de entidades subcontratadas que usted utiliza.

Después de la pregunta final, FloCert le proporciona al instante una estimación de la tasa total, disponible como una copia en PDF descargable, y dividida en costos de solicitud, certificación y cargos adicionales.

Fuente: http://www.flocert.net/ fairtrade-services/fairtrade-certification/fees.

\section{3. ¿Qué más está garantizado?}

\subsubsection{Servicios}

A veces, se ofrecen a los productores servicios como la capacitación como parte del sistema de garantía para crear la capacidad de los productores para aplicar prácticas agrícolas sostenibles.

\section{LISTA DE VERIFICACIÓN}

Preguntas sobre los servicios

1. ¿Se incluyen orientaciones y/o capacitaciones en el sistema de garantía?

2. ¿Se incluye el seguimiento y la orientación en el sistema? Si es así, ¿con qué frecuencia se haría esto (trimestral, en cada ciclo de cultivo, semestral)?

3. ¿Los responsables del sistema de garantía proporcionan continuamente actualizaciones sobre los nuevos avances en los sistemas alimentarios sostenibles después de la emisión de los certificados?

4. ¿Existen servicios adicionales ofrecidos en el sistema de garantía? 


\subsubsection{Alcance y equivalencia}

Algunas normas y sistemas de garantía proporcionan una equivalencia entre las normas nacionales, mientras que otras funcionan en más de un país. El sistema de garantía que usted elige usar puede dictar los límites de su mercado dependiendo de su área de cobertura. Al buscar el sistema de garantía óptimo, pregunte a los certificadores sobre el alcance y la equivalencia de la norma.

\subsubsection{Cumplir con la ley}

Es importante asegurarse de que el sistema de garantía que desea adoptar siga las leyes locales y nacionales que rigen la sostenibilidad.

Si desea comprobar la equivalencia de los diferentes sistemas de garantía, visite: http://www.ifoam.bio/sites/default/files/irocb_equitool_2012_0.pdf.

\section{LISTA DE VERIFICACIÓN}

\section{Cumplimiento legal}

1. ¿Existen leyes en su país con requisitos específicos para los sistemas de garantía?

2. ¿Sigue el sistema elegido los códigos y principios del CODEX, IFOAM, ISEAL, ISO o programas relacionados y acuerdos bilaterales entre países?

3. ¿Están reguladas por el Gobierno las palabras (orgánico/natural/ certificado/etc) y, en caso afirmativo, qué tipo de sistema de garantía se requiere para utilizarlos?

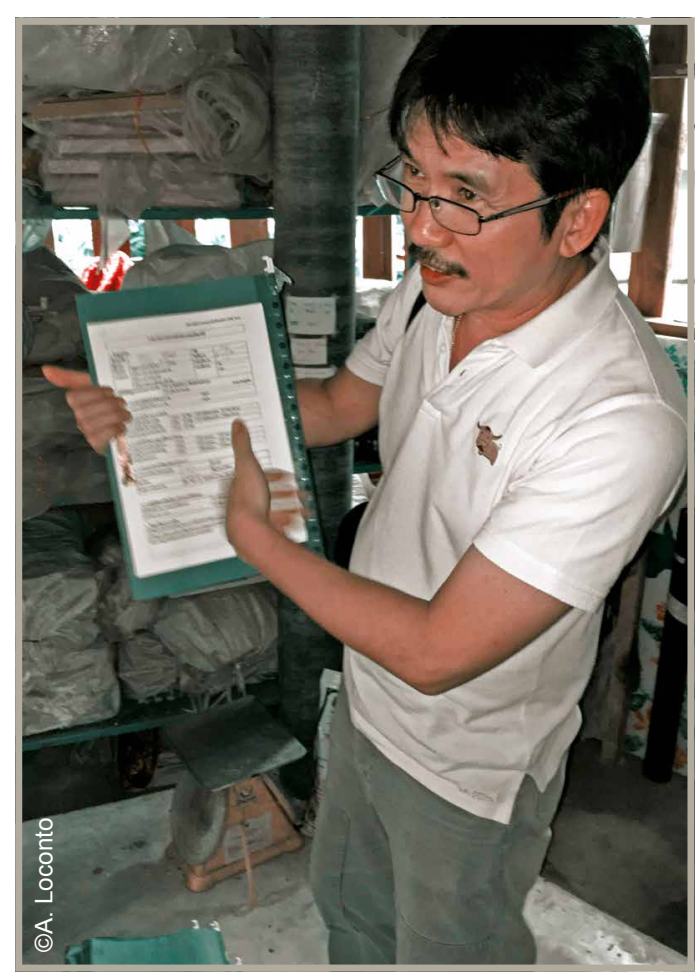




\section{4. ¿CÓMO COMUNICAR SU GARANTía?}

Dado que se establecen sistemas de garantía para diferenciar a los productores sostenibles de los no sostenibles, la comunicación con los consumidores es crucial. Dependiendo del sistema de garantía que usted decida implementar, el proceso de informar a los consumidores puede ser verbal, visual o una combinación de ambos.

1. Si solo se está comunicando verbalmente con, por ejemplo, una autocertificación informal, se deben seguir algunas técnicas sencillas para ser más eficaz: utilizar mensajes simples y claros para describir sus prácticas sostenibles.

2. La mayoría de los sistemas de garantía permiten el uso de etiquetas que los consumidores pueden asociar inmediatamente con una certificación específica. Si está usando una etiqueta, asegúrese de que se muestra en sus paquetes y en la comunicación escrita.

\section{5. ¿CÓMO PUEDE SU SISTEMA DE GARANTÍA AYUDAR A LOS AGRICULTORES A CUMPLIR CON NORMAS ADICIONALES?}

Siempre que sea posible, los sistemas de garantía simplifican los asuntos administrativos para los productores y los intermediarios transparentes, y deben hacerse esfuerzos entre los actores públicos y privados para reconocer mutuamente las garantías. Además de las normas de sostenibilidad, los agricultores también deben cumplir las normas de seguridad alimentaria, contratación pública y protección del medio ambiente. Al elegir un sistema de garantía, se debe considerar esta gama de normas.

\section{CONSEJO 32}

Simplificar y estandarizar los procesos administrativos

1. ¿Pueden sus grupos de agricultores ser utilizados como cooperativas legales que pueden ser registradas para subsidios públicos o servicios de extensión?

2. ¿Pueden utilizarse sus garantías para recopilar información sobre la seguridad alimentaria y registrar a los agricultores ante estas autoridades?

3. ¿Puede utilizar un certificado SPG para registrarse ante las autoridades de contratación pública?

4. ¿Se puede utilizar su sistema de garantía para realizar un seguimiento de los servicios de los ecosistemas o de la captura de carbono y registrar a sus agricultores para estos subsidios o mercados? 
SPG, registro de inocuidad de los alimentos y contratación pública (Bolivia)

67

En Bolivia, la "Ley de Agricultura Ecológica" (3525) ha autorizado un sistema nacional de reglamentación para los sistemas de garantía participativa. Cada SPG está registrado tanto en las oficinas municipales como con las autoridades nacionales, con el fin de acceder a los servicios de extensión locales (incluso para la producción ecológica) y utilizar la etiqueta orgánica nacional. Además, todos los SPG están registrados en la autoridad de seguridad alimentaria, lo que facilita la entrega de certificados que autorizan a los agricultores de SPG a vender a programas de contratación pública y a acceder a mercados formales en todo el país. Aunque los agricultores implementan sus SPG dentro de sus comunidades, pueden acceder a los mercados nacionales.

Fuente: Pilar Santacoloma, FAO.

\section{6. ¿QUÉ PASA SI NADIE PIDE UNA GARANTÍA?}

Algunos consumidores simplemente no están interesados en adquirir alimentos sostenibles. Si usted ya está produciendo de manera sostenible, puede que quiera prepararse para la posibilidad eventual de que los consumidores la pidan. Comience por desarrollar un componente de ventas directas en su estrategia de marketing, de modo que comience a construir un sistema de garantía informal con un subgrupo de sus consumidores.

\section{CONSEJO 33}

\section{Iniciar un sistema de garantía (cuando nadie lo pide todavía)}

El grupo de productores en cuestión puede:

- publicar un boletín informativo para informar y comunicar a la gente sobre temas relevantes de la granja, tales como seguridad, salud y garantía de suministro.

- comparta recetas y comunique temas de interés común y eventos sociales para atraer el interés de los consumidores y generar confianza.

- introduzca una política de reembolso razonable en caso de que los consumidores no estén completamente satisfechos con la calidad del producto. Este sistema tendrá que planificarse cuidadosamente, y ejecutarse adecuadamente con condiciones que desalienten cualquier tipo de abuso flagrante por parte de consumidores deshonestos.

- Invite a los consumidores a desempeñar un papel más importante en la granja: a través de visitas, proyectos de desarrollo colectivo, o incluso a través de la venta de participación en la cosecha (por ejemplo, con la construcción de un modelo ASC). 
declarar proactivamente sus prácticas sostenibles, mostrándolas en los puntos de recogida, en las furgonetas de entrega o en los paquetes, para aumentar la conciencia del consumidor, la confianza y la credibilidad en la granja. De hecho, se trata de una forma de garantía alternativa.

- elija ser más transparente. La divulgación voluntaria de información sobre las prácticas en la granja (lo bueno y lo malo) genera confianza.

- la creación de alianzas con otras granjas utilizando prácticas similares, crea confianza entre los agricultores y permite la diversificación de productos vendibles. En las primeras etapas, es importante organizar visitas a las granjas agrícolas, para conocer las prácticas de producción y comercialización de los demás.

\section{CONSEJO 34}

\section{Proporcionar una garantía}

- No todos los mercados requieren el mismo tipo de garantía.

- Al establecer su sistema de garantía, elija el enfoque en el que más confían sus principales consumidores.

- Compare los honorarios y las estructuras de honorarios entre los diferentes certificadores, y luego mida esto frente al precio que sus consumidores están dispuestos a pagar por sus productos.

- ¡Esté preparado! Si sus consumidores no exigen una garantía de sostenibilidad, configure su sistema de todas formas. Finalmente, jalguien está obligado a preguntar!

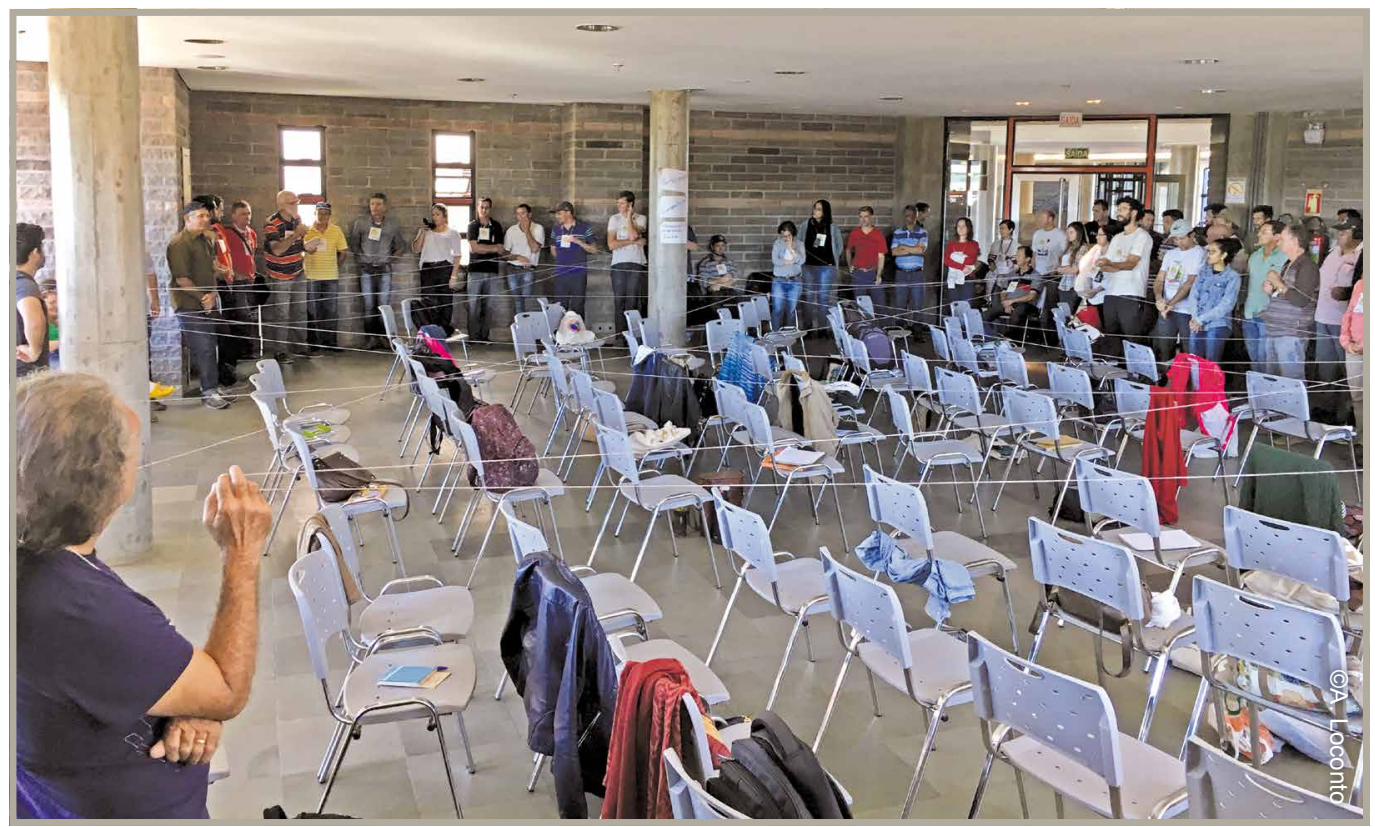




\section{LA AVENTURA DEL APRENDIZAJE, ¿DÓNDE SEGUIR?}

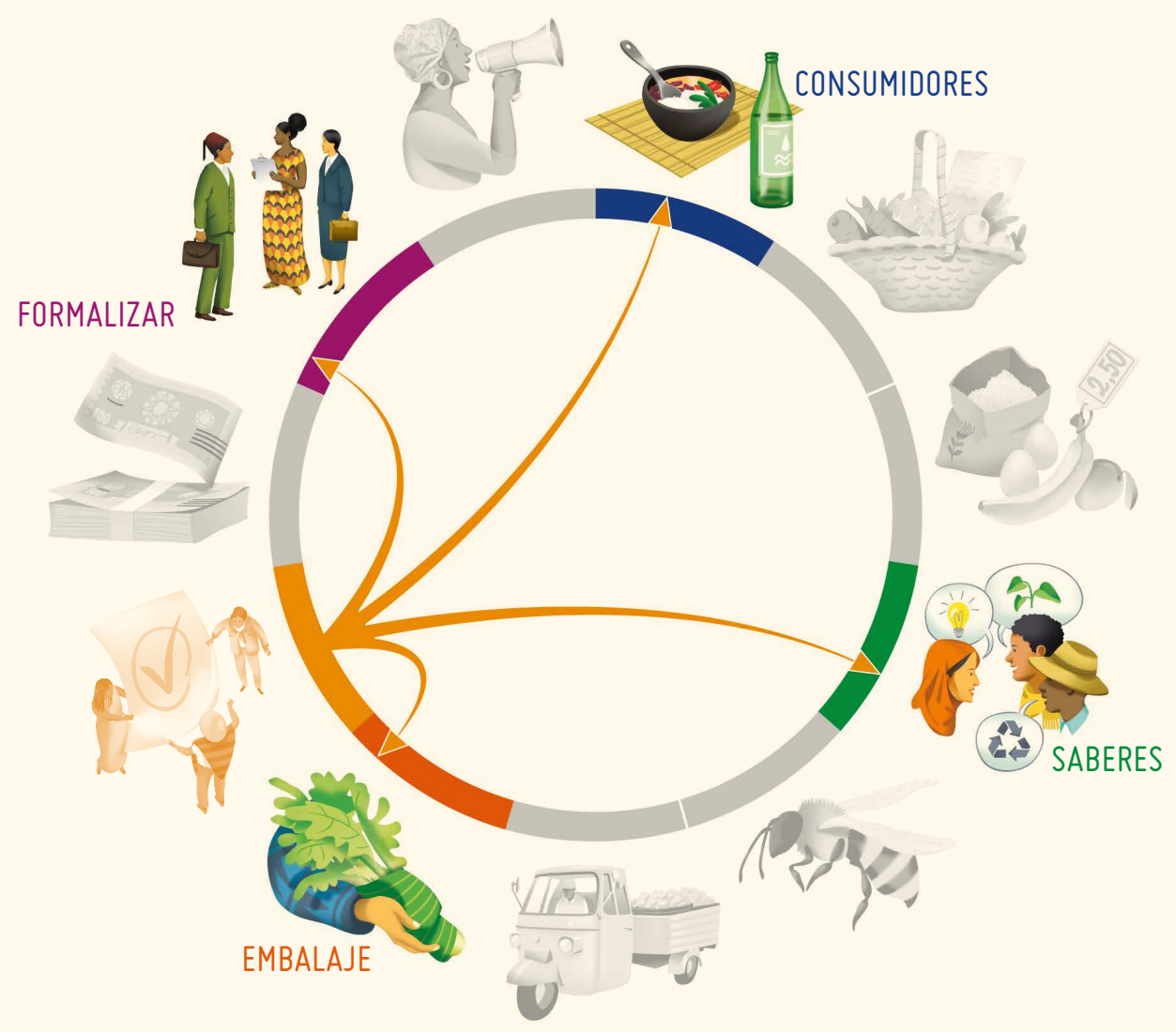

- ¿Desea obtener más información sobre cómo las etiquetas pueden ayudar a comunicar mejor los valores de su producto? Lea el Capítulo 7: Embalaje sostenible.

- ¿Quiere mejorar su comunicación con los consumidores? Pruebe algunos de los trucos descritos en el Capítulo 1: Atraer a los consumidores y mantenerlos comprometidos.

- ¿Desea proporcionar servicios de extensión en su sistema de garantía? Visite el Capítulo 4: Compartir y cocrear conocimientos para una producción sostenible, para obtener algunas ideas sobre cómo establecer uno.

- ¿Quiere que su sistema de garantía sea más formalizado, pero no está seguro de cuál es el modelo organizativo correcto? Aventúrese en el Capítulo 10: Formalizar el trabajo colectivo.

... o pase a otro capítulo de su elección... 


\section{ORGANIZARSE}

Uno de los aspectos más desafiantes de la construcción de sistemas alimentarios sostenibles, o la transición de un sistema convencional a uno sostenible, es organizarse. El cambio no puede suceder por sí solo, ni es responsabilidad de las personas. El cambio es un esfuerzo colectivo, dirigido a encontrar nuevas formas de colaborar que valoren las prácticas sostenibles.

En el siguiente grupo de capítulos, aprenderá sobre formas innovadoras de financiar la colaboración, técnicas y razones para mantener el equilibrio adecuado entre los colaboradores, ideas para cuándo asociarse con otros, y cuándo necesita obtener más apoyo del público o de los responsables políticos.

Si usted está lanzando una iniciativa, o está buscando ideas frescas, puede ser que desee comenzar su aventura aquí.

FINANCIAMIENTO INNOVADOR

FORMALIZAR EL

TRABAJO COLECTIVO

ALIANZAS Y PROMOCIÓN

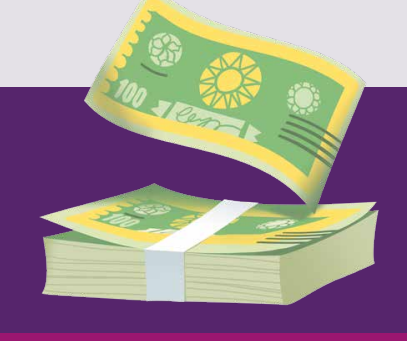



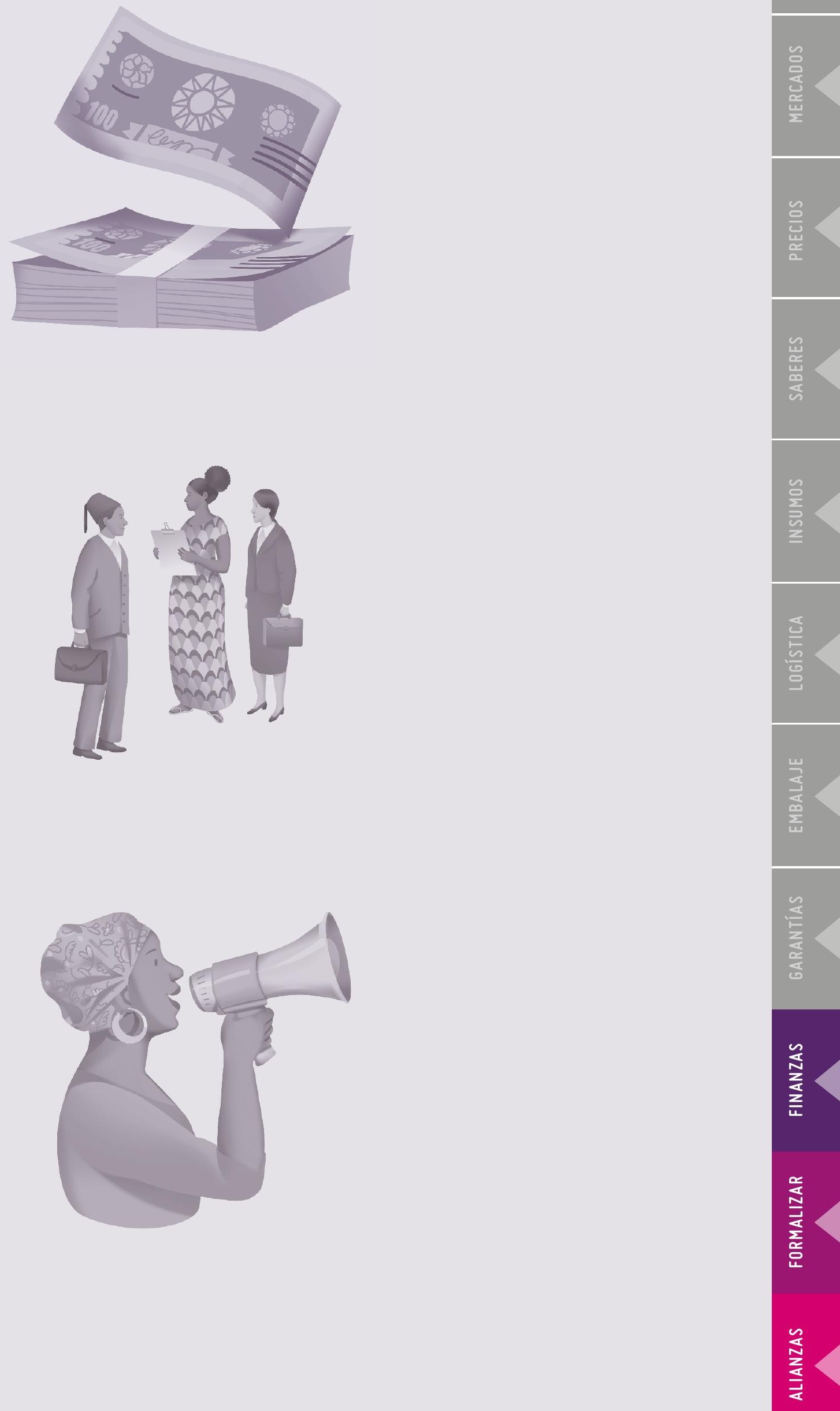


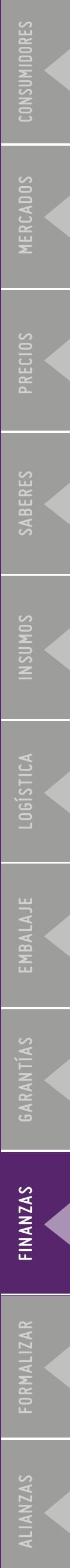


\section{1. ¿POR QUÉ ESTO ES IMPORTANTE?}

Asegurar la estabilidad financiera de las colaboraciones innovadoras plantea un desafio constante a muchos actores en los sistemas alimentarios sostenibles. Los modelos de negocio y la escala se consideran a menudo demasiado arriesgados o demasiado pequeños para calificar para los préstamos de bancos comerciales, y demasiado grandes para ser considerados por los programas de microfinanzas.

Para algunas iniciativas, la capacidad de crear independencia financiera de los bancos comerciales se incluye en su visión de un sistema alimentario sostenible.

\section{2. ¿CUÁLES SON LAS OPCIONES?}

Una iniciativa necesita financiación por tres razones principales:

1. Mantener las puertas abiertas: Debería haber suficiente dinero para cubrir los costos operacionales (es decir, personal, electricidad, transporte, espacio de oficinas) que permitan la iniciativa de conectar consumidores y productores sostenibles.

2. Inversiones: las innovaciones, mejoras, renovaciones, reemplazos, expansiones y otras actividades que van más allá de los costos normales de funcionamiento de la iniciativa.

3. Servicios: Los productores, los consumidores, los funcionarios públicos y otros agentes del sistema alimentario necesitan una serie de servicios que puedan facilitar la transición hacia la sostenibilidad (es decir, educación, capacitación, eventos, asistencia técnica, sistemas de garantía, espacios comunes, etc.). Algunos de estos servicios pueden cobrar una cuota, pero muchos otros requerirán financiamiento externo.

En general, esta financiación se puede obtener a través de dos fuentes de ingresos: interna y externa.

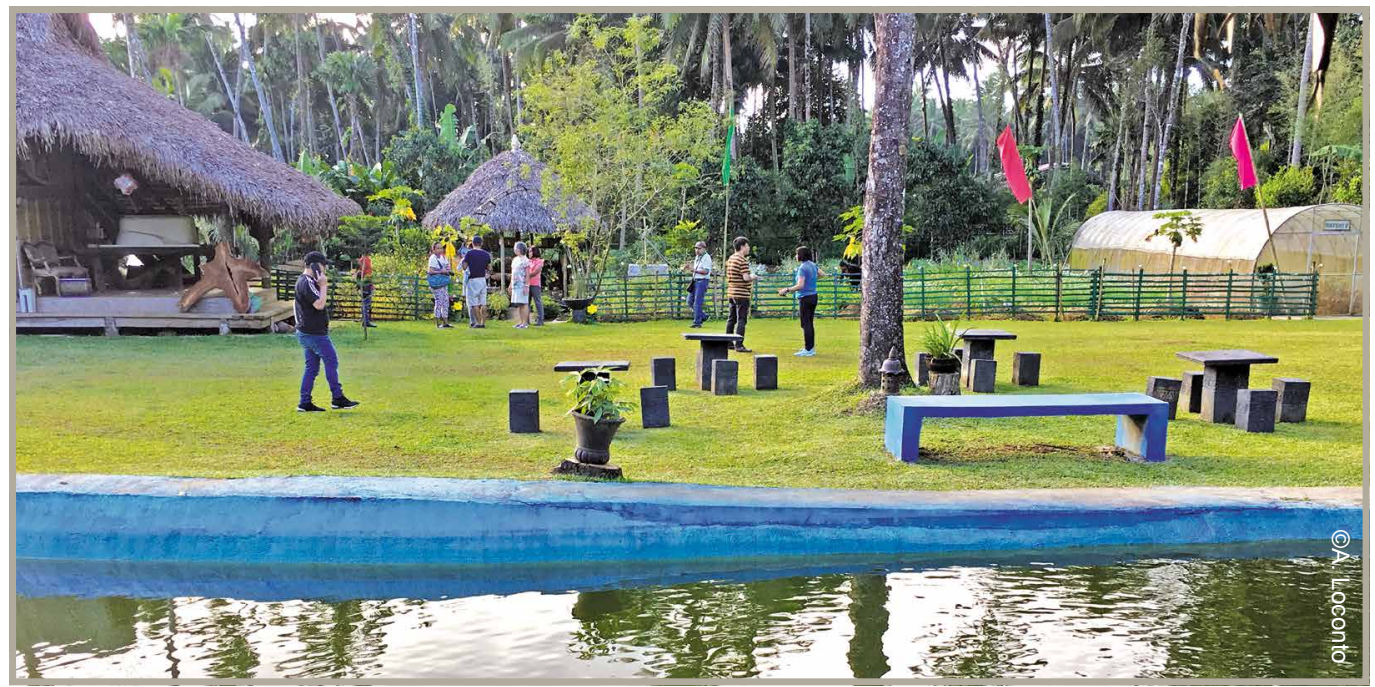




\subsection{Fondos internos}

Los fondos internos son el resultado de inversiones combinadas realizadas por diferentes actores (por ejemplo, agricultores, consumidores de ASC y accionistas) que comparten los riesgos de su iniciativa. Este dinero normalmente no es reembolsado. La ganancia generada por la venta de productos y servicios es la principal forma de financiación interna, aunque los miembros y socios también pueden beneficiarse de las ganancias que no se reinviertan en la iniciativa.

\subsubsection{Ventas de productos}

Es común que las iniciativas autofinancien sus operaciones, reinvirtiendo los ingresos del negocio (venta de productos y servicios) para pagar sus costos operacionales. Utilizar los ingresos en forma de efectivo o en especie (por ejemplo, un saco de arroz o café de los miembros agricultores) es una fuente financiera estable que debería ser la base de cualquier iniciativa.

\section{CONSEJO 35}

\section{Reinvierta dinero de las ventas de productos}

Mantenga un balance general con una columna de ingresos y gastos. Empiece por usar las ventas de productos para pagar sus gastos de operación.

- Si tiene más ingresos que gastos, piense en las inversiones que pueden aumentar las ventas de productos y permitir que la iniciativa crezca:

¿Quiere comprar equipo de procesamiento para añadir más valor a sus productos?

¿Necesita un camión para transportar mercancías?

- ¿Necesita puntos de recogida e instalaciones de almacenamiento para ampliar el alcance de su red de producción?

¿Puede ofrecer mejoramiento de capacidades o formación a los productores, consumidores o personal de la iniciativa?

¿Qué tal participar en conferencias o ferias comerciales para ampliar sus mercados, redes y conocimiento? Necesitará de un presupuesto de viaje para eso.

¿Puede contratar a algunas personas para que se especialicen en los servicios que ofrece a productores y consumidores?

¿Necesita espacio de oficina, tecnología de la información (TI) y suministros?

- ¿Puede empezar a ahorrar algunos de los fondos en una cuenta que devengue intereses por períodos de tiempo más largos para construir una reserva para emergencias financieras?

¿Necesita un espacio de venta a tiempo completo? Tener una vitrina de tienda permanente puede ayudar a los consumidores a saber dónde encontrarle. 


\subsubsection{Grupos de ahorro de miembros productores}

Muchas iniciativas se lanzan a través de una colaboración de productores que se han reunido recientemente para juntar mayores cantidades de sus productos. Una práctica cooperativa común es hacer pequeñas contribuciones de "capital" que se depositan en un fondo mutuo administrado colectivamente. Durante las asambleas generales, los miembros votan sobre cómo utilizar los ahorros. A menudo, se gastan en las necesidades de los miembros individuales, aunque también se pueden utilizar para inversiones más grandes destinadas a aumentar las capacidades individuales o colectivas. Los ahorros también son importantes para asegurar un fondo de emergencia en tiempos más dificiles.

סָ

El acceso a la financiación es un factor clave para el desarrollo empresarial de los pequeños agricultores. A lo largo de los años, se han adoptado planes comunitarios de ahorro y préstamo para mejorar la capacidad del grupo para acceder a los préstamos y ahorros. Esto da lugar a una capacidad colectiva para aumentar las inversiones agrícolas y los ingresos de las pequeñas empresas. PELUM Kenya se ha comprometido a promover la mejora de este modelo viable de agricultores para el desarrollo empresarial; algunos ejemplos incluyen grupos de agricultores, como el Grupo de Agricultores Kamicha Kabondo y el Grupo de Autoayuda TIKwenda Kwitu. En estos colectivos, los ahorros se utilizan como una inversión colectiva para crear capacidad comercial en lugar de un fondo rotativo individual.

Fuente: Rosinah Mbenya, PELUM Kenya.

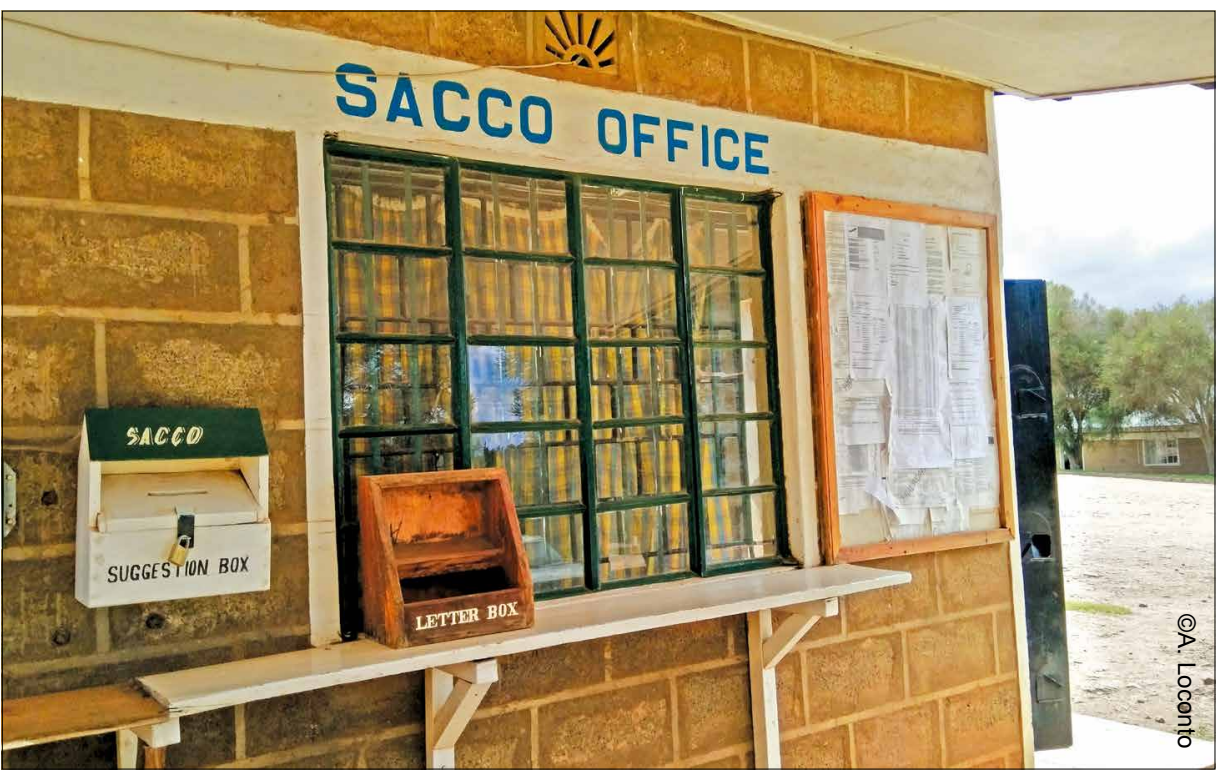




\subsubsection{Inversión de consumidores}

Convencer a los consumidores de que inviertan en la producción de bienes y servicios es un enfoque reciente para crear socios locales en una iniciativa. Como práctica común utilizada en los modelos cooperativos para fortalecer el compromiso productor-consumidor, los miembros pagarán una cuota anual que se utiliza en la iniciativa para cubrir los costos de operación. En las iniciativas de la ASC, los consumidores compran una participación agrícola al comienzo de la temporada de cultivo para proporcionar el dinero necesario para la producción.

\section{Hay muchas opciones para las contribuciones de los consumidores - isea creativo!}

\section{Crowdfunding (China)}

Shared Harvest Farm utilizó un mecanismo de crowdfunding basado en relaciones personales.

Durante las primeras etapas del proyecto, el equipo calculó sus necesidades financieras, y determinó que se necesitaban 150 miembros en el primer año, además de unos dos meses de flujo de caja (aproximadamente equivalentes a CNY 300.000). Shi Yan reunió a diez personas que conocía personalmente y que estaban dispuestas a invertir en los primeros cinco años de operación. Dado que el precio estimado de las verduras durante un año era de aproximadamente CNY 6.000 por familia (USD 940), un anticipo de pago a cinco años equivalía a CNY 30.000 (USD 4.700). Esta fuente de financiación era fundamental para Shared Harvest Farm, porque todos estos "inversionistas" esperaban consumir verduras orgánicas durante cinco años y se dedicaron a apoyar una nueva iniciativa sostenible

Fuente: Shi Yan, cosecha compartida, China.

\section{Controles verdes de los consumidores (Brasil)}

La Asociación de Consumidores de Productos Agroecológicos de Paraná (ACOPA), parte de la Red de Certificación Participativa Ecovida, conecta a consumidores agroecológicos y agricultores. A través de las visitas de campo a los agricultores, la asociación tiene como objetivo organizar a los consumidores e incentivar el intercambio de conocimientos y experiencias entre consumidores y productores. ACOPA también creó un mecanismo de Verificación Verde, que ayuda a los agricultores con inversiones basadas en el consumo. A través de este mecanismo, un grupo de consumidores paga una cuota para financiar las actividades de los agricultores. Los agricultores que reciban la Verificación Verde deberán reembolsar un importe equivalente con sus productos. Este mecanismo fomenta las relaciones de solidaridad y confianza.

Fuente: José Antonio da Silva Marfil, Ecovida. 


\subsubsection{Participación en la empresa comunitaria/ préstamos a los miembros}

Las empresas comunitarias, que pueden ser cooperativas legalmente registradas o grupos de agricultores, pueden reunir capital de sus miembros como accionistas. Los miembros pueden aumentar sus participaciones con el tiempo, y las ganancias se distribuyen a través de dividendos anuales. Esta propiedad colectiva proporciona una importante base de capital, y a menudo equivale a un mayor compromiso y participación de los miembros para superar períodos dificiles.

Las compras de cosecha estacional (como el arroz o el café) requieren grandes cantidades de capital para almacenar la materia prima. En el Nature Care Club, en Kut Chum, Yasothorn, Tailandia, los miembros ahorran dinero a una tasa de interés mucho mejor que la ofrecida por los bancos, mientras que la empresa campesina paga mucho menos en intereses de lo que pagaría por un préstamo bancario. Esto ahorra mucho dinero a la empresa y al mismo tiempo fortalece la riqueza de la comunidad.

\section{CONSEJO 36}

\section{Usar un presupuesto participativo}

El presupuesto participativo nace de los ejercicios del sector público para tratar de incluir a los ciudadanos en las decisiones sobre cómo gastar los fondos públicos. Sin embargo, el enfoque participativo puede aplicarse fácilmente a las iniciativas privadas de sostenibilidad sin una estructura organizativa dominante. A continuación, se ofrecen varios consejos sobre cómo llevar a cabo un ejercicio presupuestal participativo:

1. Evitar demasiados detalles: Si bien usted puede tener números detallados disponibles, trate de usar algo más sencillo para su proceso participativo. El propósito principal es entender las prioridades, no cuántos centavos se asignan. Así que, comience con números enteros, incluso que se redondeen por debajo de su presupuesto real, y utilice éstos para discutir posibilidades.

2. Debate abierto solo sobre partidas presupuestales que usted esté dispuesto a cambiar: Algunas partes de su presupuesto son simplemente inflexibles, a saber, los costos operativos (por ejemplo, facturas de electricidad, alquiler, etc). Debe centrar la discusión en las posibles inversiones que se deben realizar y en cualquier aumento o disminución de los costos de personal. Haga accesible todo el presupuesto para garantizar la transparencia y la confianza dentro de su iniciativa.

3. Esté preparado para explicar las consecuencias reales de decisiones presupuestales específicas: Reconozca las posibles consecuencias de los recortes presupuestales (es decir, reducir el presupuesto de transporte en un $20 \%$ significa que habrá que reducir el número de entregas). Lo mismo se aplica a los aumentos de presupuesto 0 a las inversiones. Especifique los tipos de beneficios que un nuevo espacio de oficina puede ofrecer a corto y largo plazo. Si usted está pidiendo a la gente que participe de una manera significativa, las consecuencias de sus opciones necesitan ser entendidas claramente.

4. Trate de vincular discusiones en línea y físicas sobre el presupuesto: Antes de discutir presupuestos dentro de sus asambleas generales u otras reuniones cara a cara, las herramientas de presupuestos participativos en línea se pueden utilizar para comenzar este proceso. Las herramientas en línea pueden evitar un sentimiento de exclusión entre los miembros que no pueden asistir. Utilice siempre herramientas TIC que sean apropiadas para sus comunidades. Si una gran parte de sus productores y consumidores no tienen acceso a Internet, entonces una herramienta en línea es redundante e ineficaz. 


\subsection{Fondos externos}

Estos provienen de fuentes que no tienen participación en la iniciativa y que son consideradas como "acreedores", es decir, personas y organizaciones que dan o prestan dinero. Dependiendo del tipo de fuente externa, es posible que tenga que pagar algún dinero si es un préstamo(no es necesario reembolsar los subsidios).

\subsubsection{Fondos públicos}

A escala mundial, los gobiernos suelen proporcionar a los ciudadanos fondos para subvencionar determinados tipos de producción agrícola o estimular las economías locales. Las grandes subvenciones suelen ser administradas a nivel nacional por organizaciones públicas o privadas, y no son fácilmente accesibles para los pequeños productores o innovadores que están en transición hacia sistemas alimentarios sostenibles. Sin embargo, por lo general hay fuentes de financiación pública ocultas que se utilizan para financiar algunas actividades. A menudo se trata de fondos de nivel municipal, subnacional o supranacional. Para encontrarlas, necesita tiempo y esfuerzo para enviar solicitudes, iy buenos socios del sector público y privado!

\section{Plan Paramparagat Krishi Vikas} Yojana (PKVY) del Ministerio de Agricultura (India)

\section{1}

Durante la última década, el Gobierno de la India ha desarrollado planes innovadores para incentivar, promover y financiar la agricultura sostenible. Uno de esos planes, que forma parte de la Misión Nacional sobre Agricultura Sostenible (NMSA en inglés), se llama "Paramparagat Krishi Vikas Yojana (PKVY)", que se traduce en "Plan Progresivo de la Agricultura Tradicional". El PKVY proporciona fondos para que grupos de agricultores se reúnan y se unan en el SPG, apoyándolos durante tres años con fondos asignados a formación, creación de capacidad, compra de bioinsumos, pruebas de muestras de suelo, conversión de tierras para producción orgánica y compra de herramientas agrícolas, entre otros. El plan también financia el apoyo a la construcción del mercado, como el material de embalaje, la marca y el etiquetado de productos, el apoyo a la compra de vehículos y la organización de ferias orgánicas para la venta y promoción de productos. Como resultado, más de 200.000 agricultores de toda la India y más de 100.000 hectáreas de tierras agrícolas han sido incluidos en el sistema SPG. El mercado también está siendo abastecido con productos envasados para los consumidores finales. En la próxima década, se espera que más de 1 millón de agricultores y 1 millón de hectáreas de tierra sean incluidos directamente en este plan, dados los modelos gubernamentales inminentes para programas de desarrollo de grupos de aldeas orgánicas y planes de incentivos de aldeas biológicas. Además, el Ministerio de Desarrollo Rural ha decidido aplicar un SPG, específicamente para los pequeños agricultores, mediante su programa Mahila Kisan Sashaktikaran Program (MKSP).

Fuente: Ashish Gupta, Jaivik Haat. 


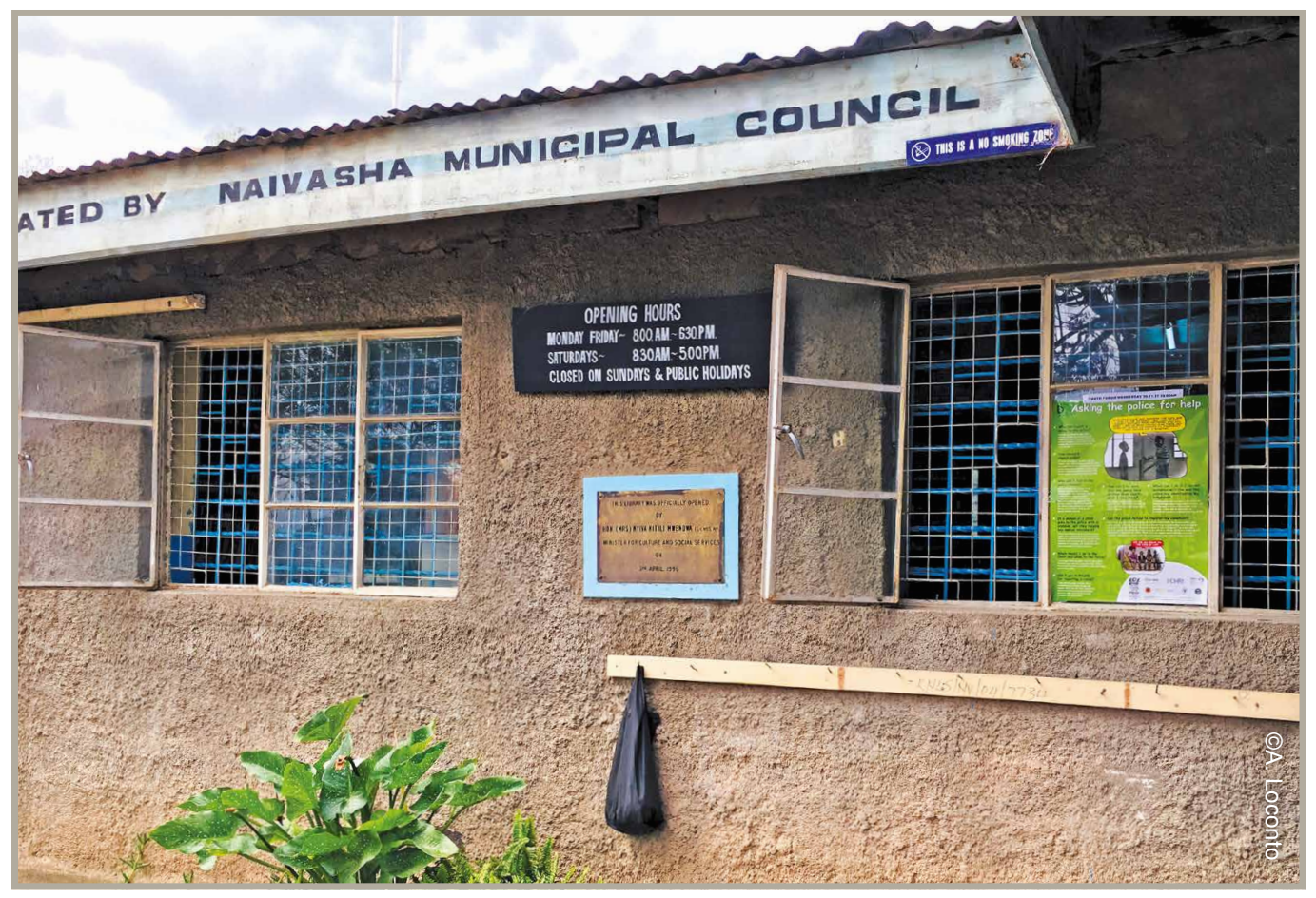

\section{Uso de celebridades para patrocinar su iniciativa (Perú)}

Frutos de la Tierra es una marca colectiva de la Asociación Nacional de Productores Orgánicos del Perú (ANPE PERÚ). Fue creada con el propósito de apoyar la agricultura familiar orgánica y promover la biodiversidad asociada con sus sistemas agrícolas. La marca fue lanzada en septiembre de 2013, y fue patrocinada por el mundialmente famoso chef peruano Gastón Acurio, líder en el sector de la gastronomía, para destacar y reconocer la cocina peruana, los pequeños productores orgánicos y los valores culturales. El chef Gastón Acurio es el principal embajador de "Frutos de la Tierra" en la alianza cocinero-chef promovida por ANPE PERÚ y Agroferias Campesinas.

Los agricultores, con esta marca colectiva, abastecen los restaurantes de Gastón Acurio,

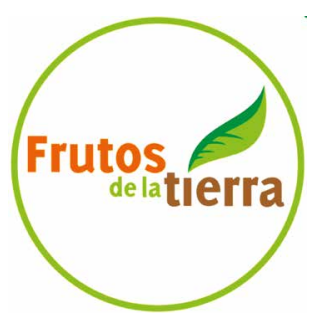

participan en la feria alimentaria "Mistura" y representan casi todas las regiones del Perú con más de 200 productos orgánicos diferentes. Esta estrategia ha ayudado a ANPE Perú a acceder a fondos de cooperación internacional y ha captado la atención del Ministerio de Agricultura. Los fondos se han utilizado para mejorar la comercialización de productos, incluida la creación de una plataforma de ventas en línea.

Fuente: Patricia Flores, IFOAM Organics International. 


\subsubsection{Acceso a fuentes públicas no tradicionales}

La mayoría de las fuentes públicas no tradicionales se encuentran a través de "convocatorias de concurso" que se publican periódicamente a diferentes niveles gubernamentales. Existen directrices claras para los tipos de iniciativas elegibles, aunque existe la libertad de crear consorcios, pagar por el fortalecimiento de capacidad y montar estructuras físicas (por ejemplo, estanterias de mercado). Cada país anuncia la disponibilidad de sus fondos de manera diferente y, en la mayoría de los casos, es importante tener relaciones positivas con los actores públicos locales.

\section{Financiación de proyectos nacionales de innovación (Chile)}

En 2010, en Chile, el Ministerio de Agricultura lanzó una convocatoria de propuestas en el marco de su "fondo de innovación". La Cooperativa Kom Kelluhayin respondió con un proyecto para vincular a la comunidad agrícola indígena con restaurantes locales y grupos de consumidores. Su objetivo era aumentar la disponibilidad de quinua orgánica para el desarrollo del turismo local y la promoción de la cocina tradicional mapuche. El proyecto financiado permitió a Kom Kelluhayin construir una instalación de procesamiento de quinua que sirve como oficina de la cooperativa, como una instalación de procesamiento de mermeladas y como un espacio de almacenamiento para otros productos de los agricultores. También proporcionó a Kom Kelluhayin los fondos básicos necesarios para aumentar la demanda de los consumidores locales. En particular, invirtieron en un puesto de alquiler para el mercado turístico local y en el desarrollo de la etiqueta Wemapu para los productos de sus miembros.

Fuente: Gabriel Curilef, Wemapu.

\section{Movilización de fondos públicos de desarrollo regional (Croacia)}

En 2013, la institución pública para el desarrollo y la coordinación de la región de Split-Dalmacia (RERA SD) desarrolló un proyecto para que los pequeños agricultores y jóvenes recibieran subvenciones públicas. Este proyecto combinó el desarrollo de infraestructura de apoyo para agricultores y agroempresarios, un programa de fortalecimiento de capacidades y apoyo técnico (es decir, ayuda en la identificación y llenado de los formularios de solicitud). Dado que Croacia entró en la Unión Europea (Organización Miembro) en julio de 2013, la RERA SD se centró principalmente en las fuentes de financiación de la UE, en particular en el Fondo Social Europeo para el fortalecimiento de capacidad de capacidades, el Fondo Europeo de Desarrollo Regional para la Infraestructura de apoyo, y el Fondo Europeo Agrícola de Desarrollo Rural para las subvenciones de los agricultores.

En particular, la RERA SD, como organización pública regional, utilizó sus contactos dentro de las instituciones públicas para prestar servicios a sus agricultores locales. Al construir un paquete de apoyo completo, el dinero público movilizado de tres fuentes diferentes permitió a RERA SD proporcionar dos servicios clave a 
los productores. En primer lugar, el programa de fortalecimiento de capacidades establecido a través del proyecto EkoBiz en 2015, utilizó la capacitación, el apoyo empresarial y el desarrollo de aptitudes empresariales para mejorar la transferencia de conocimientos y las aptitudes en el sector orgánico. Hasta el momento, más de 100 jóvenes han recibido formación y apoyo empresarial (con, por ejemplo, la concepción de planes empresariales y asesoramiento para presentar sus solicitudes de financiación de la UE). EkoBiz ya ha contribuido directamente al establecimiento de 15 nuevos negocios. En segundo lugar, el centro agroempresarial lanzado en 2013 en Čaporice (pueblo de Trilj) amplió la "zona comercial Čaporice", para incluir 23 nuevas hectáreas y la construcción de tres edificios para apoyar las nuevas empresas en la industria de procesamiento de alimentos (incubadoras), un moderno laboratorio de pruebas de alimentos, espacios de almacén, un centro de formación y un centro de exposiciones. La fase final del proyecto, denominada Centro de competencias $3 \mathrm{LJ}$, representará un centro de investigación aplicada en agricultura.

Fuente: Jelena Petrov, rera sd, Croacia.

\section{Fondos de Asistencia Oficial para el Desarrollo (AOD) (Alemania e India)}

Como parte del acuerdo de Tokio de 2008, los países del G8 promovieron y facilitaron el establecimiento de la Asociación Mundial para la Agricultura y la Seguridad Alimentaria (GPAM). Gracias a los fondos de la AOD vinculados al programa "Un Mundo sin Hambre" (SEWOH), Alemania ha prestado asistencia a diversos programas en la India y África. Como parte de este programa, se presta apoyo a agricultores pequeños y marginales y a los grupos tribales de las diversas zonas rurales de la India a través de organizaciones como Welthungerhilfe (WHH). En la última década (2005-2014), la participación de la India en el total de los fondos mundiales del AOD (USD 1.634 millones) y en el total de los fondos del AOD agrícola (USD 76 millones) representa aproximadamente el $3 \%$. Sin embargo, en términos de las participaciones de los fondos alemanes totales del AOD (USD 125 billones) y de los fondos alemanes del AOD agrícola (USD 3.6 billones), la India tiene una proporción del $4 \%$ y el $6 \%$, respectivamente, lo que indica una preferencia notable por la
India y en particular por el sector agrícola de la India. Alemania aporta casi una octava parte de su AOD a la India, y su participación en la AOD destinada a la agricultura se mantiene en el $9 \%$. Como resultado de ello, iniciativas como las organizaciones de la sociedad civil (OSC) y los grupos de agricultores de la India Oriental, en sus propios términos y a través del apoyo de los donantes (incluyendo donantes alemanes como el Ministerio Federal de Cooperación y Desarrollo Económicos [BMZ]), han sido pioneros en los movimientos relacionados con la agricultura sostenible, y han integrado la agricultura siguiendo los principios de la agroecología. Las inversiones del Fondo de Desarrollo Agrícola del BMZ en agricultura sostenible y sistemas agrícolas integrados en tres estados, han demostrado que es posible compartir la prosperidad, la equidad de género y la sostenibilidad con una mayor resiliencia de las pequeñas explotaciones agrícolas. Iniciativas como "Green Colleges" y la campaña "BhoomiKA - India for Eco Food" han demostrado ser exitosas y han impactado positivamente los medios de vida de los pequeños propietarios al establecer cadenas de suministro sostenibles.

Fuente: Ashish Gupta, Jaivik Haat. 


\subsubsection{Bancos de Desarrollo}

Los bancos regionales de desarrollo son responsables de proporcionar fondos de inversión a gran escala, que suelen centrarse en el desarrollo rural. Aunque generalmente se centran en la infraestructura a gran escala, hay oportunidades dedicadas a los mercados y apoyo a iniciativas innovadoras a pequeña y mediana escala. Es importante conocer los bancos nacionales de desarrollo rural y ponerse en contacto con las autoridades públicas que participan en la ejecución de los proyectos financiados.

\section{Fondo Nacional de Desarrollo Agro-Silvo-Pastoril (Senegal)}

En 2011, Senegal creó el Fondo Nacional

de Desarrollo Agro-Silvo-Pastoril (FNDASP) (Orden $n^{\circ} 10203$ del 2 de noviembre de 2011), bajo la supervisión técnica del Ministerio de Agricultura y la supervisión financiera del Ministerio de Economía y Finanzas. Los fondos administrados y distribuidos por el FNDASP provienen de: asignaciones anuales del presupuesto del Estado; contribuciones de asociaciones interprofesionales en forma de gravámenes de los sectores agro-silvo-pastoril y pesquero; cofinanciamiento de proyectos con comunidades locales; cofinanciamiento de proyectos con el sector privado; socios técnicos y financieros bilaterales (es decir CEDEAO, FAO, FIDA, Banco Mundial, UEMOA); donaciones, legados y subsidios autorizados.

\begin{abstract}
El objetivo del Fondo es proporcionar financiación competitiva y basada en contratos para: 1) servicios de extensión agro-silvo-pastoril y pesquera a través de asociaciones interprofesionales en múltiples sectores; 2) capacitación de productores; 3 ) apoyo institucional a organizaciones de productores; y 4) apoyo financiero para programas de investigación agro-silvo-pastoril y pesquera a través del Fondo Nacional de Investigación Agrícola y Agroalimentaria (FNRAA). Hasta la fecha, el fondo ha financiado con éxito los sectores de ganado (lácteos y carne), granos (maíz, arroz) y verduras (tomate, cebolla), al tiempo que fomenta las prácticas sostenibles (variedades y razas nativas, uso de energía solar) y crea mercados locales para estos productos.
\end{abstract}

Fuente: FNDASP, http://fndasp.sn.

\subsubsection{Proyectos de investigación}

La investigación participativa se practica y financia cada vez más. Puede centrarse en diferentes aspectos de los sistemas alimentarios sostenibles (por ejemplo, producción, elaboración, comercialización, salud, etc) donde los investigadores y los profesionales coproducen y comparten conocimientos. La financiación proporcionada para estos proyectos puede sufragar el personal, los servicios y las inversiones en infraestructura. El acceso a estos fondos generalmente implica un proceso competitivo que requiere de un período de espera de aproximadamente seis meses para averiguar si su solicitud ha sido seleccionada. La preparación de propuestas de proyectos es un esfuerzo que requiere mucho tiempo y necesita colaboración con investigadores locales (y a menudo internacionales). Comience poniéndose en contacto con los investigadores que conoce personalmente y busque colectivamente las convocatorias publicadas por fundaciones científicas nacionales e internacionales. 


\subsubsection{Pagos por servicios ecosistémicos}

A la luz del cambio climático, los gobiernos nacionales están desarrollando cada vez más pagos para los programas de servicios de los ecosistemas. Estos programas ponen de relieve que los gobiernos pueden desempeñar un papel en la preservación de la biodiversidad y la conservación de los recursos naturales pagando a los agricultores que practican la agricultura sostenible. Cada país coordina estos esquemas de manera diferente, ya sea a través de organizaciones internacionales o supranacionales (por ejemplo, reduciendo las emisiones de los programas de deforestación y degradación de los bosques [REDD+]), o a través de programas a nivel municipal. En cualquiera de los dos casos, suelen ser administrados por los Ministerios de Medio Ambiente o Turismo.

\section{El programa del Fondo} Comunitario de Ecoturismo (Trinidad y Tobago)

En 1997, la Empresa de Turismo y Desarrollo Industrial de Trinidad y Tobago (TIDCO), administrada por el Gobierno, financió a 12 comunidades rurales para administrar sus recursos turísticos a través de un programa de acción de turismo comunitario, que asignó un Comité de Acción de Turismo a cada comunidad. Brasso Seco TAC es uno de los pocos que logró ser sostenible mediante el desarrollo de un enfoque para la preservación de su entorno natural y tradiciones culturales locales. En 2000, TIDCO organizó un concurso culinario intercomunitario en Brasso Seco. Al año siguiente, el evento se convirtió en un Festival Gastronómico (Cookfest) basado en la comunidad, que se celebra anualmente en octubre durante la temporada tradicional de la "carne silvestre". A partir de las ganancias de este evento, junto con la asistencia adicional de TIDCO, Brasso Seco invirtió en la construcción de una instalación de visitantes para mejorar la experiencia ecoturística para excursionistas y observadores de aves, y para ampliar sus productos y servicios para incluir alimentos y artesanías hechos por miembros de la comunidad. La instalación emplea a ocho residentes. En 2005, la comunidad ganó una oferta para convertirse en contratista del Programa Nacional de Reforestación y Rehabilitación de Cuencas (NRWRP), para ayudar a conservar la selva tropical cercana. Este contrato continuo proporciona empleo a 35 miembros de la comunidad, que son responsables de la creación y mantenimiento de 12 rutas de senderismo, bancos y cobertizos hechos de materiales naturales en el bosque, y de la señalización de caminos. En 2006, Brasso Seco TAC recibió más apoyo del Ministerio de Turismo para acceder a una parcela de 15 acres de tierra, que era antes una plantación de cacao y café. En colaboración con el Instituto Interamericano de Cooperación para la Agricultura (IICA) y el Instituto del Cacao de la Universidad de las Indias Occidentales, rehabilitaron la plantación para producir cacao y café sostenibles. Construyeron una instalación tradicional de secado al sol en el bosque, donde se celebra un festival anual de cosecha con una "danza del cacao" colectiva tradicional para aplastar los granos de cacao. Embalan el cacao en la instalación adyacente, y lo exportan con su propia marca y las etiquetas de certificación orgánica de los Estados Unidos.

Fuente: Roxanne Waithe, IICA y Elaine Philipps, Brasso Seco Paria TAC, Trinidad y Tobago. 


\section{Un caso de servicios ecológicos} adquiridos por el Gobierno (China)

La ciudad de Hulun Buir, en China, está situada en medio de las tres mayores áreas de suelo negro del mundo, cubriendo 11 millones de hectáreas de tierra. Se considera una de las mayores áreas de producción de granos a nivel nacional, y depende significativamente de fertilizantes químicos. Con el tiempo, estos productos han degradado la materia orgánica del suelo a una tasa anual de 0.5 puntos. A fin de lograr un uso sostenible del suelo negro y obtener una base estable de cereales orgánicos para garantizar la seguridad alimentaria nacional, el Gobierno de Hulun Buir cooperó con la Corporación de Tecnología Biológica Jia Bowen de Beijing para elaborar un plan de recuperación. La preferencia de los consumidores por un tipo específico de grano sirvió como punto de partida. Basándose en la industria del reciclaje, y centrándose en la innovación para mantener la alta calidad de la tierra, protegieron y mejoraron el suelo negro y aumentaron el uso efectivo del ganado y el estiércol de aves de corral a través de una estrategia de "reducción de estiércol tres en uno". También implementaron un servicio de monitoreo de datos del suelo.

Después de tres años de producción de trigo negro y orgánico, se documentaron progresos notables. El nivel de tierra en riesgo disminuyó de cuatro a tres, y el contenido de materia orgánica en el suelo aumentó en 0.2 puntos, la superficie del suelo aumentó de $20 \mathrm{~cm}$ a $30 \mathrm{~cm}$, los nutrientes del suelo se duplicaron y la resistencia a la sequía aumentó. En 2017, la ciudad utilizó una oferta de contratación pública para implementar la misma estrategia en 13.300 hectáreas de tierra. El proyecto recicló 48.000 toneladas de estiércol de ganado y aves de corral, y las redistribuyó en el sistema de producción y en los ciclos naturales de nutrientes. Este uso de estiércol ha resuelto el problema de tener una cantidad de estiércol equivalente a la producida en una operación intensiva de 200.000 cerdos, lo que afecta negativamente al medio ambiente.

Fuente: Shi Yan, cosecha compartida, China.

\subsubsection{Fondos privados}

Si bien los bancos comerciales son la fuente más común de financiación privada, los sistemas alimentarios sostenibles pueden buscar otras fuentes de financiación privada aparte del sector financiero tradicional. Debido a que la sostenibilidad se valora para los futuros sistemas alimentarios, las iniciativas pueden encontrar socios ansiosos del sector privado dispuestos a apoyar prácticas sostenibles de consumo y producción.

\subsubsection{Bancos éticos}

Existen bancos éticos en algunos países. Divergen de los bancos comerciales, ya que tienen en cuenta los temas sociales en sus carteras financieras. Por lo general, son más flexibles en sus condiciones de préstamo y están dispuestos a aceptar formas de garantía alternativas. Identifique los bancos éticos que operan en su área, y determine los tipos de apoyo financiero que pueden ofrecer. 


\section{Certificación Fairtrade como garantía crediticia (América Latina y África)}

La noción de que los certificados que garantizan la sostenibilidad podrían actuar como garantía para los préstamos bancarios (ya que demuestran la confiabilidad de los productores y prometen contratos con ventas éticas) comenzó a circular ya en el año Internacional de las Microfinanzas en 2005. Sin embargo, fue solo en 2012 que se creó el Fondo Fairtrade Access. Incofin Investment Management, Fairtrade International y Grameen Foundation USA, se asociaron en un fondo de inversión internacional con una inversión de USD 1.3 millones de Starbucks. Incofin administra el fondo, Grameen proporciona una gama única de productos de préstamo (a corto y largo plazo) y asistencia técnica diseñada para satisfacer las necesidades de las cooperativas de productores a pequeña escala, Fairtrade facilita el acceso a los mercados internacionales, proporciona una red de seguridad de precio mínimo y otros servicios de apoyo para el desarrollo democrático de empresas, mientras que Starbucks otorga el dinero en efectivo como parte de su programa de Responsabilidad Social Corporativa (RSC) para apoyar a sus proveedores (Starbucks compra grandes cantidades de café con certificación Fairtrade). En 2018, el fondo ha prestado USD 128 millones a agricultores que cultivan 11 cultivos en 19 países.

Fuente: http://incofinfaf.com/\#mission.

\subsubsection{Concursos de innovación}

En los últimos 5 a 10 años, se han creado una serie de concursos y premios para estimular la innovación. Aunque a menudo se centran en las nuevas empresas y en tecnologías específicas, en el campo de la alimentación sostenible, los modelos organizativos también se reconocen

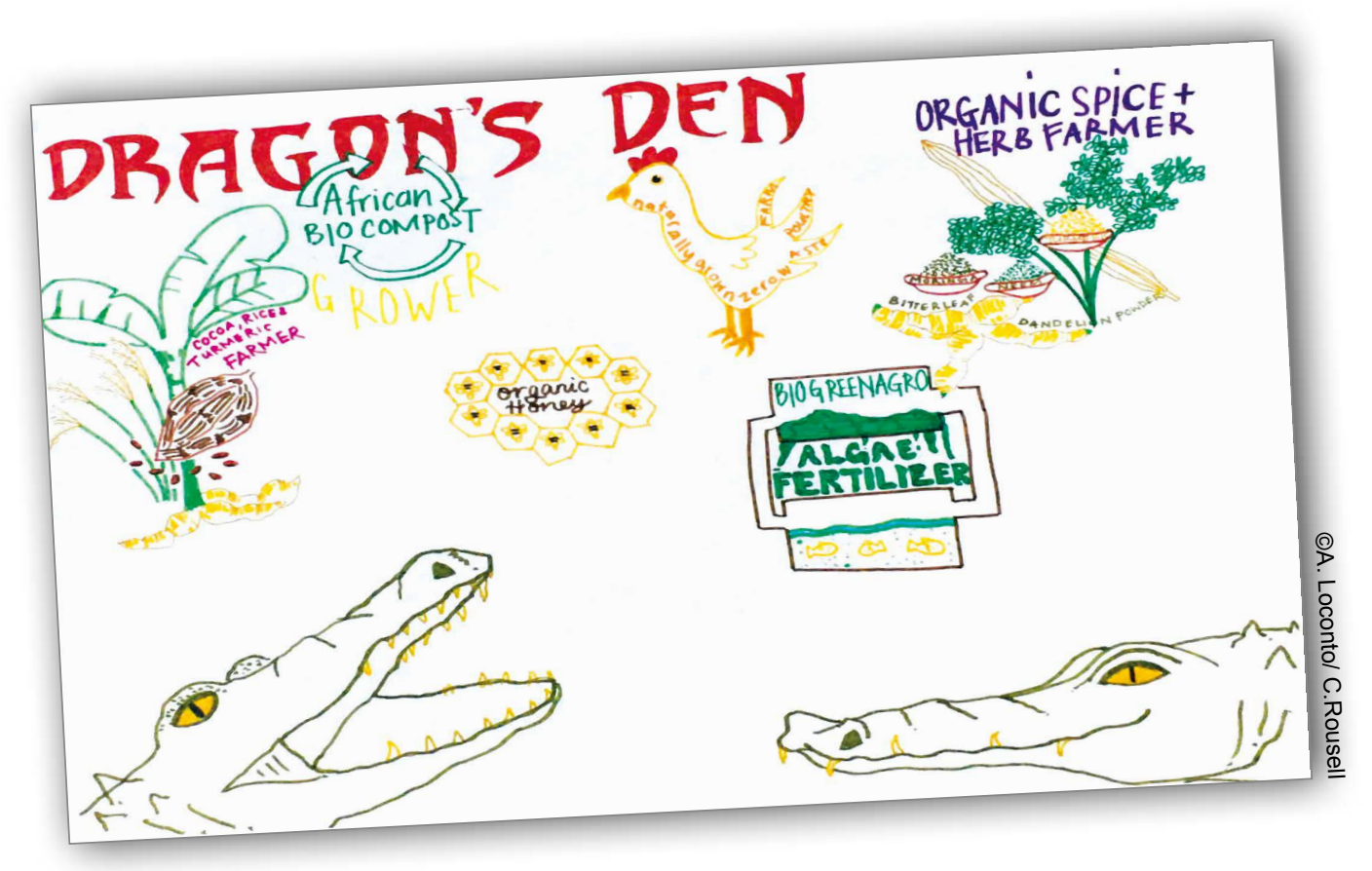


como innovaciones. Cada concurso es diferente, y puede ser diseñado para ofrecer un premio monetario por el trabajo ya terminado o para nuevas ideas que buscan financiación. Cuando no hay premio monetario, se organiza un evento para reunir a los innovadores para generar nuevas ideas y conocer a los inversionistas. La información sobre estos concursos se encuentra a menudo en los periódicos, Internet y en las redes sociales.

\subsubsection{Programas de Responsabilidad Social Corporativa (RSC) y fundaciones privadas}

Las fundaciones privadas y los programas de RSE de las grandes empresas privadas están cada vez más interesados en financiar innovaciones orientadas al desarrollo de sistemas alimentarios sostenibles. Las empresas están particularmente interesadas en invertir en las comunidades donde están operando sus cadenas de suministro. Si usted está vendiendo algunos de sus productos en cadenas de suministro globales, póngase en contacto con sus clientes para ver si están dispuestos a financiar algunas de sus actividades.

\section{Programas de RSE en la industria del chocolate (Costa de Marfil)}

Algunos productos tropicales, como el cacao, el café, el té, el azúcar y el aceite de palma, sirven como ingredientes clave para los productos de los grandes procesadores de alimentos. Debido a la presión de las ONG con respecto a las prácticas insostenibles de la mayoría de los sistemas de producción de monocultivo, los procesadores de alimentos han forjado alianzas con programas de certificación de sostenibilidad de terceros como Fairtrade International y Rainforest Alliance para hacer que estos sistemas sean más sostenibles. Estos programas han reconocido cada vez más el impacto perjudicial de los monocultivos, especialmente en los paisajes forestales, y que los productores son capaces y necesitan diversificar sus sistemas de producción.

En ECOOKIM, una unión de 23 cooperativas de cacao y marañón en Costa de Marfil, se desarrolló un programa de producción de yuca, financiado con el dinero que reciben de los programas RSE de los chocolateros Ferrero, Mars y Tony's Chocolonely. Este programa, que lleva el título de "empoderamiento de la mujer", ha adquirido materiales de plantación, y ha proporcionado capacitación a las agricultoras que se han organizado en cooperativas de aldea para gestionar la producción, elaboración y venta de yuca en el mercado local. Aunque el propósito inicial de la producción de yuca era estabilizar la seguridad alimentaria de los hogares, las mujeres acabaron con excedentes, una señal del éxito de su cooperativa. Como resultado, las comunidades han estado utilizando el dinero recibido del Fondo Social Fairtrade para seguir invirtiendo en este sector mediante la compra de máquinas de molienda y procesamiento de yuca, con el objetivo de diversificar su gama de productos y reducir la mano de obra física. La diversificación también puede ayudarles a incluir más cultivos alimentarios que puedan venderse en los mercados locales. INRAE y Aminata Bamba, ECOOKIM, Costa de Marfil. 


\subsubsection{Fondos cívicos}

La mayoría de las iniciativas locales que han pasado a sistemas alimentarios sostenibles han dependido de fondos de base de sus comunidades y otros esfuerzos dirigidos por los ciudadanos. Si bien esos planes de financiación siguen siendo eficaces, hay algunos enfoques nuevos que permiten que las iniciativas tengan un impacto más allá de sus comunidades inmediatas. Al mismo tiempo, algunas comunidades experimentan con la generación de sistemas locales autofinanciados que puedan operar de manera autónoma.

\subsubsection{Crowdfunding}

El crowdfunding se está convirtiendo en una forma común de recibir pequeñas contribuciones de un gran número de personas a través de plataformas en línea que suelen incluir un breve resumen de la organización y su solicitud específica de financiación. Hay algunos sitios internacionales como Kickstarter, Gofundme, Indiegogo, Crowdrise, así como sitios emergentes nacionales y regionales como m-changa, afrikwity, SliceBiz e iroko project. Ejecute una búsqueda en Internet para obtener "crowdfunding" para ver qué está funcionando en su región.

\section{Creación de redes de tres} empresas social y ambientalmente sostenibles (Hungría)

Cyclonomia es una cooperativa social de la bicicleta del hágalo usted mismo. Zsamboki Biokert es una granja de hortalizas orgánicas y un centro de educación comunitaria de agricultura sostenible que distribuye cajas de verduras semanales a las comunidades de alimentos en Budapest, Hungría. Kantaa es una empresa autoorganizada de mensajería y entrega de bicicletas. Juntos, han creado más de 20 oportunidades de empleo locales y sostenibles en la región de Budapest. Se dedican a asegurar que sus alimentos se distribuyan utilizando bicicletas de carga fabricadas localmente, y han construido un centro logístico que ofrece soluciones de transporte urbano sostenible para los miembros de la comunidad.

Con el fin de ampliar su alcance, Cargonomia lanzó una campaña de financiación colectiva para recaudar fondos para inversiones específicas:

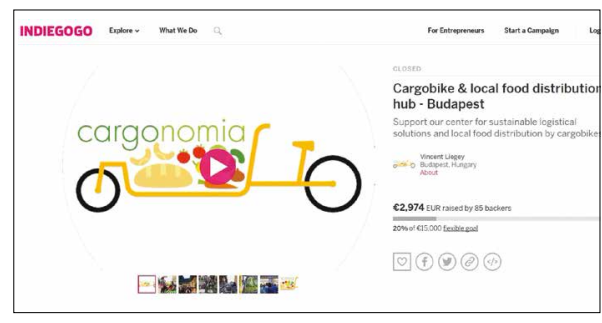

cuatro nuevas bicicletas de carga long john, a ser hechas a mano en Cyclonomia en Budapest;

- dos motores eléctricos para ayudar a las entregas de bicicletas en las zonas montañosas de la ciudad;

$\checkmark$ un prototipo de centrifugador de ensaladas hecho a mano y movido por humanos para una entidad asociada: el Jardín Orgánico de Zsambok; y

- materiales adicionales para desarrollar instalaciones para el transporte y almacenamiento de verduras y panes. Fuente: Orsolya Lazanyi, Cargomania. 


\subsubsection{Moneda local}

Algunas comunidades están experimentando con la creación de monedas locales utilizadas para el intercambio de productos y servicios dentro de la comunidad. Estos enfoques mantienen cierto valor dentro de la comunidad, mientras que ayudan a los miembros marginados a implicarse más en el sistema alimentario local. Algunos ejemplos pueden consistir en sistemas simples de trueque basados en alimentos que ya se han utilizado durante milenios. Otros sistemas son más complejos y se basan en facturas impresas. Es importante señalar que estas iniciativas son muy dificiles de sostener, y generalmente debenincluir bienes y servicios aparte de los alimentos.

\section{Monedas locales, lo que funciona y lo que no (Colombia)}

La moneda local de Familia de la Tierra fue una iniciativa que aprovechó una situación recurrente en Bogotá: jóvenes desempleados en situaciones vulnerables que carecen de derechos y oportunidades, y granjas urbanas de producción de semillas atendidas por adultos mayores que no podían realizar las actividades físicas necesarias para aumentar la producción. Una moneda local fue emitida de tal manera que los jóvenes fueron pagados por su trabajo y luego utilizaron el dinero para comprar productos de Familia de la Tierra (alimentos, semillas, etc.)

\section{¿Qué funcionó?}

1. El ejercicio generó la mano de obra necesaria para producir semillas, y la inversión fue sólo una fracción de lo que habría sido con la moneda nacional, que en general es escasa y difícil de obtener.

2. La comunidad tenía fuertes lazos sociales y se entendía mejor el funcionamiento de una moneda y de la economía en general.

3. Se produjeron semillas para varias huertas urbanas más y se preservaron otras.

\section{¿Qué no funcionó?}

1. La continuidad del ejercicio no tuvo lugar como se esperaba debido al limitado número de actores. El sistema económico local no tuvo suficiente rotación para generar bienestar para más habitantes.

2. El tamaño de la iniciativa fue favorable. Sin embargo, si se hubiera ampliado, habrían surgido problemas relacionados con la falsificación y/o la pérdida de moneda.

3. El costo de la impresión del dinero fue cubierto por una entidad pública, por lo que su mantenimiento ya no era factible.

4. Los mecanismos de comunicación dentro de la comunidad eran insuficientes, y se necesitaba más organización para que las monedas locales funcionaran eficientemente.

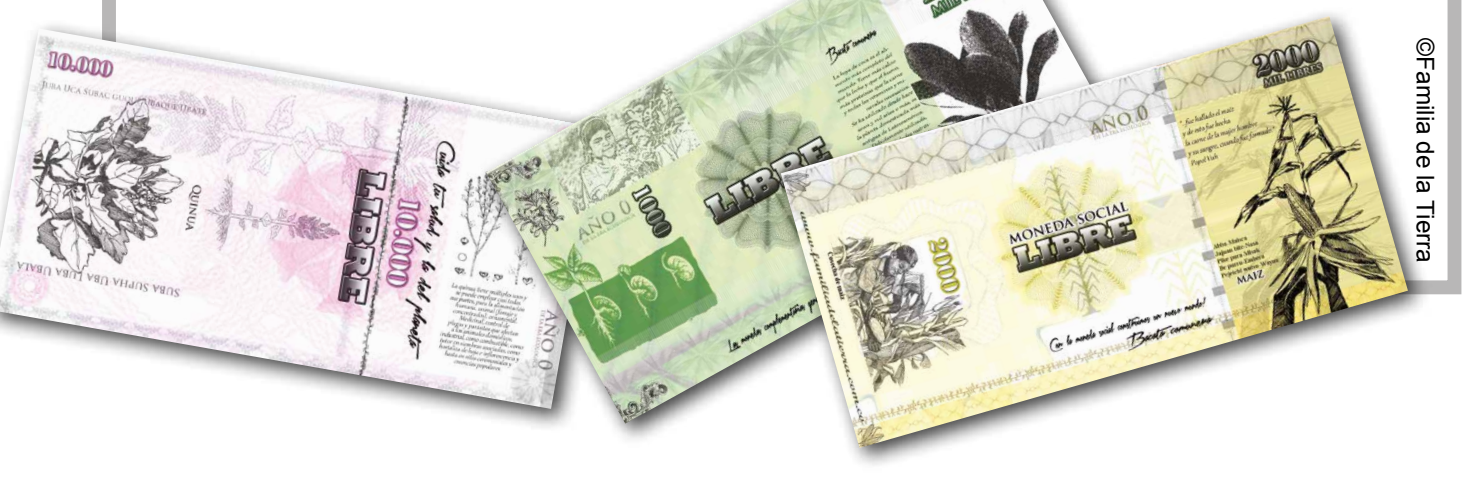




\section{3. ¿CÓMO PUEDE ENCONTRAR LOS FONDOS QUE NECESITA?}

Recuerde que las finanzas pueden ser en efectivo o en especie (por ejemplo, servicios, mano de obra, equipos, productos alimenticios). Tenga esto en cuenta para reconocer una oportunidad de financiamiento cuando vea una. Pruebe los siguientes trucos:

1. Analice las fuentes internas y externas, especialmente las fortalezas y debilidades de cada fuente (se necesita un plan de negocios antes del análisis) y una combinación de fuentes. Esto puede cambiar con el tiempo.

2. Desarrolle criterios para evaluar las fuentes financieras, como la sostenibilidad de las normas de los prestamistas (por ejemplo, qué tipo de bancos, qué tipo de RSE existe en una empresa) y sea consciente de que las empresas emergentes pueden tener opciones limitadas. En segundo lugar, debe ser práctico, y no ser demasiado idealista. Es más probable que comience con autofinanciamiento (interno), porque las nuevas iniciativas no suelen tener registros para demostrar su viabilidad financiera.

3. Desarrolle un conjunto de planes de respaldo, por ejemplo, el plan A y B, ya que las subvenciones competitivas significan que usted no siempre puede ganar la competencia.

4. Gestione su membresía de una manera que fortalezca el compromiso de sus miembros con la iniciativa y la voluntad de invertir su propio dinero personal.

5. Desarrolle asociaciones con actores públicos y privados basadas en la confianza y las garantías mutuas.

\section{CONSEJO 37}

Financie su iniciativa

- Aunque existen muchas opciones de financiación, el acceso a ellas no suele ser fácil. Piense fuera de la caja y sea creativo con cómo usted mezcla y combina sus opciones.

- El ciclo de vida de una iniciativa no es estático, por lo que es posible que necesite diferentes cantidades de dinero en diferentes momentos. Trate de mantener un registro de las posibles fuentes de financiamiento a las que puede hacer referencia cuando sea necesario.

- Sus miembros son un gran recurso para movilizar fondos internos y para encontrar fondos externos. Mantenga relaciones transparentes con los miembros para asegurar la lealtad de los miembros a largo plazo.

- Si la autonomía financiera es un objetivo, el apoyo financiero debe ser principalmente de fuentes internas que de fuentes externas, ya que esto es en más sostenible en última instancia. Sin embargo, si usted está pensando en la expansión, eventualmente necesitará encontrar fondos externos. 


\section{LA AVENTURA DEL APRENDIZAJE, ¿DÓNDE SEGUIR?}

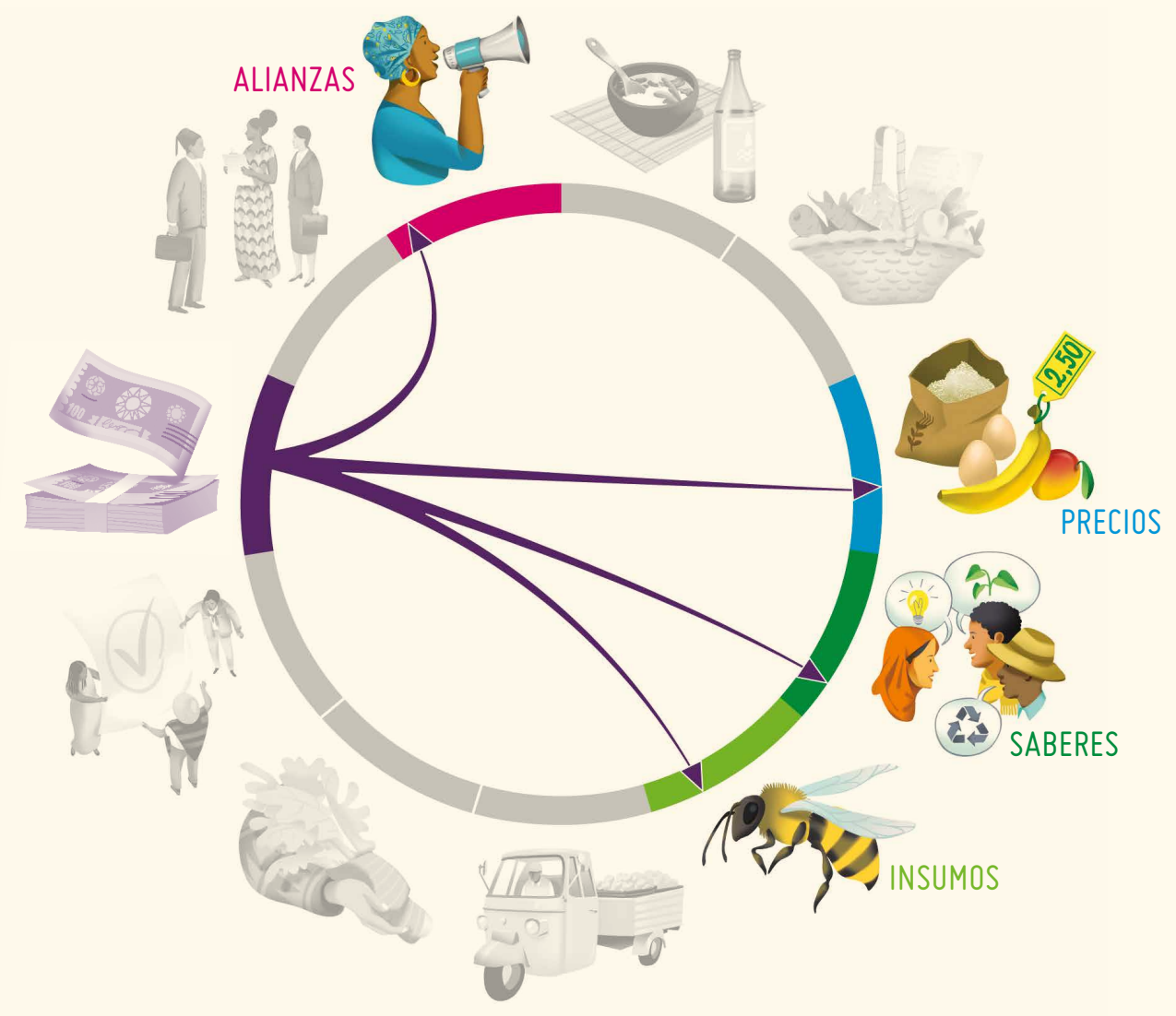

- ¿Desea movilizar las redes de sus miembros para financiar una nueva inversión? Encuentre algunos consejos sobre cómo hacer esto en el Capítulo 11: Alianzas y promoción.

- ¿Ha decidido solicitar financiación para la investigación y necesita colaborar con los investigadores? Explore algunas opciones en el Capítulo 4: Compartir y cocrear conocimientos para una producción sostenible.

- ¿Desea utilizar las ventas de productos como su estrategia de financiación principal, pero no está seguro de cuánto puede cobrar por ellos? Lea el Capítulo 3: Encontrar el precio "correcto", para leer algunos consejos.

- ¿Financia insumos para sus miembros y está buscando soluciones más sostenibles? Esto es posible, así que trate de hacer referencia al Capítulo 5: Conocer y acceder a insumos sostenibles.

¿Qué tal pasar a otro capítulo que llama su atención? 


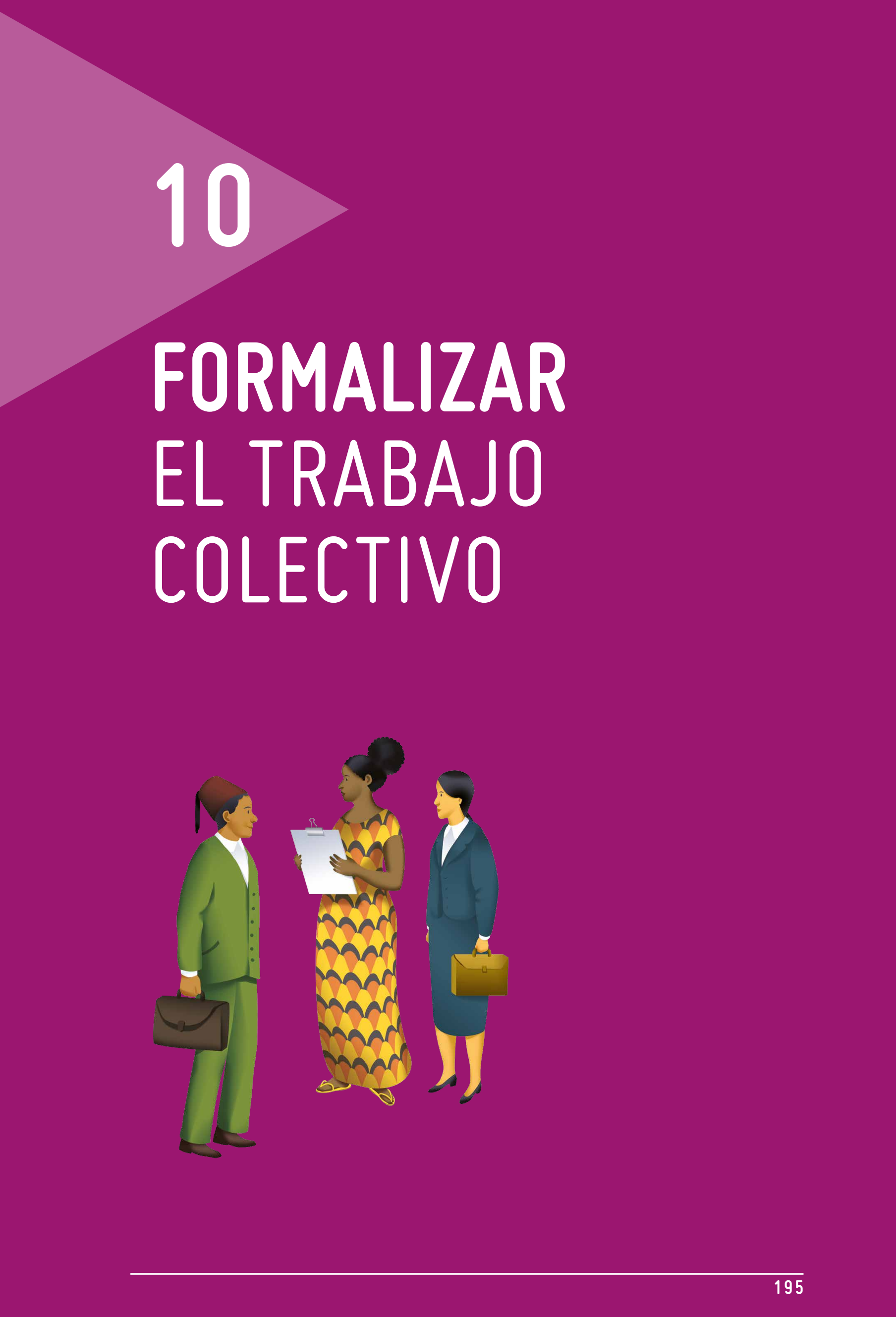




\section{1. ¿POR QUÉ ESTO ES IMPORTANTE?}

¿Está pensando en lanzar una nueva iniciativa o formalizar su trabajo colectivo?

El desarrollo de un nuevo proyecto es un desafío, que requiere diversas estrategias para transformar las ideas en realidades. La organización interna es clave para el éxito de una iniciativa.

Cómo se asignan las responsabilidades a las diferentes personas dentro de una organización o entre una red de organizaciones, quién toma parte en la toma de decisiones, quién tiene responsabilidad financiera o jurídica para la iniciativa, y cómo registrar su organización con las autoridades públicas, todo condicionará una parte considerable de las actividades de su iniciativa.

Cada modelo conlleva diferentes oportunidades y desafios, y dependiendo de lo que usted está tratando de lograr, puede querer elegir un modelo diferente.

\section{ESTABLECER OBJETIVOS COMUNES PARA LA ORGANIZACIÓN}

Facilitar un proceso de grupo siempre requiere de un proceso inicial de autodefinición. A continuación, se presentan algunas preguntas importantes para facilitar la reflexión colectiva sobre objetivos comunes:

1. ¿Quién es usted?

2. ¿En qué quiere convertirse?

3. ¿Qué quiere lograr? ¿Crear? ¿Producir?

4. ¿Cuánto tiempo quiere que dure este proceso?

5. ¿Cómo va a llegar allí?

6. ¿Cómo sabrá cuando hayamos logrado estos objetivos?

\subsection{Visión, Misión, Objetivos y Valores}

La visión, misión, objetivos y valores (VMOV) de una organización son herramientas básicas para construir una colaboración sólida y sostenible. Algunos países tienen requisitos legales para registrar una organización. La VMOV son conceptos complementarios; el articular cómo vinculan sus diferentes actividades puede ayudar a mantener a todo el grupo en el mismo camino.

- La visión es una imagen conceptual del futuro. Abarca lo que la organización aspira a largo plazo. Es el sueño que guiará a la organización hacia el futuro.

- La misión es la razón de ser de una organización. Es el propósito sobre el que se basan las estrategias de la organización. Responde a la pregunta: ¿por qué se estableció la organización?

- Las Metas (objetivos) indican lo que la organización planea lograr. Todas las actividades están destinadas a lograr estos objetivos. Las metas reflejan planes específicos a corto o largo plazo. 
Deben ser SMART, por su acrónimo en inglés, (Específicas, Medibles, Realizables, Realistas y Oportunas). Los objetivos y metas comunes deben ser revisados periódicamente por el grupo, utilizando un proceso de planificación estratégica.

Tenga en cuenta que, en los grupos de producción comunitarios, todos los productores deben tener objetivos y metas similares. Compartir un objetivo de producción común es muy necesario, ya que se relaciona con el compromiso de los agricultores y sus niveles de producción, y también ayuda a satisfacer las expectativas de los clientes.

- Los valores impulsan las decisiones de las iniciativas del sistema alimentario sostenible, y ayudan a los miembros a crear una identidad central. También orientan a los no miembros sobre las expectativas de compromiso. Son la base de todas las reglas y estándares adoptados por la organización.
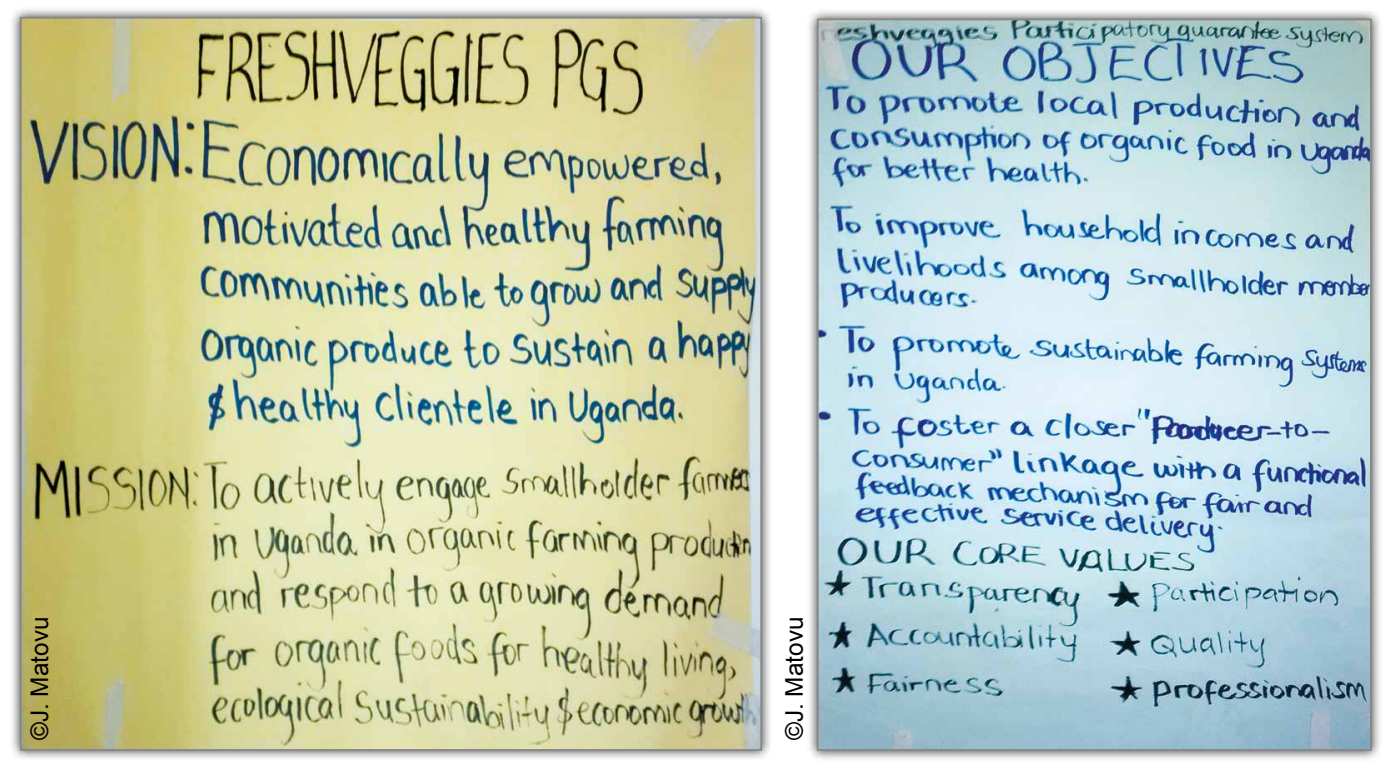

Fuente: FreshVeggies, trabajo de establecimiento de la Visión/Misión/Metas/Valores del Grupo SPG.

\section{LISTA DE VERIFICACIÓN}

Preguntas guía para definir su VMOV

1. ¿Solo queremos vender una pequeña cantidad durante los fines de semana?

2. ¿Estamos trabajando hacia la producción a tiempo completo?

3. ¿Cuánto crecimiento queremos experimentar?

4. ¿A cuántos mercados/restaurantes/tiendas queremos atender? 


\subsection{Definiendo la identidad de grupo}

Definir quién es el grupo da forma a su composición, y la composición define sus objetivos. Esta identidad debe basarse en los valores fundamentales de la organización. ¿Qué pasa si hay otros actores, es decir, defensores, patrocinadores, miembros de la academia, figuras religiosas o agentes gubernamentales que buscan ser miembros y no comparten los mismos valores? Para una organización de multiactores, el grupo necesita llegar a un consenso sobre los criterios de afiliación y asociación y sobre cómo distinguir ambas categorías.

Para determinar estas diferencias, invite a todos los posibles colaboradores a discutir conjuntamente los VGMV, y a determinar dónde se puede llegar a un acuerdo para construir una estrategia y una identidad. Alternativamente, puede que no tenga la información necesaria para saber si otros comparten los mismos intereses que usted. En este caso, lance una convocatoria abierta para el interés en un tema (tal vez organizar una discusión pública o seminario), y vea si los interesados están dispuestos a formalizar un proyecto basado en grupo.

\section{CONSEJO 38}

Formar una iniciativa de sistema alimentario sostenible

1. ¿Está el proyecto liderado por el productor o por el consumidor?

Saber quién motiva su proyecto ayudará a enfocar la estructura organizativa general, y dará consenso a quién dirigirá las discusiones de toma de decisiones.

2. ¿Existe un acceso adecuado a la tierra, al agua, a la mano de obra, las finanzas o los insumos, y esos recursos son adecuados para el tipo de producción previsto?

Si bien esto puede parecer obvio, es uno de los principales obstáculos para iniciar cualquier proyecto agrícola.

3. ¿Existe un plan de negocios bien desarrollado (basado en un plan de aproximadamente tres años (o una temporada)?

Si el agricultor está empleado externamente, o si el agricultor está iniciando el proyecto, es importante estimar el tamaño del mercado necesario para la viabilidad de las empresas, y cómo satisfacer las necesidades de consumo con un cultivo diversificado. Este plan de negocios, basado en una estrategia financiera, también afecta la sostenibilidad general. También deben abordarse las preguntas sobre posibles fuentes de ingresos variadas.

4. ¿Queremos ampliar nuestra misión e incluir a la juventud y la educación, y si es así, cómo? Los proyectos educativos para consumidores adultos y niños pueden añadir valor y profundidad a los sistemas alimentarios sostenibles locales. Requieren de una cuidadosa planificación pedagógica, y a menudo exigen coordinación con las autoridades educativas locales. 


\subsection{Buen liderazgo}

En un sistema alimentario sostenible, todos los miembros del grupo tienen un papel que desempeñar, pero también es necesario que alguien (o un grupo) guíe a otros. El estilo de liderazgo es muy importante, ya que puede tener un impacto positivo o negativo en el trabajo colectivo y en el logro de objetivos.

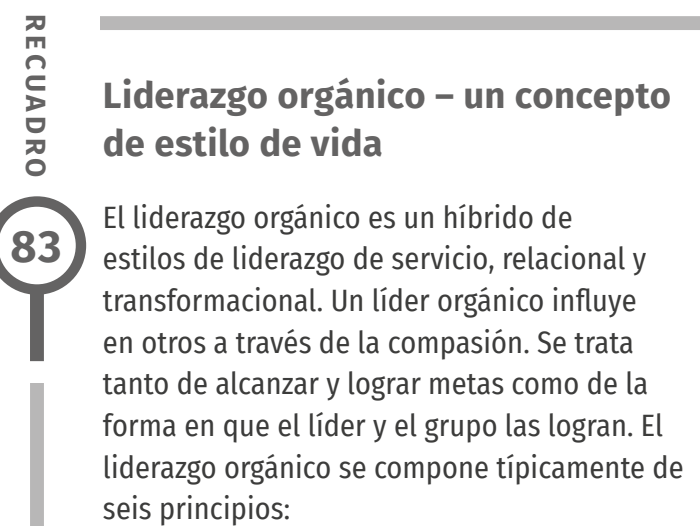
seis principios:
1. Relaciones moldeadas por la colaboración.

2. Comunidad formada por la narrativa.

3. Influencia moldeada por la compasión.

4. Dirección moldeada por el descubrimiento.

5. La autenticidad está conformada por la responsabilidad.

6. Redes conformadas por estructuras de gente.

Fuente: Patricia Flores, IFOAM Organics International (extraído de Organic Leadership: An Emerging Leadership Style, K. Heitzman).

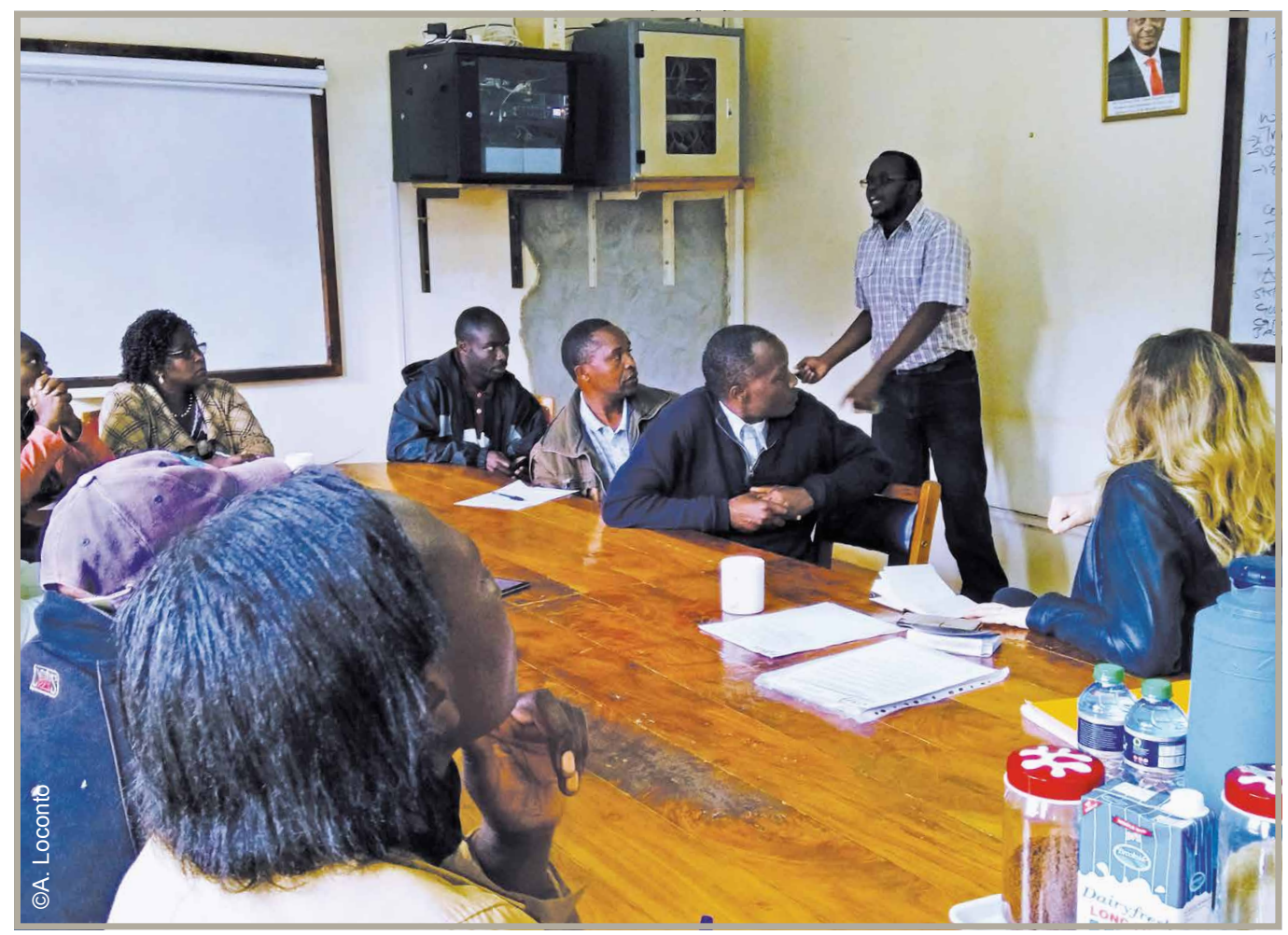




\section{ESTABLECIENDO UN MODELO ORGANIZATIVO PARA SU GRUPO}

La forma en que los actores se reúnen y establecen una estructura común para sus operaciones conjuntas depende en gran medida del contexto local. Independientemente de cómo sean los actores creativos, las organizaciones formales están conformadas por marcos legales nacionales.

\section{LISTA DE VERIFICACIÓN}

Determinar la flexibilidad que necesita en su organización

1. ¿Qué tan formal es su compromiso?

2. ¿Está tratando de garantizar un ingreso decente para el productor en un contexto global sostenible?

3. ¿Está tratando de minimizar las tensiones/conflictos estableciendo las reglas del juego?

4. ¿Está intentando hacer que la iniciativa sea sostenible durante un largo período de tiempo?

5. ¿Está tratando de estructurar las operaciones y dividir las responsabilidades en aras de la eficiencia y la claridad dentro de la organización?

6. ¿Está esperando cambiar su escala de operación mediante el crecimiento o la ampliación (haciéndose más grande o inspirando a otros a probar enfoques similares)?

Cuando los agricultores, los intermediarios transparentes y los consumidores cooperan para fomentar un cambio en el sistema alimentario, su participación debe registrarse formalmente de conformidad con las leyes y reglamentos nacionales. En algunos países, por ejemplo, no se permite a un grupo de agricultores vender sus productos a menos que estén registrados como cooperativas de agricultores.

Discuta las diferentes opciones posibles con sus agencias públicas locales. Por lo general, dependen del tamaño previsto de la empresa, la cantidad de capital, el tipo de negocio (nacional o internacional) y el número y tipo de propietarios. Normalmente puede encontrar esta información en línea o visitando oficinas específicas en su área. Intente pedir información en:

- Cámaras de Comercio en línea o en persona; y/o

- Oficinas de negocios locales en línea o en persona.

\section{CONSEJO 39}

Inicie un negocio

- ¿Es fácil abrir un negocio en su país? Visite el siguiente sitio web para averiguar cuántos días, en promedio, tendrá que esperar antes de obtener diferentes tipos de autorizaciones:

http://www.doingbusiness.org/reports/global-reports/doing-business-2017 
Cada país utiliza diferentes términos y regulaciones para regular posibles formas organizativas. Por ejemplo, una cooperativa no tiene el mismo significado en diferentes países: pueden ser sin ánimo de lucro, con ánimo de lucro o incluso proscritas. Sin embargo, hay un par de «grandes familias de modelos organizativos», que pueden ayudarle a entender cuáles son las opciones. A continuación, ofrecemos ejemplos de modelos que hemos utilizado.

\subsection{Empresas sociales y otros tipos de empresas}

\subsubsection{Empresa social}

Las empresas sociales, son entidades generadoras de ingresos que tienen dos objetivos: 1) lograr un resultado social, cultural, económico comunitario y/o ambiental positivo; y 2) obtener ingresos. Estos negocios pueden ser organizaciones sin ánimo de lucro u organizaciones con ánimo de lucro. Mientras que en la superficie muchos de estos negocios parecen actividades tradicionales, son excepcionalmente dirigidos por la misión, y a menudo tienen la generación de ingresos como una prioridad secundaria.

\section{CONSEJO 40}

Verifique el registro legal de las empresas sociales en su país

\subsubsection{Empresa propiedad de los empleados}

Hay varios tipos de empresas de propiedad de los empleados, entre ellas: la propiedad directa de los empleados (los empleados son accionistas principales de la organización), la propiedad indirecta de los empleados (los empleados son propietarios de las acciones colectivas de la organización a través de una fiducia) y/o una combinación de estos dos modelos. En este modelo, los empleados adoptan el papel de propietarios, convirtiéndolos en actores comprometidos con un interés en el éxito de la empresa.

\section{刃

Creada por un grupo de jóvenes empresarios en 2012, ChocoTogo es la primera empresa procesadora de cacao en Togo, que es propiedad colectiva de sus empleados, y es la primera marca nacional de chocolate en grano a barra. Para colmar una brecha en el mercado de la producción y distribución de chocolate en el país, estos chocolateros capacitados han desarrollado una instalación de producción y un centro de capacitación a pequeña escala. El empleo de las mujeres locales es uno de sus principales pilares. Desde su fundación, ChocoTogo ha abierto el mercado a los chocolates finos controlados y producidos por Togo.

Fuente: Nathalie Kpante, CHOCOTOGO, Togo http://www.chocofair.org/en/chocotogo. 


\subsubsection{Negocio familiar}

Las empresas familiares son el modelo empresarial más común del mundo (http://www.ffi.org/). Dado que varían mucho a escala mundial y de una empresa a otra, es difícil tener una sola definición. Esencialmente, las empresas familiares consisten en un modelo en el que varios miembros de la familia participan como principales propietarios o gerentes, y/o en el que la mayoría de los derechos de toma de decisiones son mantenidos por miembros de la familia relacionados con el fundador de la empresa. Algunos países exigen que las empresas se registren como empresas de capital privado.

\subsubsection{Empresa comercial}

Una empresa comercial es un negocio que trabaja con una variedad de bienes producidos vendidos a consumidores, a otras empresas o directamente a los gobiernos. Las empresas comerciales a menudo compran bienes, intermedian con ellos y coordinan las entregas de bienes a los consumidores, pero por lo general no poseen o almacenan bienes ellas mismas. Una empresa de transporte, por otra parte, puede ser propietaria de camiones y almacenes y también puede ser registrada como una empresa comercial. Las empresas comerciales pueden funcionar bajo diversos marcos legales, incluyendo modelos de responsabilidad limitada, identidades no constituidas, o con derechos territoriales.

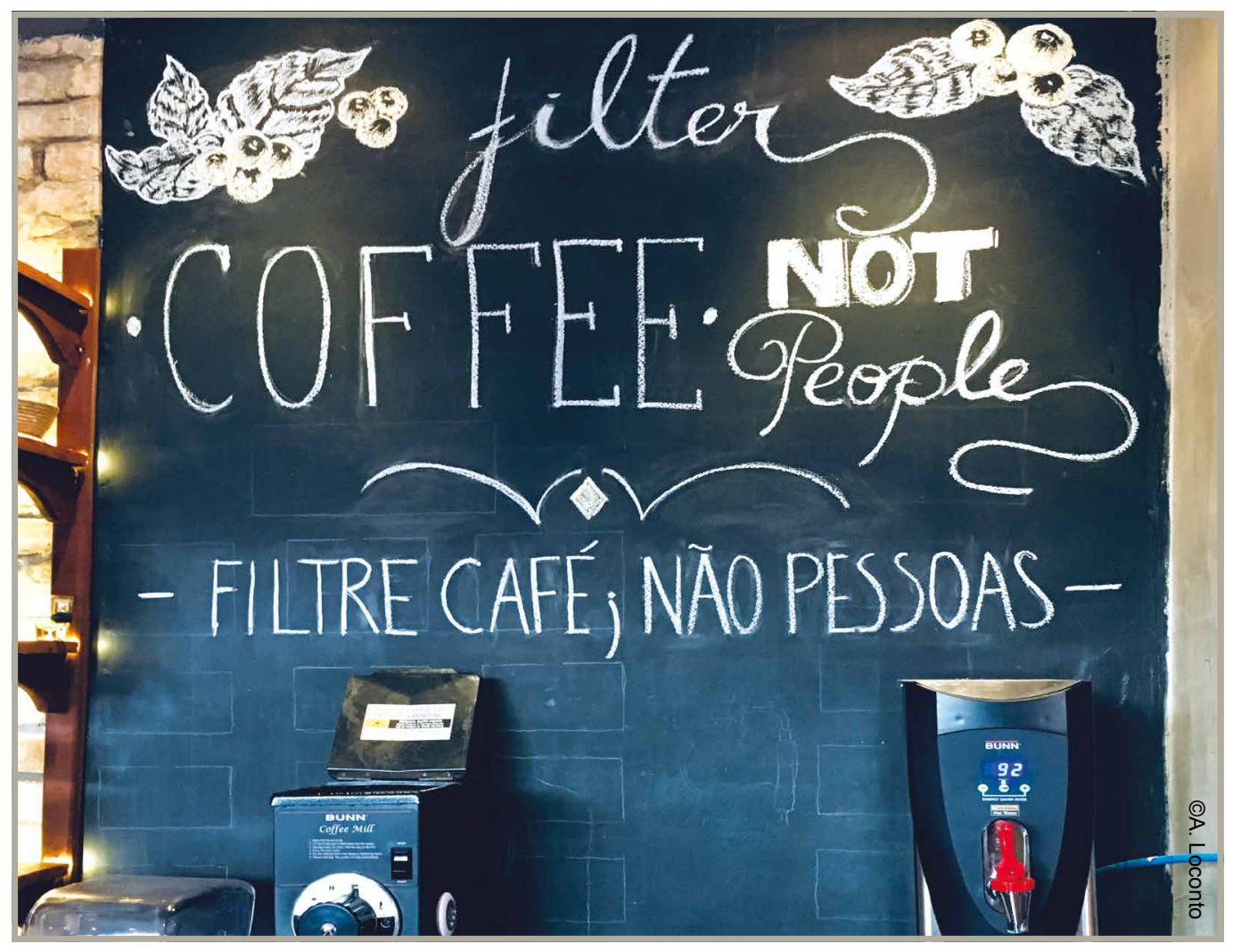




\subsection{Cooperativas}

Según la definición de la Alianza Cooperativa Internacional ( $\mathrm{ACl}$ ), "una cooperativa es una asociación autónoma de personas unidas voluntariamente para satisfacer sus necesidades y aspiraciones económicas, sociales y culturales comunes, a través de una empresa de propiedad conjunta y controlada democráticamente". Las cooperativas pueden ser establecidas por productores, consumidores y/o comerciantes. Funcionan según los siguientes principios:

1. membresía voluntaria y abierta,

2. control democrático de los miembros,

3. participación económica de los miembros,

4. autonomía e independencia,

5. educación, formación e información,

6. cooperación entre cooperativas, y

7. preocupación por la comunidad.

\section{Hansalim - una estructura} cooperativa de agricultores y consumidores

\section{5} (República de Corea)

Hansalim es una de las cooperativas agrícolas sostenibles más grandes del mundo. Con sede en República de Corea, se estableció en 1986 y en 2016, y sus consumidores constituyen más de medio millón de hogares. Con 22 cooperativas de consumidores, 204 escaparates y un total de ingresos por ventas de USD 362 millones, Hansalim conectó con éxito 112 comunidades agrícolas con más de 200 familias en el mercado. Estas escalas se gestionan mediante la cooptación de estructuras existentes, como las cooperativas de consumidores regionales y las asociaciones de agricultores. Cada órgano tiene su propia estructura de gobierno y nominados en la junta directiva de Hansalim. Anualmente, los miembros de ambas estructuras se reúnen y deciden sobre diversos temas como precios de productos, su disponibilidad y el presupuesto para la estabilización de precios y producción,

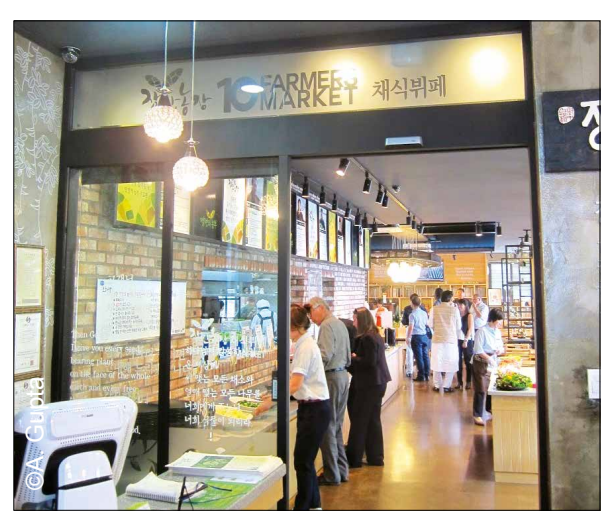

y organizan otras reuniones sociales como festivales y reuniones de celebración. Cada una de las subestructuras se gestiona utilizando términos democráticos de gobernanza. Cualquier trabajo de promoción realizado por Hansalim se lleva a cabo en nombre de los consumidores y los productores.

Fuente: Hansalim, República de Corea, http://eng.hansalim.or.kr. 


\subsection{Organizaciones y fundaciones sin ánimo de lucro}

Tener un establecimiento sin ánimo de lucro con una estructura o cooperativa orientada a las ganancias, permite acceder a las ONG y a los fondos públicos/ de donantes, además de los ingresos privados.

\subsubsection{ONG que proporcionan apoyo/espacio de mercadeo}

Las ONG son grupos del sector privado (generalmente sin ánimo de lucro y no sectarias) que participan en proyectos de educación, capacitación, ayuda humanitaria y/o proyectos de cooperación. Estas pueden incluir importantes organizaciones mundiales o grupos más pequeños y centrados localmente. Algunas ONG fomentan la actividad en torno a un solo tema (como los derechos humanos o los temas ambientales), mientras que otras tienen un papel más orientado al análisis o la investigación.

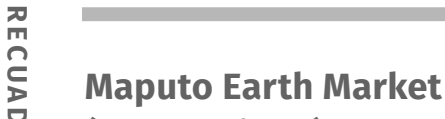 (Mozambique)}

\section{6}

Establecido en 2013, el Mercado de la Tierra de Maputo surgió de una colaboración entre la ONG italiana "Gruppo di Volontariato Civile" (GVC) y Slow Food International. Con 13 cultivadores y productores de la provincia de Maputo en Mozambique, el Mercado de la Tierra es un punto central de distribución de frutas y verduras, huevos frescos $y$ mermeladas preparadas, todo ello respetando el mantra de "local, estacional, limpio y artesanal". El mercado fue creado como parte de un consorcio de ONG (incluyendo GVC y Essor, con sede en Italia), la Unión Nacional de Agricultores de Mozambique, y el convivium local de Slow Food. Se trata de una asociación que destaca la interacción entre los sectores público y privado, y el papel que las organizaciones no gubernamentales pueden desempeñar en la prestación de apoyo relacional, analítico, financiero y de investigación a nuevas organizaciones.

Fuente: Stelio Miguel Joaquim, Maputo Earth Market, Mozambique http://www.earthmarkets.net/network/maputo.

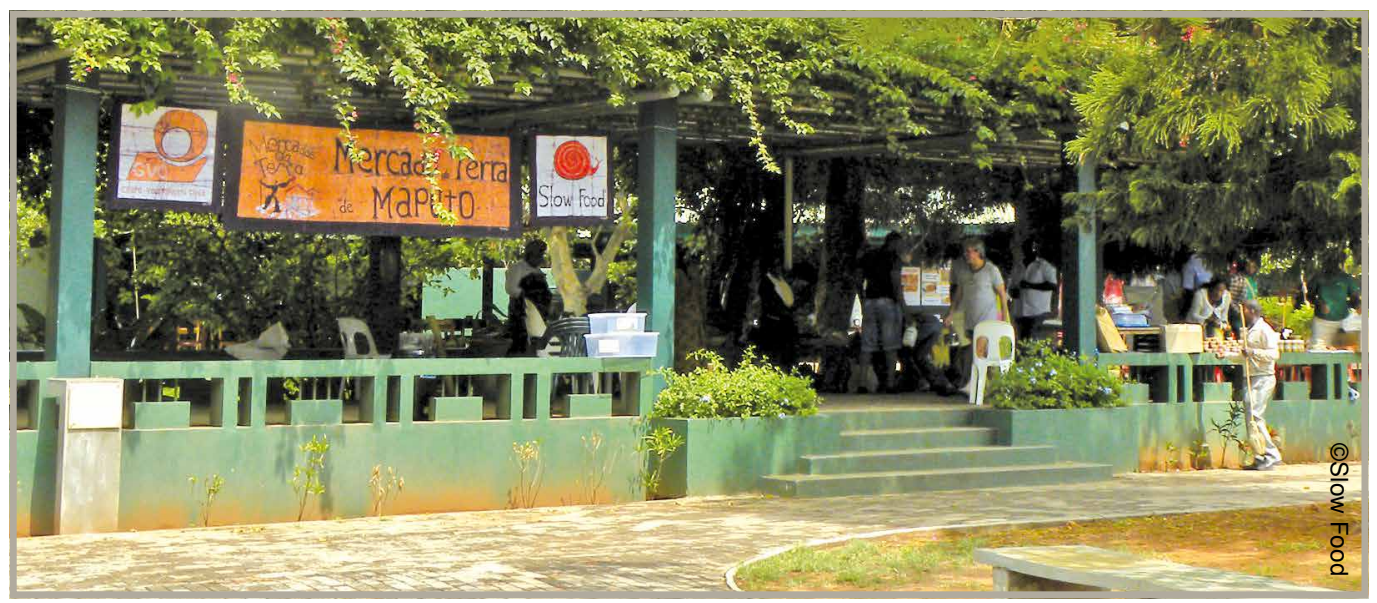




\subsubsection{Fundaciones}

Las fundaciones se dividen en dos categorías: fundaciones benéficas y fundaciones privadas. Las fundaciones benéficas son una categoría legal de organizaciones sin ánimo de lucro especializadas en donaciones o en el apoyo financiero a organizaciones públicas o privadas. Las fundaciones privadas tienen una función similar, aunque tradicionalmente están dotadas por un individuo o una familia, y tienen un estatus y requisitos legales diferentes.

\section{Green Net Cooperative/Earth Net Foundation (Tailandia)}

Como se observa en Green Net, Tailandia, las diferentes estructuras organizativas pueden tener necesidades diferentes. Green Net fue registrada por primera vez como Green Net Cooperative, porque esta estructura se ajustaba a los valores de comercio justo de Green Net, y permitía el reconocimiento legal como una organización comercial y exportadora. Más tarde, Green Net se registró como Earth Net Foundation, una organización sin ánimo de lucro. Este tipo de estructura era elegible para recibir financiación externa para el trabajo de desarrollo, para proporcionar capacitación y apoyo a nuevos agricultores para convertirlos hacia los métodos orgánicos, para desarrollar empresas de grupos de agricultores, y para promover la conciencia de los consumidores sobre los productos orgánicos y el comercio justo. Se creó una tercera organización, Green Net SE Co. Ltd., una sociedad empresarial social limitada, para desarrollar el proyecto de café orgánico forestal, ya que se requerían niveles muy altos de inversión para desarrollar conocimiento, infraestructura y para la compra de granos de café a un precio justo. Como asociación limitada, los inversionistas sociales fueron bienvenidos a invertir mayores cantidades de capital, permitiendo así el lanzamiento del proyecto.

Fuente: Michael Commons, Green Net, Tailandia http://www.greennet.or.th/en/about/earthnet.

\subsection{Otros modelos organizativos}

\subsubsection{Granjas comunitarias}

En los últimos 50 años, han aparecido nuevas formas de procesos grupales. Por ejemplo, las granjas comunitarias han evolucionado de las granjas comunales de la década de 1960, para convertirse en una manifestación madura de reivindicación de los comunes y la protección de la propiedad o arrendamiento de tierras comunitarias a través de fideicomisos comunitarios de tierras u otros acuerdos similares, que aseguran la tierra para la producción colectiva de alimentos. 


\subsubsection{Agricultura sostenida por la comunidad}

Una ASC es una asociación entre una granja y los consumidores, donde los riesgos y las recompensas agrícolas son compartidos. Como parte de un enfoque activo para relocalizar la economía, una ASC se basa en una asociación, generalmente formalizada como un contrato individual entre cada consumidor y el productor, y caracterizada por un compromiso mutuo de proveerse mutuamente (con dinero y alimentos) durante un período prolongado de tiempo. Las ASC tienen algunos objetivos fundamentales:

- restaurar la soberanía alimentaria local,

- crear solidaridad entre productores y consumidores para construir comunidades más justas y socialmente sostenibles,

- compartir los riesgos y beneficios basados en la producción,

- defender la salud y la nutrición a través de la alimentación, y

- desarrollar la responsabilidad cívica.

\subsubsection{Red (estructura informal)}

En un modelo de red, no existe una secretaría central, ni un sistema central de coordinación para la prestación de servicios porque las relaciones de red son informales. Tradicionalmente, las redes son asociaciones sueltas de organizaciones o personas que trabajan colectivamente en torno a una idea o meta común. Algunas redes están más legalmente formalizadas para proporcionar seguridad a las partes involucradas.

\section{Contratos de red (Italia)}

La italiana Contratto di Rete es una herramienta innovadora que permite la

88 colaboración entre empresas, al tiempo que mantienen su independencia empresarial individual. El objetivo es aumentar la innovación y la competitividad general del mercado. Todas las partes involucradas firman un contrato a través de una escritura pública, un notario privado o de un modelo aprobado de firma electrónica. Con casi 20.000 de estos contratos actualmente utilizados en Italia, sirven como ejemplo innovador de marcos legales para las empresas emprendedoras.

Fuente: Contratto di Rete Registro http://contrattidirete.registroimprese.it/reti/ index.action. 


\section{GESTIONAR EL CRECIMIENTO Y ENCONTRAR LA ESCALA ADECUADA}

Es fundamental decidir si se debe ampliar o reducir la escala o cómo hacerlo. Dependiendo del modelo de organización seleccionado, a menudo es más beneficioso crecer hacia fuera de una manera creativa, trabajando dentro de una red de productores complementarios, que crecer hacia arriba en tamaño. Varios mercados locales complementarios se pueden conectar en red de manera coherente mediante el trabajo con las autoridades locales, incluyendo las iniciativas de venta directa, y con programas locales de contratación pública para escuelas, hospitales y hogares geriátricos. El crecimiento también se puede dar a través de esquemas de procesamiento a pequeña escala basados en cooperativas.

La revisión sistemática de los objetivos de su organización debe considerar la escala de operación deseada, que puede dividirse en diferentes escalas para diferentes fases.

Recuerde: las diferentes escalas requieren diferentes estructuras físicas y organizativas.

Tierra Viva, Agricultores Orgánicos (Chile)

Tierra Viva es una asociación de agricultores orgánicos con sede en Santiago, Chile. Fundada hace 23 años, es pionera del movimiento orgánico chileno, cuyo propósito es organizar a los agricultores orgánicos para los mercados locales. Con solo 10 clientes para empezar, ahora ofrece comida a más de 500, incluyendo restaurantes y hoteles. Desde 2008, Tierra Viva es un SPG acreditado por el Estado. Andrea Tuczek, fundador y agricultor líder dice:

"Con la nueva regulación orgánica que abarca los sistemas de autocertificación de las organizaciones de agricultores (o SPG), los nuevos agricultores y organizaciones exigieron formar parte de nuestra iniciativa. Nos dimos cuenta de que después de unos años, una vez que son educados y saben cómo manejar el sistema, regresan a sus comunidades para crear sus propios sistemas. Comprendimos que,

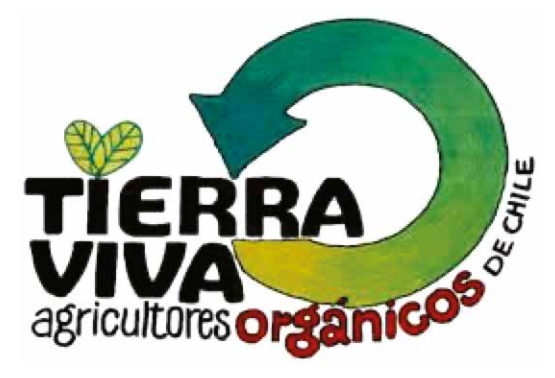

aunque no aumentemos nuestra membresía, podemos ayudar a los recién llegados a establecer un sistema de garantía creíble."

En otras palabras, Tierra Viva, sin tener intención de desempeñar este papel, es una incubadora de iniciativas SPG para agricultores orgánicos que tratan de cumplir con las normas del Servicio Agrícola y Ganadero (SAG), la autoridad nacional competente para la agricultura orgánica.

Fuente: Patricia Flores, IFOAM, Perú. 


\subsection{Gestión del crecimiento en cifras}

Los grupos comunitarios suelen empezar pequeños y crecen continuamente. Algunos evolucionan hacia grandes empresas. En cualquier caso, la gestión del crecimiento es un factor esencial de la construcción de grupos. El crecimiento significa la ampliación del número de agricultores, así como el crecimiento en términos de alcanzar los objetivos del mercado.

\section{LISTA DE VERIFICACIÓN}

Factores que afectan las dimensiones de su grupo

Hay muchos factores que afectan al tamaño de la organización y es difícil aislar solo a unos pocos. Sin embargo, las siguientes preguntas pueden ayudarle a definir la dimensión correcta para el crecimiento previsible de su organización:

1. ¿Cuál es la escala del movimiento sostenible de alimentos en su ciudad/área (es decir, hay insumos fácilmente disponibles para tratamientos ecológicos, semillas, mercados, investigación, etc)?

2. ¿Existe una demanda específica de sus productos?

3. ¿Cuál es la tendencia del consumo (tanto a nivel local como mundial)?

4. ¿Tiene los fondos necesarios para mantener una red funcional?

5. ¿Cuál es la escala de la organización que desea construir?

6. ¿Necesita su organización crecer en número o consolidarse?

7. ¿Hay más personas que quieran unirse a la organización?

8. ¿Cuáles son los canales que puede utilizar para la comunicación interna con los miembros? (teléfono móvil, aplicaciones de chat, Facebook, etc)

\subsubsection{Elegir el ajuste adecuado}

No todo el mundo encaja en un grupo determinado. Como productor, usted necesita identificar y colaborar con miembros individuales que compartan objetivos similares. Esto mejorará el éxito y el crecimiento colectivos. Un jubilado criando aves de corral para su propio consumo, por ejemplo, puede no tener el mismo interés y el mismo impulso para el crecimiento que una pareja joven que quiere cultivar profesionalmente. Muchas angustias y conflictos se pueden evitar cuando todos los miembros del grupo comparten la misma meta. 


\section{El crecimiento de un modelo de red (Colombia)}

El modelo de red de Familia de la Tierra

(FDT) les permite responder a la dinámica socioeconómica local: nuevos mercados, proyectos de investigación con inclusión familiar, innovaciones de productos con inclusión familiar, nuevos productos desarrollados y/o en demanda, etc.

Actualmente, 25 familias rurales de Bogotá están involucradas en la red, plantando papas nativas y cultivos andinos, mientras atienden a 12 restaurantes, tres hoteles y diez tiendas en Bogotá, Cali y Medellín. FDT ha aunado sus esfuerzos con tres organizaciones asociadas que operan en Cundinamarca rural, que en conjunto incluyen a unas 118 familias. También trabajan con la Facultad de Ciencias Agrarias de la Universidad Nacional de Colombia, con profesores del SENA (Servicio Nacional de Aprendizaje), con cocineros independientes, con profesores de gastronomía y con estudiantes universitarios que estudian el sistema alimentario en cuestión.

FDT ha crecido siguiendo el ritmo del mercado y de la economía local en torno a la agricultura orgánica, lo que ha dado lugar a una creciente participación de los actores, que no solo incluye a los productores orgánicos. Se han ido ampliando para adaptarse a una economía cambiante y, sobre todo, a la creciente demanda de alimentos saludables y locales en hoteles y restaurantes.

Fuente: Jaime Aguirre, Óscar Nieto y Familia de la Tierra, Colombia.

\subsection{2. ¿Está su grupo preparado para dar la bienvenida a nuevos miembros?}

El grupo debe reconocer que los nuevos miembros pueden crear animosidad, y a veces, los nuevos miembros pueden salir o causar que los viejos se vayan. El grupo debe estar preparado para hacer frente a la sensación potencial de malestar que se deriva de la llegada de nuevos miembros o la pérdida de los antiguos.

\subsubsection{Cómo manejar nuevos miembros}

El seguimiento con nuevos miembros es útil para identificar las razones de su retirada y para entender mejor la dinámica de grupo. Si a los nuevos miembros les gusta el grupo, infórmeles sobre la próxima reunión. Si los miembros se van y no son reemplazados por otros nuevos, será un desafío sostener el crecimiento de su organización.

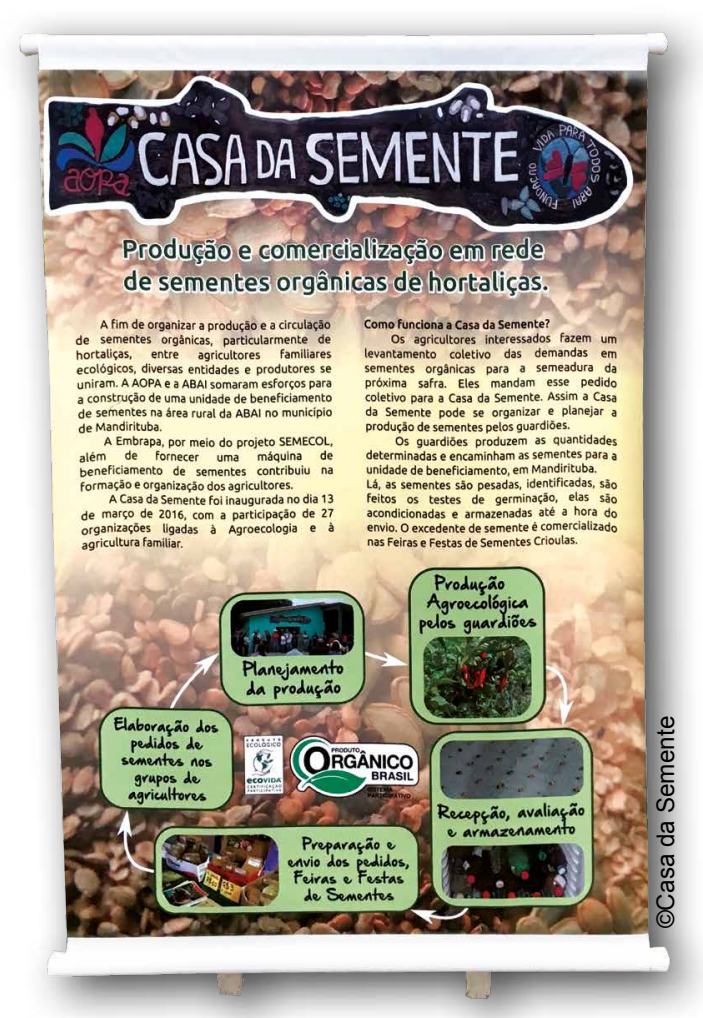




\section{2. ¿Cómo equilibrar las metas y las capacidades?}

Afirme sus metas y reconozca sus habilidades. Utilice los siguientes trucos para encontrar este equilibrio:

- La transparencia es un factor clave del éxito de cualquier empresa colectiva.

- La equidad es crucial.

- Compense el tiempo de quienes más trabajan para evitar un sentido de desigualdad y frustración entre los miembros más diligentes.

\subsubsection{Toma de decisiones conjunta sobre cuestiones clave}

Un mejor equilibrio de poder no solo se traduce en estatus, sino también en procesos de toma de decisiones conjuntas. Cuestiones clave, como la creación de precios, pueden convertirse en un elemento central de ese proceso. Para todos los actores involucrados en la operación, esto puede ser un factor importante de empoderamiento y sentido de propiedad.

Recuerde: los grupos evolucionan constantemente, y como tales, tratan de establecer estructuras flexibles para revisar las reglas y prioridades cuando sea necesario. La asignación de tareas específicas a diferentes personas distribuye el poder y la voz entre el grupo, y conduce a un sistema de gobierno más «naturalmente» estructurado.

\subsubsection{Dinámica}

No se establecen objetivos comunes de una vez por todas. Deben ser reevaluados regular y colectivamente a medida que la organización crece y cambia. El análisis FODA puede utilizarse para comprobar el rendimiento de una organización en relación con sus objetivos.

FODA es un acrónimo para las Fortalezas y las Debilidades internas de la organización y su operación. Las Oportunidades y las Amenazas son presiones externas que condicionan la forma en que la organización puede trabajar.

- Cree un cuadro de $2 \times 2$ y rellene los FODA relevantes para su organización.

- Una vez que los haya enumerado, puede determinar si tiene puntos fuertes y oportunidades que puedan contrarrestar las debilidades y amenazas.

- Priorice las cuestiones urgentes movilizando sus fortalezas y oportunidades. Ponga en marcha planes de fortalecimiento de capacidades o planes de acción para reducir las debilidades y evitar las amenazas. 


\section{5. ¿CÓMO ASEGURAR EL FUTURO DE LA ORGANIZACIÓN? ¡INVOLUCRE A LOS JÓVENES!}

\subsection{Cree un empleo que sea atractivo para los jóvenes}

Los jóvenes no siempre se sienten atraídos por el trabajo agrícola, pero esto no significa que todos los empleos en sistemas alimentarios sostenibles sean poco atractivos.

La elaboración de alimentos sostenibles es un ejemplo del empleo de los jóvenes en la agricultura. El aumento de la dependencia de la tecnología de la información, la comunicación con teléfonos inteligentes, los paneles solares, las tecnologías de transporte y vigilancia electrónica están atrayendo cada vez más a jóvenes educados a convertirse en empresarios agrícolas.

\section{Participación de jóvenes y mujeres en iniciativas agroecológicas sostenibles (Brasil)}

91

Con el fin de captar valor agregado y crear empleo, la Red Ecovida logró desarrollar varias pequeñas plantas de procesamiento agroecológico en los últimos años. Mientras que en 2000 había aproximadamente diez de estas plantas, hay más de 150 hoy en día, y el $90 \%$ de ellas son administradas por mujeres y jóvenes. Las mujeres y los jóvenes experimentan numerosos beneficios de estos nuevos trabajos:

- mayor confianza en sí mismo y autonomía,

- creación de nuevas líneas de crédito en bancos locales específicamente dirigidas a jóvenes y mujeres rurales, nuevas fuentes de ingresos y posibilidades de acceso a los mercados agroecológicos y a los programas de contratación pública (hoy un joven o una mujer que se haya inscrito en una planta de procesamiento agroecológico y venda a programas institucionales puede ganar hasta USD 7.000 al año);

$\checkmark$ permanencia de los jóvenes en la agricultura y en las zonas rurales, y

- la creación de nuevos conocimientos técnicos relacionados con la elaboración de alimentos.
Fuente: José Antonio da Silva Marfil, Ecovida, Brasil.

\subsubsection{Educación comunitaria}

La educación basada en la comunidad es una herramienta poderosa para involucrar a las generaciones futuras en su organización. Piense en cómo incluir a niños y adolescentes, teniendo en cuenta que esto a menudo va acompañado de nuevos requisitos legales.

Recuerde verificar las definiciones legales para el trabajo, el aprendizaje y el voluntariado en su país, y respetarlas al construir su programa. 


\section{LISTA DE VERIFICACIÓN}

1. ¿Ha verificado los requisitos de registro legal en su país?

2. ¿Utilizó un proceso participativo para definir la misión de su grupo?

3. ¿Encontró un modelo que mejor se ajuste a su misión y a sus valores?

4. ¿Adaptó el modelo para que se ajuste a su contexto local?

5. ¿Dividió las diferentes responsabilidades de los diferentes actores de su grupo?

6. ¿Estableció un sistema para tratar los problemas que surgen?

7. ¿Registró su grupo ante las autoridades?

\section{CONSEJO 41}

Encuentre y mantenga el equilibrio adecuado

- Encontrar el equilibrio de grupo adecuado y mantenerlo a lo largo del tiempo no es una tarea sencilla. Compartir los valores y responsabilidades fundamentales facilita este proceso.

- Aunque la informalidad tiene ventajas, formalizar y registrar su iniciativa la hará accesible a los programas de financiación públicos y privados.

- Se requieren diferentes formas organizativas en diferentes momentos a lo largo del ciclo de vida de su iniciativa. Mantenga sus estructuras lo más flexibles posible para poder hacer frente a las oportunidades y amenazas que aparecen de forma eficaz.

- Cambiar la escala de operaciones es una parte natural del desarrollo organizacional. Asegúrese de que su grupo esté de acuerdo en la mejor manera de crecer hacia arriba o externamente para que pueda mantener la cohesión de este a largo plazo.

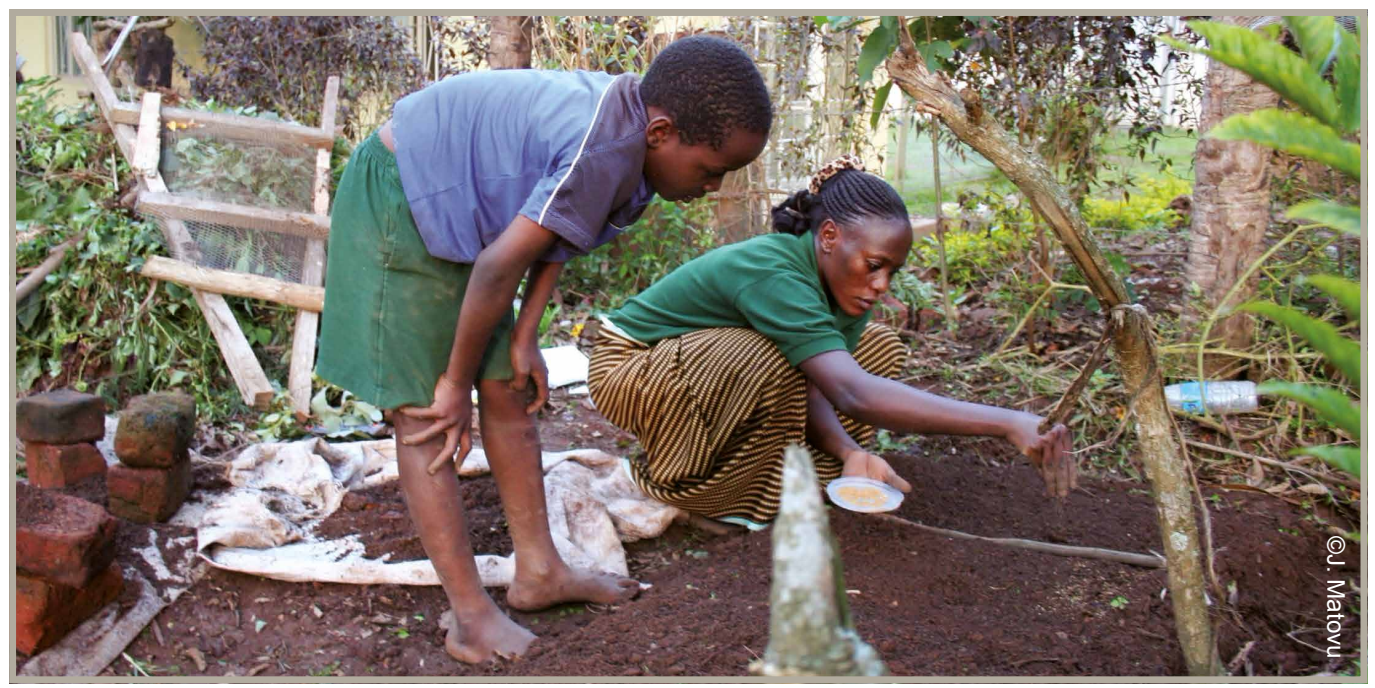




\section{LA AVENTURA DEL APRENDIZAJE, ¿DÓNDE SEGUIR?}

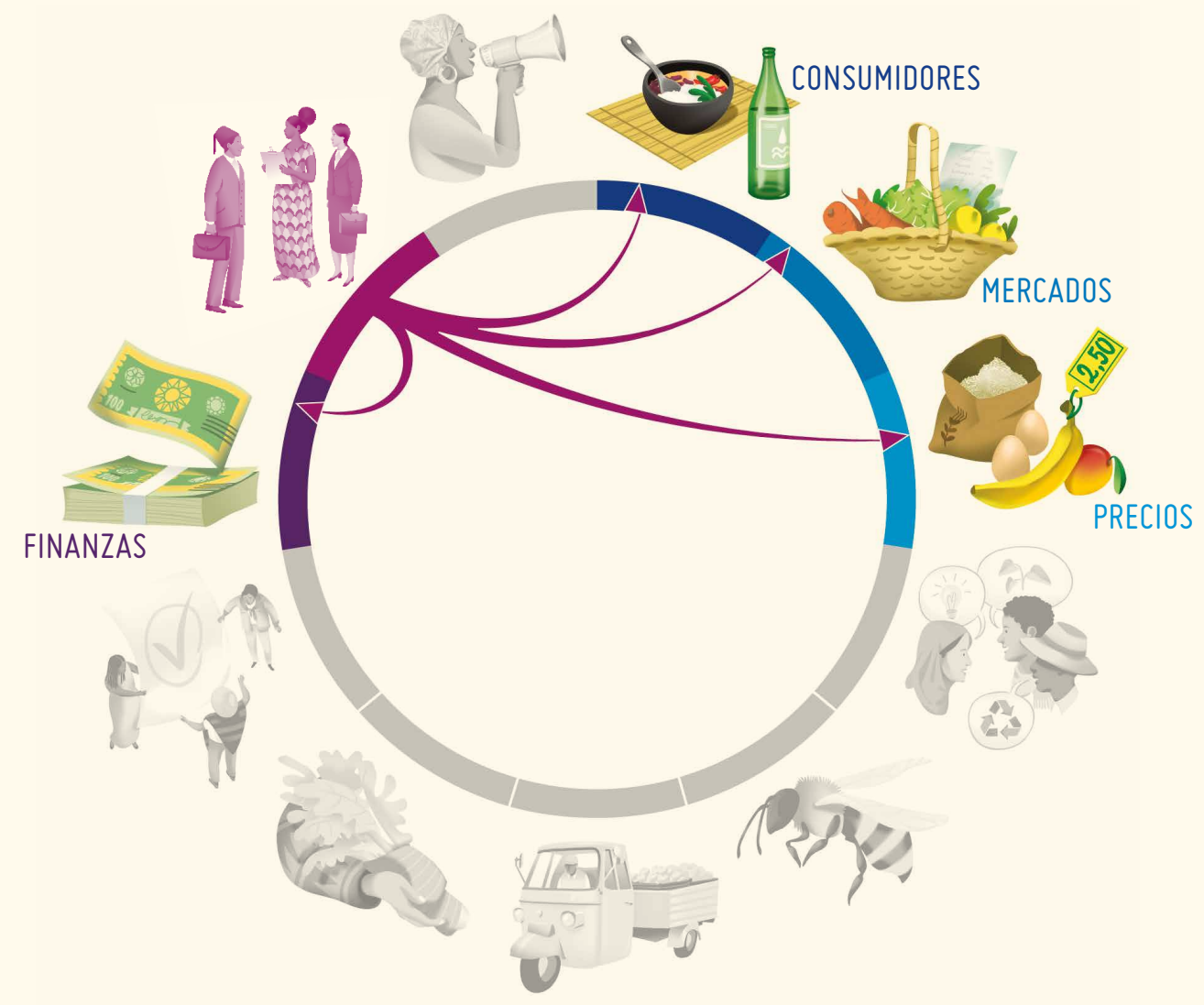

¿Está pensando en desarrollar una ASC? Vaya al Capítulo 2: Conocer sus mercados, para aprender más sobre este modelo.

- ¿Tiene un componente de educación juvenil rural en su proyecto? Vuelva al Capítulo 1: Atraer a los consumidores y mantenerlos comprometidos, para aprender sobre algunos ejemplos.

- ¿Quiere establecer un comité de fijación de precios como una manera de construir procesos democráticos en su organización? Vaya al Capítulo 3: Encontrar el precio "correcto".

- Ahora que ha registrado a su grupo, ¿tiene los fondos operativos o de inversión necesarios? Vuelva al Capítulo 9: Financiamento innovador, para reunir algunas ideas.

¿O quizás otro capítulo le viene a la mente? ¡Vaya a comprobarlo! 


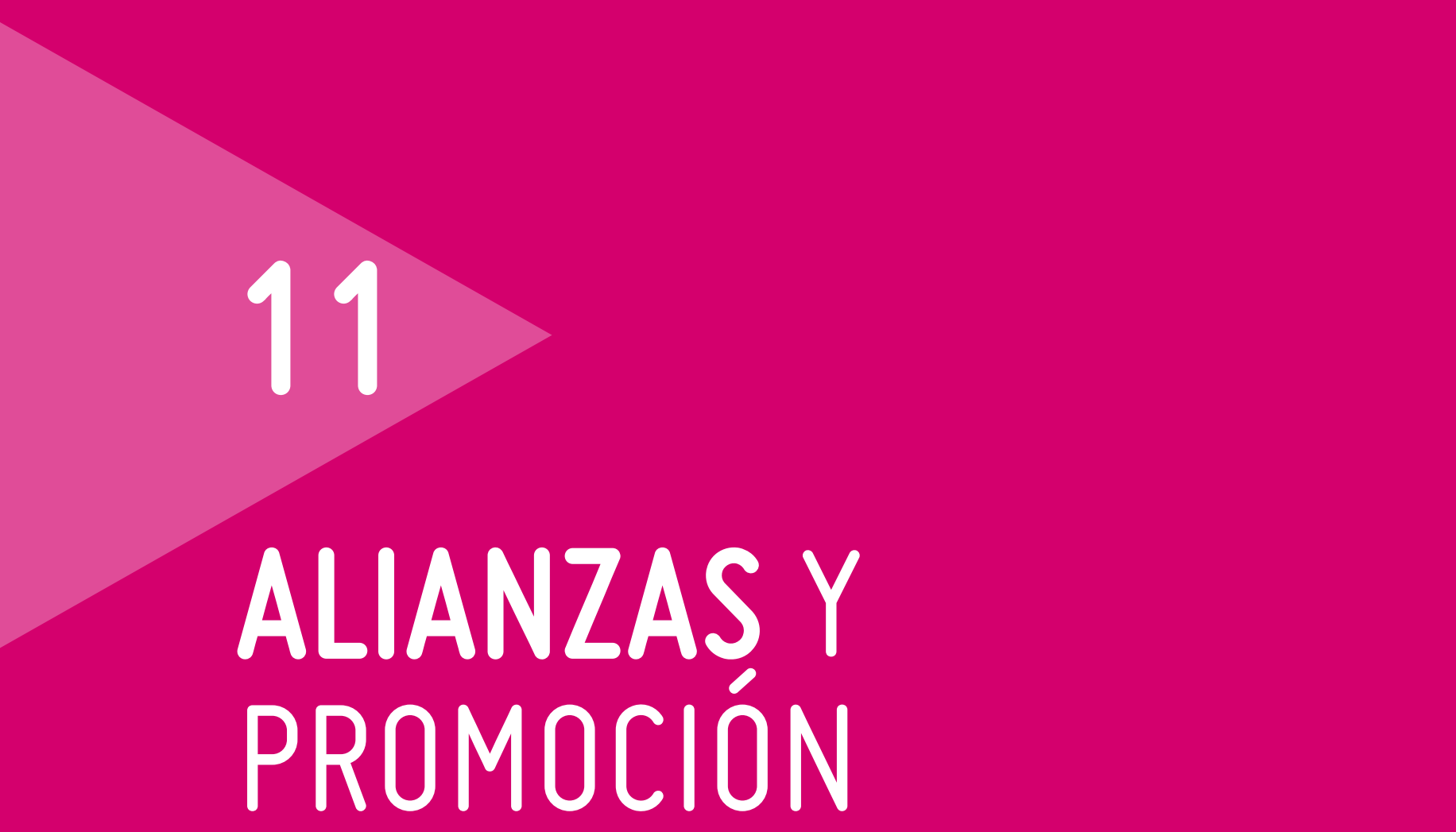

뜽
응
롤
$\overline{2}$
흥

ALIANZAS Y PROMOCION
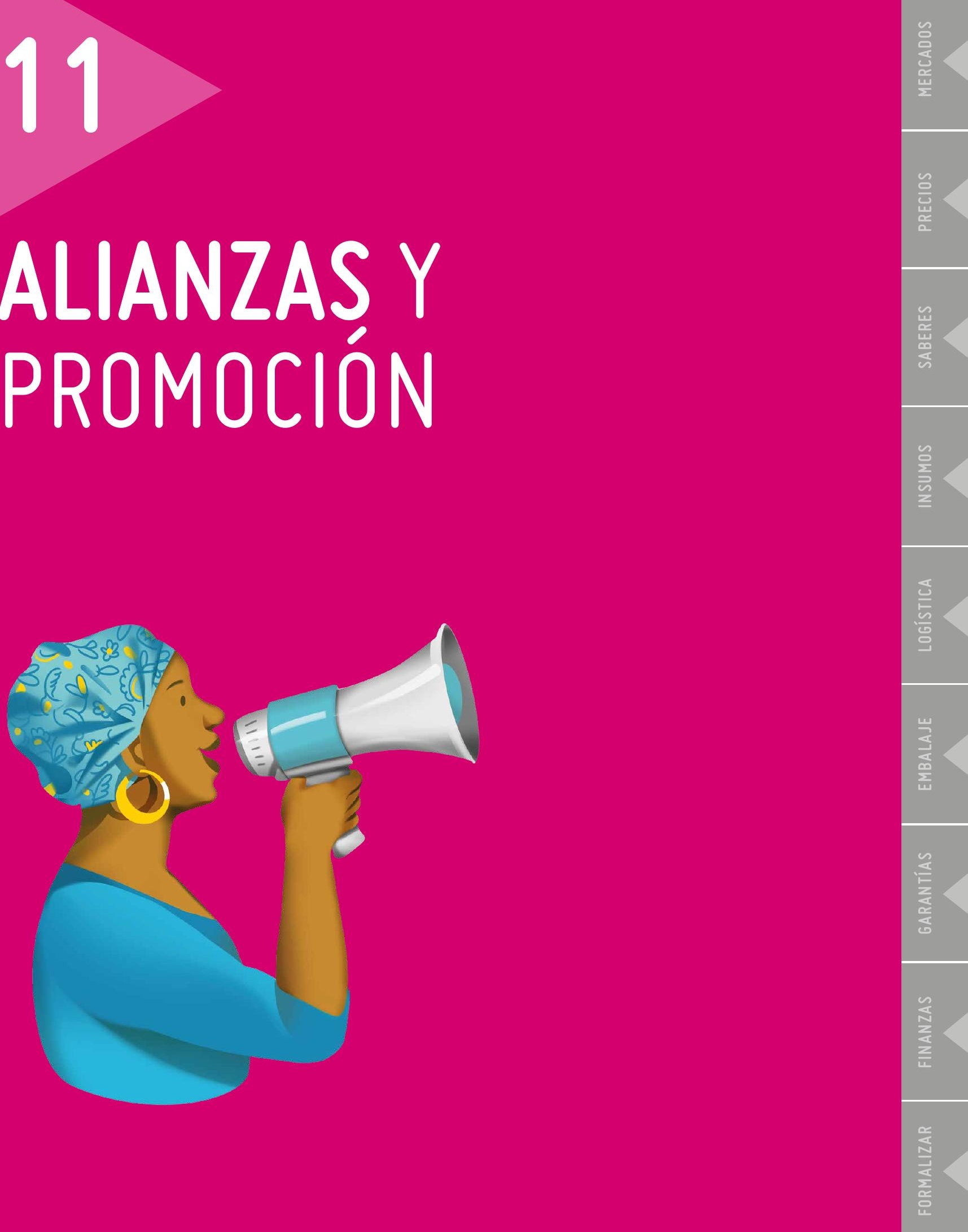


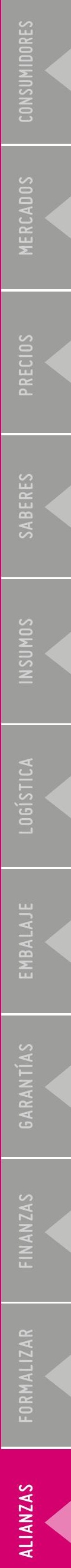




\section{1. ¿POR QUÉ ESTO ES IMPORTANTE?}

La innovación es el proceso de aportar nuevas ideas a los usuarios, a través de nuevas estructuras organizativas y medios de colaboración. Los socios y los promotores pueden desempeñar un papel importante en el establecimiento de puentes entre estas conexiones y en la captación del interés de consumidores y productores.

La asociación significa crear redes, acuerdos, alianzas, colaboraciones y coaliciones para intercambiar información y crear "ruido" en torno a su innovación, mientras que beneficia mutuamente a todos los socios.

La promoción significa pedir ayuda. Es necesaria para evitar que una innovación sea capturada y apropiada por otra organización o empresa privada, que excluya a sus practicantes reales, aprovechándose de una situación "exitosa". Esto podría ser hecho por cualquier persona, especialmente por empresas de gran escala con experiencia con cabildeos especializados, que puede afirmar que le representan.

\section{CONSEJO 42}

\section{Convenza a las partes interesadas}

1. Los responsables de la formulación de políticas (Gobierno) tienden a escuchar más a los grupos organizados. La institucionalización de un sistema alimentario innovador y sostenible es un desafío fundamental. Una vez que una innovación se institucionaliza, pierde su novedad y los innovadores corren el riesgo de perder el control sobre su sistema. El compromiso a largo plazo con el Gobierno y los actores del mercado disminuye este riesgo. Los grupos de coalición y las alianzas entre los actores de un sector (asociaciones interprofesionales) pueden proporcionar un mecanismo de apoyo para la promoción a largo plazo. Por nuestra experiencia, los responsables de la formulación de políticas escuchan a estos grupos, actúan sobre sus recomendaciones o peticiones, o negocian un acuerdo para aliviar las potenciales tensiones sociales. En algunos países es obligatorio que los grupos organizados ayuden a los tomadores de decisiones a elaborar directrices de aplicación de políticas para sus innovaciones.

2. Los datos/información de fuentes confiables (líderes de opinión, investigadores, científicos, figuras religiosas) aumentan la credibilidad. Al ver cómo las innovaciones desafían el orden existente en los sistemas alimentarios, el apoyo de esas fuentes es crucial para demostrar la eficacia (por ejemplo, en términos de rentabilidad, beneficios ambientales y sociales e inocuidad de los alimentos).

3. Para acceder a otros y/o mercados más grandes. Cuando la demanda es alta, la producción aumenta. La alta demanda proviene de los puntos de venta establecidos y/o principales, tales como grandes cadenas de supermercados, restaurantes y tiendas especializadas. Sin embargo, la entrada en estos mercados significa cumplir ciertos requisitos de calidad y cantidad del suministro, que son generalmente más estrictos que en las ventas directas. Por lo tanto, la creación de un apoyo de red y la asociación con otros grupos de agricultores o procesadores pueden ser útiles. A veces, un respaldo o una carta de apoyo de una red o socio respetados es suficiente para convencer al gerente de logística o producto para que surta los productos de un proveedor diferente. 
4. Las asociaciones y las redes permiten a los innovadores movilizar fondos. Tener suficiente dinero para operar es esencial. En la mayoría de los casos, las innovaciones se autofinancian, aunque esto suele limitar su capacidad de ampliación. Los socios de financiación locales e internacionales suelen requerir pruebas de un historial satisfactorio (es decir, tres años de operaciones, membresía, alcance de operación e impacto social) para poder recibir asistencia financiera. Un sistema establecido de red de apoyo podría ayudar a mejorar el acceso a fuentes de financiación externas.

5. La confianza es crucial para asociarse. Las asociaciones se basan en objetivos comunes y en una visión compartida y prospectiva creada a través del compromiso, la confianza y el compromiso sostenido de los asociados involucrados.

\section{SPG: redes, asociaciones y promoción en el trabajo (Filipinas)}

El SPG comenzó en Filipinas en 2004 con Magsasaka at Siyentista Para sa Pag-unlad ng Pagsasaka (MASIPAG), registrada como MASIPAG Farmers Guarantee System (MFGS). Los grupos de agricultores, a los que MASIPAG ayudó a organizar y apoyar, fueron los responsables de su implementación. En 2012, la Provincia de Quezon, en busca de un sistema de certificación adecuado para pequeños agricultores orgánicos locales que venden en el mercado semanal de la capital provincial, inició un SPG adaptado localmente mediante el establecimiento de una asociación con MASIPAG para capacitar a los productores orgánicos de la provincia. La experiencia de Quezon PGS inspiró a los responsables de la toma de decisiones de otras provincias a utilizar el SPG en lugar de la certificación de terceros para sus propios mercados locales.

En 2013, PGS Pilipinas fue lanzada oficialmente como una red de iniciativas de SPG en todo el país. Desde su creación, PGS Pilipinas creó una asociación con IFOAM para obtener el reconocimiento oficial y gubernamental del SPG. Esta actividad de promoción dio lugar a una moratoria de tres años en la aplicación de la Ley de la República (RA) de 10068, la regulación orgánica nacional que reconoce exclusivamente la certificación de terceros para la certificación orgánica. La moratoria de tres años permitió que los sistemas de información y datos de seguridad de todo el país se fortalecieran y ampliaran.

En 2017, tras la moratoria, el Departamento de Agricultura, a través de la Oficina de Normas de Agricultura y Pesca (BAF), invitó a PGS Pilipinas y otros miembros de la red al Grupo Técnico de Trabajo (TWG) a que elaboraran directrices para establecer un SPG nacional (una revisión a la RA10068 destinada a reconocer oficialmente a los SPG). En junio de 2017, el proyecto final de las directrices fue aprobado por los miembros del TWG, y se utiliza como referencia para las revisiones legales.

Fuente: Carmen Cabling, Quezon PGS. 


\section{2. ¿CÓMO CONSTRUIR ASOCIACIONES?}

Las alianzas con otras organizaciones pueden consistir en asociaciones sueltas a través de las cuales los miembros colaboran temporalmente para lograr un objetivo específico. En otras ocasiones, las asociaciones pueden durar mucho tiempo y evolucionar gradualmente hasta convertirse en nuevas organizaciones con sus propias estructuras de gestión y gobernanza. No existe ninguna norma que indique que una asociación a corto plazo no puede convertirse en una asociación a largo plazo, o viceversa.

Para empezar, es importante hacerse dos preguntas:

- “Qué intereses comunes tienen los socios potenciales con mi iniciativa?" Dos (o más) entidades o personas decidirán convertirse en socios una vez que hayan reconocido sus intereses comunes. - “Qué tipo de subsidiariedad existe con los socios potenciales?" En este sentido, la subsidiariedad se entiende como el principio de que las asociaciones ayudarán a resolver los problemas que las organizaciones individuales no pueden resolver localmente.

Una vez que responda a estas dos preguntas, identifique sus principales actividades de asociación, que influirán en la selección de posibles socios. Estas incluyen:

1. Compartir experiencias: La necesidad de apoyo mutuo, y de compartir experiencias, es la razón fundamental por la que deben unirse iniciativas innovadoras dispersas. Es dificil imaginar un sistema alimentario sostenible que crezca en total aislamiento de otras iniciativas alimentarias locales. Los nuevos cultivadores necesitan de agricultores experimentados para compartir sus conocimientos, los administradores de cadenas de suministro cortas necesitan aprender de los sistemas de distribución preexistentes, los grupos de consumidores necesitan marcos organizativos y herramientas de trabajo para comenzar su trabajo colectivo. Por todas estas razones, la respuesta a la pregunta “¿con quién establecer una asociación?" es: compañeros agricultores, compañeros consumidores, compañeros logísticos, compañeros minoristas y compañeros procesadores.

2. Comunicación externa: Comunicación externa significa "comunicación a un público más amplio". Uno de los retos iniciales es la incorporación de miembros o clientes. Un festival local de alimentos basado en platos tradicionales, por ejemplo, sería más eficaz a este respecto que cualquier acción establecida por un grupo solitario. Organizar tal festival sería el trabajo resultante de una asociación u organización paraguas, ya conocedora de los grupos objetivo y los medios para llegar a ellos. Si no hay ninguna red activa en la zona, las ONG o las autoridades locales podrían organizar anualmente este tipo de actividad.

3. Promoción: Algunas cuestiones no pueden abordarse por separado mediante una sola asociación. Este es el caso de cuestiones jurídicas complejas como el acceso a la tierra, una dimensión clave de los sistemas alimentarios sostenibles. Se necesitan alianzas fuertes, típicamente durante períodos más largos, para que la promoción sea efectiva. A fin de influir en los encargados de adoptar decisiones y los marcos jurídicos, la cooperación con organizaciones especializadas de promoción puede ser más eficaz que los vínculos directos con los representantes elegidos.

4. Investigación: Varios pioneros del sistema alimentario sostenible decidieron, en una etapa temprana, asociarse con un equipo de investigación. Los objetivos principales son llevar a 
cabo investigaciones para apoyar los logros de la innovación desde diferentes perspectivas, y producir nuevos conocimientos sobre la sostenibilidad. Las demostraciones científicas proporcionan datos importantes que pueden apoyar las campañas de promoción. Sin embargo, la investigación no sólo puede servir a estos propósitos. Es fundamental investigar sistemáticamente los problemas que enfrentan los actores del sistema alimentario sostenible para encontrar soluciones.

5. Acceso a los mercados: Sin un acceso estable al mercado, ninguna empresa puede ser económicamente sostenible. El acceso a los mercados se basa en asociaciones: cada transacción puede considerarse una asociación. Para que estas asociaciones duren, se necesitan cadenas de suministro sólidas con objetivos a largo plazo. Los modelos basados en las ventas directas pueden garantizar asociaciones a largo plazo, y directas, entre productores $y$ consumidores, aunque existen otras formas de garantizar el acceso a los mercados, incluyendo los que dependen de intermediarios transparentes. El punto importante que hay que recordar es que los intercambios dependen de la confianza.

6. Finanzas: Algunas asociaciones se crean sólo para movilizar fondos, como la recaudación de fondos para actividades de promoción, operaciones o inversiones. Dependiendo de los usos múltiples previstos de los fondos, es posible asociarse con diferentes tipos de organizaciones.

\section{Campaña de consumidores ¡Que Rico Es! (Ecuador)}

En 2009, el colectivo Agroecológico del Ecuador y el Movimiento por una Economía Solidaria y Social lanzaron una campaña abierta dirigida por los ciudadanos, titulada "Qué Rico Es Comer Sano y de Nuestra Tierra" (www.QueRicoEs.org). La iniciativa conecta a las personas, e intenta contrarrestar la invasión de los alimentos industrializados, creando mercados para los productos agroecológicos de los agricultores familiares y mejorando la salud y la calidad de vida de las personas rurales y urbanas. Ponen la responsabilidad de la transición en los sistemas alimentarios sostenibles directamente en manos de "las personas que comen".

Inspirado por el potencial de movilizar al "consumidor-ciudadano" en una fuerza política, en octubre de 2014, el Colectivo Agroecológico de Ecuador lanzó una nueva estrategia nacional llamada "250 mil familias". La campaña, que sigue en curso, se basa en la noción de «consumo responsable», y tiene por objeto movilizar una masa crítica de «ciudadanos consumidores» para apoyar los esfuerzos de política pública en favor de «alimentos agroecológicos y saludables para una sociedad sana». Piden a los consumidores que inviertan al menos la mitad del presupuesto mensual de alimentos y bebidas de su familia en compras directas de consumidores y productores, o en ventas de productos orgánicos/agroecológicos y cultivos andinos. El objetivo principal de la campaña es llegar y conectar a 250.000 familias que comen "sabroso, saludable y local». Para alcanzar ese objetivo, se aplican numerosas estrategias centradas en la visibilidad, la conexión y la identidad. Se organizan diversos talleres y foros, y se elaboró una guía que hace un mapa de todos los mercados campesinos del país. Además de varios talleres y foros organizados, la campaña estableció un boletín informativo quincenal sobre consumo responsable.

Fuente: Ross Mary Borja, Fundación Ekorural, Ecuador.

Para saber más, visite: http://www.fao.org/3/a-bs916s.pdf. http://www.quericoes.org. 


\section{CONSEJO 43}

\section{Cree asociaciones para el trabajo de promoción}

1. Cree asociaciones deliberadas: Con muchas estrategias de asociación posibles, seleccione estratégicamente cuáles son las más adecuadas para su organización. Sea muy claro con quién quiere trabajar (es decir, personas que comparten sus valores y/o objetivos similares), y específicamente diríjase a estas personas y grupos a través de diversos medios de comunicación. Trabajar con socios que comparten una misión y visión comunes fortalece los recursos y genera cambios en el sistema alimentario.

2. Desarrolle una estrategia de promoción: ¡Haga un plan! Una estrategia de promoción ayuda a todos a entender la situación, analizar a los actores, abordar cómo debe ocurrir el cambio y a establecer metas claras para el futuro. Una estrategia sólida de promoción alinea las metas para los temas clave en puntos específicos en el tiempo durante el ciclo de vida del proyecto.

3. Involucre a los asociados en todas las etapas de la promoción: La participación activa y comprometida, desde las primeras etapas del proyecto, mejora y permite la participación fuera del círculo primario (por ejemplo, la creación de relaciones s productivas con los responsables de la formulación de políticas).

4. Identifique los puntos fuertes de todos los socios: Conocer los puntos fuertes de cada socio maximiza la dinámica de la relación y los resultados generales del proyecto. Algunos socios aportan sus habilidades financieras, mientras que otros tienen capacidades de red y/o habilidades de pensamiento estratégico. Capitalice estos puntos fuertes e intereses para mantener a todos contentos y comprometidos. Naturalmente, algunos socios también serán más activos que otros, mientras que otros pueden requerir un poco más de aliento... ¡eso está bien! La creación de asociaciones estratégicas requiere de negociación, paciencia y flexibilidad continua.

5. Construya conexiones creativas: Al construir una red para asociaciones de promoción, piense fuera de la caja. Diferentes herramientas son eficaces para diferentes entornos, identifique las mejores herramientas para los distintos socios y utilicelas. Por ejemplo, establecer una conferencia o convención para reunir a las personas interesadas, escribir un artículo de revista para una publicación académica para obtener apoyo, 0 asistir a un taller educativo.

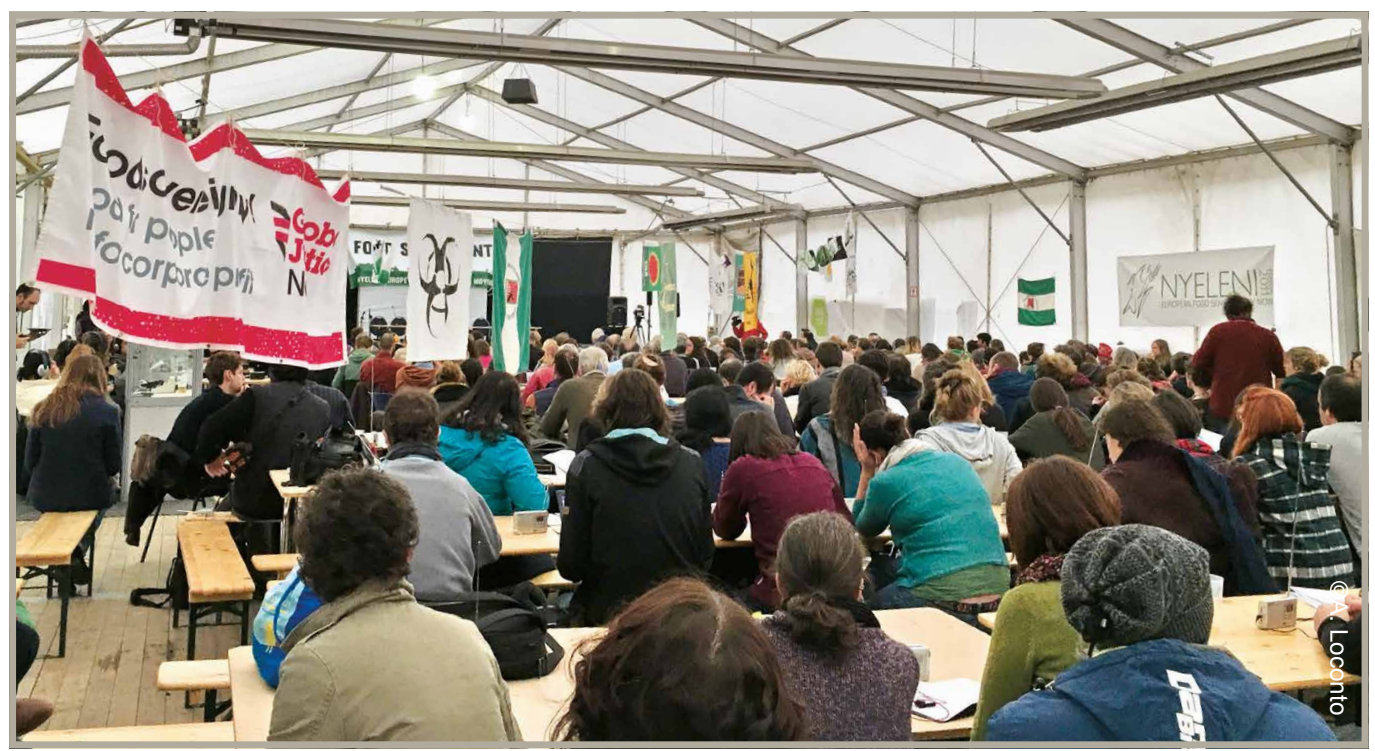




\section{3. ¿QUIÉN SE MOVILIZARÁ PARA LAS ASOCIACIONES?}

\subsection{Otros actores del sistema alimentario sostenible}

Obtener el apoyo de otros actores es un reto. Si hay un sentido de la competencia en un mercado pequeño, saturado y de nicho, la voluntad de compartir éxitos, fracasos y planes para el futuro es muy probable que esté ausente. Si, por el contrario, se construye un sentido de comunidad a través de la creación de capital social, la colaboración debería ser más fácil.

Se podría establecer una asociación entre otros actores:

a. a través de un mecanismo formal, como un Sistema Participativo de Garantía (hemos encontrado que los SPG son buenos para proporcionar garantías, pero también son una herramienta pedagógica para el aprendizaje en grupo y la construcción de capital social); o

b. a través de reuniones de intercambio de experiencias para recoger las últimas noticias de todas las diferentes operaciones y para discutir dudas y preocupaciones (hemos encontrado que las reuniones multilaterales regulares para intercambiar sobre temas comunes son útiles).

En nuestra experiencia, los restaurantes pueden convertirse en excelentes socios si sus chefs buscan relaciones a largo plazo con los proveedores. Por supuesto, el riesgo es para el productor o el comerciante, de convertirse en dependiente en un mercado único para todas las ventas. El principio de la diversidad es importante en este caso, para evitar la creación de asociaciones basadas en la dependencia.

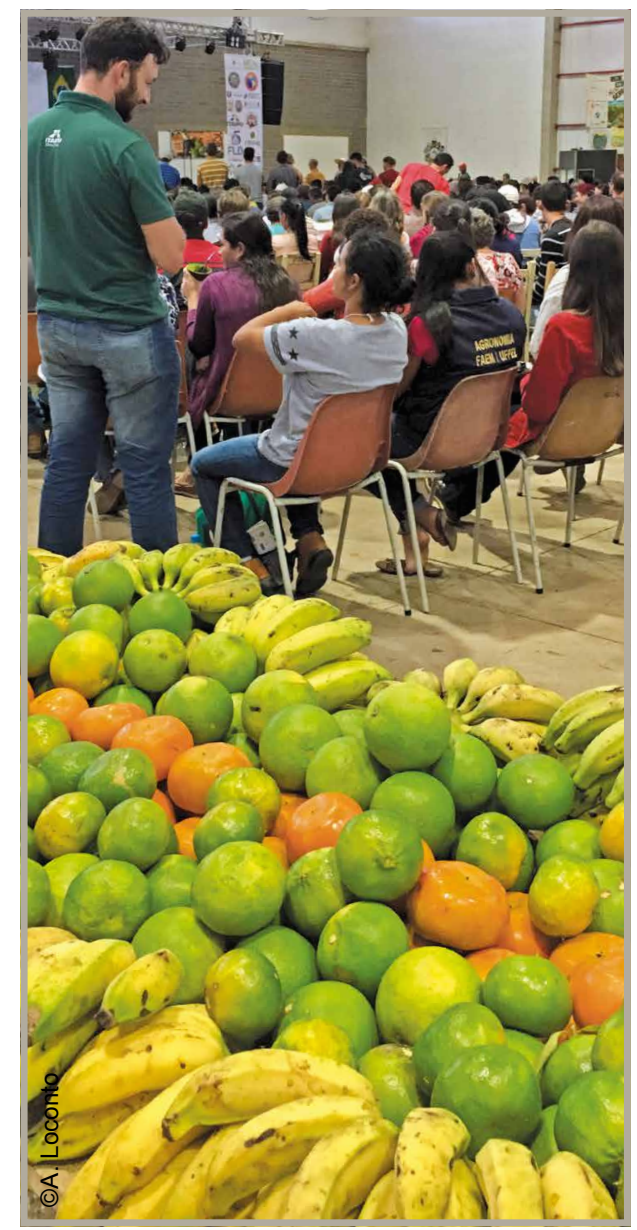




\section{Modelos de canastas: creación de capital social (Ecuador)}

En Ecuador, cuando se estableció una alianza entre la asociación de consumidores "Canastas Comunitarias" y la organización de productores "Asociación de Productores Nueva generación", se promovieron varias estrategias de ambos líderes del grupo para fortalecer su cohesión.

El proceso progresivo se basó en la construcción de diferentes tipos de relaciones. Una vez que los grupos se reunieron y desarrollaron un sentido de familiaridad, se estableció una asociación basada en valores, sentimientos, intereses y experiencias compartidas a través de visitas de intercambio entre productores y consumidores. Si los productores y consumidores se conocen entre sí, pueden comprender sus respectivos procesos y experiencias de manera diferente. Después de cada entrega de la canasta, los productores participaron en reuniones de evaluación de consumidores donde se discutieron las impresiones sobre los productos entregados, la calidad, la cantidad, así como cualquier otro tema de interés. Otra estrategia consistió en dar retroalimentación a los miembros de la asociación de productores durante las sesiones de trabajo, quienes también participaron en las asambleas generales de Canasta Comunitaria para discutir el establecimiento de precios, la construcción/ fortalecimiento de un sistema de garantía, leyes sobre semillas, soberanía alimentaria y consumo responsable.

Un espacio para el diálogo ayuda a productores y consumidores a comprenderse mutuamente, a compartir entre sí y, con el tiempo, a establecer y tejer relaciones de reciprocidad, también conocidas como capital social.

- El primer paso es crear una relación basada en la confianza.

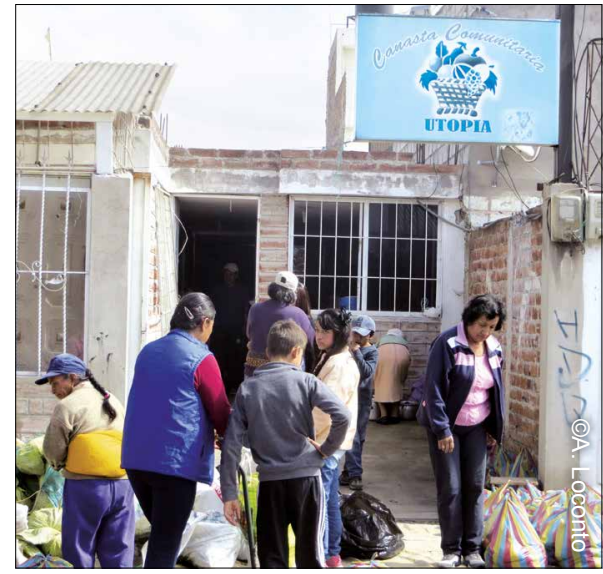

- El segundo paso es determinar principios o directrices comunes para la participación de los socios (por ejemplo, si bien se necesita crítica, también se deben proponer soluciones).

- En tercer lugar, es necesario fortalecer y ampliar los dos primeros pasos. Los mercados y las entregas de canastas deben incluir otras actividades orientadas a la venta y compra de productos que buscan fortalecer las relaciones ya establecidas, generar nuevas y fomentar alianzas, interacciones y valores en torno a los alimentos.

Los tres pasos se pueden lograr mediante el compromiso de asociación para cumplir las tareas requeridas (por ejemplo, hacerse cargo de la logistica, organizar una actividad práctica) y representar al grupo en diferentes espacios (por ejemplo, gestionar las relaciones con los gobiernos locales que pueden implicar la necesidad de defender una posición determinada). Debe difundirse un sentimiento de valiosa contribución entre los miembros: sus aportes, como conocimientos y experiencia, entre otros, lo que conduce a niveles más altos de compromiso y apoyo del grupo.

Fuente: Ross Mary Borja, Fundación Ekorural. 


\subsection{Organizaciones no gubernamentales}

Algunas ONG han construido una imagen pública positiva en sus países de operación. Si se forma adecuadamente, una asociación puede atraer la atención pública y aumentar la visibilidad de la iniciativa. Las asociaciones con las ONG pueden entrañar ciertos riesgos, como que las ONG sean percibidas como competidoras por parte de los actores del sistema alimentario sostenible. Es importante que una nueva ONG no sustituya a los actores actuales de la iniciativa, manteniendo su papel de «apoyo», y no más.

\section{Asociación con ONG (Togo)}

En la ciudad capital de Lomé, Togo, el centro cultural Mytro Nunya ha sido sede de actividades de ASC durante varios años. Fue una asociación sin ánimo de lucro la que compartió información sobre temas de solidaridad internacional, que tenía una biblioteca, y que organizó conferencias, debates, conciertos y representaciones teatrales. Temas de desarrollo sostenible, salud y medio ambiente fueron los valores clave en la visión cívica promovida por el centro. Por lo tanto, parece bastante natural que el personal del centro se conecte con los productores orgánicos locales y establezca una asociación para sus clientes habituales. Una distribución de dividendos, combinada con un mercado campesino, fue organizada regularmente en Mytro Nunya, que se llevó a cabo juntamente con otras actividades: películas, biblioteca, conferencias y debates.

Los consumidores se sintieron atraídos por este tipo de actividades, ya que buscaban participar en nuevos modelos de consumo responsable. Por supuesto, no hay una solución posible para llegar a los miembros potenciales: identificar los grupos de interés más cercanos requiere creatividad.

Fuente: Judith Hitchman, URGENCI.

\subsection{Generadores de políticas}

Las innovaciones suelen llamar la atención de los encargados de formular políticas: los representantes locales están interesados en hacer seguimiento a los logros de los empresarios en su territorio. Ellos ven un potencial para producir empleos locales, y son proclives a apoyar acciones que refuercen la cohesión social y comunitaria. Por supuesto, la dimensión ambiental del desarrollo sostenible también puede ser atractiva para algunos. Los fuertes vínculos con los encargados de formular políticas entrañan algunos riesgos, como la posible "captura" de la iniciativa sostenible por un partido político específico, que se utiliza para su propio propósito. Por lo tanto, es necesario, en cualquier asociación de este tipo, exponer claramente el carácter no político del sistema innovador. La estrategia utilizada para abordar a los encargados de formular políticas también puede ser arriesgada. Por ejemplo, si se basa en una relación personal, todos los esfuerzos podrían perderse en el caso de que surja un conflicto personal o si la persona se retira de los deberes políticos. Al igual que las prácticas agrícolas y de comercialización, la diversificación de las relaciones políticas refuerza la capacidad de resistencia de la iniciativa. 


\section{Búsqueda y acercamiento a personas influyentes en las políticas (Kenya)}

La estrategia de promoción de la Gestión Ecológica del Uso de la Tierra (ELUM) fue desarrollada por la red PELUM Kenya. Su propósito era establecer una estructura para coordinar las acciones respectivas de promoción s de los miembros. Utilizando un enfoque basado en la evidencia a nivel de condado y nacional, esta estrategia aborda simultáneamente cuestiones de base con las comunidades locales, tales como las relacionadas con la agricultura, la adaptación al cambio climático, el uso de la tierra, la asignación presupuestal para la agricultura sostenible y la creación de capacidad.

En 2015, cuando se estaba desarrollando la Política Agrícola Nacional, la red presionó para incluir a PELUM en la política agrícola. Basándose en las organizaciones miembros de PELUM y sus contactos, los representantes de PELUM se dirigieron al presidente de la comisión parlamentaria para la agricultura, quien luego movilizó a otros cuatro miembros del Parlamento y celebró una reunión de desayuno. El director de políticas del Ministerio de Agricultura, Ganadería y Pesca también fue contactado por el presidente del comité de promoción, que había interactuado con él en foros anteriores. Antes de estas reuniones, se redactó un documento informativo en el que se esbozaban la posición, los comentarios y las aportaciones de PELUM con respecto a la Política Agrícola Nacional. Este informe fue compartido durante las reuniones, además de la evidencia y los datos de apoyo basados en investigadores. $\mathrm{Si}$ bien no fue fácil convencer a estas personas clave al instante, los representantes de PELUM siguieron constantemente con notas, reuniones informales, sesiones informativas verbales y llamadas telefónicas. El resultado del proceso fue que el Ministerio de Agricultura, Ganadería y Pesca incorporó una cláusula en la política agrícola que reconocía oficialmente el uso de los conocimientos tradicionales y nativos en la agricultura.

Fuente: Rosinah Mbenya, PELUM.

\subsection{Investigadores}

Un número cada vez mayor de innovaciones se identifican en una etapa temprana y son monitoreadas durante un largo período de tiempo por una unidad de investigación asociada; esto es especialmente cierto para las nuevas prácticas agrícolas (agricultura orgánica, permacultura). Los resultados científicos son igualmente cruciales para convencer a los demás agricultores y responsables de la toma de decisiones, y para mejorar los hábitos de trabajo de la iniciativa. Sin embargo, existen algunos riesgos asociados:

1. La apropiación de conocimientos puede beneficiar a los competidores (es decir, la concesión de patentes de propiedad intelectual por parte de actores deshonestos).

2. Los resultados de la investigación pueden ser desfavorables y revelar debilidades en su modelo, lo que puede traer atención no deseada a su iniciativa.

Asegúrese de equilibrar lo honesto y transparente que es con los riesgos anteriores para garantizar que una asociación de investigación es a la vez científicamente sólida y que no se sentirá explotada o traicionada. Al igual que cualquier otra asociación, la creación de confianza con los investigadores es esencial. 


\subsection{Sector privado}

La mayoría de las veces, las asociaciones con otras empresas giran en torno a necesidades específicas de productos (por ejemplo, colaboración con diseñadores para publicidad o embalaje) o planes de desarrollo sectorial. (por ejemplo, asociaciones con otros agricultores, procesadores, transportadores, escuelas de cocina y minoristas). El sector privado es grande, y puede haber oportunidades de asociarse con empresas nacionales o internacionales en campañas de promoción o en el establecimiento de normas industriales que también puedan ser beneficiosas para los actores del sistema alimentario sostenible. Es importante pensar estratégicamente en cómo se involucra con los actores del sector privado debido al riesgo de "cooptación" de su mensaje, de la propiedad intelectual (como marcas, ideas de productos) y la distribución equitativa de las ganancias (no todas las empresas del sector privado tienen los mismos modelos de negocio; los márgenes y las ganancias muy posiblemente se calcularán de forma diferente).

\section{CONSEJO 44}

Encuentre socios y portavoces

- No todas las asociaciones deben ser permanentes. Algunas pueden estar orientados hacia un tema temporal y único, mientras que otras pueden ser a largo plazo.

- Elija a sus socios sabiamente, sin importar de qué sector provengan, y asegúrese de compartir los mismos objetivos.

- Diversificar a sus socios de acuerdo con los intereses compartidos es importante, pero trate de evitar la sobrecarga de la asociación... ¡esto puede llevar a olvidar su propia misión!

- La promoción es una asociación, por lo que es fundamental institucionalizar el cambio que está haciendo en su sistema alimentario. No obstante, tenga cuidado con quien se asocia...jasegúrese de que sean promotores creíbles de su causa!

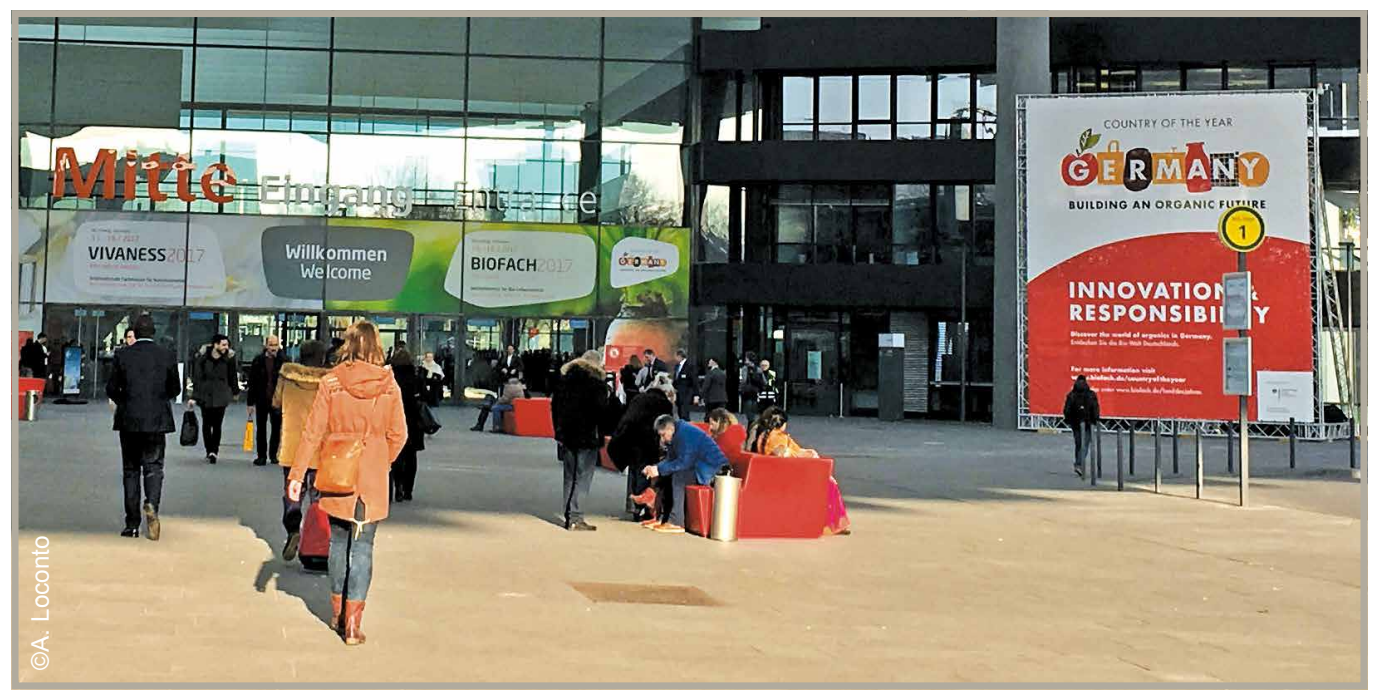




\section{LA AVENTURA DEL APRENDIZAJE, ¿DÓNDE SEGUIR?}

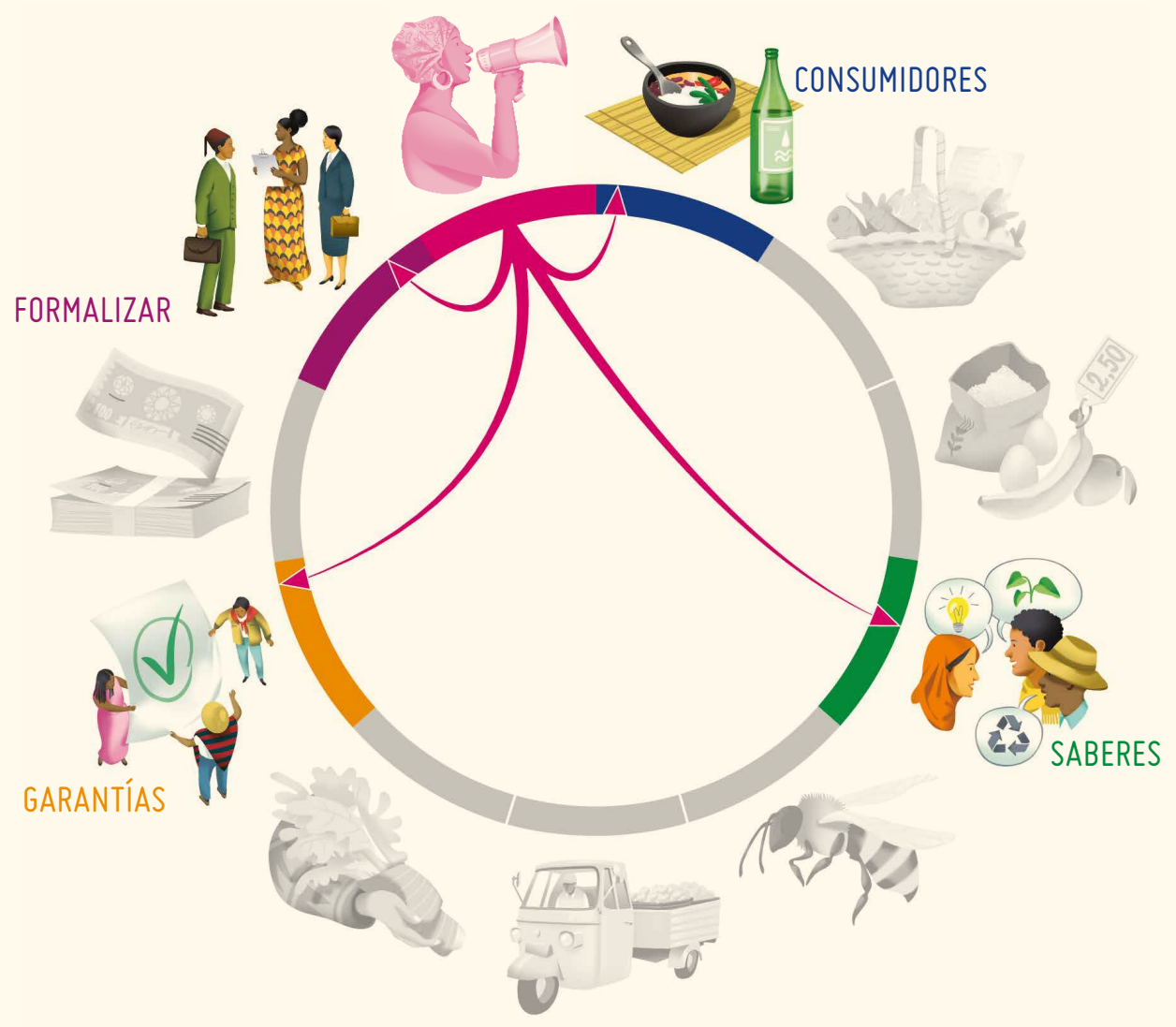

- ¿Desea asociarse con grupos de consumidores? Descubra en qué está interesado visitando el Capítulo 1: Atraer a los consumidores y mantenerlos comprometidos.

- ¿Está buscando ejemplos de asociaciones exitosas con investigadores? Vuelva al Capítulo 4: Compartir y cocrear conocimiento para una producción sostenible.

- ¿Necesita mejorar su iniciativa antes de asociarse con otros? Vuelva al Capítulo 10: Formalizar el trabajo colectivo.

- ¿Desea utilizar un SPG para crear una asociación? Obtenga más información en el Capítulo 8: Garantías para la sostenibilidad.

¿0 tal vez quiera volver a un capítulo que se ha saltado? ¡Búsquelo! 


\section{BIBLIOGRAFÍA}

Bashford, Jade, Kathleen Cross, Wolfgang Eichinger, Andreas Georgakakis, Morgane Iserte, Fabian Kern, Daniel Lešinský, et al. 2013. European Handbook on Community Supported Agriculture. Sharing experiences. Vienna. 21 págs. (disponible en: http://urgenci.net/wp-content/uploads/2015/03/ CSA4EUrope_Handbook.pdf).

Brondizio, ES, J Settele, S Díaz, \& HT Ngo. 2019. Global assessment report on biodiversity and ecosystem services of the Intergovernmental Science-Policy Platform on Biodiversity and Ecosystem Services. Bonn, DE. 1700 págs. (disponible en: https://ipbes.net/global-assessment).

Crutzen, Paul J. 2006. The "Anthropocene". In Eckart Ehlers and Thomas Krafft, eds., Earth System Science in the Anthropocene, 13-18. Berlin, Heidelberg, Springer Berlin Heidelberg.

FAO. 2003. Environmental and social standards, certification and labelling for cash crops. Roma. 120 págs. (disponible en: http://www.fao.org/3/a-y5136e.pdf).

FAO. 2007. Agro-industrial supply chain management: concepts and applications. Roma. 71 págs. (disponible en: http://www.fao.org/3/a-a1369e.pdf).

FAO. 2012. World agriculture towards 2030/2050: the 2012 revision. Roma. 154 págs. (disponible en: http://www.fao.org/3/a-ap106e.pdf).

FAO. 2014. The State of Food and Agriculture. Innovation in Family Farming. Roma. 161 págs. (disponible en: http://www.fao.org/3/a-i4040e.pdf).

FAO. 2016a. Innovative markets for sustainable agriculture: How innovations in market institutions encourage sustainable agriculture in developing countries. Roma. 390 págs. (disponible en: http:/ / www.fao.org/3/a-i5907e.pdf).

FAO. 2016b. Traceability: a management tool for business and governments. Roma. 68 págs. (disponible en: http://www.fao.org/3/a-i6134e.pdf).

FAO. 2017. Full cost accounting. [en línea]. Food and Agriculture Organization of the United Nations. [Citado el 13 de marzo de 2020] http://www.fao.org/nr/sustainability/full-cost-accounting/en.

FAO. 2018a. Los 10 elementos de la agroecología: Guía para la transición hacia sistemas alimentarios y agrícolas. Rome. 15 págs. (disponible en: http://www.fao.org/3/19037ES/i9037es.pdf).

FAO. 2018b. Constructing markets for agroecology. An analysis of diverse options for marketing products from agroecology. Roma. 214 págs. (disponible en: http://www.fao.org/3/i8605en/ I8605EN.pdf).

FAO. 2018c. FAO's work on agricultural innovation. Sowing the seeds of transformation to achieve the SDGs. Roma. 20 págs. (disponible en: http://www.fao.org/3/ca2460en/ca2460en.pdf). 
FAO. 2018d. The International Symposium on Agricultural Innovation for Family Farmers. [en línea]. Food and Agriculture Organization of the United Nations. [Citada el 13 de marzo de 2020] http:// www.fao.org/about/meetings/agricultural-innovation-family-farmers-symposium/about/en/.

FAO, FIDA, UNICEF, PMA, \& OMS. 2017. The State of Food Security and Nutrition in the World. Building resilience for peace and food security. Roma, Organización de las Naciones Unidas para la Agricultura y la Alimentación. 132 págs. (disponible en: http://www.fao.org/3/a-17695e.pdf).

Fressoz, Jean-Baptiste, \& Christophe Bonneuil. 2016. L'événement anthropocène. La Terre, l'histoire et nous: La Terre, l'histoire et nous. París, Points. 334 págs.

Gibson-Graham, Julie Katherine. 2008. Diverse economies: performative practices forother worlds'. Progress in human geography 32 (5): 613-632.

HLPE. 2014. Food losses and waste in the context of sustainable food systems. A report by the High Level Panel of Experts on Food Security and Nutrition of the Committee on World Food Security. Rome. 8 pp. (disponible en: http://www.fao.org/3/a-av037e.pdf).

IFOAM. 2019. Definition of Participatory Guarantee Systems. [en línea]. International Federation of Organic Agriculture Movements. [Citado el 13 de marzo de 2020] https://www.ifoam.bio/sites/ default/files/pgs_definition_in_different_languages.pdf.

ISO. 2012. Conformity assessment -- Requirements for bodies certifying products, processes and services. ISO/IEC Guide 17065. Ginebra. 27 pp. (disponible en: https://www.iso.org/standard/46568.html).

Juliane, Reinecke, \& Ansari Shaz. 2015. ¿Qué es un precio «justo»? Ethics as Sensemaking. Organization Science 26 (3): 867-888. https://ideas.repec.org/a/inm/ororsc/v26y2015i3p867-888.html.

Kamaraj, R. 2015. POLICY NOTE 2015-2016. Demand No. 13. Tamil Nadu. 30 pp. (disponible en: http:// cms.tn.gov.in/sites/default/files/documents/food_e_pn_2015_16.pdf).

Kanie, Norichika, \& Frank Biermann. 2017. Governing through goals: Sustainable development goals as governance innovation. Earth System Governance. Cambridge, MA, MIT Press. 333 págs.

Morgan, David L. 1997. Focus groups as qualitative research. Thousand Oaks, CA, Sage. 80 págs.

Ostrom, Marcia, Kathryn de Master, Egon Noe, \& Markus Schermer. 2017. Values-based Food Chains from a Transatlantic Perspective: Exploring a Middle Tier of Agri-food System Development. International Journal of Sociology of Agriculture \& Food 24 (1): 1-14.

Swensson, Luana F. Joppert. 2015. Institutional Procurement of Food from Smallholder Farmers. The Case of Brazil. Food and Agriculture Organization of the United Nations (Rome).

TNAU. 2015. Cost of Cultivation : Paddy (2014-15). [en línea]. TNAU Agritech Portal. [Citado el 13 de marzo de 2020] http://agritech.tnau.ac.in/agriculture/agri_costofcultivation_rice.html.

UN Environment. 2020. One Planet Network: Sustainable Food Systems Programme. [en línea]. [Citado el 13 de marzo de 2020] https://www.oneplanetnetwork.org/sustainable-food-system. 
URGENCI. 2016. Overview of Community-Supported Agriculture in Europe. Aubagne, Kernel Editions. 138 pp. (disponible en: https://urgenci.net/wp-content/uploads/2016/05/Overview-of-CommunitySupported-Agriculture-in-Europe.pdf).

Vatin, François. 2013. Valuation as Evaluating and Valorizing. Valuation Studies Vol. 1 (1) 2013: 31-50.

Whitaker, Sarah, Marie Clotteau, Vlatko Andonovski, Joao Azevedo, \& Thomas Egger. 2017. Innovation and Circular Economy in the Mountain Forest Supply Chain: How to close the loop? Paris. 75 págs. (disponible en: http://www.euromontana.org/wp-content/uploads/2017/03/Innovationand-Circular-Economy-in-the-Mountain-Forest-Supply-Chain_FINAL.pdf).

Willett, Walter, Johan Rockström, Brent Loken, Marco Springmann, Tim Lang, Sonja Vermeulen, Tara Garnett, et al. 2019. Food in the Anthropocene: the EAT-Lancet Commission on healthy diets from sustainable food systems. The Lancet 393 (10170): 447-492. 
NOTAS 


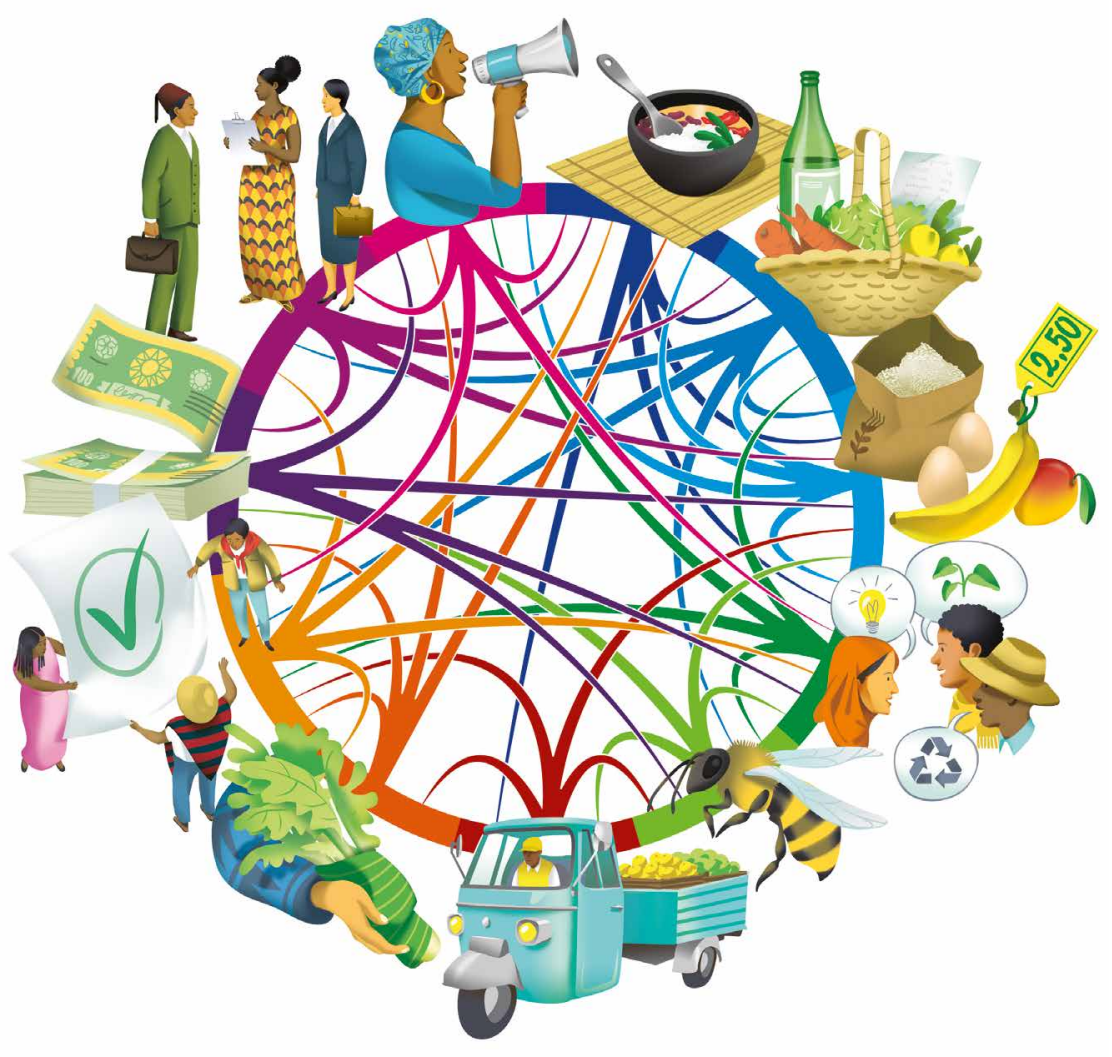



Los sistemas alimentarios sostenibles son fundamentales para garantizar que las generaciones actuales y futuras tengan seguridad alimentaria y puedan llevar una dieta saludable. Para hacer la transición hacia la sostenibilidad, es necesario reconstruir muchas actividades del sistema alimentario, y un sinnúmero de actores en todo el mundo están empezando a actuar localmente. Si bien algunos cambios son más fáciles que otros, saber cómo navegar a través de ellos para promover prácticas de consumo y producción sostenibles requiere un conjunto complejo de aptitudes.
El presente manual está dirigido a los “innovadores de sistemas alimentarios sostenibles", y es realizado por un grupo de innovadores de Asia, África, América y Europa que están dirigiendo iniciativas para cultivar, compartir, vender y consumir alimentos más sostenibles en sus contextos locales. Incluye experiencias que están cambiando las estructuras organizativas de los sistemas alimentarios locales para hacerlos más sostenibles.

Esta guía está escrita como un libro donde "eliges tu propia aventura". Cada lector - solo o en un grupo facilitado - puede desarrollar un viaje personalizado de aprendizaje y acción en línea con sus propias prioridades. Los temas tratados en esta guía son organizados en cuatro categorías de innovaciones: involucramiento de los consumidores, producción de manera sostenible, llevando los productos al mercado y organización.
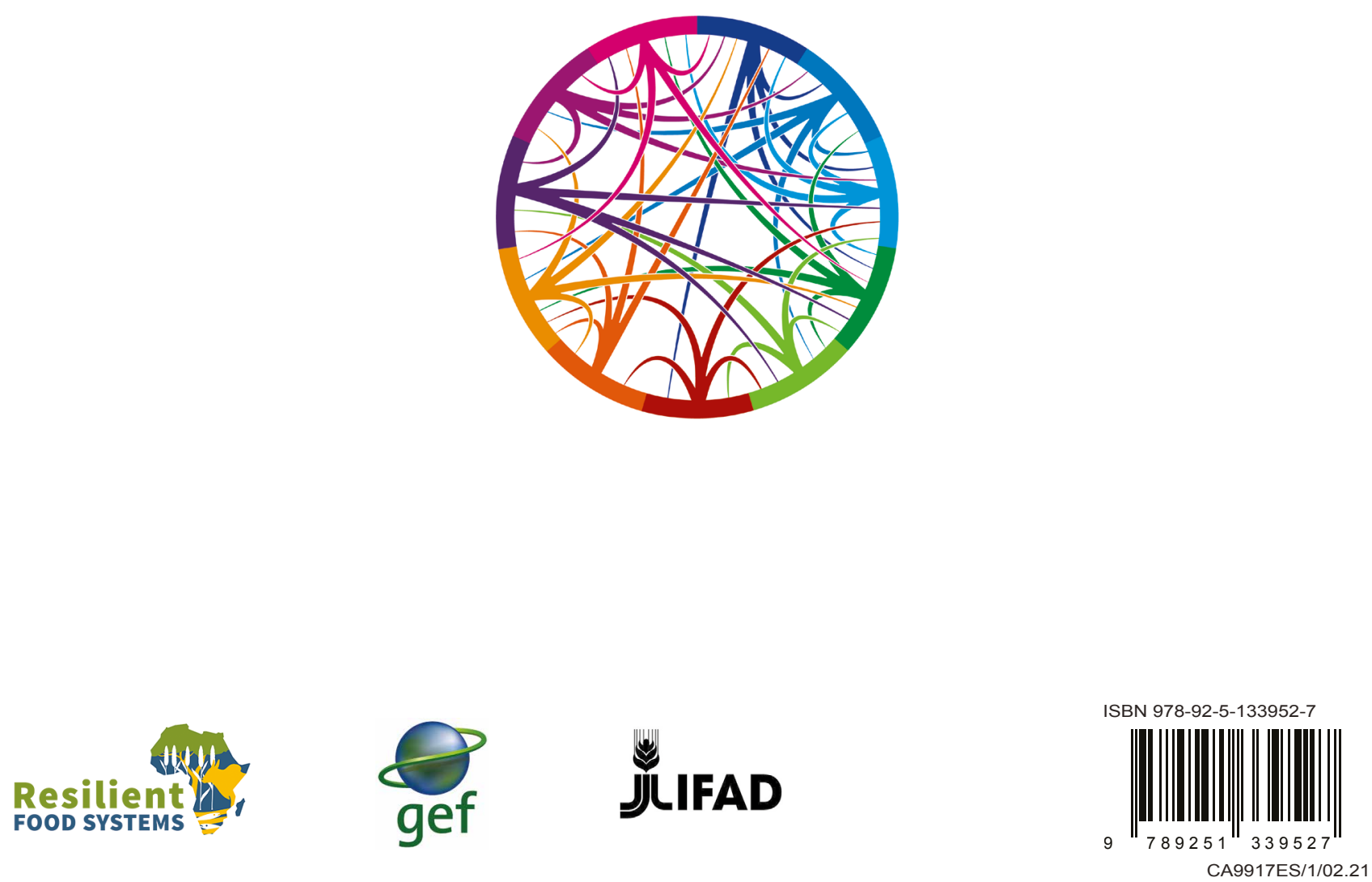